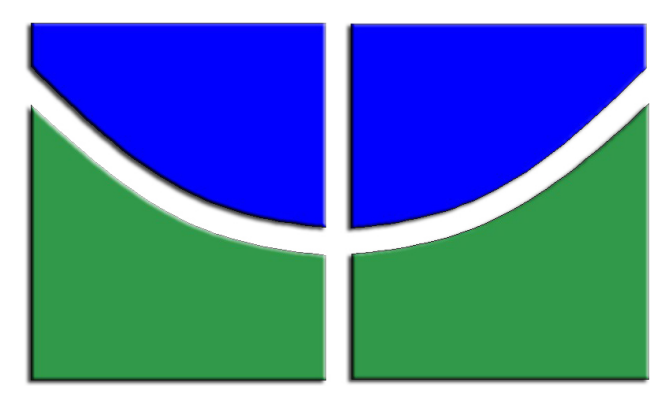

\author{
UNIVERSIDADE DE BRASÍLIA \\ INSTITUTO DE FÍSICA \\ PROGRAMA DE PÓS-GRADUAÇÃO EM FÍSICA
}

TESE DE DOUTORADO

\title{
ESTUDO TEÓRICO DO TRANSPORTE DE CARGA EM SEMICONDUTORES ORGÂNICOS E DAS PROPRIEDADES ELETRÔNICAS E ÓPTICAS DE MOLÉCULAS CONJUGADAS
}

Igo Tôrres Lima

Orientador: Prof. Dr. Demétrio Antônio da Silva Filho

Brasília-DF, Brasil

Março - 2015 


\title{
UNIVERSIDADE DE BRASÍLIA INSTITUTO DE FÍSICA PROGRAMA DE PÓS-GRADUAÇÃO EM FÍSICA
}

\section{ESTUDO TEÓRICO DO TRANSPORTE DE CARGA EM SEMICONDUTORES ORGÂNICOS E DAS PROPRIEDADES ELETRÔNICAS E ÓPTICAS DE MOLÉCULAS CONJUGADAS}

\author{
Igo Tôrres Lima
}

Tese de Doutorado apresentada ao Instituto de Física da Universidade de Brasília como parte dos requisitos necessários para a obtenção do título de Doutor em Física.

Orientador: Prof. Dr. Demétrio Antônio da Silva Filho

Brasília-DF, Brasil

Março - 2015 


\title{
"Estudo Teórico do transporte de carga em semicondutores orgânicos e das propriedades eletrônicas e ópticas de moléculas conjugadas."
}

Por

\author{
Igo Tôrres Lima
}

Tese submetida ao Instituto de Física da Universidade de Brasília como parte dos requisitos para a obtenção do grau de Doutor em Física.

Aprovada por:
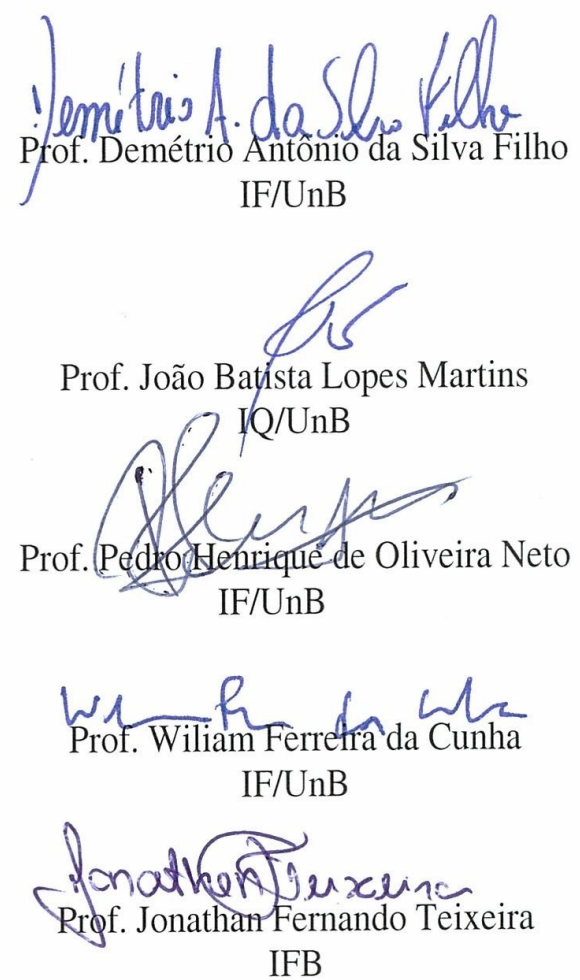

Prof. Dr. Fernando de Oliveira Albuquerque

Coordenador de Pós-Graduação

Instituto de Física 
Dedico esta tese aos meus pais Inácio Pereira Lima e Violêta Tôrres de Sousa Lima. 


\section{Agradecimentos}

Agradeço a Deus pela oportunidade de cumprir mais esta etapa da minha vida.

Aos meus pais, pelo carinho, apoio e esforço concedidos a minha educação.

Aos meus irmãos Léo e Kamilla pela amizade e companheirismo.

À Patrícia Helene por todo o carinho, compreensão e incentivo que me deu durante esses anos.

Aos meus amigos Rodolpho, Amanda, Eri, Afonso, Nádia, Queila, Monica, Edson, Marcos, Argleydson, Rafael, Leander, Luis Jr, Giovanni, Rhuiago, Ana Cláudia, Sara e Tamires pela amizade que se estabeleceu nesse período de convivência e discussões sobre Física.

Aos professores e funcionários do Instituto de Física da Universidade de Brasília que possibilitaram condições de trabalho neste Instituto.

Um agradecimento especial ao meu orientador, Prof. Demétrio Antônio da Silva Filho pela orientação, discussões e comentários, amizade e apoio nos momentos difíceis.

Ao Prof. Jean-Luc Brédas, por ter me recebido em seu grupo de pesquisa no Instituto de Tecnologia da Georgia, possibilitando-me uma grande oportunidade para minha formação como pesquisador.

Aos colegas Chad Risko, Veaceslav Coropceanu, Paul Winget, Naga Rajesh Tummala, Travis Kemper, Christopher Sutton, Alexandr (Sasha) Fonari, Yao-Tsung, Merçalles Capdevila e Stefan Knippenberg por tantas idéias no período de minha visita ao grupo do Prof. Brédas.

Aos professores Heibbe Cristhian do Instituto de Química e Wiliam Cunha do Instituto de Física da Universidade de Brasília pelas colaborações e boas idéias apresentadas sobre este trabalho.

Ao Prof. Celso Pinto de Melo e ao grupo de Polímeros Não-Convencionais do Departamento de Física da Universidade Federal de Pernambuco, que certamente estão torcendo por meu sucesso.

À Coordenação de Aperfeiçoamento de Pessoal de Nível Superior (CAPES), pela bolsa de estudos concedida, como também pela oportunidade de passar um ano no exterior, pelo Programa de Doutorado Sanduíche no Exterior (PDSE). 


\section{Sumário}

Lista de Figuras $\quad$ iv

Lista de Tabelas $\quad$ ix

Resumo $\quad$ xi

Abstract $\quad$ xii

1 Introdução 1

1.1 Semicondutores Orgânicos . . . . . . . . . . . . . . . . . 6

2 Fundamentação Teórica $\quad 9$

2.1 Aproximação de Born-Oppenheimer . . . . . . . . . . . . . . . . . . . 10

2.2 Orbitais e o Determinante de Slater . . . . . . . . . . . . . . . . . 12

2.3 Aproximação Hartree-Fock . . . . . . . . . . . . . . . . . . . . . . . . . . . 14

2.4 Energias dos Orbitais e o Teorema de Koopmans . . . . . . . . . . . . . . . 17

2.5 Teoria do Funcional da Densidade . . . . . . . . . . . . . . . . . . . . . . . 19

2.5.1 Equações de Kohn-Sham . . . . . . . . . . . . . . . . . . . . 20

2.5.2 Aproximações para o Funcional de Troca-Correlação . . . . . . . . . 23

2.6 Teoria do Funcional da Densidade dependente do tempo . . . . . . . . . . 26

3 Propriedades de Transporte de Carga em Sistemas Orgânicos 30

3.1 Energia de Reorganização . . . . . . . . . . . . . . . . . . 36

3.2 Região Invertida . . . . . . . . . . . . . . . . . . . . . . . . . 38

3.3 Acoplamento Eletrônico . . . . . . . . . . . . . . . . . . . . . . . . . 39 
4 Estrutura Eletrônica e Óptica de Derivados do triindole

4.1 Propriedades Eletrônicas . . . . . . . . . . . . . . . . . . . 44

4.2 Propriedades Ópticas . . . . . . . . . . . . . . . . . . . . . . . 49

4.3 Energia de Reorganização . . . . . . . . . . . . . . . . 51

4.4 Acoplamento Eletrônico . . . . . . . . . . . . . . . . . . 52

4.4.1 Procedimentos Computacionais . . . . . . . . . . . 53

4.4.2 Acoplamento Eletrônico via Teorema de Koopmans . . . . . . . . . 55

4.4 .3 Acoplamento Direto . . . . . . . . . . . . . . . . . . 57

5 Caminho de Conjugação Linear vs Ortogonal nos Polímeros DoadorAceitador

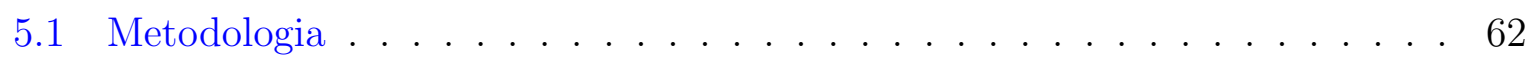

5.2 Propriedades Geométricas e Eletrônicas . . . . . . . . . . . . . . . . . 64

5.3 Transições do Estado Excitado Singleto . . . . . . . . . . . . . . . . . 70

6 Propriedades Eletrônicas e Ópticas dos Carotenóides $\quad 80$

6.1 Propriedades Estruturais e Eletrônicas . . . . . . . . . . . . . . . . . 82

6.2 Propriedades Ópticas . . . . . . . . . . . . . . . . . . . . . . . . . . 89

7 Considerações Finais $\quad 94$

A Propriedades Eletrônicas e Ópticas dos Sistemas DA via B3LYP/6$31 \mathrm{G}(\mathrm{d}, \mathrm{p}) \quad 96$

B Propriedades Eletrônicas e Ópticas dos Carotenóides via $\omega$ B97 /6-31G(d,p) $\begin{array}{ll}\text { com o Parâmetro } \omega \text { Otimizado } & 101\end{array}$

$\begin{array}{llr}\text { C Artigo } 1 & 104\end{array}$

Referências Bibliográficas $\quad 112$ 


\section{Lista de Figuras}

1.1 (a) Diodo orgânico emissor de luz branca; (b) Painel fotovoltaico orgânico flexível; (c) Leitor eletrônico flexível; (d) Rótulo de Rádio-frequência baseado em semicondutor orgânico. . . . . . . . . . . . . . . . . . 2

1.2 Etapas entre a injeção de cargas e a emissão de luz (OLEDs) e a absorção de luz e coleta de cargas (OPVs), destacando-se a importância do transporte de cargas no funcionamento do dispositivo. . . . . . . . . . . . . . . . 3

1.3 (a) Formação de bandas de energia na molécula de benzeno devido à superposição dos orbitais moleculares. (b) Aproximação de banda rígida para uma cadeia polimérica infinita. . . . . . . . . . . . . . . . 7

1.4 Estruturas do (a) triindole e (b) carbazol. . . . . . . . . . . . . . . . . . . 8

2.1 Sistema de coordenadas molecular utilizado para escrever o Hamiltoniano $\hat{H}: i, j=$ elétrons; $A, B=$ núcleos. . . . . . . . . . . . . . . 10

3.1 Curvas de energia potencial do doador $V_{r}(q)$ e do aceitador $V_{p}(q)$, onde $\Delta G^{\ddagger}$ é a energia de ativação térmica e $\Delta G^{0}$ é a energia livre do sistema. . . 31

3.2 Representação esquemática da intersecção dos níveis vibracionais dos reagente e produto. Aqui a separação no cruzamento não é mostrada e o overlap ideal do nível vibracional inicial $n=0$ é com o nível vibracional $n^{\prime}=1$ do produto

3.3 Superfícies de energia potencial do doador e aceitador em um processo de transferência de elétrons. Neste caso, assumindo que o doador e o aceitador é a mesma espécie molecular, temos que: $\lambda_{t o t}=\lambda_{0}+\lambda_{1}=\left(E^{0 / 1}-E^{0 / 0}\right)+$

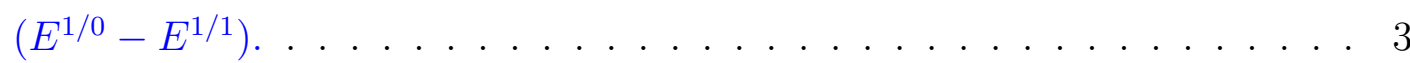


3.4 Dependência entre a taxa de reação, $k$, e a energia descrevendo a as regiões normal $\left(\lambda>\left|\Delta G^{0}\right|\right)$ e invertida $\left(\lambda<\left|\Delta G^{0}\right|\right)$. O pico da curva representa o ponto onde a taxa de transferência de elétrons é máxima $\left(\lambda=\left|\Delta G^{0}\right|\right)$. . .

3.5 a) Superfícies de energia para uma reação diabática. b) Superfície de energia para uma reação adiabática. . . . . . . . . . . . . . . . . .

3.6 a) HOMO de duas moléculas de etileno separadas a uma grande distância (esquerda e direta) e de um dímero (centro) onde as duas moléculas se encontram uma sobre a outra, separadas por uma certa distância $d$. O desdobramento em energia dos níveis $(\Delta E)$ é aproximadamente igual ao dobro da integral de transferência para buracos $\left(2 t_{H O M O}\right)$. b) Ilustração da função de onda para os orbitais correspondentes aos níveis da Figura 3.6 a. c) LUMO para a mesma situação. O desdobramento em energia dos níveis $(\Delta E)$ é, neste caso, aproximadamente igual ao dobro da integral de transferência para elétrons $\left(2 t_{L U M O}\right)$. d) Ilustração da função de onda para os orbitais correspondentes aos níveis da Figura 3.6 c. . . . . . . . . . . .

4.1 Molécula do triindole funcionalizada de três diferentes formas. Para cada uma delas utilizamos cinco diferentes grupos funcionais (Br, $\mathrm{CHO}$, Et, $\mathrm{MeO}$ $\left.\mathrm{e} \mathrm{NO}_{2}\right) \ldots \ldots \ldots \ldots \ldots \ldots \ldots$

4.2 Energia dos orbitais moleculares de fronteira do triindole funcionalizado com diferentes radicais e nas configurações A, B e C obtidos a nível B3LYP /6-

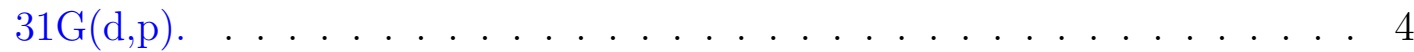

4.3 Ilustração dos orbitais moleculares de fronteira HOMO e LUMO para a molécula de triindole funcionalizada determinados em nível B3LYP/6$31 \mathrm{G}(\mathrm{d}, \mathrm{p})$. Os triindoles funcionalizados estão nas configurações (a) A, (b) $\mathrm{B}$ e $(\mathrm{c}) \mathrm{C} \ldots \ldots \ldots \ldots \ldots \ldots \ldots \ldots$

4.4 Espectro de absorção simulado $(\mathrm{FWHM}=30 \mathrm{~nm})$ para a molécula de triindole funcionalizada determinado com TDDFT a nível de teoria B3LYP/6$31 \mathrm{G}(\mathrm{d}, \mathrm{p})$ nas configurações (a) A, (b) B e (c) C. . . . . . . . . . . . . 50 
4.5 (a) Dímero usado para calcular as integrais de transferência associadas às rotações da geometria da molécula de triindole orimizada. (b) Geometria do dímero obtido da estrutura cristalina. . . . . . . . . . . . . . . . 54

4.6 Integral de transferência na geometria otimizada como função do ângulo de rotação. a) Integral de transferência de buracos. b) Integral de transferência de elétrons. . . . . . . . . . . . . . . . . . . 56

4.7 Dímero da molécula de triindole não funcionalizada. . . . . . . . . . . . . 58

4.8 Integral de transferência de elétrons da molécula de triindole não funcionalizada como função do ângulo de rotação. . . . . . . . . . . . . . . . . . 59

5.1 Caminho de conjugação (a) linear e (b) ortogonal. . . . . . . . . . . . . . . 61

5.2 Estruturas químicas das unidades monoméricas de: PbTBT $\equiv$ poly [4methyl-7- (5'-methyl- [2,2'-bithiophen]-5-yl) benzo[c][1,2,5]thiadiazole]; P$\mathbf{b T T P} \equiv$ poly [5-methyl-7- (5'-methyl- [2,2'-bithiophen] -5-yl) thieno [3,4b] pyrazine]; PCzBT $\equiv$ poly [4- (7,9-dimethyl-9H-carbazol-2-yl)-7-methylbenzo[c] $[1,2,5]$ thiadiazole]; PCzTP $\equiv$ poly [5- (7,9-dimethyl-9H-carbazol2-yl)-7-methylthieno[3,4-b] pyrazine]; PCzTh-TVDCN $\equiv$ poly [(E)-2((5-(2-(5-(7,9-dimethyl-9H-carbazol-2-yl)-2-methylthiophen-3-yl) vinyl) thiophen-2-yl) methylene) malononitrile]; PTTh-TVDCN $\equiv$ poly [(E)-2-((5(2-(5,5”-dimethyl- [2,2':5',2”-terthiophen]-3-yl) vinyl) thiophen-2-yl) methylene) malononitrile]. . . . . . . . . . . . . . . . . . . .

5.3 Ângulos de torção ao longo do esqueleto conjugado dos oligômeros DA. . .

5.4 Comprimento característico $(1 / \omega)$ como função do tamanho do oligômero obtido usando a nível LC-BLYP/6-31G(d,p). A escala do comprimento característico sobre o qual o tratamento do operador de Coulomb muda de curto-alcance (SR) para longo-alcance (LR) com a diminuição do valor de $\omega .66$

5.5 Energias do HOMO (topo) e LUMO (abaixo) com relação ao número de unidades repetidas (n) no oligômero. Para referência, a linha tracejada em cada gráfico representa a energia do HOMO (topo) e LUMO (abaixo) para o fulereno $\mathrm{PC}_{71} \mathrm{BM}$. Valores determinados a nível LC-BLYP/6-31G(d,p) com o parâmetro $\omega$ otimizado. . . . . . . . . . . . . . . . . . 68 
5.6 Ilustração dos orbitais moleculares de fronteira HOMO e LUMO para os tetrâmeros calculados a nível LC-BLYP/6-31G(d,p) com o parâmetro $\omega$ otimizado. . . . . . . . . . . . . . . . . . 69

5.7 Evolução da energia de transição vertical $S_{0} \rightarrow S_{1}$ (topo) e valor absoluto do momento de dipolo de transição (abaixo) com relação ao inverso do número de unidades repetidas $(1 / n)$. Valores determinados em nível LCBLYP/6-31G(d,p) com o parâmetro $\omega$ otimizado. . . . . . . . . . . . . 7

5.8 Valores absolutos das componentes do momento de dipolo de transição $S_{0} \rightarrow S_{1}$ calculador a nível TD-LC-BYLP/6-31G(d,p) com o parâmetro $\omega$ otimizado. . . . . . . . . . . . . . . . . . .

5.9 Espectro de absorção simulado $(\mathrm{FWHM}=0,3 \mathrm{eV})$ para os tetrâmeros determinados com TDDFT a nível de teoria LC-BLYP/6-31G(d,p) com parâmetro $\omega$ otimizado: (topo) sistemas com carbazol e (abaixo) com tiofeno no esqueleto conjugado.

5.10 Ilustração dos orbitais naturais de transição (NTO) descrevendo a transição $S_{0} \rightarrow S_{1}$ para os sistemas lineares determinados a nível TDDFT LCBLYP/6-31G(d,p) com o parâmetro $\omega$ otimizado. $\lambda$ representa o peso associado à contribuição partícula-lacuna para uma dada transição eletrônica descrita pelos NTOs. . . . . . . . . . . . . . . . . 77

5.11 Ilustração dos orbitais naturais de transição (NTO) descrevendo a transição $S_{0} \rightarrow S_{1}$ para os sistemas ortogonalmente conjugados determinados a nível TDDFT LC-BLYP/6-31G(d,p) com o parâmetro $\omega$ otimizado. . . . . . . . 78

6.1 Estruturas químicas dos carotenóides. . . . . . . . . . . . . . . . . 81

6.2 Ângulos de torção ao longo do esqueleto conjugado dos carotenóides. . . . 83

6.3 Ligações químicas consideradas para o cálculo da BLA ao longo da cadeia dos carotenóides. . . . . . . . . . . . . . . . . . 85 
6.4 Energia dos orbitais moleculares de fronteira, HOMO e LUMO, determinados através do funcional B3LYP, como também através dos funcionais LC-BLYP e $\omega$ B97 com o parâmetro $\omega$ otimizado. Todos os cálculos foram

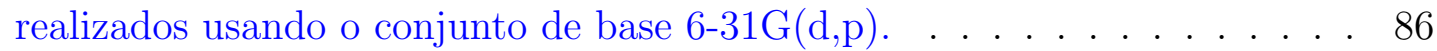

6.5 Ilustração dos orbitais moleculares de fronteira HOMO e LUMO para os carotenóides calculados a nível LC-BLYP/6-31G(d,p) com o parâmetro $\omega$

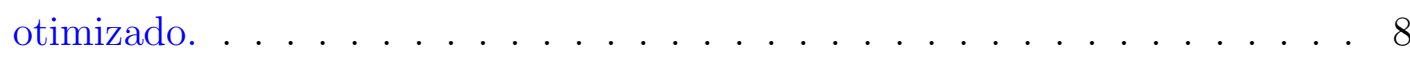

6.6 Espectro de absorção para as cinco moléculas calculadas a nível B3LYP/6$31 \mathrm{G}(\mathrm{d}, \mathrm{p})$ (topo) e LC-BLYP/6-31G(d,p) (abaixo) . . . . . . . . . . . . . 90

A.1 Evolução das energias dos orbitais HOMO (topo) e LUMO (abaixo) como função do inverso do número de unidades repetidas $(1 / n)$ nos oligômeros calculados a nível B3LYP/6-31G(d,p). . . . . . . . . . . . . . 96

A.2 Evolução da energia de transição vertical $S_{0} \rightarrow S_{1}$ (topo) e valor absoluto do momento de dipolo de transição (abaixo) como função do inverso do número de unidades repetidas $(1 / \mathrm{n})$, calculados a nível B3LYP/6-31G(d,p). 97

A.3 Espectro de absorção UV-Vis do PCzTh-TVDCN calculados a nível B3LYP/631G(d,p) e LC-BLYP/6-31G(d,p) com o parâmetro $\omega$ otimizado. A curva experimental foi extraída da referência [68] para uma comparação com os resultados teóricos. . . . . . . . . . . . . . . . . . . . . . 100

B.1 Ilustração dos orbitais moleculares de fronteira HOMO e LUMO para os carotenóides calculados a nível $\omega \mathrm{B} 97 / 6-31 \mathrm{G}(\mathrm{d}, \mathrm{p})$ com o parâmetro $\omega$ otimizado.

B.2 Espectro de absorção para as cinco moléculas calculadas a nível $\omega$ B97/6-

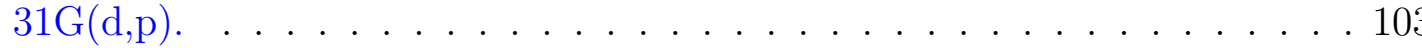




\section{Lista de Tabelas}

2.1 Comparação entre DFT e TDDFT. . . . . . . . . . . . . . . . . . 28

4.1 Energias dos orbitais moleculares HOMO e LUMO e gap HOMO-LUMO $\left(\mathrm{E}_{\text {gap }}\right)$ para o triindole ligado a diferentes grupos funcionais. . . . . . . . . 47

4.2 Energias de relaxação $(\mathrm{meV})$ e energia de reorganização intramolecular $(\mathrm{meV})$ para o triindole ligado a diferentes grupos funcionais. . . . . . . . . 52

5.1 Ângulos de torção (graus) ao longo do esqueleto conjugado dos tetrâmeros.

5.2 Energia de transição vertical $\left(E_{01}\right)$ e comprimento de onda $\left(\lambda_{01}\right)$, força do oscilador $(f)$, momento de dipolo de transição total $\left(\mu_{01}\right)$ e suas componentes $x, y, z$ determinadas para os maiores oligômeros da série. Todos os cálculos foram realizados a nível TD-LC-BLYP/6-31G(d,p) com o parâmetro $\omega$ otimizado. . . . . . . . . . . . . . . . . . . . . 72

5.3 Configurações eletrônicas determinadas para os maiores oligômeros da série determinados a nível TD-LC-BLYP/6-31G(d,p) com o parâmetro $\omega$ otimi-

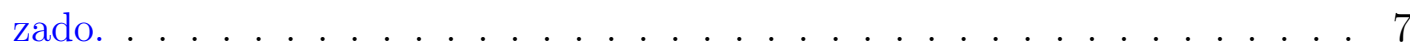

6.1 Ângulos de torção $(\Phi)$ ao longo do esqueleto conjugado dos carotenóides. . 83

6.2 Valores otimizados do parâmetro $\omega\left(\mathrm{Bohr}^{-1}\right)$ e comprimento característico $1 / \omega$ (Bohr) para os cinco carotenóides determinados pelos funcionais LCBLYP e $\omega$ B97 usando o mesmo conjunto de base 6-31G(d,p). Os valores de referência para o $(\omega)$ são: $\omega_{(L C B L Y P)}=0,47$ e $\omega_{(\omega B 97)}=0,4 \mathrm{Bohr}^{-1}$. . . 84

6.3 Valores da BLA obtidas via funcional B3LYP e pelos funcionais LRC, LCBLYP e $\omega$ B97, ambos utilizando os valores padrão e otimizado para o parâmetro ômega. . . . . . . . . . . . . . . . . . . .

6.4 Comprimentos de onda de absorção máxima $\lambda_{\max }$. Valores experimentais, B3LYP, LC-BLYP e $\omega$ B97 com os valores de $\omega$ otimizado e padrão. . . . . 91 
6.5 Energias de transição vertical $S_{0} \rightarrow S_{1}\left(E_{01}\right)$, força do oscilador $(f)$, momentos de dipolo de transição $\left(\mu_{01}\right)$, e configurações eletrônicas dos carotenóides determinados a nível de teoria LC-BLYP/6-31G(d,p) com o parâmetro $\omega$ otimizado. . . . . . . . . . . . . . . . . . . . . 92

A.1 Valores de $\omega$ (bohr ${ }^{-1}$ ) otimizados determinados via gap-fitting a nível de cálculo LC-BLYP $/ 6-31 G(\mathrm{~d}, \mathrm{p}) \ldots \ldots \ldots$

A.2 Energias dos orbitais moleculares HOMO e LUMO e gap HOMO-LUMO $\left(\mathrm{E}_{\text {gap }}\right)$ determinados via funcional LC-BLYP e B3LYP com o conjunto de base $6-31 \mathrm{G}(\mathrm{d}, \mathrm{p}) . \ldots \ldots \ldots \ldots \ldots \ldots$

B.1 Energias de transição vertical $S_{0} \rightarrow S_{1}\left(E_{01}\right)$, força do oscilador $(f)$, momentos de dipolo de transição $\left(\mu_{01}\right)$, e configurações eletrônicas dos carotenóides determinados a nível de teoria $\omega \mathrm{B} 97 / 6-31 \mathrm{G}(\mathrm{d}, \mathrm{p})$ com o parâmetro $\omega$ otimizado. . . . . . . . . . . . . . . . . . . . . . . . . 101 


\section{Resumo}

O presente trabalho consiste em um estudo teórico sobre os parâmetros importantes envolvidos no transporte de carga de semicondutores orgânicos, tais como o acoplamento eletrônico e a energia de reorganização. Esses parâmetros foram investigados para uma nova classe de semicondutores orgânicos que apresentam simetria $C_{3}$. Tais sistemas se apresentam como uma plataforma versátil com potencial para aplicação em eletrônica molecular. Nesta etapa, realizamos o cálculo do acoplamento eletrônico para o dímero de um dos derivados de triindole utilizando métodos Hartree-Fock (HF) e Teoria do Funcional Densidade (DFT). Confirmamos a forte dependência dos valores para o acoplamento eletrônico com relação ao método utilizado no cálculo de Química Quântica.

Como parte da investigação de novos compostos orgânicos para aplicação em dispositivos de eletrônica molecular, nós examinamos as propriedades eletrônicas e ópticas de um conjunto de moléculas $\pi$-conjugadas para aplicação em dispositivos de eletrônica molecular. Os sistemas estudados constituem uma série de copolímeros do tipo doadoraceitador que diferem na natureza da conjugação: sistemas que apresentam o tradicional caminho de conjugação linear ao longo do eixo do esqueleto conjugado, como também aqueles nos quais a conjugação entre as unidades aceitadoras é ortogonal ao eixo molecular. Diferenças significativas nas propriedades ópticas foram observadas nos sistemas conjugados ortogonalmente comparados aos polímeros mais tradicionais, onde os fragmentos doador e aceitador estão em série ao longo da direção do esqueleto conjugado. Os resultados obtidos nesta etapa de análises mostram que as propriedades eletrônicas e ópticas são muito influenciadas pela escolha dos fragmentos doador-aceitador, e estas propriedades podem ser vistas como uma função do caminho de conjugação.

Além disso, estudamos as propriedades eletrônicas e ópticas dos principais carotenóides presentes no óleo de Buriti. Os resultados mostram que o comprimento de conjugação molecular tem influência significativa no gap de energia e absorção óptica. Outro ponto discutido é a precisão dos resultados teóricos comparados aos dados experimentais. Aqui destacamos a dificuldade que os métodos de Química Quântica têm para descrever corretamente os sistemas que apresentam longas cadeias conjugadas, como o poliacetileno e a família das cianinas. 


\section{Abstract}

In this work we present a theoretical study of the important parameters involved in charge transport of organic semiconductors, such as the electronic coupling and reorganization energy. These parameters were investigated for a new class of organic semiconductors that exhibit $C_{3}$ symmetry. These systems represent a versatile platform with potential application for the molecular electronics. In this step, we perform the evaluation of the electronic coupling for a dimer of triindole derivatives using Hartree-Fock methods (HF) and Density Functional Theory (DFT). We confirmed the strong dependence of the electronic coupling values depending on the method used in the calculation.

As part of the investigation of new organic compounds for application in molecular electronics devices, we theoretically examine the electronic and optical properties of a set of molecules $\pi$-conjugated for application in molecular electronics devices. The studied systems constitute a series of donor-acceptor copolymers which differ in the nature of the conjugation pathway: Traditional linear conjugation having combined donor and acceptor units linked along the backbone of the conjugated axis as well as those where the combination of the acceptor units orthogonally attached to the axis of the conjugated backbone. Significant differences in optical properties were observed in the orthogonally conjugated systems compared to the more traditional polymers, where donor and acceptor fragments are in series along the direction of the conjugated backbone. The results of this analysis show that the electronic and optical properties are greatly influenced by the choice of donor-acceptor fragments, and these properties can be seen as a function of the conjugation pathway.

In addition, we studied the electronic and optical properties of the major carotenoids present in Buriti oil. The results show that the molecular conjugation length has a significant influence on the energy gap and optical absorption. Another discussed subject is the accuracy of the theoretical results compared to the experimental data. Here we highlight the difficulty that Quantum Chemical methods have to correctly describe systems that have long conjugated chains, such as polyacetylene and cyanines. 


\section{Introdução}

Hoje em dia a tecnologia tornou-se uma parte importante de nossas vidas. É comum vermos telefones móveis, notebooks, tocadores de música e muitos outros dispositivos eletrônicos, a qualquer momento e em qualquer lugar. Como a complexidade dos aparelhos móveis vem aumentando, a miniaturização e armazenamento de dados tornaram-se questões importantes. Todos os aparelhos requerem armazenamento de dados ou memórias. Memórias convencionais são implementadas em circuitos integrados à base de semicondutores, tais como transistores e capacitores. A principal força motora por trás da tecnologia de memórias e dispositivos é a demanda para aplicações móveis e também, a necessidade de aumentar a capacidade e desempenho dos sistemas, diminuir o consumo de energia, construir dispositivos de tamanho menor e reduzir o custo dos dispositivos. Entretanto, uma série de fatores físicos e econômicos ameaça a continuidade dos dispositivos de memória atuais à base de semicondutores inorgânicos [1]. Portanto, o fim, a vista, da tecnologia do silício e a necessidade de uma nova tecnologia em escala atômica/molecular têm despertado o interesse da comunidade acadêmica e também no setor industrial para o desenvolvimento de novas tecnologias. Dentro dessa perspectiva, a eletrônica molecular, tal como é observada na riqueza e complexidade de funcionamento dos seres vivos, surge como uma importante alternativa.

Ao contrário das tecnologias atualmente dominantes, em que os efeitos de memória estão associados a uma estrutura de célula especial, as novas tecnologias são baseadas na bi-estabilidade elétrica dos materiais decorrentes de alterações em certas propriedades intrínsecas, como magnetismo, polaridade, fase, conformação e condutividade, em resposta ao campo elétrico aplicado. Materiais orgânicos e polímeros são candidatos promissores para futuras aplicações de memória em escala molecular. Dentre suas propriedades atraentes listamos a boa processabilidade, dimensões miniaturizadas e a possibilidade de design molecular através da síntese química [2]. Tem sido demonstrado que um número pequeno de moléculas ou moléculas individuais, montadas dentro de andaimes endereçáveis, podem conduzir e chavear correntes elétricas, e podem reter bits de informações elétricas. As vantagens de memórias orgânicas e polímeros também 
incluem simplicidade na estrutura do dispositivo, potencial de baixo custo, operação à baixa potência, propriedades de estados múltiplos, capacidade de empilhamento tridimensional e grande capacidade de armazenamento de dados [1,3]. Em particular, materiais poliméricos possuem propriedades únicas, tais como resistência mecânica, flexibilidade e, a mais importante de todas, o custo de processamento e os equipamentos necessários para produzí-los são bem inferiores quando comparado aos custos envolvidos no caso dos semicondutores inorgânicos [1].

Desde os trabalhos iniciais de Aviram e Ratner [4], ainda na década de 70, muito se tem discutido sobre a construção de dispositivos eletrônicos como retificadores e transistores que tenham por base moléculas orgânicas. Através do uso de semicondu-

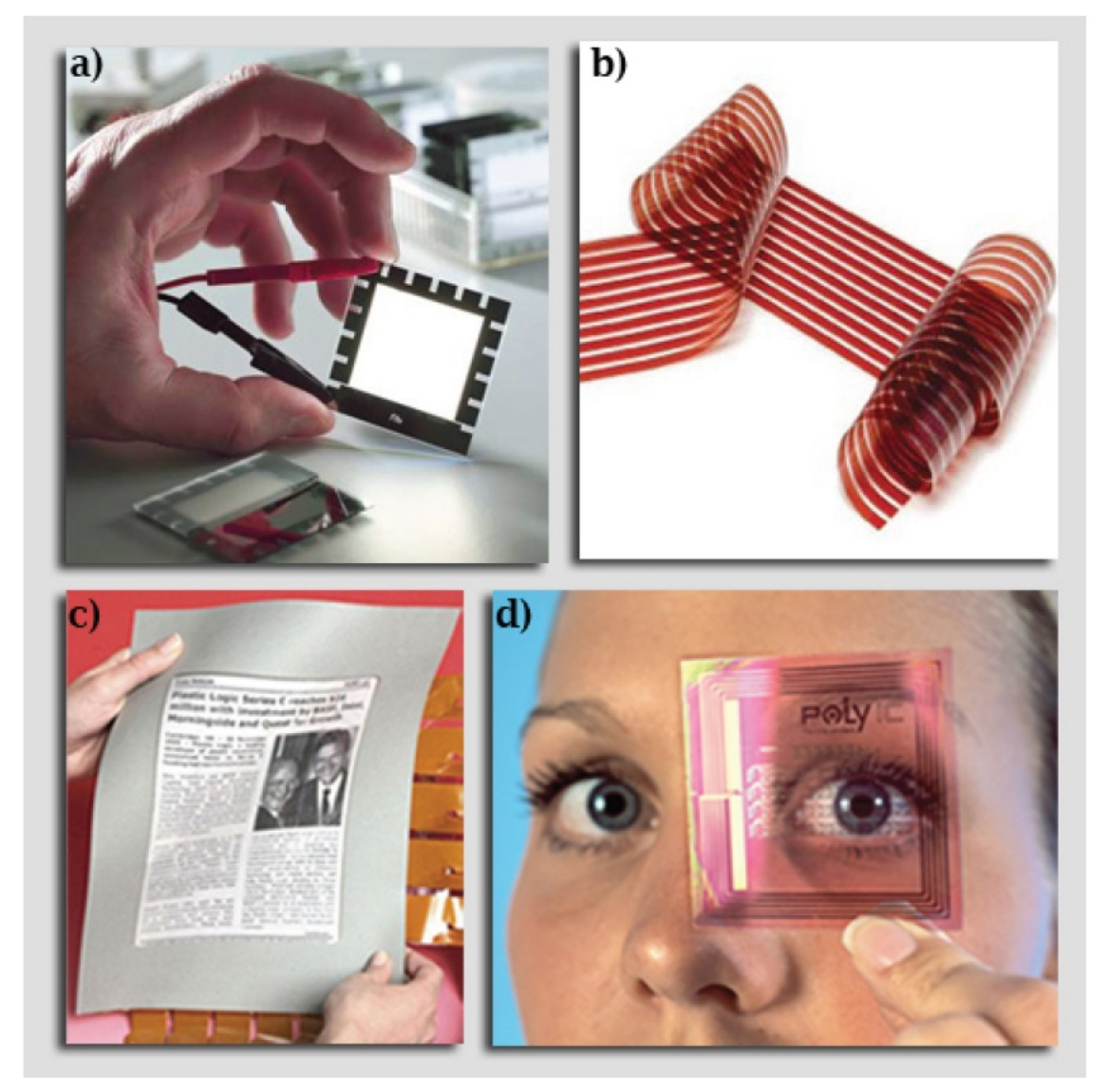

Figura 1.1: (a) Diodo orgânico emissor de luz branca; (b) Painel fotovoltaico orgânico flexível; (c) Leitor eletrônico flexível; (d) Rótulo de Rádio-frequência baseado em semicondutor orgânico.

tores orgânicos será possível, por exemplo, a produção de leitores eletrônicos (e-readers) flexíveis, lâmpadas onde a luz é emitida de uma superfície plana, painéis fotovoltaicos 
flexíveis e rótulos de rádio-frequência (RFID) de baixo custo (ver Figura 1.1), que poderão vir a substituir o código de barra que é utilizado atualmente na identificação de produtos.

A flexibilidade de síntese proporcionada pela química do carbono permite desenharmos moléculas específicas para determinadas aplicações. Este design, no entanto, depende do conhecimento detalhado dos processos envolvidos desde a entrada de portadores de carga no dispositivo a emissão de luz, no caso dos diodos orgânicos emissores de luz (OLEDs) ou da chegada de fótons a saída de portadores de carga do dispositivo, no caso dos dispositivos orgânicos fotovoltaicos (OPVs).

A Figura 1.2 apresenta, de forma resumida, o conjunto de processos que ocorrem nos OLEDs e nos OPVs. Pesquisas recentes indicam que o transporte de cargas dentro dos dispositivos, em ambos os casos, é uma das etapas mais importantes na sua eficiência global e que a otimização desta etapa terá um impacto direto na eficiência do dispositivo como um todo [5].

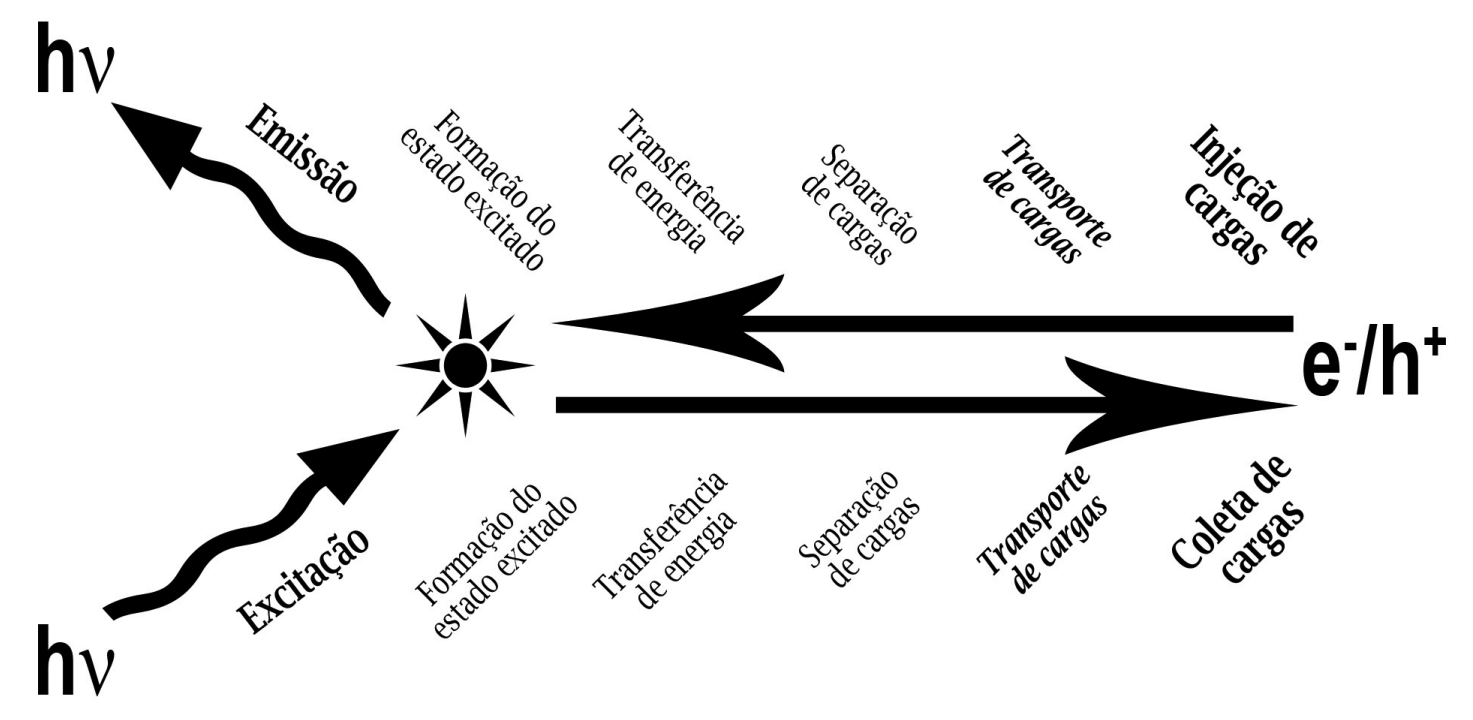

Figura 1.2: Etapas entre a injeção de cargas e a emissão de luz (OLEDs) e a absorção de luz e coleta de cargas (OPVs), destacando-se a importância do transporte de cargas no funcionamento do dispositivo.

O desempenho dos dispositivos eletrônicos baseados em semicondutores orgâni$\cos \pi$-conjugados depende em grande parte da eficiência no processo de transporte de carga. Em nível microscópico, um dos parâmetros principais que governam as propriedades de transporte é a amplitude das integrais de transferência de elétrons e buracos 
entre moléculas adjacentes ou cadeias poliméricas. Este parâmetro, também chamado de acoplamento eletrônico será objeto de estudo do nosso trabalho. Partindo disso, neste trabalho, nós realizamos cálculos de Química Quântica em derivados de triindole para abordar a forma como as integrais de transferência entre moléculas adjacentes são afetadas pelo nível de cálculo empregado na otimização de geometria da molécula. A seguir é dada uma motivação para o estudo realizado e os objetivos desta tese. Além disso, uma breve discussão é feita sobre semicondutores orgânicos e suas propriedades importantes para o processo de transferência de carga. O capítulo 2 traz uma breve discussão sobre os métodos de Química Quântica que foram utilizados nos cálculos que realizamos. No capítulo 3 será apresentada uma abordagem sobre a Teoria de Marcus utilizada para calcular a taxa de transferência de elétrons em reação de transferência de carga. Além disso, será explorado o conceito da energia de reorganização e do acoplamento eletrônico. Esses parâmetros são de extrema importância no processo de transporte de carga em semicondutores orgânicos, como veremos a seguir.

Uma das propostas deste trabalho é estudar, teoricamente, os parâmetros mais importantes envolvidos no transporte de carga de semicondutores orgânicos, a fim de não somente caracterizar as moléculas já sintetizadas mas, também traçar estratégias que permitam a identificação de moléculas promissoras. Entender o comportamento desses parâmetros, tal como o acoplamento eletrônico sobre uma pilha de moléculas, é uma das condições necessárias para a compreensão do processo de transporte de carga pela molécula. Estes cálculos foram aplicados para uma nova classe de semicondutores orgânicos baseados no triindole, uma plataforma com simetria $C_{3}$, que se apresenta como uma plataforma promissora para o transporte de carga. Aqui, cálculos teóricos foram utilizados para avaliar a possibilidade de se melhorar o acoplamento eletrônico das moléculas na fase sólida através da funcionalização da molécula de partida (o triindole). A possibilidade de funcionalização dessas moléculas em diferentes posições oferece uma enorme versatilidade sintética e um grande potencial para se modular as propriedades eletrônicas e a organização supramolecular de forma independente.

O estudo teórico de novos materiais requer não somente o cálculo de parâmetros envolvidos no transporte de carga, mas também vários outros cálculos que caracterizam a estrutura eletrônica e geométrica destes materiais. Muito embora estes cálculos sejam essencialmente de rotina, vale a pena salientar que foram utilizadas metodologias que 
representam o estado da arte para a execução dos mesmos, como por exemplo, cálculos utilizando a Teoria do Funcional Densidade (DFT). Estes cálculos são conduzidos com a finalidade de caracterizar os novos sistemas e explicar as propriedades físico-químicas obtidas experimentalmente (quando houver resultados experimentais disponíveis).

No capítulo 5 será apresentado um estudo sobre o impacto que diferentes caminhos de conjugação exercem sobre as propriedades geométricas, eletrônicas e ópticas dos copolímeros doador-aceitador (DA). Este trabalho foi realizado em um período de estágio no grupo do Prof. Jean-Luc Brédas, no Instituto de Tecnologia da Geórgia (Estados Unidos), pelo Programa de Doutorado Sanduíche no Exterior (PDSE) da CAPES. Os caminhos de conjugação considerados nesse estudo foram: i) o de conjugação linear (em série) entre as unidades doadora e aceitadora, e ii) o caminho de conjugação em que as unidades aceitadoras são anexadas ortogonalmente ao esqueleto conjugado linear, formado somente por unidades doadoras. Para esse estudo, foi realizado uma investigação através de cálculos de Química Quântica em nível DFT. Os funcionais híbridos de longo alcance (LRC) foram usados na investigação das propriedades desses sistemas, e o parâmetro de longo alcance dos oligômeros foi otimizado para fornecer uma estimativa da extensão do comprimento de conjugação como função da arquitetura do oligômero. Diferenças significativas nas propriedades eletrônicas e ópticas foram determinadas como função da natureza do caminho de conjugação, característica essa que deve ser levada em consideração no design de copolímeros do tipo DA.

Também fez parte do programa de doutorado uma colaboração com o Prof. Wiliam Cunha, do Instituto de Física da Universidade de Brasília. Nesta colaboração, fizemos um estudo sobre as propriedades eletrônicas e ópticas dos carotenóides, que são um grupo de moléculas de pigmentos naturais e ocupam posição de destaque por realizarem uma série de funções essenciais a vida. A forte absorção óptica na região do visível indica que os carotenóides podem ser potenciais candidatos para aplicações em dispositivos de eletrônica molecular. A descrição das propriedades eletrônicas e ópticas desses sistemas foi feita através de cálculos de química quântica com o método DFT, aplicando as técnicas obtidas no período de estágio no grupo do Prof. Jean-Luc Brédas. A performance dos resultados teóricos obtidos via DFT com funcionais híbridos e funcionais híbridos de longo alcance modificado pode ser melhor comparada com os experimentais (quando disponíveis). 
Concluímos este trabalho no capítulo 7, apresentando um sumário dos principais resultados obtidos e as conclusões alcançadas nesta tese.

\subsection{Semicondutores Orgânicos}

A eletrônica molecular vem experimentando um rápido desenvolvimento nos últimos anos desde pesquisas básicas até a construção de dispositivos a base de moléculas, que já são viáveis comercialmente [1]. Estes dispositivos têm em comum o fato de sua performance depender da eficiência da injeção de portadores de carga e como são transportados em diferentes camadas orgânicas. Portanto, os avanços alcançados neste campo estão conectados ao aprimoramento da mobilidade dos portadores de carga nos sistemas moleculares. Entretanto, a incorporação de sistemas orgânicos em dispositivos eletrônicos ainda apresenta sérias limitações de estabilidade das moléculas e processamento. No caso das propriedades de transporte, um conjunto de variáveis (qualidade dos contatos, tamanho e pureza dos cristais, etc) precisa ser otimizado antes mesmo de se fazer qualquer medida. Um dos fatores críticos é a dependência das propriedades de transporte com o empacotamento das moléculas. Além disso, a medida da mobilidade das cargas é uma tarefa muito trabalhosa. Nesta etapa, uma das principais necessidades é encontrar novos materiais orgânicos semicondutores que resultem em dispositivos com mobilidade maior. Um dos materiais que ganhou destaque entre tais semicondutores é a família dos oligoacenos. Estes materiais atraíram a atenção de experimentais e teóricos devido a alta mobilidade dos portadores de carga no estado sólido [5]. No entanto, a alta reatividade destes compostos com o oxigênio torna-os pouco úteis para aplicações práticas, já que pretende-se utilizar os semicondutores orgânicos em dispositivos de baixo custo onde, por exemplo, o encapsulamento do dispositivo seja também uma etapa simples.

Uma das características importantes dos semicondutores orgânicos é a delocalização dos elétrons $-\pi$, ou seja, os elétrons podem mover-se de um átomo a outro. Esta propriedade está associada ao fato de que a energia de ligação dos elétrons $\pi$ é bem menor do que no caso dos orbitais $\sigma$, podendo assim, ser mais facilmente excitados. Na Figura 1.3 (a) ilustra-se qualitativamente a formação dos níveis de energia para uma molécula de benzeno. Cada átomo de carbono do benzeno contribui com um nível de energia para o sistema- $\pi$. O nível de energia mais baixo no conjunto de orbitais anti-ligantes 
$\pi^{*}$ é denominado LUMO. O nível de energia mais alto no conjunto de orbitais ligantes $\pi$ é denominado HOMO. Estendendo esta análise para o caso de uma cadeia polimérica infinita, ocorre uma grande sobreposição dos orbitais $\pi$ fazendo com que o elétron fique delocalizado na cadeia polimérica. Se considerarmos $n$ infinito e a molécula como um sistema unidimensional, pode ser observada a formação de uma banda de energia similar àquela encontrada em semicondutores inorgânicos (ver Figura 1.3(b)), onde a banda $\pi$ corresponde a banda de valência e a banda $\pi^{*}$ a banda de condução.

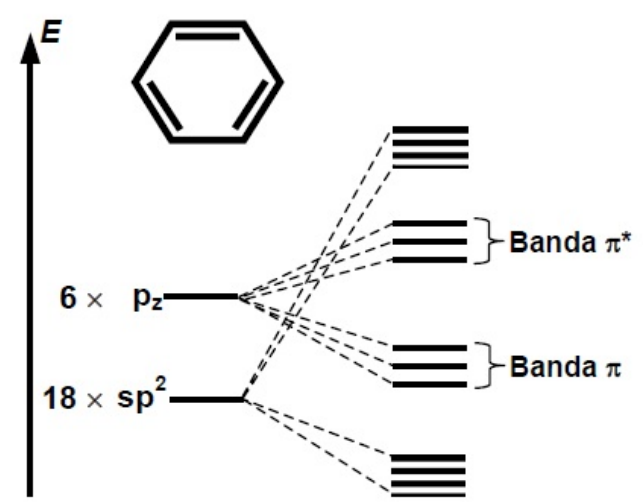

(a)

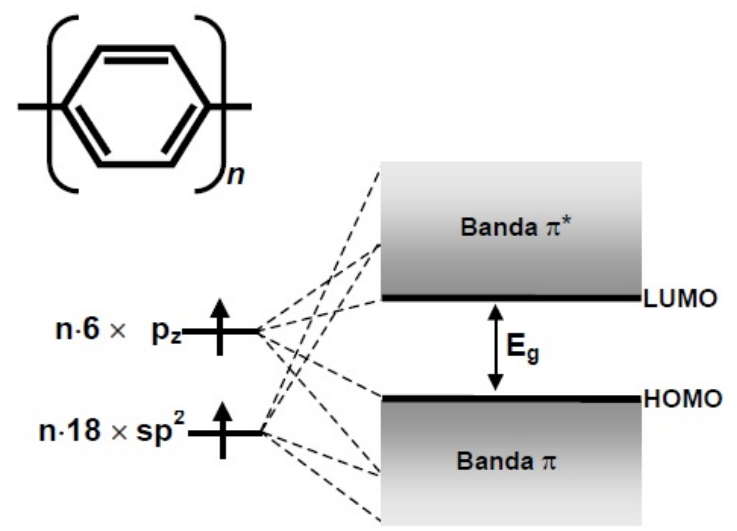

(b)

Figura 1.3: (a) Formação de bandas de energia na molécula de benzeno devido à superposição dos orbitais moleculares. (b) Aproximação de banda rígida para uma cadeia polimérica infinita.

Os orbitais nos átomos ou moléculas adjacentes passam a interagir tão fortemente, que os orbitais do sistema são descritos como estendidos, sobre todo o sistema molecular. A quebra de degenerescência produz um intervalo contínuo de níveis de energia possíveis, formando bandas. O perfil das bandas de energia depende das distâncias interatômicas e da natureza da ligação química. Cada banda representa uma grande quantidade de estados eletrônicos permitidos. Entre essas bandas de energias permitidas existe uma região de energia não acessível aos elétrons, denominada de banda ou lacuna de energia proibida, também conhecida com "gap". Dependendo da ocupação eletrônica e da energia associada ao "gap", o sólido é classificado como: isolante, semicondutor ou condutor.

Na busca de novos sistemas moleculares para aplicação em eletrônica mo- 

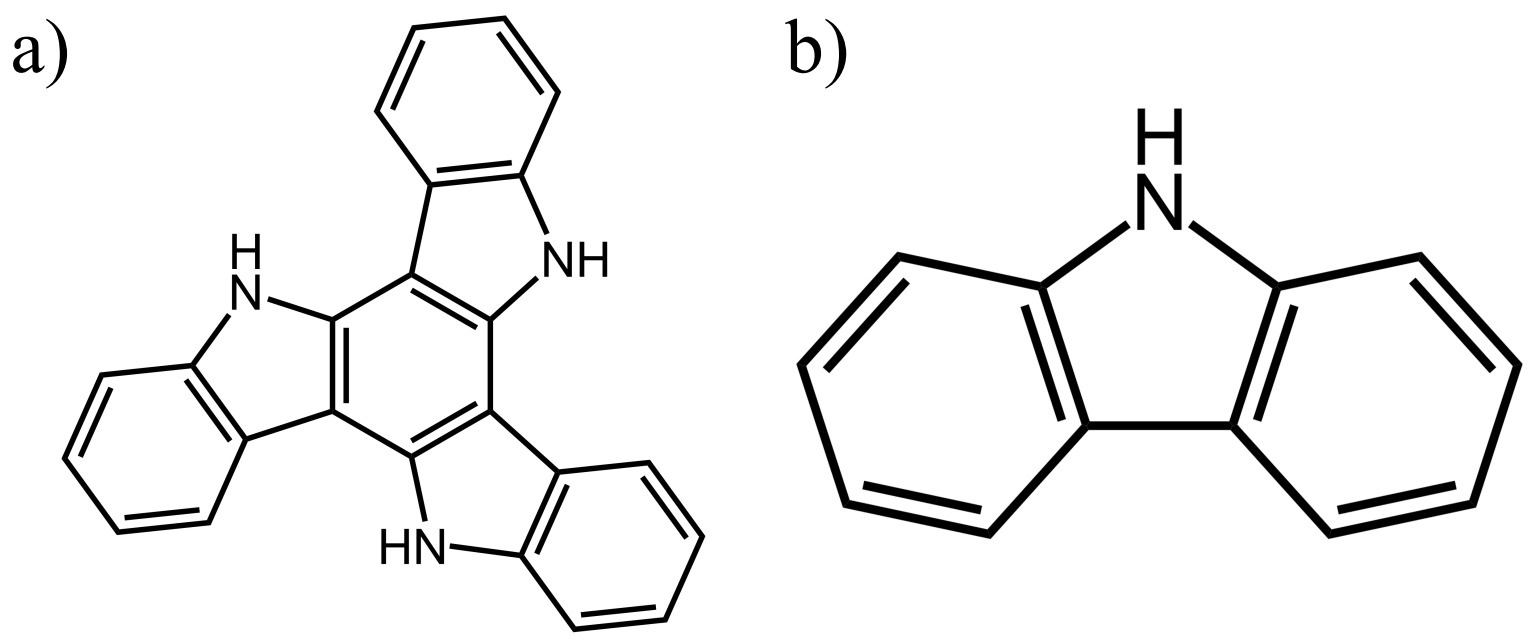

Figura 1.4: Estruturas do (a) triindole e (b) carbazol.

lecular, os sistemas orgânicos baseados nas novas plataformas com simetria $C_{3}$ - uma molécula que possui três eixos de simetria, a exemplo dos derivados do triindole - aparecem como uma importante alternativa pois já foi demonstrado ser um esqueleto rico em elétrons ocasionando uma alta mobilidade de buracos [6-15]. Este tipo de molécula pode ser considerado como um sistema $\pi$-estendido em que três unidades de carbazol compartilham um único anel aromático (ver Figura 1.4). A relação particular deste sistema aromático policíclico com o conhecido transportador de buracos (carbazol) [6], juntamente com sua estrutura $\pi$-estendida projetaram os triindoles como importantes candidatos para eletrônica orgânica. Também é importante destacar que já foram obtidos experimentalmente cristais e cristais líquidos baseados na molécula de triindole com alta mobilidade de buracos para semicondutores orgânicos $\left(\approx 0,4 \mathrm{~cm}^{2} \mathrm{~V}^{-1} \mathrm{~s}^{-1}\right)[6-15]$, resultado destas propriedades intrínsecas da molécula (sistemas $\pi$-conjugado, rico em elétrons, de fácil oxidação reversível, etc). Uma das características importantes desse sistema é a formação de pilhas de moléculas altamente ordenadas e com separação intramolecular curta $(\approx 3,50$ A). Estes são dois ingredientes favoráveis ao transporte de cargas e, consequentemente, para se obter um bom semicondutor orgânico. 


\section{Fundamentação Teórica}

Neste Capítulo, apresentamos alguns métodos de aproximação que serão utilizados na descrição das propriedades eletrônicas dos sistemas moleculares. Aqui um dos objetivos é encontrar soluções aproximadas da equação de Schrödinger não-relativística e independente do tempo:

$$
\hat{H} \Phi=E \Phi
$$

onde $(\hat{H})$ é o operador Hamiltoniano e $(E)$ é a energia total de um sistema molecular.

Supondo um sistema molecular composto de $M$ núcleos e $N$ elétrons, descritos pelos vetores posição $\left\{\vec{R}_{A}\right\}$ e $\left\{\vec{r}_{i}\right\}$, respectivamente (ver Figura 2.1), o operador Hamiltoniano $\hat{H}$, em unidades atômicas, é escrito como:

$$
\hat{H}=-\frac{1}{2} \sum_{i=1}^{N} \nabla_{i}^{2}-\sum_{A=1}^{M} \frac{1}{2 M_{A}} \nabla_{A}^{2}-\sum_{i=1}^{N} \sum_{A=1}^{M} \frac{Z_{A}}{r_{i A}}+\sum_{i=1}^{N} \sum_{j>i}^{N} \frac{1}{r_{i j}}+\sum_{A=1}^{M} \sum_{B>A}^{M} \frac{Z_{A} Z_{B}}{R_{A B}}
$$

Na equação 2.2, $r_{i A}=\left|\vec{r}_{i A}\right|=\left|\vec{r}_{i}-\vec{R}_{A}\right|$ é a distância entre o $i$-ésimo elétron e o núcleo $A, r_{i j}=\left|\vec{r}_{i j}\right|=\left|\vec{r}_{i}-\vec{r}_{j}\right|$ é a distância entre o elétron $i$ e o elétron $j, R_{A B}=\left|\vec{R}_{A B}\right|=$ $\left|\vec{R}_{A}-\vec{R}_{B}\right|$ é a distância entre o núcleo $A$ e o núcleo $B, M_{A}$ é a razão entre a massa do núcleo $A$ e a massa de um elétron, $Z_{A}$ é o número atômico do núcleo $A$ e os operadores Laplaciano $\nabla_{i}^{2}$ e $\nabla_{A}^{2}$ envolvem derivadas em relação as coordenadas do $i$-ésimo elétron e o núcleo $A$, respectivamente. O primeiro termo na equação 2.2 corresponde ao operador energia cinética dos elétrons; o segundo termo ao operador energia cinética dos núcleos; o terceiro termo representa a interação eletrostática (atração coulombiana) entre os elétrons e os núcleos; o quarto e quinto termos representam a repulsão entre os elétrons e entre os núcleos, respectivamente.

Com o Hamiltoniano acima, a equação 2.2 é complicada de ser resolvida quando tratamos com sistemas de muitas partículas. Para a solução de sistemas mais complexos (moléculas e sólidos) é comum fazermos o uso de apróximações teóricas que simplifcam a resolução do problema, tal como descrevemos a seguir. 


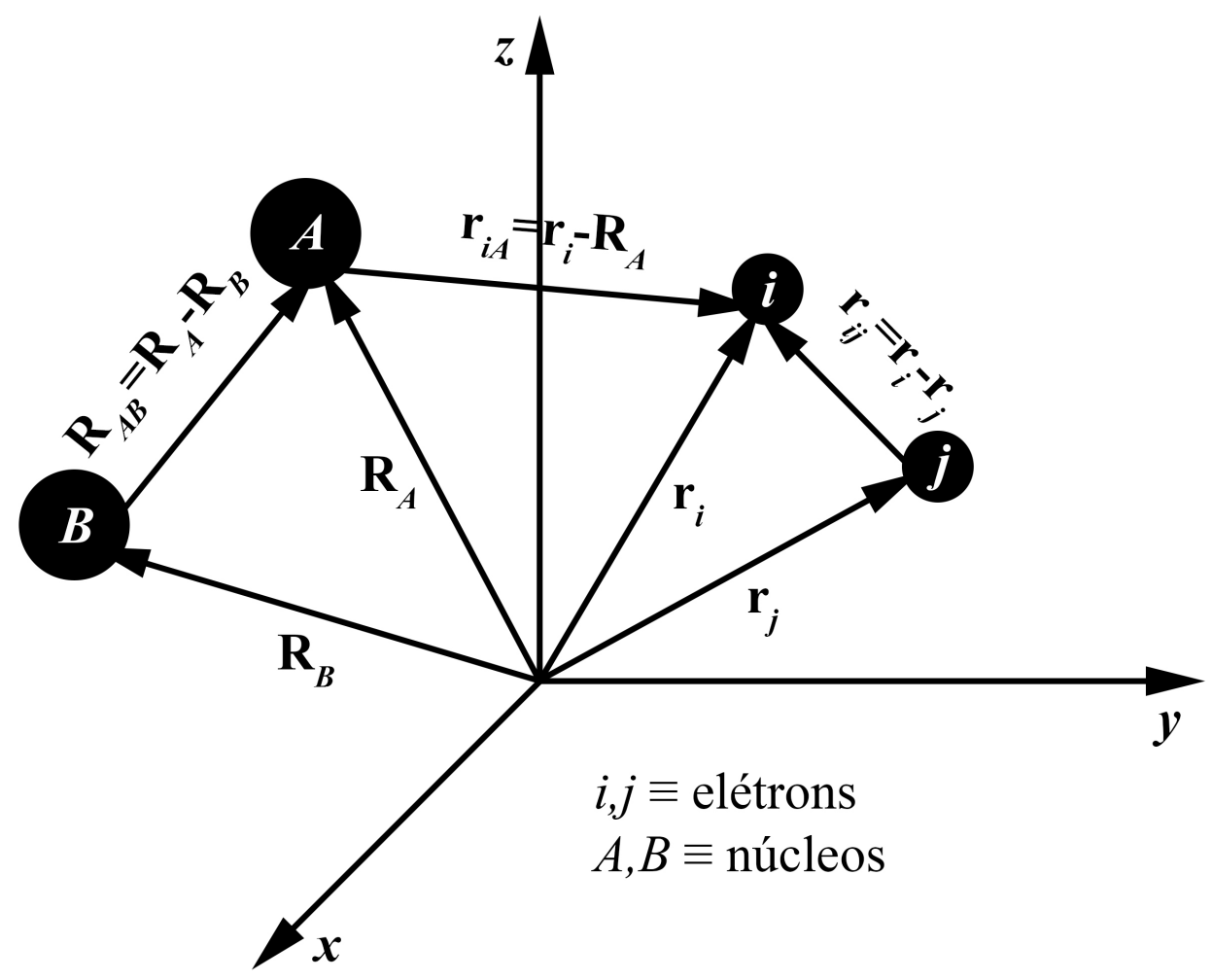

Figura 2.1: Sistema de coordenadas molecular utilizado para escrever o Hamiltoniano $\hat{H}$ : $i, j=$ elétrons; $A, B=$ núcleos.

\subsection{Aproximação de Born-Oppenheimer}

Nos compostos moleculares os núcleos são consideravelmente mais pesados e mais lentos do que os elétrons. Isto permite que certas aproximações sejam feitas para tornar possível a solução da equação 2.2. Neste caso, este comportamento sugere a idéia de que os elétrons podem se ajustar instantaneamente a qualquer mudança nas posições dos núcleos atômicos, ou ainda, os elétrons em uma molécula seguem "suavemente" as vibrações e rotações dos núcleos. Este modelo foi desenvolvido quantitativamente por Born e Oppenheimer e é conhecido como a aproximação de Born-Oppenheimer. Dentro desta aproximação o segundo termo na equação 2.2 (equivalente a energia cinética dos núcleos) é muito menor que os demais termos podendo ser desprezado e o último termo, que descreve a repulsão entre os núcleos, pode ser considerado uma constante. Qualquer constante adicionada a um operador não tem efeito sobre suas autofunções, apenas sobre seus autovalores. Estes, por sua vez, passarão a estar acrescidos dessa constante. Os 
termos remanescentes definem o chamado Hamiltoniano eletrônico $\left(\hat{H}_{e l}\right)$ dado por:

$$
\hat{H}_{e l}=-\frac{1}{2} \sum_{i=1}^{N} \nabla_{i}^{2}-\sum_{i=1}^{N} \sum_{A=1}^{M} \frac{Z_{A}}{r_{i A}}+\sum_{i=1}^{N} \sum_{j>i}^{N} \frac{1}{r_{i j}} .
$$

Este hamiltoniano é então usado na equação de Schrödinger para a descrição do movimento dos elétrons no campo potencial dos núcleos fixos no espaço,

$$
\hat{H}_{e l} \psi\left(\left\{\overrightarrow{r_{i}}\right\} ;\left\{\overrightarrow{R_{A}}\right\}\right)=E_{e l}\left(\left\{\overrightarrow{R_{A}}\right\}\right) \psi\left(\left\{\overrightarrow{r_{i}}\right\} ;\left\{\overrightarrow{R_{A}}\right\}\right)
$$

onde a função de onda total é reduzida para função de onda eletrônica $\left(\psi\left(\left\{\overrightarrow{r_{i}}\right\} ;\left\{\overrightarrow{R_{A}}\right\}\right)\right)$, que descreve o movimento dos elétrons e depende explicitamente das coordenadas eletrônicas $\left\{\vec{r}_{i}\right\}$ e parametricamente das coordenadas nucleares $\left\{\overrightarrow{R_{A}}\right\}$. O mesmo vale para a energia eletrônica,

$$
E_{e l}=E_{e l}\left(\left\{\vec{R}_{A}\right\}\right)
$$

Por uma dependência paramétrica entende-se que, para diferentes arranjos nucleares, $\psi$ é uma função diferente das coordenadas eletrônicas. Mas as coordenadas nucleares não aparecem explicitamente em $\psi$. A energia total para os núcleos fixos também deve incluir o termo constante devido à repulsão nuclear,

$$
E_{t o t}=E_{e l}+\sum_{A=1}^{M} \sum_{B>A}^{M} \frac{Z_{A} Z_{B}}{R_{A B}} .
$$

As equações anteriores constituem o problema eletrônico.

Uma vez resolvido o problema eletrônico, podemos resolver em seguida o problema nuclear sob as mesmas hipóteses que usamos para formular o primeiro. Como os elétrons se movem bem mais rapidamente que os núcleos, uma aproximação razoável é supor que os núcleos sentem apenas um potencial médio devido aos elétrons. Isto, então, gera um Hamiltoniano nuclear para o movimento dos núcleos no campo médio dos elétrons,

$$
\begin{aligned}
\hat{H}_{N} & =-\sum_{A=1}^{M} \frac{1}{2 M_{A}} \nabla_{A}^{2}+\left\langle-\frac{1}{2} \sum_{i=1}^{N} \nabla_{i}^{2}-\sum_{i=1}^{N} \sum_{A=1}^{M} \frac{Z_{A}}{r_{i A}}+\sum_{i=1}^{N} \sum_{j>i}^{N} \frac{1}{r_{i j}}\right\rangle+\sum_{A=1}^{M} \sum_{B>A}^{M} \frac{Z_{A} Z_{B}}{R_{A B}} \\
& =-\sum_{A=1}^{M} \frac{1}{2 M_{A}} \nabla_{A}^{2}+E_{e l}\left(\left\{\vec{R}_{A}\right\}\right)+\sum_{A=1}^{M} \sum_{B>A}^{M} \frac{Z_{A} Z_{B}}{R_{A B}} \\
& =-\sum_{A=1}^{M} \frac{1}{2 M_{A}} \nabla_{A}^{2}+E_{\text {tot }}\left(\left\{\vec{R}_{A}\right\}\right) .
\end{aligned}
$$


A energia total, $E_{t o t}\left(\left\{\vec{R}_{A}\right\}\right)$, provê um potencial para o movimento nuclear. Os núcleos, na aproximação de Born-Oppenheimer, movem-se sobre uma superfície de potencial obtida ao resolvermos o problema eletrônico. As soluções da equação de Schrödinger nuclear,

$$
\hat{H}_{N} \phi=E \phi
$$

descrevem as vibrações, rotações e translações de uma molécula. E, que é a energia total na aproximação de Born-Oppenheimer, inclui a energia eletrônica, vibracional, translacional e rotacional. A aproximação correspondente para a função de onda total da equação 2.1 é:

$$
\Phi\left(\left\{r_{i}\right\},\left\{R_{A}\right\}\right)=\psi\left(\left\{r_{i}\right\} ;\left\{R_{A}\right\}\right) \phi\left(\left\{R_{A}\right\}\right)
$$

\subsection{Orbitais e o Determinante de Slater}

O Hamiltoniano eletrônico na equação 2.3 depende apenas das coordenadas espaciais dos elétrons. Entretanto, para descrever completamente o estado de um elétron, é necessário especificar a sua coordenada de spin. Isto é feito, no contexto da nossa teoria não-relativística, introduzindo duas funções de $\operatorname{spin} \alpha(\omega)$ e $\beta(\omega)$, uma correspondendo ao "spin para cima" e a outra ao "spin para baixo", respectivamente [18]. Estas funções, de uma variável de spin não especificada $\omega$, formam um conjunto completo e ortonormal,

$$
\begin{aligned}
& \int d \omega \alpha^{*}(\omega) \alpha(\omega)=\int d \omega \beta^{*}(\omega) \beta(\omega)=1 \\
& \int d \omega \alpha^{*}(\omega) \beta(\omega)=\int d \omega \beta^{*}(\omega) \alpha(\omega)=0 .
\end{aligned}
$$

Dessa forma, o elétron é descrito não somente pelas coordenadas espaciais $(r)$, mas também por uma coordenada de spin $(\omega)$. Portanto, denotaremos o conjunto das quatro coordenadas por $(x)$. A função de onda para um sistema de $N$ elétrons é então, uma função de $x_{1}, x_{2}, \ldots, x_{N}$, ou seja, $\Phi\left(x_{1}, x_{2}, \ldots, x_{N}\right)$.

Note que o operador Hamiltoniano não faz referência às coordenadas de spin. Assim, um requerimento adicional para tratar as partículas de spin semi-inteiro, como é o caso dos elétrons, consiste em assumir que: "Uma função de onda de muitos elétrons deve ser anti-simétrica com respeito à troca das coordenadas $x$ de quaisquer dois elétrons":

$$
\Phi\left(x_{1}, \ldots, x_{i}, \ldots, x_{j}, \ldots, x_{n}\right)=-\Phi\left(x_{1}, \ldots, x_{j}, \ldots, x_{i}, \ldots, x_{n}\right)
$$


Este requerimento é chamado de princípio de anti-simetria e é uma definição mais geral do princípio de exclusão de Pauli. Este é um postulado independente da Mecânica Quântica não-relativística. Assim, a função de onda que descreve um sistema de muitos elétrons, deve não somente satisfazer a equação de Schrödinger, como também deve ser anti-simétrica.

Uma vez definidos os requerimentos aos quais a função de onda deve satisfazer, podemos agora construí-la, incluindo as coordenadas espaciais e de spin. Fazemos isto multiplicando a função de onda espacial pela função de spin $\alpha(\omega)$ ou $\beta(\omega)$. A função de onda do elétron, que descreve tanto a parte espacial quanto o seu spin é chamada de spin-orbital, $\chi(x)$ :

$$
\chi(x)=\left\{\begin{array}{c}
\psi(r) \alpha(\omega) \\
\mathrm{ou} \\
\psi(r) \beta(\omega) .
\end{array}\right.
$$

Esta é a função de onda de um único elétron em um sistema molecular.

Para determinar a função de onda de um conjunto de $N$ elétrons podemos voltar à equação 2.3 e observar que a ausência do termo associado à interação entre dois elétrons, isto é, o terceiro termo à direita da igualdade, o problema de $N$ elétrons se resumiria a $N$ equações de um elétron:

$$
\hat{H}=\sum_{i} h(i)
$$

onde $h(i)$ é um operador de um elétron que envolve os termos relativos ao elétron $i$ nos dois primeiros somatórios da equação 2.3. Para cada elétron, teríamos então uma equação de autovalores do tipo:

$$
h(i) \chi_{j}\left(x_{i}\right)=\epsilon_{j} \chi_{j}\left(x_{i}\right)
$$

e a equação de Schrödinger para o sistema molecular seria dada por:

$$
\hat{H} \Phi^{P H}=\sum_{i} h(i) \Phi^{P H}=\sum_{i} \epsilon_{i} \Phi^{P H}
$$

que é uma equação separável e $\Phi^{P H}$ pode ser escrito como:

$$
\Phi^{P H}\left(x_{1}, x_{2}, \ldots, x_{N}\right)=\chi_{i}\left(x_{1}\right) \chi_{j}\left(x_{2}\right) \ldots \chi_{k}\left(x_{N}\right)
$$

Agora devemos impor a condição de anti-simetria para a função de onda. Então, podemos construir uma combinação do produto de Hartree $\left(\Phi^{P H}\right)$, que é a solução exata do 
problema sem repulsão eletrônica e que satisfaz o princípio da exclusão de Pauli:

$$
\Phi=\frac{1}{(N !)^{1 / 2}}\left|\begin{array}{cccc}
\chi_{1}\left(x_{1}\right) & \chi_{2}\left(x_{1}\right) & \ldots & \chi_{2 K}\left(x_{1}\right) \\
\chi_{1}\left(x_{2}\right) & \chi_{2}\left(x_{2}\right) & \ldots & \chi_{2 K}\left(x_{2}\right) \\
\vdots & \vdots & \ddots & \vdots \\
\chi_{1}\left(x_{2 K}\right) & \chi_{2}\left(x_{2 K}\right) & \ldots & \chi_{2 K}\left(x_{2 K}\right)
\end{array}\right|
$$

Esta forma de representar a solução anti-simétrica do "problema de Hartree" é chamada de Determinante de Slater, onde a troca de duas partículas quaisquer implica na troca de duas linhas do determinante, mudando o sinal de $\Phi$.

Para resolver o problema de forma realística precisamos incluir o termo de repulsão Coulombiana entre os elétrons. A equação diferencial resultante não tem solução analítica na grande maioria dos casos. Uma solução aproximada, proposta por Hartree, Fock e Slater [16], consiste em usar o princípio variacional, em que os spin-orbitais figuram como funções (parâmetros) variacionais no processo de minimização da energia, como será discutido na próxima seção.

\subsection{Aproximação Hartree-Fock}

Nosso interesse aqui é o de apresentar esta aproximação em linhas gerais e não desenvolveremos certas demonstrações que achamos mais apropriadas para um texto específico sobre o tema. Referimos o livros do Szabo [16] e Cramer [17] como referência para um estudo mais detalhado.

Uma vez feita a separação dos movimentos eletrônicos e nucleares, a função de onda eletrônica pode ser escrita como um determinante de Slater,

$$
\left|\Phi_{0}\right\rangle=\left|\chi_{1}, \chi_{2}, \ldots, \chi_{a}, \chi_{b}, \ldots, \chi_{N}\right\rangle
$$

onde $\chi_{a}$ é a função que descreve tanto as coordenadas espaciais quanto as coordenadas de spin do elétron $a$ e a energia $E_{0}=\left\langle\Phi_{0}|\hat{H}| \Phi_{0}\right\rangle$ é um funcional dos spin-orbitais $\left\{\chi_{a}\right\}$. Para obter as equações de Hartree-Fock é necessário minimizar $E_{0}\left[\left\{\chi_{a}\right\}\right]$ com respeito aos spin-orbitais, sujeitos ao vínculo que os spin-orbitais permaneçam ortonormais, isto é,

$$
\int d x_{1} \chi_{a}^{*}(1) \chi_{b}(1)=\langle a \mid b\rangle=\delta_{a b} .
$$


Tendo em mente as regras do princípio variacional, podemos encontrar o conjunto otimizado dos orbitais moleculares minimizando a energia $E_{0}$. A energia do estado fundamental é dada por:

$$
E_{0}=\left\langle\Phi_{0}|H| \Phi_{0}\right\rangle=\sum_{a=1}^{N} h_{a a}+\frac{1}{2} \sum_{a=1}^{N} \sum_{b=1}^{N}\left(J_{a b}-K_{a b}\right)
$$

onde o primeiro termo da soma corresponde as integrais de um elétron que contém os termos de energia cinética e de energia potencial de atração elétron-núcleo:

$$
h_{a a}=\langle a|\hat{h}| a\rangle=\int d x_{1} \chi_{a}^{*}\left(x_{1}\right)\left(-\frac{1}{2} \nabla_{1}^{2}-\sum_{A} \frac{Z_{A}}{r_{1 A}}\right) \chi_{a}\left(x_{1}\right) .
$$

A segunda soma da equação 2.20 é composta pelo termo de Coulomb $\hat{J}$ e de troca $\hat{K}$ :

$$
\hat{J}_{a b}=\int d x_{1} d x_{2} \chi_{a}^{*}\left(x_{1}\right) \chi_{b}^{*}\left(x_{2}\right) \frac{1}{r_{12}} \chi_{a}\left(x_{1}\right) \chi_{b}\left(x_{2}\right)
$$

$\mathrm{e}$

$$
\hat{K}_{a b}=\int d x_{1} d x_{2} \chi_{a}^{*}\left(x_{1}\right) \chi_{b}^{*}\left(x_{2}\right) \frac{1}{r_{12}} \chi_{b}\left(x_{2}\right) \chi_{a}\left(x_{1}\right)
$$

Enquanto o termo de Coulomb, interpretado como o potencial eletrostático médio sentido por um elétron devido a presença dos outros N-1 elétrons, é um termo local, o termo de troca, decorrente da natureza antisimétrica da função de onda, é não-local no sentido de que não existe uma função potencial simples definida em um ponto específico $x_{a}$.

Através do método de multiplicadores de Lagrange podemos então minimizar a energia $E_{0}$ e, consequentemente encontrar a melhor função de onda eletrônica. Assim, a equação para os spin-orbitais utilizando o método dos multiplicadores de Lagrange é dada por:

$$
f \chi_{a}(1)=\sum_{b=1}^{N} \epsilon_{b a} \chi_{b}(1)
$$

onde $\epsilon_{b a}$ são os multiplicadores de Lagrange e $f$ é o operador de Fock.

As equações ainda podem ser escritas na forma canônica. Para isso, uma transformação unitária da forma,

$$
\chi_{a}^{\prime}=\sum_{b} \chi_{b} U_{b a}
$$


é realizada sobre os spin-orbitais $\left\{\chi_{a}\right\}$, tal que a matriz que representa os multiplicadores de Lagrange torna-se diagonal,

$$
\epsilon^{\prime}=\mathbf{U}^{\dagger} \epsilon \mathbf{U}
$$

Assim, o novo conjunto de spin-orbitais que diagonaliza a matriz $\epsilon$ são chamados de spin-orbitais canônicos, e a equação de Hartree-Fock (HF) reduz-se, portanto, a:

$$
f(1) \chi_{a}(1)=\epsilon_{a} \chi_{a}(1)
$$

A equação 2.27 é chamada de pseudo-equação de autovalor, uma vez que o valor do operador de Fock tem uma dependência funcional, através dos operadores de Coulomb e troca, sobre as soluções desta equação. Portanto, as equações de Hartree-Fock são equações acopladas e devem ser resolvidas iterativamente, obedecendo a um critério de convergência, até que a autoconsistência seja alcançada. Para uma descrição mais detalhada do método, o leitor deve consultar a referência [16].

Os resultados obtidos pelo método Hartree-Fock incluem grande parte da energia eletrônica do sistema e representam o melhor resultado que se pode obter a partir de um único determinante. Entretanto, o método Hartree-Fock desconsidera uma pequena fração da energia total do sistema. Isto se deve ao fato de uma das aproximações utilizadas no método HF ser a de que uma partícula se movimenta em um campo médio gerado pelos núcleos e pelos demais elétrons. Ou seja, o método HF trata o problema de interação elétron-elétron de uma forma média, ou como uma iteração autoconsistente [19] em que cada elétron participa do potencial que gera o movimento de todos os elétrons. Nesta aproximação não há um tratamento detalhado a respeito do movimento correlacionado dos elétrons. Portanto, é comum definir essa pequena fração da energia total do sistema (denominada energia de correlação), como sendo a diferença entre a energia exata não-relativística e a energia limite de Hartree-Fock:

$$
E_{\text {corr }}=E_{\text {exata }}-E_{H F} \text {. }
$$

Esta contribuição na energia é importante para a descrição detalhada das propriedades que sejam mais sensíveis à qualidade da função de onda, como por exemplo, momento de dipolo, polarizabilidades, etc. Diante da importância de se determinar sistematicamente a energia de correlação, vários métodos que consideram esse efeito em suas estratégias de cálculos têm sido desenvolvidos, os chamados métodos pós Hartree-Fock. 


\subsection{Energias dos Orbitais e o Teorema de Koopmans}

A minimização da energia de uma função de onda do tipo Slater $\left|\Phi_{0}\right\rangle=$ $\left|\chi_{1}, \chi_{2}, \ldots, \chi_{a}, \chi_{b}, \ldots, \chi_{N}\right\rangle$ leva à equação de autovalores $f\left|\chi_{a}\right\rangle=\epsilon_{a}\left|\chi_{a}\right\rangle$ para os $N$ spinorbitais ocupados $\chi_{a}$. O operador de Fock tem uma dependência funcional nesses spinorbitais ocupados, mas uma vez que os spin-orbitais são conhecidos, o operador de Fock terá um número infinito de auto-funções [16], isto é:

$$
f\left|\chi_{j}\right\rangle=\epsilon_{j}\left|\chi_{j}\right\rangle \quad j=1,2, \ldots, \infty
$$

Cada uma das soluções $\left|\chi_{j}\right\rangle$ da equação acima tem uma energia $\epsilon_{j}$. Os $N$ spin-orbitais com as energias mais baixas são os chamados spin-orbitais ocupados, que compõem $\left|\Phi_{0}\right\rangle$, para os quais se costuma usar os índices $a, b, \ldots$ O número infinito de spin-orbitais remanescente com alta energia são os spin-orbitais virtuais ou desocupados e são rotulados pelos índices $r, s, \ldots$ Para obter as expressões para as energias orbitais $\epsilon_{a}$ e $\epsilon_{r}$, multiplicamos a equação 2.29 por $\left\langle\chi_{i}\right|$, temos:

$$
\left\langle\chi_{i}|f| \chi_{j}\right\rangle=\epsilon_{j}\left\langle\chi_{i} \mid \chi_{j}\right\rangle=\epsilon_{j} \delta_{i j}
$$

As energias orbitais podem ser expressas como:

$$
\epsilon_{i}=\left\langle\chi_{i}|h| \chi_{i}\right\rangle+\sum_{i}\langle i b|| i b\rangle
$$

Assim, temos que:

$$
\epsilon_{a}=\langle a|h| a\rangle+\sum_{b=1}^{N}\langle a b|| a b\rangle,
$$

e

$$
\epsilon_{r}=\langle r|h| r\rangle+\sum_{b=1}^{N}\langle r b|| r b\rangle .
$$

Sabendo que $\langle a a \| a a\rangle=0$, podemos reescrever as equações acima da seguinte forma:

$$
\epsilon_{a}=\langle a|h| a\rangle+\sum_{b \neq a}\langle a b \mid a b\rangle-\langle a b \mid b a\rangle
$$

e

$$
\epsilon_{r}=\langle r|h| r\rangle+\sum_{b}\langle r b \mid r b\rangle-\langle r b \mid b r\rangle
$$


A energia orbital $\epsilon_{a}$ representa a energia de um elétron no spin-orbital $\left|\chi_{a}\right\rangle$. Esta energia é igual a energia cinética e a atração do núcleo $(\langle a|h| a\rangle)$ adicionada à energia de Coulomb $(\langle a b \mid a b\rangle)$ e troca $(-\langle a b \mid b a\rangle)$ com cada um dos $(N-1)$ elétrons restantes nos $(N-1)$ spin-orbitais remanescentes $\left|\chi_{b}\right\rangle$, com $b \neq a$. A integral $\langle a b \mid b a\rangle$ é não nula apenas se os spins dos elétrons em $\left|\chi_{a}\right\rangle$ e $\left|\chi_{b}\right\rangle$ forem paralelos. Já, a energia do spin-orbital virtual $\left(\epsilon_{r}\right)$ tem um caráter distinto. Ela inclui a energia cinética e a atração nuclear de um elétron em $\left|\chi_{r}\right\rangle$, isto é $\langle r|h| r\rangle$, mas inclui as interações de Coulomb $(\langle r b \mid r b\rangle)$ e de troca $(-\langle r b \mid b r\rangle)$ com todos os $N$ elétrons do estado fundamental Hartree-Fock $\left|\Phi_{0}\right\rangle$, isto é, interações com todos os $N$ spin-orbitais. Tudo se passa como se um elétron fosse adicionado a $\left|\Phi_{0}\right\rangle$ para produzir um estado com $(N+1)$ elétrons e $\epsilon_{r}$ representa a energia deste elétron extra.

O Teorema de Koopmans nos diz que:

Dado um determinante de Slater, solução da equação de Hartree-Fock para um sistema de $N$ elétrons, $\left.\left({ }^{N} \Phi_{0}\right\rangle\right)$ com energias dos orbitais ocupados e virtuais iguais a $\epsilon_{a} e$ $\epsilon_{r}$, respectivamente, então, o potencial de ionização para produzir um determinante de $(N$ - 1) elétrons $\left.\left(\left.\right|^{N-1} \Phi_{a}\right\rangle\right)$ obtido ao se remover um elétron do spin-orbital $\chi_{a}$, e a afinidade eletrônica, para produzir um determinante de $(N+1)$ elétrons, obtido ao se adicionar um elétron ao spin-orbital $\chi_{r}$, são iguais $a-\epsilon_{a} e-\epsilon_{r}$, respectivamente.

O Teorema de Koopmans fornece uma maneira de se calcular potenciais de ionização e afinidades eletrônicas. A aproximação de "orbitais congelados" assume que os spin-orbitais dos $(N \pm 1)$ estados eletrônicos permaneceram idênticos aos do estado de $N$ elétrons. Esta aproximação despreza a relaxação dos spin-orbitais de $\left|{ }^{N-1} \Phi_{a}\right\rangle$ ou $\left.\left.\right|^{N+1} \Phi_{r}\right\rangle$. Ao otimizarmos os spin-orbitais dos determinantes de $(N \pm 1)$ elétrons, realizando um cálculo Hartree-Fock para estes estados, teremos uma diminuição das energias ${ }^{N-1} E_{a}$ e ${ }^{N+1} E_{r}$ e, portanto, ao desprezarmos a relaxação no Teorema de Koopmans, tenderemos a produzir potenciais de ionização mais positivos e afinidades eletrônicas mais negativas. Além disso, a aproximação de representar uma função de onda por um único determinante leva a erros, e os efeitos de correlação que podemos levar em conta apenas usando aproximações que vão além da Teoria de HF produzirão correções adicionais aos resultados obtidos pelo Teorema de Koopmans. Em particular, as energias de correlação são maiores para os sistemas com maior número de elétrons. Portanto, os efeitos de correlação tendem a cancelar o erro cometido ao se desprezar a relaxação dos orbitais no 
cálculo do potencial de ionização, mas se adicionam ao erro associado a relaxação no caso da afinidade eletrônica. Dessa forma, os potenciais de ionização obtidos usando a aproximação contida no Teorema de Koopmans são comparáveis com os valores experimentais, enquanto que as afinidades eletrônicas são razoavelmente diferentes dos valores obtidos experimentalmente.

Assim, o Teorema de Koopmans, em nível HF, fornece uma maneira para estimar a energia de ionização para remover um elétron de um sistema, como sendo o negativo da energia orbital. As energias $\epsilon_{a}$ são geralmente negativas e os potenciais de ionização, positivos. Quando adicionamos um elétron a um spin-virtual, a adição desse elétron é simplesmente o negativo da energia orbital deste spin-orbital virtual, resultando em uma afinidade eletrônica positiva. Os efeitos de correlação são desprezados na aproximação Hartree-Fock.

Uma maneira mais eficiente e precisa em avaliar os potenciais de ionização é através do Teorema de Koopmans dentro da teoria do funcional da densidade (DFT). Porém, cálculos realizados a partir desta teoria subestimam a energia de gap do orbital molecular mais alto ocupado para o orbital molecular mais baixo desocupado, atribuídos a descontinuidade do potencial de troca e correlação dentro da abordagem de Kohn-Sham. O Teorema de Koopmans fornece uma maneira de se calcular potenciais de ionização e afinidades eletrônicas, que iremos utilizar em uma das nossas aproximações para o cálculo do acoplamento eletrônico, ao descrever a função de onda do sistema carregado positivamente (negativamente), através da função de onda do HOMO (LUMO), como veremos a seguir. Também comentaremos adiante sobre a validade deste teorema no âmbito da Teoria do Funcional Densidade.

\subsection{Teoria do Funcional da Densidade}

A Teoria do Funcional Densidade descreve um sistema de elétrons interagentes sujeito a um potencial externo em termos da densidade eletrônica. Esta teoria foi formulada por Hohenberg e Kohn [20] e Kohn e Sham [21], e pode ser considerada como tendo sua origem na teoria de Thomas-Fermi, visto que a densidade eletrônica é o fundamento de ambas. Esta teoria é uma alternativa aos métodos de correlação eletrônica baseados 
no modelo Hartree-Fock e sua principal vantagem se deve ao baixo custo computacional e resultados precisos nos cálculos realizados.

A Teoria do Funcional Densidade tem como alicerce dois teoremas propostos por Hohenberg e Kohn [20], que em linhas gerais fornecem:

Teorema 1: O potencial externo $v(\vec{r})$ sentido pelos elétrons é um funcional único da densidade eletrônica $\rho(\vec{r})$, a menos de uma constante aditiva.

Teorema 2: A energia do estado fundamental $E_{0}[\rho]$ é mínima para a densidade $\rho(\vec{r})$ exata,

$$
E[\rho]=\langle\psi|\hat{T}+\hat{V}+\hat{U}| \psi\rangle
$$

Considerando a equação 2.36, podemos escrevê-la da forma:

$$
\begin{aligned}
E[\rho] & =\langle\psi|\hat{T}+\hat{U}| \psi\rangle+\langle\psi|\hat{V}| \psi\rangle \\
& =F[\rho]+\langle\psi|\hat{V}| \psi\rangle
\end{aligned}
$$

onde $F[\rho]$ é um funcional universal válido para qualquer sistema coulombiano e o termo $\langle\psi|\hat{V}| \psi\rangle$ depende do sistema estudado.

Assim, pode-se afirmar que encontrando a densidade eletrônica $\rho(\vec{r})$, as propriedades eletrônicas do sistema no estado fundamental podem ser descritas com base nestes dois teoremas. Para determinar a densidade eletrônica é necessário no entanto, resolver as equações de Kohn-Shan, que são discutidas a seguir.

\subsubsection{Equações de Kohn-Sham}

Considerando que as interações de Coulomb são de longo alcance, é conveniente separar a parte clássica da parte quântica,

$$
F[\rho]=\frac{1}{2} \iint \frac{\rho(\vec{r}) \rho\left(\vec{r}^{\prime}\right)}{\left|\vec{r}-\vec{r}^{\prime}\right|} d^{3} \vec{r} d^{3} \vec{r}^{\prime}+G[\rho]
$$

tal que

$$
E[\rho]=\int v(\vec{r}) \rho(\vec{r}) d^{3} \vec{r}+\frac{1}{2} \iint \frac{\rho(\vec{r}) \rho\left(\vec{r}^{\prime}\right)}{|\vec{r}-\vec{r}|} d^{3} \vec{r} d^{3} \vec{r}^{\prime}+G[\rho]
$$

aqui $G[\rho]$ também é um funcional universal. 
Em 1965, Kohn e Sham [21] foram os primeiros a apresentar uma estratégia para o cálculo de estrutura eletrônica de sistemas envolvendo muitas partículas com o uso de $E[\rho]$. A estratégia traçada por eles consistia em substituir o problema original de vários corpos interagentes, por um problema auxiliar com partículas independentes. Assim, o funcional $G[\rho]$ pode ser escrito da forma:

$$
G[\rho] \equiv T_{0}[\rho]+E_{e x}[\rho]
$$

em que $T_{0}[\rho]$ é a energia cinética de um sistema de elétrons não interagentes com densidade $\rho(\vec{r})$ e $E_{e x}[\rho]$ contém a energia de troca e energia de correlação de um sistema interagente com densidade $\rho(\vec{r})$. A parte que contém a correção da energia cinética desse sistema também está nesse funcional $E_{e x}[\rho]$. Vale lembrar que a fórmula funcional exata para $E_{\text {ex }}[\rho]$ não é simples, e nem mesmo conhecida.

De acordo com o teorema variacional, tomando a variação de $E[\rho]$, com o vínculo que a carga eletrônica total seja fixa temos

$$
\int \rho(\vec{r}) d^{3} \vec{r}=N \Rightarrow \int \rho(\vec{r}) d^{3} \vec{r}-N=0
$$

Da condição de extremo incluindo o vínculo (equação 2.41), ou seja,

$$
\delta\left(E[\rho]-\mu\left[\int \rho(\vec{r}) d^{3} \vec{r}-N\right]\right)=0
$$

obtemos

$$
\int \delta \rho(\vec{r})\left\{\frac{\delta T_{0}}{\delta \rho}+v(\vec{r})+\int \frac{\rho\left(\vec{r}^{\prime}\right)}{\left|\vec{r}-\vec{r}^{\prime}\right|} d^{3} \vec{r}^{\prime}+v_{x c}[\rho]-\mu\right\} d^{3} \vec{r}=0
$$

aqui $\mu$ é um multiplicador de Lagrange que representa o potencial químico do sistema e $v_{x c}$ é o potencial de troca-correlação, dado por:

$$
v_{x c}[\rho]=\frac{\delta E_{x c}}{\delta \rho} .
$$

Escrevendo $T_{0}[\rho]$ como:

$$
T_{0}[\rho]=-\frac{1}{2} \sum_{i} \int \psi_{i}^{*} \nabla^{2} \psi_{i} d^{3} \vec{r}
$$

e dada a densidade de carga auxiliar

$$
\rho(\vec{r})=\sum_{i=1}^{N}\left|\psi_{i}(\vec{r})\right|^{2},
$$


a solução da equação 2.43 satisfazendo (2.41) e (2.46) pode ser obtida resolvendo a equação de Schrödinger de uma partícula. Esta equação ficou conhecida como equação de KohnSham (KS) complementar, dada pela expressão:

$$
\hat{h}^{K S} \psi_{i}(\vec{r})=\left(-\frac{1}{2} \nabla^{2}+v^{K S}[\rho]\right) \psi_{i}(\vec{r})=\epsilon_{i} \psi_{i}(\vec{r})
$$

onde, os $\epsilon_{i}$ são os autovalores de energia do hamiltoniano de Kohn-Sham e $v^{K S}[\rho(\vec{r})]$ é o potencial efetivo de Kohn-Sham dado por

$$
v^{K S}=v(\vec{r})+\int \frac{\rho\left(\vec{r}^{\prime}\right)}{\left|\vec{r}-\vec{r}^{\prime}\right|} d^{3} \vec{r}^{\prime}+v_{x c}[\rho] .
$$

Usando as equações 2.45, 2.46 e 2.47 pode-se obter a energia total do sistema em função da soma dos autovalores do hamiltoniano de Kohn-Sham. Multiplicando-se a equação 2.47 pela esquerda por $\psi_{i}^{*}(\vec{r})$, integrando em todo espaço e somando sobre todos os orbitais ocupados temos:

$$
\sum_{i=1}^{N} \epsilon_{i}=T_{0}[\rho]+\int v(\vec{r}) \rho d^{3} \vec{r}+\iint \frac{\rho(\vec{r}) \rho\left(\vec{r}^{\prime}\right)}{\left|\vec{r}-\vec{r}^{\prime}\right|} d^{3} \vec{r} d^{3} \vec{r}^{\prime}+\int v_{x c}[\rho] \rho(\vec{r}) d^{3} \vec{r} .
$$

Quando comparado com o funcional da energia na equação 2.39, obtemos a expressão:

$$
E[\rho]=\sum_{i=1}^{N} \epsilon_{i}-\frac{1}{2} \iint \frac{\rho(\vec{r}) \rho\left(\vec{r}^{\prime}\right)}{\left|\vec{r}-\vec{r}^{\prime}\right|} d^{3} \vec{r} d^{3} \vec{r}^{\prime}+\int \rho(\vec{r})\left[\epsilon_{x c}[\rho]-v_{x c}[\rho]\right] d^{3} \vec{r}
$$

que é a energia total escrita em função dos autovalores $\epsilon_{i}$.

O potencial de troca-correlação $\left(v_{x c}[\rho]\right)$ representa a energia relacionada a correlação eletrônica e às possibilidades relativas aos elétrons ocuparem estados quânticos diferenciados, ou seja, um potencial que contém a informação sobre a interação elétronelétron e a auto-interação do elétron. Este termo não possui expressão analítica, o que leva a um erro para o DFT pois nesse caso é necessário a utilização de aproximações no cálculo da estrutura eletrônica.

Em resumo, o formalismo de Kohn-Sham expressa a densidade eletrônica $\rho(\vec{r})$ em termos de um conjunto de orbitais não interagentes, permitindo que a energia e a densidade eletrônica do estado fundamental sejam obtidas, desde que exista uma aproximação razoável para a energia de troca-correlação $E_{x c}[\rho(\vec{r})]$. 


\subsubsection{Aproximações para o Funcional de Troca-Correlação}

A formulação de Kohn-Sham mapeia um problema de elétrons interagentes sujeitos a um potencial $v(r)$, em um problema de elétrons não interagentes sujeitos a um potencial externo $v_{x c}[\rho]$. Toda a complexidade do problema de $N$ corpos, é incorporada no funcional energia de troca-correlação $E_{x c}[\rho]$, tal que o potencial de troca-correlação é dado pela equação 2.44, que pode depender da densidade em todo o espaço. O que a teoria garante é que este potencial existe e pode ser definido. No entanto, sua forma exata não é conhecida e, na prática, o que se faz são aproximações para obter uma expressão adequada para este termo. Aqui são apresentadas as idéias básicas de algumas das aproximações para o termo de troca-correlação, conhecidas como LDA, de "Local Density Approximation", GGA, de "Generalized Gradient Approximation", Funcionais Híbridos e também os Funcionais de Longo alcance (LRC).

A energia total, em termos do funcional densidade, é escrita como,

$$
E[\rho]=T[\rho]+U[\rho]+V[\rho]=T_{S}[\rho]+U_{H}[\rho]+E_{x c}[\rho]+V[\rho]
$$

e portanto, a energia cinética é separada em um termo correspondente à energia cinética de elétrons não interagentes com densidade $\rho(r), T_{S}[\rho]$, e o restante é escrito como $T_{c}[\rho]$, onde o subscrito $c$ vem de correlação. A energia de interação eletrônica $U[\rho]$, é separada em um termo clássico $U_{H}[\rho]$, o restante entra em $E_{x c}[\rho]$ (junto com $T_{c}[\rho]$ ). A energia de troca-correlação é muitas vezes decomposta em um termo de troca e um de correlação,

$$
E_{x c}=E_{x}+E_{c}
$$

o primeiro termo corresponde à energia de troca e o segundo à de correlação. A energia de troca pode ser escrita explicitamente em termos de orbitais de Kohn-Sham,

$$
E_{x}\left[\left\{\psi_{i}(\vec{r})\right\}\right]=-\frac{1}{2} \sum_{j k} \int d \vec{r} d \vec{r}^{\prime} \frac{\psi_{j}^{*}(\vec{r}) \psi_{k}^{*}\left(\vec{r}^{\prime}\right) \psi_{j}\left(\vec{r}^{\prime}\right) \psi_{k}(\vec{r})}{\left|\vec{r}-\vec{r}^{\prime}\right|} .
$$

No entanto, uma expressão exata em termos da densidade não é conhecida. Uma forma de entender este termo, é considerar que termos como este surgem quando a função de onda deixa de ser escrita como um produto de orbitais (aproximação de Hartree), passando a ser escrita como um produto de determinantes de Slater, ou seja, uma conseqüência da indistinguibilidade quântica, em particular de serem férmions, que obedecem o princípio 
de Pauli. A correlação responde pelo resto da energia tal que a soma resulte na energia exata.

$\mathrm{Na}$ aproximação LDA, usualmente são utilizados resultados para a energia de troca-correlação para um gás homogêneo de elétrons interagentes, e considera-se que pode ser feita uma aproximação local, usando o valor da densidade $\rho(r)$ no ponto $r$. A energia de troca-correlação é escrita como,

$$
E_{x c}[\rho] \cong E_{x c}^{L D A}[\rho]=\int d^{3} \vec{r} \rho(\vec{r})\left[\epsilon_{x}(\rho(\vec{r}))+\epsilon_{c}(\rho(\vec{r}))\right]=\int d^{3} \vec{r} \rho(\vec{r}) \epsilon_{x c}^{h o m}(\rho(\vec{r})) .
$$

$\epsilon_{x c}^{h o m}$ é a energia de troca-correlação por elétron de um gás de elétrons homogêneo com densidade $\rho(\vec{r})$. Apesar do grande sucesso da LDA, suas limitações sugerem muito cuidado quanto à sua aplicação. Para sistemas onde a densidade varia muito lentamente, a LDA tende a reproduzir bem o comportamento químico do sistema. No entanto, em sistemas fortemente correlacionados, em que o modelo de partículas independentes deixa de ser válido, a LDA é muito imprecisa.

Uma aproximação utilizada para melhorar o modelo LDA é considerar um gás de elétrons com densidade não uniforme. Neste caso um refinamento do método LDA expressa o funcional de troca-correlação não somente da densidade eletrônica, mas também do gradiente dessa densidade. Tal método é conhecido como GGA e o termo de troca-correlação tem a seguinte forma,

$$
E_{x c}^{G G A}(\rho)=\int d^{3} \vec{r} f(\rho(\vec{r}), \nabla \rho(\vec{r})),
$$

que inclui portanto informações sobre a variação local da densidade. Diferentes aproximações GGA correspondem a diferentes escolhas para a função $f$. São funções em geral construídas para satisfazer um certo número de vínvulos. As aproximações GGA variam muito mais entre elas do que as LDA.

Alguns funcionais são chamados de funcionais híbridos. A ideia básica por trás dos funcionais híbridos é misturar uma fração do termo de troca HF exato no funcional de troca do DFT. Os funcionais híbridos têm apresentado bons resultados como a redução do erro de auto-interação e, portanto, a inclusão do termo de troca HF exato ao funcional de troca DFT é uma forma de melhorar a performance do cálculo DFT [19].

O funcional híbrido B3LYP é amplamente usado nos cálculos de química quântica e tem apresentado grande sucesso na descrição das propriedades de uma grande 
variedade de sistemas moleculares. A forma funcional do B3LYP é dado pela expressão:

$$
E_{x c}^{B 3 L Y P}=0.2 E_{x}^{H F}+0.8 E_{x}^{L D A}+0.72 \Delta E_{x}^{B 88}+0.81 E_{c}^{L Y P}+0.19 E_{c}^{V W N},
$$

onde $E_{x}^{H F}$ representa o termo de energia de troca Hartree-Fock e os coeficientes foram ajustados de modo que os cálculos teóricos estejam em concordância com os dados experimentais. Os funcionais híbridos fornecem boas descrições para uma série de propriedades, como por exemplo as geometrias de equilíbrio, frequências vibracionais e momentos dipolares. Além disso, o grande sucesso dos funcionais híbridos pode ser atribuído também a uma redução parcial do erro de auto-interação, muito comum nos métodos DFT. O erro de auto-interação (SIE, do inglês, Self-Interaction Error) está associado ao fato que a energia de interação dos funcionais não se cancela no caso de sistemas com $\mathrm{N}=1$ partícula, mantendo uma interação do elétron com ele mesmo.

Existe uma grande quantidade de funcionais híbridos e não existe uma regra global na quantidade da contribuição HF exata, pois isto vai depender do sistema sob investigação e das propriedades de interesse.

Dentre os vários desenvolvimentos das aproximações para o funcional densidade, destacamos para uma breve discussão os funcionais híbridos de longo alcance corrigidos (LRC, do inglês, Long-Range Corrected). A idéia central por trás dos funcionais LRC é particionar o operador de Coulomb em dois termos: a componente de curto alcance (SR), na qual um funcional de troca-correlação semilocal é frequentemente usado, e uma componente de longo alcance (LR), em que a parte de troca é tratada em nível Hartree-Fock exato. Tipicamente, a separação dos dois termos é feita através da função erro mostrada abaixo:

$$
\frac{1}{r}=\frac{\operatorname{erfc}(\omega)}{r}+\frac{\operatorname{erf}(\omega)}{r}
$$

A função erro é apenas uma das possíveis funções de alcance separáveis que podem ser empregadas, embora isto não ofereça benefícios para o cálculo das integrais de repulsão eletrônica sobre as funções de base gaussianas. Um outro exemplo que também vem sendo utilizado é o potencial de Yukawa $\left(e^{-\omega r}\right)$ [22]. O alcance de separação é determinado na equação 2.57 pelo parâmetro $\omega$, que é usualmente determinado empiricamente, e 1/ $\omega$ definido como o comprimento característico para a transição entre as descrições de curto e longo alcance. Vale destacar que a escala de comprimento característico sobre a qual o 
operador de Coulomb muda de curto para longo alcance aumenta com a diminuição de $\omega$. Além disso o parâmetro de separação ideal depende sensivelmente da constituição química dos sistemas $\pi$-conjugados $[23,24]$. O procedimento de otimização do $\omega$ introduzido por Kronik e Baer, que será discutido nos capítulos 4 e 5, tem mostrado progresso na descrição das propriedades eletrônicas e ópticas dos sistemas moleculares e atômicos e em particular das excitações eletrônicas [25-27]. Esse procedimento de otimização, portanto, pode gerar um funcional mais preciso, no sentido de que os funcionais LRC com $\omega$-otimizado superam claramente grande parte dos funcionais densidade normalmente empregados, quando se trata de prever valores de potencial de ionização, afinidades eletrônicas e gaps de energia.

\subsection{Teoria do Funcional da Densidade dependente do tempo}

A Teoria do Funcional Densidade dependente do tempo (TDDFT) é uma extensão do DFT com um potencial dependente do tempo. Este método é bastante usado para estudar estados excitados ou situações dinâmicas em que a evolução temporal da densidade eletrônica passa a ser relevante. A idéia central do TDDFT é o Teorema de Runge-Gross [28] que fornece uma correspondência unívoca entre o potencial externo dependente do tempo $v(\vec{r}, t)$ e a densidade eletrônica $\rho(\vec{r}, t)$ do estado inicial. Assim, a exemplo do caso estático, $\rho(\vec{r}, t)$ especifica o potencial $v(\vec{r}, t)$ e consequentemente todos os observáveis calculados a partir dele [29].

O Teorema de Teorema de Runge-Gross [28] afirma que duas densidades $\rho(\vec{r}, t)$ e $\rho^{\prime}(\vec{r}, t)$ evoluindo a partir de um mesmo estado inicial $\psi\left(t_{0}\right)$ sob a infuência de dois potenciais $v(\vec{r}, t)$ e $v^{\prime}(\vec{r}, t)$ não podem ser as mesmas, tal que os dois potenciais diferem por mais uma função do tempo,

$$
v(\vec{r}, t) \neq v^{\prime}(\vec{r}, t)+C(t) .
$$

O formalismo DFT para sistemas dependentes do tempo é baseado na equação de Schrödinger

$$
i \frac{\partial}{\partial t} \Psi(t)=\hat{H}(t) \mid \Psi(t)
$$

onde as densidades eletrônicas evoluem a partir de um estado inicial $\Psi\left(t_{0}\right)=\Psi_{0}$. 
Podemos considarar um sistema de elétrons não interagentes sujeitos a um potencial efetivo $v_{s}(\vec{r}, t)$, cuja equação de Schrödinger dependente do tempo é escrita como

$$
i \frac{\partial}{\partial t} \psi_{k}(\vec{r}, t)=\left[-\frac{\nabla^{2}}{2}+v_{s}(\vec{r}, t)\right] \psi_{k}(\vec{r}, t) .
$$

Via Teorema de Runge-Gross, $\psi_{k}[\rho](\vec{r}, t)$ é também um funcional da densidade dependente do tempo,

$$
\rho(\vec{r}, t)=\sum_{k}\left|\psi_{k}[\rho](\vec{r}, t)\right|^{2}
$$

Da mesma forma que no caso independente do tempo, procuramos um potencial efetivo que inclui todos os efeitos referentes à interação entre as partículas. Assim temos,

$$
v_{s}(\vec{r}, t)=v(\vec{r}, t)+v_{H}(\vec{r}, t)+v_{x c}(\vec{r}, t) .
$$

em que as equações (2.60), (2.61) e (2.62) constituem as equações Kohn-Sham dependentes do tempo. Portanto, podemos obter a densidade $\rho(\vec{r}, t)$ a partir da equação para partículas não interagentes submetidas a um potencial efetivo $v_{s}(\vec{r}, t)$. O preço a ser pago encontrase na necessidade de aproximações para o termo $v_{x c}(\vec{r}, t)$ que além do caráter espacial também agrega informações sobre o tempo.

Para o caso de sistemas independentes do tempo o estado fundamental do sistema pode ser determinado pela minimização do funcional de energia total

$$
E[\rho]=\langle\psi|\hat{H}| \psi\rangle
$$

Entretanto, quando se trata de sistemas dependentes do tempo, não há princípio variacional da energia total. Neste caso existe uma outra quantidade análoga à energia, a $a c ̧ \tilde{a} o$

$$
A[\psi]=\int_{t_{0}}^{t_{1}} d t\left\langle\psi(t)\left|i \frac{\partial}{\partial t}-\hat{H}(t)\right| \psi(t)\right\rangle,
$$

em $\psi(t)$ representa a função de muitos corpos e podemos, então, resolver o problema dependente do tempo através do cálculo de ponto estacionário do funcional $A[\rho]$ em que a ação é sempre nula no ponto da solução $A[\psi]=0$.

A Tabela 2.1 mostra de forma resumida uma comparação entre o DFT e o TDDFT. A primeira linha mostra que o DFT é baseado no Teorema de Hohenberg- 
Kohn [20], que estabelece a correspondência unívoca entre o potencial externo e a densidade do estado fundamental, enquanto que o TDDFT é baseado no Teorema de RungeGross [28], em que a correspondência unívoca se dá entre o potencial dependente do tempo e a densidade dependente do tempo. A segunda linha mostra que no DFT a energia total é um funcional único da densidade eletrônica. Já no TDDFT, existe uma quantidade análoga que é um funcional único da densidade. A terceira linha significa que no caso do problema independente do tempo, o estado fundamental de um sistema pode ser determinado através da minimização do funcional da energia total. Já para sistemas dependentes do tempo, o problema dependente do tempo pode ser resolvido pelo ponto estacionário do funcional da ação.

\begin{tabular}{|c|c|}
\hline DFT (Hohenberg-Kohn) & TDDFT (Runge-Gross) \\
\hline$v(\vec{r}) \Leftrightarrow \rho(\vec{r})$ & $v(\vec{r}, t) \Leftrightarrow \rho(\vec{r}, t)$ \\
\hline$\langle\psi|\vec{H}| \psi\rangle=E[\rho]$ & $\int_{t_{0}}^{t_{1}} d t\left\langle\psi(t)\left|i \frac{\partial}{\partial t}-\hat{H}(t)\right| \psi(t)\right\rangle=A[\psi]$ \\
\hline$\frac{\delta E[\rho]}{\delta \rho(r)}=0 \Rightarrow \rho(\vec{r})$ & $\frac{\delta A[\rho]}{\delta \rho(r, t)}=0 \Rightarrow \rho(\vec{r}, t)$ \\
\hline
\end{tabular}

Tabela 2.1: Comparação entre DFT e TDDFT.

Concluímos este capítulo afirmando que a implementação do método DFT leva, portanto, a um conjunto de equações cuja solução deve ser obtida da maneira usual por um processo de iteração autoconsistente. Existem diversos funcionais para os cálculos via DFT, sua diferença está na forma de aproximação utilizada para encontrar o termo de troca-correlação. Neste trabalho foi utilizado o funcional B3LYP [30,31], que trata o termo de troca via metodologia Hartree-Fock de forma híbrida e os funcionais M05 [32] M06 [33] que foram parametrizados para descrever adequadamente as interações não-covalentes. Nos capítulos 4 e 5 foram realizados cálculos de estrutura eletrônica utilizando os funcionais de longo alcance para descrever as propriedades eletrônicas e ópticas de moléculas do tipo doador-aceitador. O método DFT é bastante usado na descrição das propriedades eletrônicas das moléculas pelo fato deste método ter um baixo custo computacional e apresentar resultados precisos nos cálculos de estrutura eletrônica.

Além disso, utilizamos o método TDDFT para avaliar as propriedades de estados excitados dos sistemas moleculares, tais como as energias de transição vertical, comprimentos de onda para absorção máxima, força do oscilador e momentos de dipolo 
de transição. De maneira geral, quando uma molécula absorve um fóton de energia apropriada, que excita um elétron para um estado de energia mais alta, o estado dessa molécula é descrito por uma função de onda do estado fundamental. As transições eletrônicas dos orbitais mais externos correspondem à espectroscopia de absorção nas regiões do ultravioleta e visível. Considerando que os movimentos dos elétrons são muito mais rápidos do que os movimentos nucleares, então o tempo necessário para que uma dada transição eletrônica ocorra é muito menor do que o tempo associado às vibrações moleculares. Dessa forma os núcleos não dispõem de tempo para se adaptar à nova configuração de equilíbrio, caracterizando assim, uma transição sem mudança nas posições nucleares. Essa é a idéia fundamental do princípio de Franck-Cordon e as trasições entre os estados são representadas como linhas verticais, que ilustram a natureza instantânea de absorção da luz, durante a qual não ocorre mudança significativo da configuração nuclear. 


\section{Propriedades de Transporte de Carga em Sistemas Orgânicos}

Para que o transporte de carga seja eficiente através de um sistema orgânico, as cargas devem ser capazes de se mover eficientemente de molécula para molécula, não ficando presas em armadilhas ou sendo espalhadas. Dessa forma, a mobilidade dos portadores de carga é influenciada por muitos fatores tais como empacotamento molecular, desordem, tamanho e peso molecular, pressão, dentre outros fatores [5]. No caso dos transistores a base de semicondutores orgânicos, a mobilidade dos portadores é o parâmetro mais importante a ser otimizado. O valor da mobilidade vai determinar os semicondutores orgânicos que podem ser utilizados em dispositivos de maior valor agregado e, por conseguinte, é de interesse dos pesquisadores e engenheiros buscar o aumento da mobilidade dos portadores.

Reações em que ocorre a transferência de elétrons são comumente chamadas de reações do tipo redox. Em altas temperaturas, o sistema pode adquirir energia térmica do ambiente suficiente para que o elétron seja transportado. Experimentos mostram que em certas reações a taxa de transferência de elétrons (TE) diminui à medida em que a temperatura diminui, até se manter constante para temperaturas muito baixas. A independência da taxa com temperaturas baixas, sugere que a reação de TE nestes casos ocorra via tunelamento eletrônico. Tais reações manisfestam o caráter ondulatório de partículas, onde o elétron atravessa uma barreira de energia para passar de um sítio para outro. Geralmente, esta barreira é fruto de uma composição da energia potencial de um conjunto de átomos e moléculas. Assim, a capacidade de tunelamento depende da interação entre orbitais atômicos e moleculares em reações mais complexas.

Quando se trata da modelagem do transporte de carga em sistemas orgânicos, na maioria dos casos, lida-se com sistemas desordenados. Sendo assim, o modelo mais apropriado parece ser o modelo de hopping, ou seja, o modelo em que os portadores de cargas estão localizados nas moléculas (sítios), "saltando" de uma para outra. Uma das 
formas que tem sido utilizadas na literatura para descrever o mecanismo de hopping é através a Teoria (semiclássica) de Marcus [34-36], segundo a qual em uma reação de transferência de elétrons a carga salta de uma molécula para a molécula adjacente. O problema de calcular a taxa de reação pode ser representado pela transferência de um elétron de um grupo doador para um grupo aceitador:

$$
D+A \longrightarrow D^{+}+A^{-}
$$

em que $D+A$ representa o estado inicial do sistema e $D^{+}+A^{-}$representa o estado final do sistema após a transferência de carga. $D$ e $A$ são os grupos doador e aceitador de elétrons, respectivamente, que formam o sistema molecular, ou duas moléculas, uma de onde parte o portador e a outra em que ele chega. Considerando que os estados inicial e final podem ser descritos por funções de onda localizadas sobres os sítios, a energia potencial do doador e do aceitador em função das coordenadas nucleares pode ser representada por uma superfície de energia potencial do tipo oscilador harmônico, como mostra a Figura 3.1.

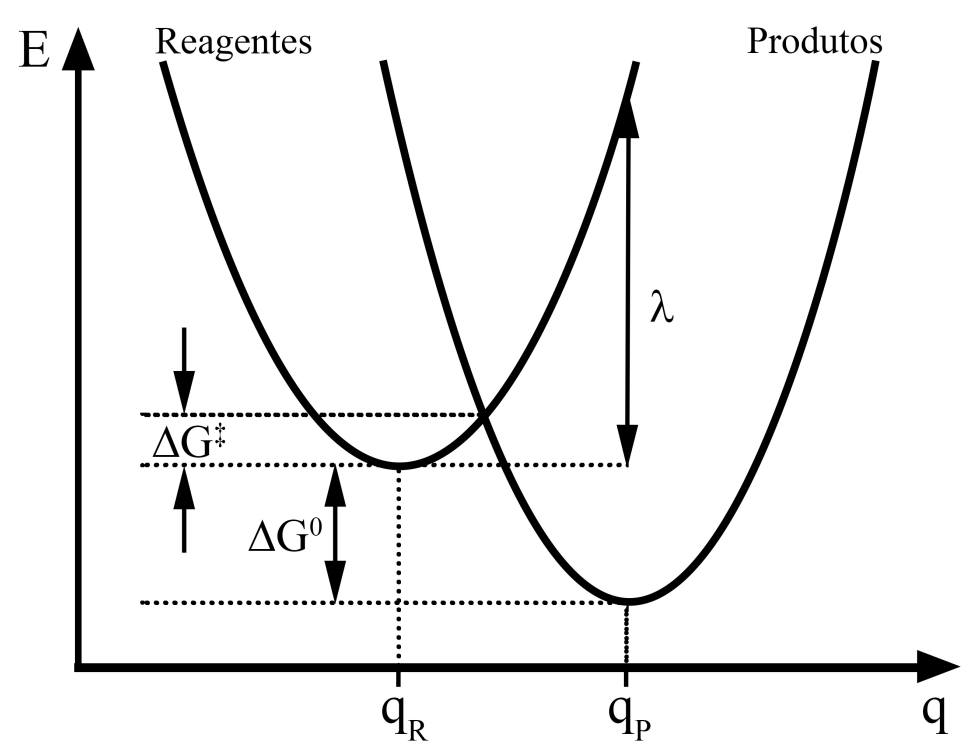

Figura 3.1: Curvas de energia potencial do doador $V_{r}(q)$ e do aceitador $V_{p}(q)$, onde $\Delta G^{\ddagger}$ é a energia de ativação térmica e $\Delta G^{0}$ é a energia livre do sistema.

Esta superfície tem um mínimo correspondente à coordenada nuclear do doador no estado inicial $D+A$. Um gráfico semelhante pode ser observado após a transferência de um elétron. No entanto, o mínimo desta superfície de energia potencial será deslocado 
em relação ao do mínimo do estado inicial ao longo da coordenada da reação e coincidirá com a coordenada nuclear do aceitador no estado final $D^{+}+A^{-}$.

A transferência de um elétron na supermolécula implica na passagem de um elétron da curva da esquerda para a curva da direita. Existem duas formas de se alcançar este objetivo: i) O sistema pode adquirir energia térmica suficiente para alcançar o ponto de intersecção entre as duas curvas para, em seguida, ocorrer a transferência do elétron, ou ii) o sistema pode absorver um fóton de energia e sofrer uma transição vertical.

As coordenadas nucleares do complexo $D+A$ e $D^{+}+A^{-}$são exatamente iguais na região de cruzamento entre as duas curvas, mas diferem daquelas no estado de equilíbrio. Portanto, o estado de transição pode ser definido como a configuração nuclear de um estado vibracional excitado. Dessa forma, as frequências de vibração dos núcleos e suas distâncias interatômicas não devem se alterar durante uma transição eletrônica. Esta observação é a base do princípio de Franck-Condon segundo o qual, uma transição eletrônica é mais provável de ocorrer sem que haja mudança nas posições dos núcleos em toda a molécula e em sua volta. O estado resultante é chamado de estado de FranckCondon e a transição é chamada de transição vertical.

Normalmente, associa-se a taxa de transferência de elétrons com a mudança na energia livre do sistema ao longo da coordenada da reação. Assume-se que esta relação seja parabólica e pode ser escrita como,

$$
V(q)=\frac{1}{2} f\left(q-q_{0}\right)^{2}
$$

onde $f$ é a constante de força e $q_{0}$ representa o ponto $q$ que minimiza a energia livre do sistema. Em uma reação de transferência de elétrons, as parábolas do reagente $V_{r}(q)$ e do produto $V_{p}(q)$ representam o sistema no seu estado de energia mínima, com o elétron localizado no reagente $\left(q_{0}=q_{r}\right)$ (configuração antes da transferência) e no produto $\left(q_{0}=\right.$ $\left.q_{p}\right)$ - configuração após a transferência.

Por definição, a mudança no sistema a partir do seu estado de menor energia com o elétron no grupo doador $V_{r}\left(q_{r}\right)$ para seu estado de menor energia com o elétron centrado no grupo aceitador $V_{p}\left(q_{p}\right)$, pode ser acompanhada por uma mudança na energia livre do sistema $\Delta G^{0}$ :

$$
V_{r}\left(q_{r}\right)=\Delta G^{0}+V_{p}\left(q_{p}\right)
$$


A energia de reorganização do sistema $(\lambda)$ é definida como a quantidade de energia necessária para reorganizar todas as coordenadas do sistema a partir de sua configuração de menor energia com o elétron centrado no grupo doador $-V_{r}\left(q_{r}\right)$ e para a configuração de menor energia com o elétron centrado no grupo aceitador, sem transferir o elétron $-V_{r}\left(q_{p}\right)$. Dada a definição anterior, a energia de reorganização pode ser escrita como,

$$
\lambda=V_{r}\left(q_{p}\right)-V_{r}\left(q_{r}\right)=\frac{1}{2} f\left(q_{p}-q_{r}\right)^{2}-\frac{1}{2} f\left(q_{r}-q_{r}\right)^{2}=\frac{1}{2} f\left(q_{p}-q_{r}\right)^{2} .
$$

O estado de transição da reação de transferência de elétrons é definido como o ponto onde há o cruzamento entre a parábola dos reagentes $V_{r}(q)$ e a parábola dos produtos $V_{p}(q)$. Este ponto no espaço $q$ é definido como $q_{c}$. Dada a mudança na energia livre do sistema associada com a reação de transferência de elétron, a equação 3.3 pode ser escrita como,

$$
V_{r}\left(q_{c}\right)=\Delta G^{0}+V_{p}\left(q_{c}\right)
$$

Substituindo na equação 3.2 e resolvendo para $q_{c}$ temos

$$
q_{c}=\frac{\Delta G^{0}}{f} \frac{1}{q_{p}-q_{r}}+\frac{q_{p}+q_{r}}{2} .
$$

Energeticamente, o estado de transição $\Delta G^{\ddagger}$ é a quantidade de energia necessária para mover o elétron ao longo da coordendada do reagente $V_{r}(q)$ a partir da configuração de menor energia $V_{r}\left(q_{r}\right)$ para o estado de transição $V_{r}\left(q_{c}\right)$ :

$$
\Delta G^{\ddagger}=V_{r}\left(q_{c}\right)-V_{r}\left(q_{r}\right) .
$$

Fazendo a substituição da forma funcional de $q_{c}$ na equação 3.7, depois substituindo a relação de energia de reorganização na equação 3.4 e resolvendo para $\Delta G^{\ddagger}$, temos então a energia de ativação de uma reação de transferência de elétrons modelada por duas parábolas como os estados dos reagentes e do produto:

$$
\Delta G^{\ddagger}=\frac{\left(\Delta G^{0}+\lambda\right)^{2}}{4 \lambda}
$$

$\mathrm{Ou}$

$$
\Delta G^{\ddagger}=\frac{\lambda}{4}\left(1+\frac{\Delta G^{0}}{\lambda}\right)^{2} .
$$

No caso de sistemas simétricos, a energia livre é nula $\left(\Delta G^{0}=0\right)$, então a relação entre a energia de ativação $\left(\Delta G^{\ddagger}\right)$ e a energia de reorganização $(\lambda)$ fica:

$$
\Delta G^{\ddagger}=\frac{\lambda}{4} .
$$


Substituindo a equação 3.8 com o termo de energia de ativação na relação de Arrhenius obtemos:

$$
k=A \exp \left(\frac{-\Delta G^{\ddagger}}{K_{B} T}\right)=A \exp \left(-\frac{\left(\Delta G^{0}+\lambda\right)^{2}}{4 \lambda K_{B} T}\right) .
$$

O prefator $A$ na equação 3.11 é resultado direto da aplicação da equação de Arrhenius na fórmula de Marcus para a energia de ativação. Se considerarmos, na expressão de Arrhenius, que duas partículas colidem para gerar uma reação química, o prefator $A$ representa a frequência de colisões que podem ou não levar a uma reação, o termo exponencial na equação 3.11 representa a probabilidade de uma colisão levar a uma reação, e $k$, o produto desses dois termos, representa a frequência de ocorrência da reação. A equação 3.11, na verdade, prevê uma taxa de transferência de elétrons nula a baixas temperaturas, em contraste com o que se observa nos experimentos. Este e outros problemas surgem a partir da suposição clássica de que a barreira de energia deve ser cruzada, enquanto que, na realidade existe uma probabilidade de tunelamento através da barreira.

As relações 3.12 e 3.13 fornecem um guia para situações em que o modo vibracional acoplado deve ser tratado com mecânica quântica e o que deve ser assumido clássico na transferência de elétrons:

$$
\begin{gathered}
\frac{\hbar \omega}{K_{B} T} \gg 1 \longrightarrow \text { quântico } \\
\frac{\hbar \omega}{K_{B} T} \ll 1 \longrightarrow \text { clássico }
\end{gathered}
$$

A necessidade de introduzir efeitos quânticos torna-se clara e isso se faz introduzindo os níveis de energia vibracional do oscilador harmônico nas curvas de potencial, como mostra a Figura 3.2.

Como pode ser observado na Figura 3.2, o tunelamento pode ocorrer entre o nível fundamental no potencial do reagente e o primeiro nível vibracional na curva do produto. O tunelamento dependerá do grau de overlap entre os estados vibracionais inicial e final. Sendo assim, uma abordagem semi-clássica é adotada para incluir efeitos quânticos na teoria clássica de Marcus. Este fenômeno da mecânica quântica é explicado considerando a "regra de ouro de Fermi" para a transferência de elétrons da forma como foi desenvolvido através da teoria de perturbação [37]:

$$
k=\frac{2 \pi}{\hbar}\left|\left\langle f\left|H^{\prime}\right| i\right\rangle\right|^{2} \rho\left(E_{f}\right)
$$




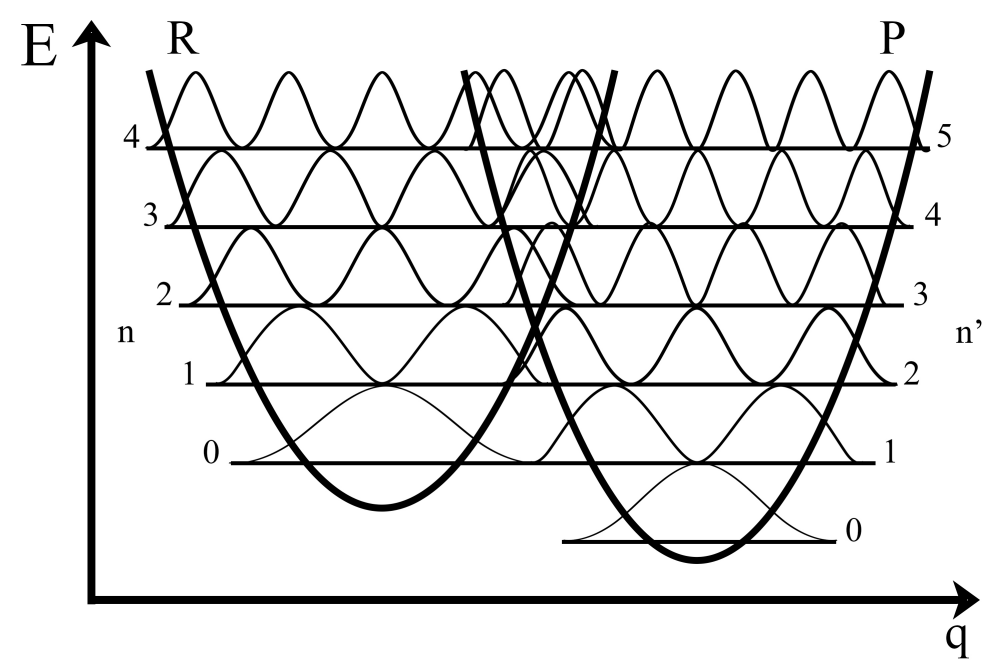

Figura 3.2: Representação esquemática da intersecção dos níveis vibracionais dos reagente e produto. Aqui a separação no cruzamento não é mostrada e o overlap ideal do nível vibracional inicial $n=0$ é com o nível vibracional $n^{\prime}=1$ do produto.

em que $\hbar$ é a constante de Planck, $\rho\left(E_{f}\right)$ é a densidade de estados final (aceitador) dependente da energia, e $\left|\left\langle f\left|H^{\prime}\right| i\right\rangle\right|^{2}$ é a quantificação do overlap entre os estados final e inicial. A equação 3.14 é a forma funcional do prefator $A$ na equação 3.11 que representa a frequência de tentativas feitas para completar a reação e também permite a ocorrência de tunelamento através da barreira da reação. Também é incluído no prefator de Arrhenius um termo de normalização que, por sua vez, dará um caráter probabilístico a contribuição de Marcus global da taxa de TE, como o termo exponencial da relação Arrhenius deve ser. Substituindo a equação 3.14 e o fator de normalização na equação 3.11 como o prefator de Arrhenius fornece a conhecida fórmula de Marcus [38]:

$$
k_{i j}=\frac{2 \pi}{\hbar}|\bar{H}(E)|^{2} \frac{1}{\sqrt{4 \pi \lambda K_{B} T}} \exp \left(-\frac{\left(\Delta G^{0}+\lambda\right)^{2}}{4 \lambda K_{B} T}\right)
$$

onde $K_{B}$ é a constante de Boltzmann, $T$ é a temperatura, $k$ é a taxa de transferência de elétrons e o termo de overlap da equação 3.14, $\left|\left\langle f\left|H^{\prime}\right| i\right\rangle\right|^{2}$, é reescrito como $|\bar{H}(E)|^{2}$. Este termo estabelece explicitamente a dependência da taxa de transferência, $H_{i j}$, no acoplamento eletrônico entre duas moléculas. 


\subsection{Energia de Reorganização}

A energia de reorganização $\lambda$ inclui as componentes vibracionais das espécies diretamente envolvidas na transferência de elétrons (energia de reoganização intramolecular ou de esfera interna) $-\lambda_{i}$, e a mudança na polarização dielétrica do solvente após a transferência (energia de reorganização do solvente ou de esfera externa) $-\lambda_{e}$ :

$$
\lambda=\lambda_{i}+\lambda_{e}
$$

A energia de reorganização de esfera externa pode ser estimada utilizando a equação:

$$
\lambda_{e}=(\Delta e)^{2}\left[\frac{1}{2 a_{1}}+\frac{1}{2 a_{2}}-\frac{1}{R}\right]\left[\frac{1}{\epsilon_{\infty}}-\frac{1}{\epsilon_{0}}\right] .
$$

Esta equação foi obtida por Marcus usando um modelo em que reagentes e produtos são tratados como esferas e o solvente como um dielétrico contínuo. Aqui $a_{1}$ e $a_{2}$ são, respectivamente, o raio do doador e aceitador no modelo de esferas de Marcus, $R$ é a distância entre os centros das esferas do doador e aceitador, $\epsilon_{\infty}$ é constante dielétrica óptica, $\epsilon_{0}$ é a constante dielétrica estática do solvente e $\Delta e$ é a quantidade de carga transferida. A diferença no inverso das constantes dielétricas está relacionado ao fato de que os graus de liberdade nuclear não podem se reajustar instantaneamente ao movimento dos elétrons e, assim, contribuir para a barreira. Neste modelo o solvente é tratado como um dielétrico contínuo e a polarização pode ser considerada como sendo constituída de duas componentes: uma componente eletrônica e uma componente vibracional de reorientação dos dipolos. Para sistemas formados por moléculas orgânicas, este termo tem sido estimado como sendo da ordem de $500 \mathrm{meV}$ a $1 \mathrm{eV}$ [5].

A contribuição de cada modo vibracional para a energia de reorganização pode ser obtida expandindo as energias potenciais dos estados catiônicos e neutros em uma série de potência da coordenada normal $(\Delta Q)$,

$$
\lambda_{i}=\sum_{j} \lambda_{i, j}=\frac{1}{2} \sum_{j} f_{j}\left(\Delta Q_{j}\right)^{2} .
$$

Aqui a soma é sobre as vibrações intramoleculares acopladas. A contribuição do $j$-ésimo modo vibracional para a energia de reorganização é dada em termos da sua constante de força $f_{j}$ e da mudança nas posições de equilíbrio entre os reagentes e produtos, $\Delta Q_{j}=$ $q_{p}-q_{r}$ 
Outra forma de calcular a energia de reorganização intramolecular, $\lambda_{i}$, é combinar as energias de relaxação da molécula doadora $\left(\lambda_{0}\right)$ e da molécula aceitadora $\left(\lambda_{1}\right)$ através de uma reação de transferência de elétrons. Tomando como base o exemplo da Figura 3.3, a transferência de um elétron ocorre do doador para o aceitador e pode ser dividida em duas etapas: i) Processo simultâneo de oxidação do doador e redução do aceitador através de uma transição vertical dos estados iniciais dos reagentes, e ii) subsequente relaxação para as geometrias mucleares do produto. Vale lembrar que ambos o princípio de Frank-Condon e o princípio de conservação da energia devem ser satisfeitos para ocorrer a transferência.

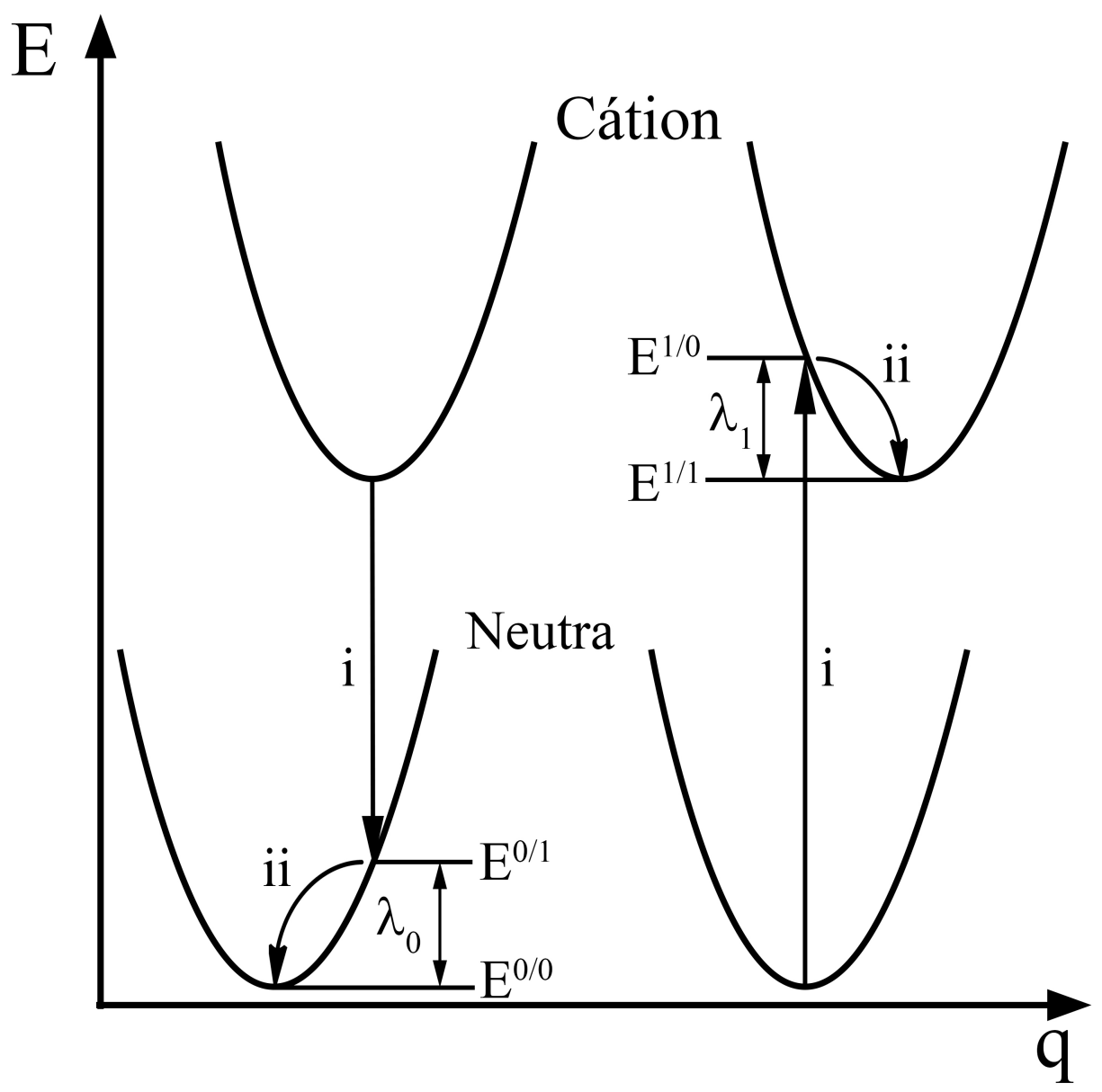

Figura 3.3: Superfícies de energia potencial do doador e aceitador em um processo de transferência de elétrons. Neste caso, assumindo que o doador e o aceitador é a mesma espécie molecular, temos que: $\lambda_{t o t}=\lambda_{0}+\lambda_{1}=\left(E^{0 / 1}-E^{0 / 0}\right)+\left(E^{1 / 0}-E^{1 / 1}\right)$. 


\subsection{Região Invertida}

Os valores de $\Delta G^{0}$ e de $\lambda$ determinam a grandeza da energia de ativação térmica $\left(\Delta G^{\ddagger}\right)$ como mostra a equação 3.8. Dessa forma a Teoria de Marcus prevê que podem ocorrer três situações para a taxa de reação, como mostra a Figura 3.4. A primeira situação ocorre quando a energia de reorganização é maior do que o valor absoluto da energia livre de Gibbs $\left(\lambda>\left|\Delta G^{0}\right|\right)$. Esta situação é conhecida como "regime normal" e deve ocorrer um aumento do valor da taxa de reação $k$. Este aumento contínuo no valor da taxa de reação continua até o ponto de máximo ser alcançado, em que $\left(\lambda=\left|\Delta G^{0}\right|\right)$. Esta é a segunda situação prevista pela Teoria de Marcus e neste ponto a energia de ativação é nula $\left(\Delta G^{\ddagger}=0\right)$. Aumentando ainda mais o valor da energia livre além deste ponto, alcançamos a terceira situação. Aqui a energia de reorganização é menor do que o valor absoluto da energia livre $\left(\lambda<\Delta G^{0}\right)$ e a energia de ativação tem valores diferente de zero $\left(\Delta G^{\ddagger} \neq 0\right)$. Esta situação é conhecida como "região invertida" e nota-se que ocorre uma diminuição na taxa de reação.

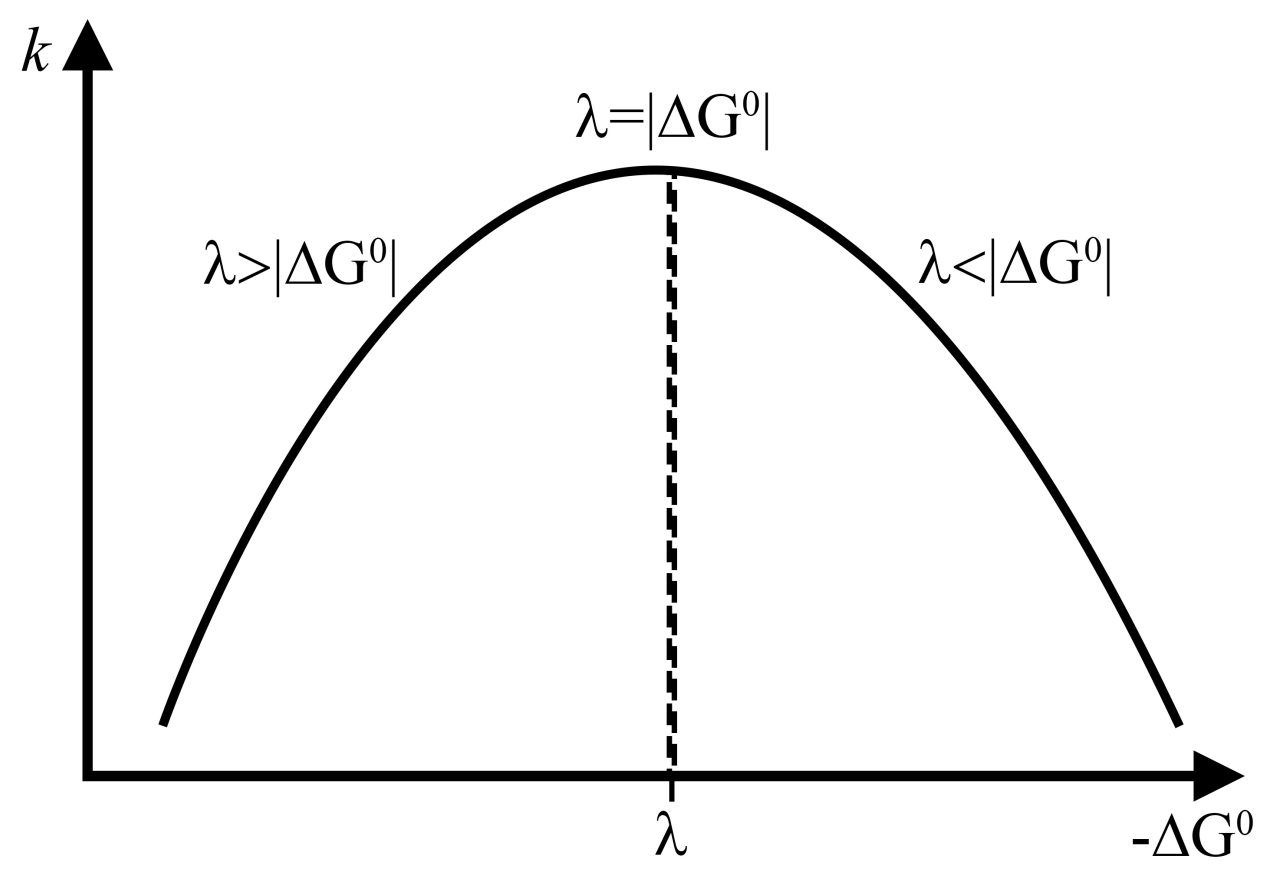

Figura 3.4: Dependência entre a taxa de reação, $k$, e a energia descrevendo a as regiões normal $\left(\lambda>\left|\Delta G^{0}\right|\right)$ e invertida $\left(\lambda<\left|\Delta G^{0}\right|\right)$. O pico da curva representa o ponto onde a taxa de transferência de elétrons é máxima $\left(\lambda=\left|\Delta G^{0}\right|\right)$. 


\subsection{Acoplamento Eletrônico}

Se $D$ e $A$ não interagem muito fortemente, ou seja, se puderem ser descritos por meio de funções de onda localizadas em $D$ e $A$, pode-se definir uma função de onda para o estado inicial, $\eta_{1}$, e para o estado final, $\eta_{2}$. Neste caso, a energia potencial do sistema nesses dois estados pode ser definida por:

$$
H_{11}=\left\langle\eta_{1}|\hat{H}| \eta_{1}\right\rangle \quad \text { e } \quad H_{22}=\left\langle\eta_{2}|\hat{H}| \eta_{2}\right\rangle
$$

onde $H$ é o Hamiltoniano do sistema. As energias calculadas por meio destas equações definem as curvas diabáticas do reagente e produto (ver Figura 3.5 (a)). O acoplamento eletrônico, nesta situação, não é necessário para que o sistema caminhe do estado inicial para o estado final.
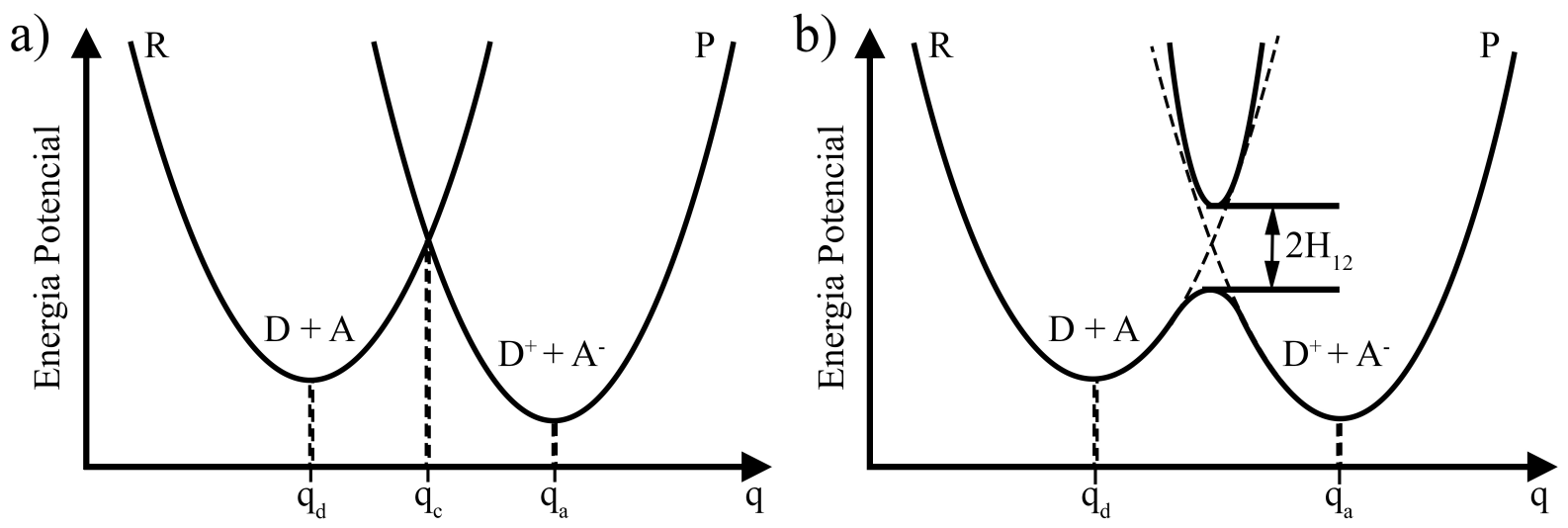

Figura 3.5: a) Superfícies de energia para uma reação diabática. b) Superfície de energia para uma reação adiabática.

Na presença de interação, o acoplamento perturba as funções de onda, removendo a degenerescência no ponto de intersecção, levando à formação de duas novas superfícies de energia potencial adiabáticas (ver Figura 3.5 (b)). Agora, os estados diabáticos não diagonalizam o Hamiltoniano $\hat{H}$.

A energia é definida por:

$$
H_{12}=\left\langle\eta_{1}|\hat{H}| \eta_{2}\right\rangle
$$

e o seguinte problema de autovalor deve ser resolvido:

$$
\left|\begin{array}{cc}
H_{11}-E & H_{12}-S_{12} E \\
H_{21}-S_{21} E & H_{22}-E
\end{array}\right|=0
$$


onde o Hamiltoniano $(H)$ e a matriz de overlap $(S)$ são dados por:

$$
H=\left(\begin{array}{ll}
H_{11} & H_{12} \\
H_{21} & H_{22}
\end{array}\right)
$$

e

$$
S=\left(\begin{array}{cc}
1 & S_{12} \\
S_{21} & 1
\end{array}\right)
$$

Diagonalizando o Hamiltoniano obtemos dois estados adiabáticos $\left(\psi_{1}\right.$ e $\left.\psi_{2}\right)$ e, consequentemente, a degenerescência das superfícies de energia diabáticas que se apresenta na região de cruzamento será então removida.

Resolvendo a equação secular, temos:

$$
\left|\begin{array}{cc}
\left\langle\eta_{1}|\hat{H}| \eta_{1}\right\rangle-E & \left\langle\eta_{1}|\hat{H}| \eta_{2}\right\rangle-E\left\langle\eta_{1} \mid \eta_{2}\right\rangle \\
\left\langle\eta_{2}|\hat{H}| \eta_{1}\right\rangle-E\left\langle\eta_{2} \mid \eta_{1}\right\rangle & \left\langle\eta_{2}|\hat{H}| \eta_{2}\right\rangle-E
\end{array}\right|=0,
$$

$\operatorname{com}\left\langle\eta_{1} \mid \eta_{2}\right\rangle=\left\langle\eta_{2} \mid \eta_{1}\right\rangle$ e, $\left\langle\eta_{1}|\hat{H}| \eta_{2}\right\rangle=\left\langle\eta_{2}|\hat{H}| \eta_{1}\right\rangle$ pois $\hat{H}$ é Hermitiano.

Depois de resolver a equação secular nós obtemos as superfícies de energia adiabáticas:

$$
\begin{aligned}
E_{ \pm} & =\frac{H_{11}+H_{22}-2 H_{12} S_{12}}{2\left(1-S_{12}^{2}\right)} \\
& \pm \frac{\sqrt{\left(H_{11}-H_{22}\right)^{2}-4\left(H_{11}+H_{22}\right) H_{12} S_{12}+4 H_{11} H_{22} S_{12}^{2}+4 H_{12}^{2}}}{2\left(1-S_{12}^{2}\right)}
\end{aligned}
$$

em que a separação entre elas $\left(\Delta \equiv E_{+}-E_{-}\right)$é dada por:

$$
\Delta=\frac{\sqrt{\left(H_{11}-H_{22}\right)^{2}-4\left(H_{11}+H_{22}\right) H_{12} S_{12}+4 H_{11} H_{22} S_{12}^{2}+4 H_{12}^{2}}}{1-S_{12}^{2}} .
$$

No ponto de cruzamento entre as parábolas $\left(R_{c}\right)$ temos que $H_{11}=H_{22}$, assim a separação das superfícies adiabáticas é dada por:

$$
\Delta_{R_{c}}=2 \frac{\left(H_{12}-H_{11} S_{12}\right)}{1-S_{12}^{2}}
$$

ou

$$
\Delta_{R_{c}}=2 \frac{\left(H_{12}-S_{12}\left(H_{11}+H_{22}\right) / 2\right)}{1-S_{12}^{2}} .
$$


Se nós definirmos $e_{i}$ e $t_{i j}$ como:

$$
H_{i i}=e_{i} \longrightarrow \text { energia do sítio }
$$

e

$$
H_{i j}=t_{i j} \longrightarrow \text { integral de transferência, }
$$

a equação 3.28 pode ser reescrita como:

$$
\Delta_{R_{c}}=2 \frac{\left(t_{12}-S_{12}\left(e_{1}+e_{2}\right) / 2\right)}{1-S_{12}^{2}}
$$

onde $\Delta R_{c}=2 t_{12}$ se $S \approx 0$.

Na prática, é complicado tratar reações de transferência de carga através do modelo descrito pela Teoria de Marcus devido à dificuldade de se fixar uma carga em uma das várias moléculas que compõem o sistema, mantendo as demais em seu estado neutro. Em um cálculo HF ou DFT, o campo auto-consistente automaticamente distribui as cargas entre todas as moléculas que constituem o sistema. No entanto, há métodos que já conseguem manter a carga fixa em uma região da molécula a exemplo do chamado Constrained DFT (CDFT), implementado no Q-Chem.

Um grande número de abordagens computacionais, baseadas em métodos $a b$ initio ou semiempíricos, foram desenvolvidas a fim de se estimar o acoplamento eletrônico. Dentre estas abordagens, a mais simples e confiável baseia-se no uso do teorema de Koopmans [39]. Neste caso, o cálculo do acoplamento eletrônico relacionado ao transporte de buraco (elétrons) é dado pela relação:

$$
t=\frac{E_{H(L+1)}-E_{H-1(L)}}{2},
$$

em que $E_{H}$ e $E_{H-1}\left(E_{L+1}\right.$ e $\left.E_{L}\right)$ são as energias dos orbitais HOMO e HOMO-1 (LUMO+1 e LUMO), respectivamente, obtidas a partir do cálculo de estrutura eletrônica do dímero formado pelas duas moléculas interagentes em seu estado neutro $\left\{M_{a}-M_{b}\right\}$ [41].

A Figura 3.6 ilustra, graficamente, o caso de duas molécula de etileno. Como pode-se observar, no caso de duas moléculas isoladas, os orbitais de fronteira HOMO e LUMO encontram-se na mesma energia. Caso estas moléculas sejam posicionadas próximas uma da outra (no caso da Figura, uma sobre a outra), estes níveis se combinarão para formar os níveis HOMO, HOMO-1, LUMO e LUMO+1 do dímero. O acoplamento 
eletrônico para elétrons e buracos, dentro da aproximação estabelecida pelo Teorema de Koopmans, pode ser obtido a partir do desdobramento destes níveis, como ilustrado na Figura 3.6(b) e (d).

a)

HOMO

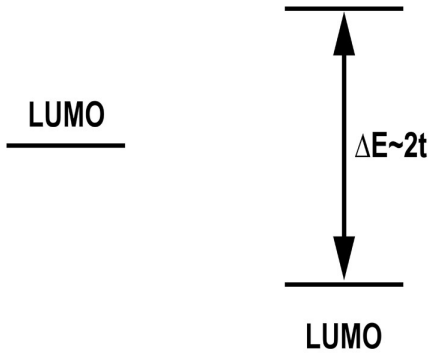

b)

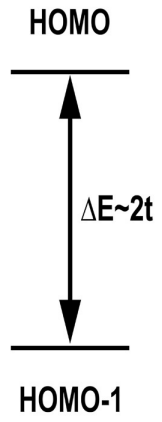

LUMO+1
LUMO

HOMO
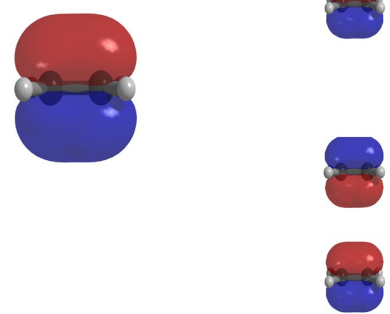

d)

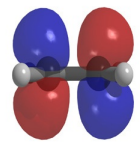

8

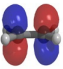

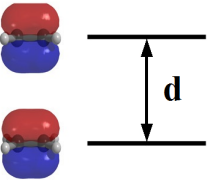
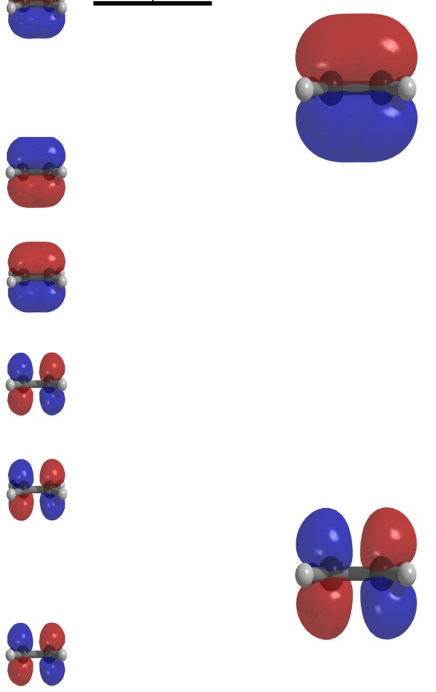

Figura 3.6: a) HOMO de duas moléculas de etileno separadas a uma grande distância (esquerda e direta) e de um dímero (centro) onde as duas moléculas se encontram uma sobre a outra, separadas por uma certa distância $d$. O desdobramento em energia dos níveis $(\Delta E)$ é aproximadamente igual ao dobro da integral de transferência para buracos $\left(2 t_{\text {HOMO }}\right)$. b) Ilustração da função de onda para os orbitais correspondentes aos níveis da Figura 3.6 a. c) LUMO para a mesma situação. O desdobramento em energia dos níveis $(\Delta E)$ é, neste caso, aproximadamente igual ao dobro da integral de transferência para elétrons $\left(2 t_{L U M O}\right)$. d) Ilustração da função de onda para os orbitais correspondentes aos níveis da Figura 3.6 c.

O acoplamento eletrônico pode ser calculado utilizando o método semiempírico INDO, dentro da abordagem apresentada anteriormente. Comparações entre os resultados obtidos utilizando este método semiempírico e uma outra abordagem mais robusta que utiliza a Teoria do Funcional Densidade (DFT) mostraram que os resultados semiempíricos são surpreendentemente parecidos aos obtidos de maneira ab initio [40], para certos sis- 
temas.

As abordagens semiempírica e ab initio se completam, uma vez que existem sistemas para os quais uma delas é mais apropriada que a outra. Por exemplo, para sistemas grandes, o cálculo ab initio torna-se praticamente inviável. Já no caso de sistemas pequenos contendo átomos não parametrizados no método semiempírico, passa a ser necessário o uso do método ab initio.

O método do desdobramento de níveis também é problemático quando a molécula apresenta outros orbitais moleculares próximos ao HOMO ou LUMO. Neste caso, fica difícil definir o valor do desdobramento. Nesta situação, o método do Constrained DFT (CDFT) é mais apropriado. 


\section{Estrutura Eletrônica e Óptica de Derivados do triindole}

Como foi dito anteriormente, o estudo dos semicondutores orgânicos atualmente é uma área de pesquisa muito ativa e desperta grande interesse tanto no meio acadêmico como também no setor industrial. De posse da discussão teórica feita nos capítulos anteriores, apresentamos neste capítulo os resultados de um estudo teórico sobre as propriedades eletrônicas e ópticas de derivados do triindole, uma promissora plataforma para portadores de buracos.

\subsection{Propriedades Eletrônicas}

Iniciamos nosso estudo através da análise das propriedades eletrônicas com a molécula de triindole funcionalizada. García-Frutos e colaboradores demonstraram, através de estudos experimentais, que a funcionalização do núcleo do triindole tem grande impacto na mobilidade dos portadores de buracos [6-9,12-15]. Aqui, nossa idéia é investigar possíveis mudanças nas propriedades eletrônicas e ópticas quando diferentes grupos funcionais são anexados ao núcleo molecular. O triindole original (mostrado na Figura 1.4) foi funcionalizado anexando grupos metil $\left(\mathrm{CH}_{3}\right)$ aos átomos de nitrogênio da estrutura molecular enquanto outros cinco grupos funcionais foram ligados aos carbonos nas extremidades molecular, como mostra a Figura 4.1. Nós consideramos três formas diferentes de funcionalização, são elas: A, B e C na Figura 4.1, para verificar como as diferentes configurações moleculares irão impactar nas propriedades eletrônicas e ópticas do triindole.

A Figura 4.2 e a Tabela 4.1 mostram a energia dos orbitais moleculares de fronteira da molécula de triindole funcionalizada. Assumindo a validade do teorema de Koopmans, a energia do HOMO pode ser usada como uma primeira aproximação para 


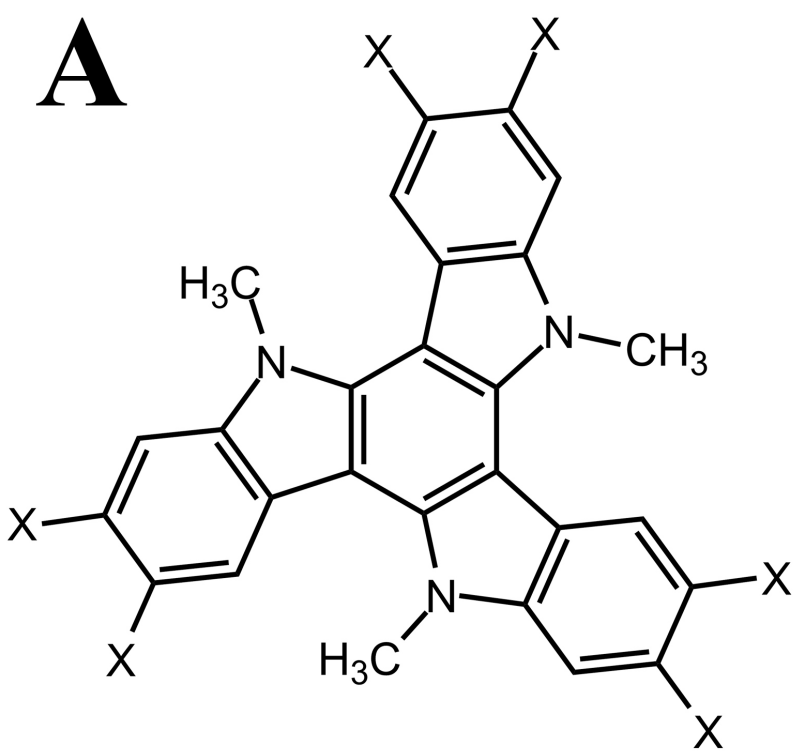

$$
\begin{aligned}
\mathrm{x}= & \mathrm{Br} \\
& \mathrm{C}_{6} \mathrm{H}_{4}-\mathrm{CHO} \\
& \mathrm{C}_{6} \mathrm{H}_{4}-\mathrm{Et} \\
& \mathrm{C}_{6} \mathrm{H}_{4}-\mathrm{MeO} \\
& \mathrm{C}_{6} \mathrm{H}_{4}-\mathrm{NO}_{2}
\end{aligned}
$$
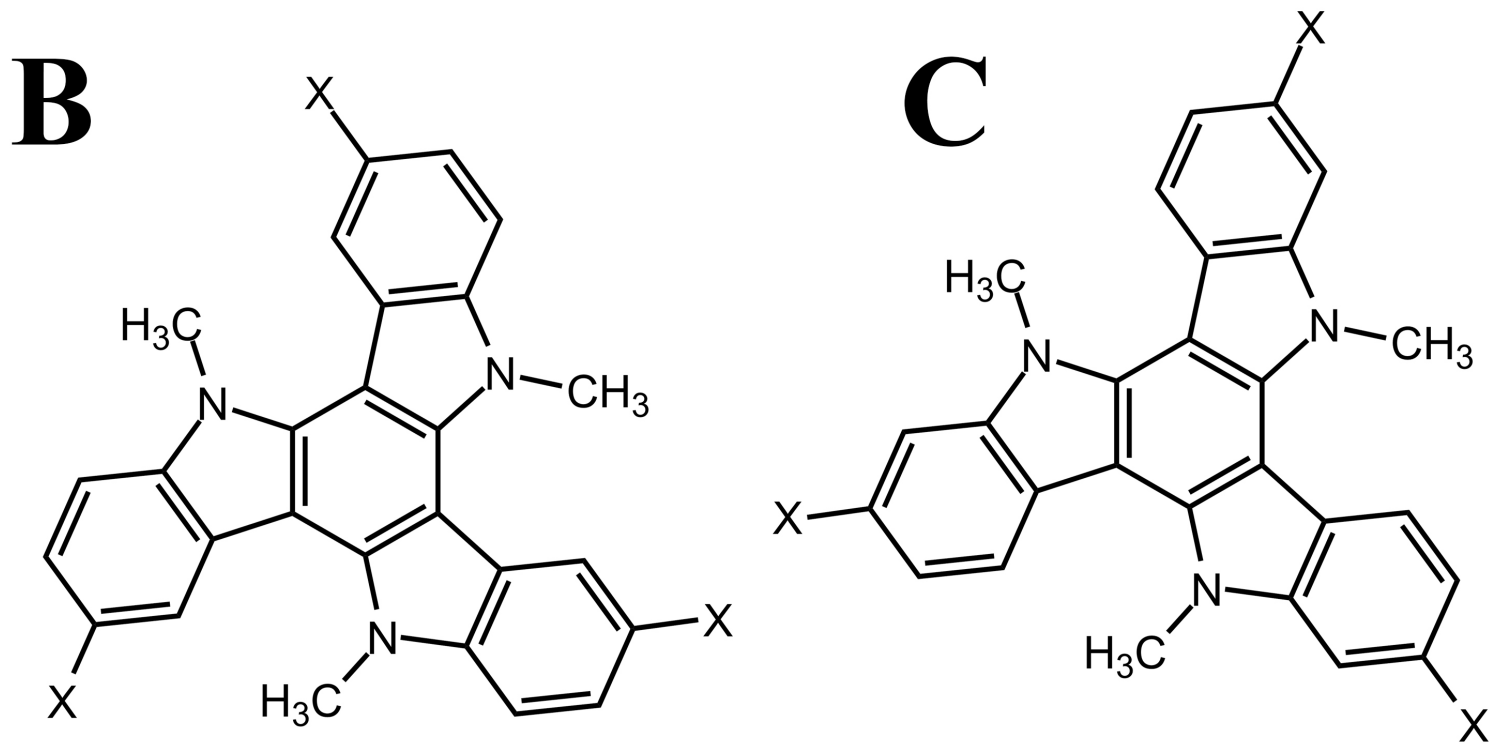

Figura 4.1: Molécula do triindole funcionalizada de três diferentes formas. Para cada uma delas utilizamos cinco diferentes grupos funcionais (Br, CHO, Et, $\mathrm{MeO}$ e $\mathrm{NO}_{2}$ ).

o potencial de ionização molecular. Sendo assim, as energias do HOMO para cada configuração investigada sugerem que o potencial de ionização do triindole funcionalizado cresça na seguinte ordem: i) Configuração A: MeO $(4,64 \mathrm{eV})<\operatorname{Et}(4,77 \mathrm{eV})<\operatorname{Br}(5,52$ $\mathrm{eV})<\mathrm{CHO}(5,56 \mathrm{eV})<\mathrm{NO}_{2}(5,94 \mathrm{eV})$. ii) Configuração B: $\mathrm{MeO}(4,75 \mathrm{eV})<\operatorname{Et}(4,83$ $\mathrm{eV})<\mathrm{Br}(5,27 \mathrm{eV})<\mathrm{CHO}(5,33 \mathrm{eV})<\mathrm{NO}_{2}(5,55 \mathrm{eV})$. iii) Configuração C: $\mathrm{MeO}(4,68$ $\mathrm{eV})<\operatorname{Et}(4,78 \mathrm{eV})<\mathrm{Br}(5,24 \mathrm{eV})<\mathrm{CHO}(5,26 \mathrm{eV})<\mathrm{NO}_{2}(5,50 \mathrm{eV})$. Da mesma forma, as energias do LUMO sugerem que a afinidade eletrônica siga a tendência: i) Configuração A : $\mathrm{MeO}(0,65 \mathrm{eV})<\operatorname{Et}(0,78 \mathrm{eV})<\mathrm{Br}(1,38 \mathrm{eV})<\mathrm{CHO}(2,14 \mathrm{eV})<\mathrm{NO}_{2}(2,82 \mathrm{eV})$. 
ii) Configuração B: $\mathrm{MeO}(0,62 \mathrm{eV})<\mathrm{Et}(0,70 \mathrm{eV})<\mathrm{Br}(1,04 \mathrm{eV})<\mathrm{CHO}(1,88 \mathrm{eV})<$ $\mathrm{NO}_{2}(2,50 \mathrm{eV})$. iii) Configuração $C: \mathrm{MeO}(0,72 \mathrm{eV})<\operatorname{Et}(0,83 \mathrm{eV})<\mathrm{Br}(1,03 \mathrm{eV})<$ $\mathrm{CHO}(1,93 \mathrm{eV})<\mathrm{NO}_{2}(2,53 \mathrm{eV})$.

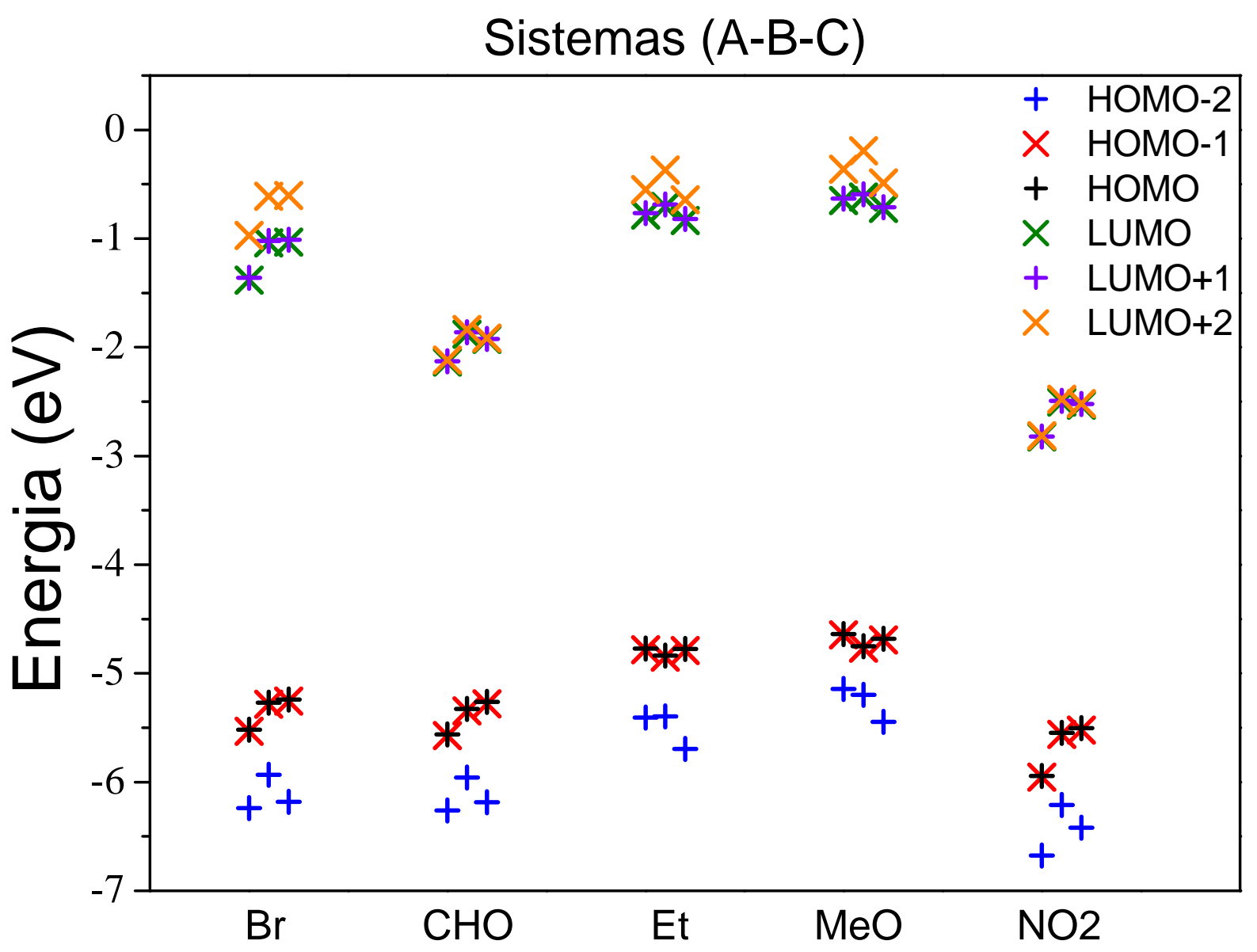

Figura 4.2: Energia dos orbitais moleculares de fronteira do triindole funcionalizado com diferentes radicais e nas configurações A, B e C obtidos a nível B3LYP/6-31G(d,p).

Podemos observar que o valor do gap de energia HOMO $\rightarrow$ LUMO é alterado conforme os grupos funcionais são anexados ao núcleo do triindole, em que o menor valor obtido é 2,97 eV para o triindole com o grupo $\mathrm{NO}_{2}$ na configuração $\mathrm{C}$, e o valor máximo é 4,23 eV para o triindole com o grupo Br na configuração B. Além disso, verificamos nas três configurações consideradas que o grupo $\mathrm{NO}_{2}$ fornece o menor valor para o gap $\mathrm{HOMO} \rightarrow$ LUMO e o contrário ocorre quando anexamos o grupo Br ao núcleo do triindole. Os valores de gap $\mathrm{HOMO} \rightarrow$ LUMO para cada sistema seguem a seguinte ordem: i) Configuração A: $\mathrm{NO}_{2}(3,12 \mathrm{eV})<\mathrm{CHO}(3,42 \mathrm{eV})<\mathrm{Et}(3,99 \mathrm{eV})=\mathrm{MeO}(3,99 \mathrm{eV})<\mathrm{Br}$ $(4,14 \mathrm{eV})$. ii) Configuração B: $\mathrm{NO}_{2}(3,04 \mathrm{eV})<\mathrm{CHO}(3,45 \mathrm{eV})<\mathrm{Et}(4,13 \mathrm{eV})=\mathrm{MeO}$ 


\begin{tabular}{|c|c|c|c|c|}
\hline Configuração & Sistema & HOMO(eV) & LUMO(eV) & $\mathrm{E}_{\text {gap }}(\mathbf{e V})$ \\
\hline $\mathrm{A}$ & $\mathrm{Br}$ & $-5,52$ & $-1,38$ & 4,14 \\
$\mathrm{~A}$ & $\mathrm{CHO}$ & $-5,56$ & $-2,14$ & 3,42 \\
$\mathrm{~A}$ & $\mathrm{Et}$ & $-4,77$ & $-0,78$ & 3,99 \\
$\mathrm{~A}$ & $\mathrm{MeO}$ & $-4,64$ & $-0,65$ & 3,99 \\
$\mathrm{~A}$ & $\mathrm{NO}_{2}$ & $-5,94$ & $-2,82$ & 3,12 \\
\hline $\mathrm{B}$ & $\mathrm{Br}$ & $-5,27$ & $-1,04$ & 4,23 \\
$\mathrm{~B}$ & $\mathrm{CHO}$ & $-5,33$ & $-1,88$ & 3,45 \\
$\mathrm{~B}$ & $\mathrm{Et}$ & $-4,83$ & $-0,70$ & 4,13 \\
$\mathrm{~B}$ & $\mathrm{MeO}$ & $-4,75$ & $-0,62$ & 4,13 \\
$\mathrm{~B}$ & $\mathrm{NO}$ & $-5,55$ & $-2,50$ & 3,04 \\
\hline $\mathrm{C}$ & $\mathrm{Br}$ & $-5,24$ & $-1,03$ & 4,21 \\
$\mathrm{C}$ & $\mathrm{CHO}$ & $-5,26$ & $-1,93$ & 3,33 \\
$\mathrm{C}$ & $\mathrm{Et}$ & $-4,78$ & $-0,83$ & 3,94 \\
$\mathrm{C}$ & $\mathrm{MeO}$ & $-4,68$ & $-0,72$ & 3,96 \\
$\mathrm{C}$ & $\mathrm{NO}$ & $-5,50$ & $-2,53$ & 2,97 \\
\hline
\end{tabular}

Tabela 4.1: Energias dos orbitais moleculares HOMO e LUMO e gap HOMO-LUMO $\left(\mathrm{E}_{\mathrm{gap}}\right)$ para o triindole ligado a diferentes grupos funcionais.

$(4,13 \mathrm{eV})<\mathrm{Br}(4,23 \mathrm{eV})$. iii) Configuração $C: \mathrm{NO}_{2}(2,97 \mathrm{eV})<\mathrm{CHO}(3,33 \mathrm{eV})<\mathrm{Et}$ $(3,94 \mathrm{eV})<\mathrm{MeO}(3,96 \mathrm{eV})<\mathrm{Br}(4,21 \mathrm{eV})$. Sabendo que para uma transferência efetiva de elétrons as moléculas que têm os menores gap de energia são mais eficientes, então as moléculas que possuem os grupos $\mathrm{NO}_{2}$ e $\mathrm{CHO}$ se apresentam como as mais favoráveis para esta propriedade. Dessa forma, verificamos que o gap de energia molecular pode ser controlado pela inclusão de grupos funcionais anexados de forma conveniente à estrutura do triindole. Vale a pena mencionar que, em todos os casos analisados, verifica-se um certo grau de degenerescência entre os orbitais moleculares de fronteira HOMO e HOMO-1, como também entre o LUMO e LUMO+1.

Vimos que, anexando os grupos $\mathrm{MeO}$, Et e Br ao núcleo do triindole, obtemos configurações moleculares com os menores valores de potencial de ionização e afinidade eletrônica do que os substituintes $\mathrm{NO}_{2}$ e CHO. Este fato também se reflete nas dis- 
a) Br CHO Et $\mathrm{MeO} \quad \mathrm{NO2}$
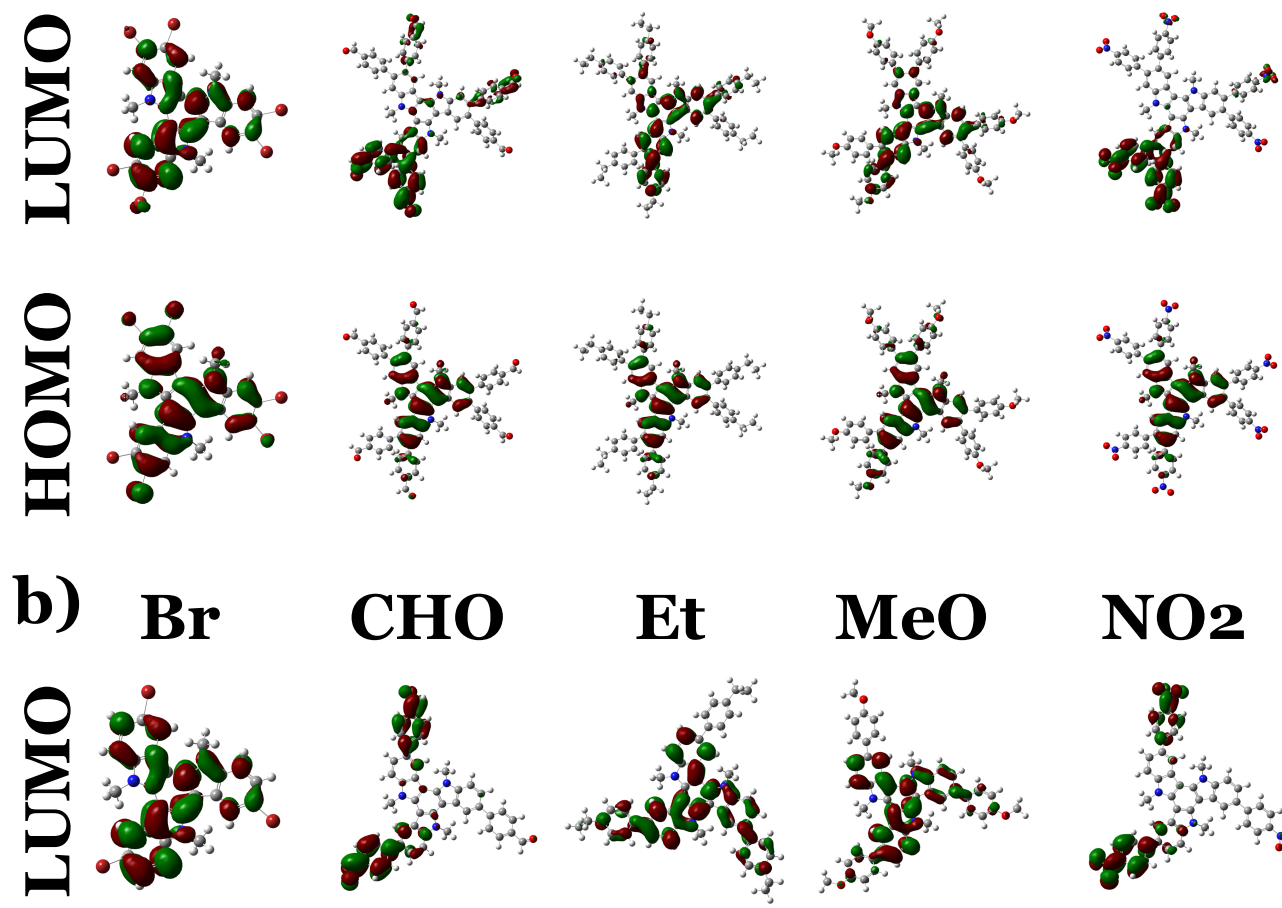

MeO

\section{NO2}
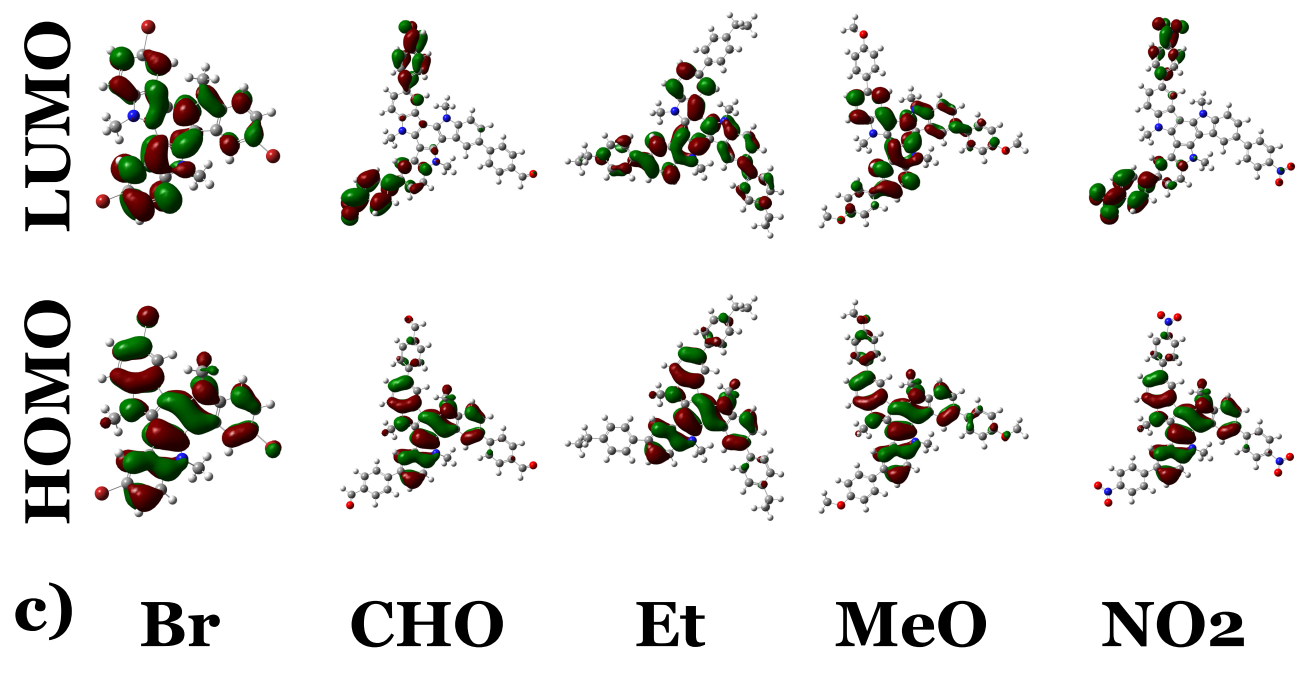

\section{CHO}

Et
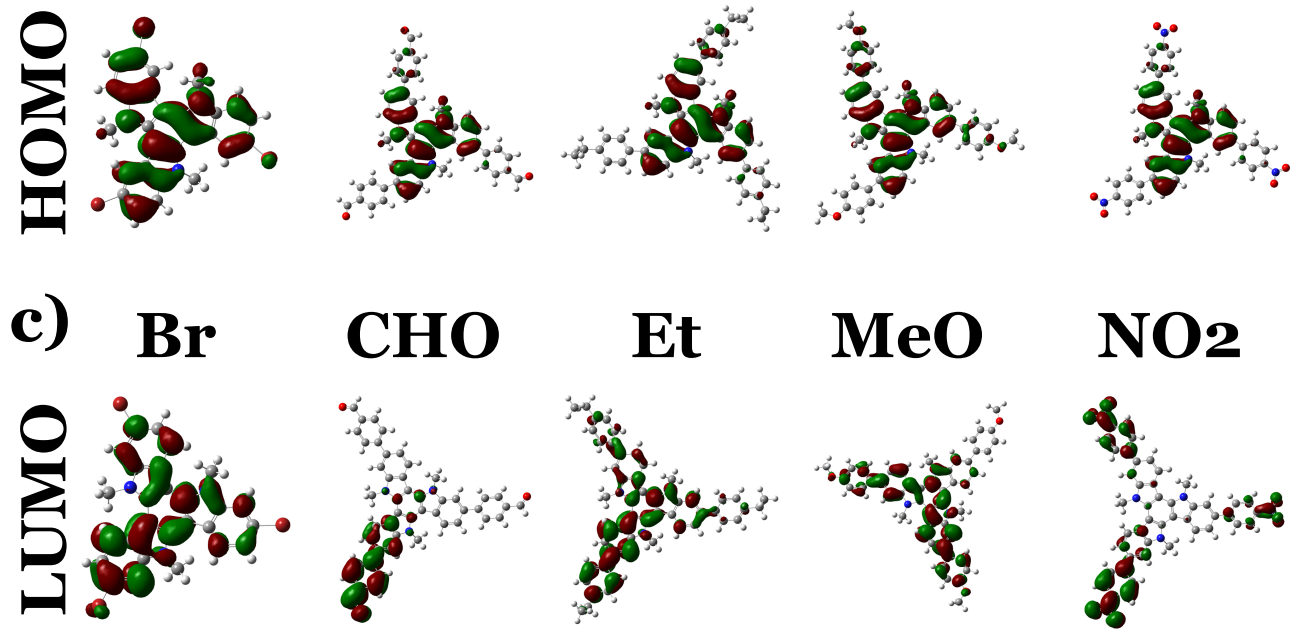

$\mathrm{MeO} \quad \mathrm{NO2}$
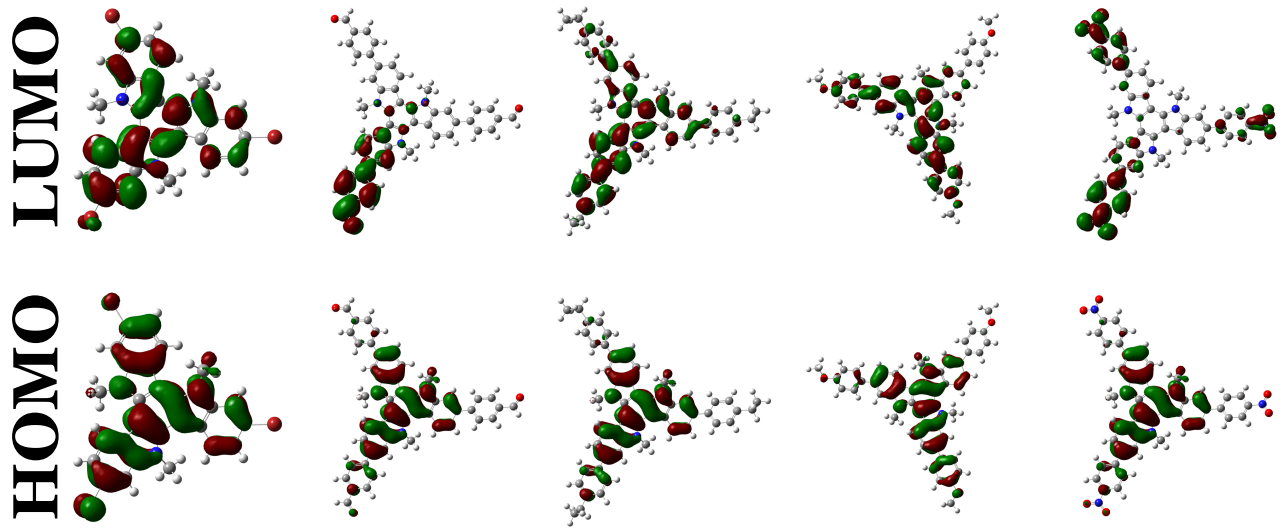

Figura 4.3: Ilustração dos orbitais moleculares de fronteira HOMO e LUMO para a molécula de triindole funcionalizada determinados em nível B3LYP/6-31G(d,p). Os triindoles funcionalizados estão nas configurações (a) A, (b) B e (c) C. 
tribuições das funções de onda HOMO e LUMO, como mostra a Figura 4.3. Nas três configurações analisadas observamos que o HOMO está mais fortemente localizado na parte central do triindole e uma pequena parte distribuída nas extremidades da molécula. Já no caso do LUMO observamos diferentes características da (de)localização dependendo do substituinte utilizado. Esta observação é importante no contexto da interação intermolecular na pilha, pois muda o potencial eletrostático no núcleo e pode gerar alterações na distância intermolecular.

Enquanto que, para os grupos $\mathrm{MeO}$, Et e Br, o LUMO segue o mesmo comportamento do HOMO, isto é, o LUMO está localizado sobre o núcleo do triindole e uma pequena parte distribuída nas extremidades da molécula, para os grupos $\mathrm{CHO}$ e $\mathrm{NO}_{2}$ observa-se que o LUMO se localiza essencialmente sobre as extremidades da molécula de triindole. Dessa análise podemos ver que uma dispersão elevada do orbital molecular de fronteira pode implicar em uma largura de banda maior.

\subsection{Propriedades Ópticas}

A descrição dos processos ópticos no triindole permite examinar como as três configurações e os diferentes grupos funcionais influenciam no espectro de absorção óptica do triindole. Nós incluímos o espectro de absorção da molécula original do triindole para observar como o espectro de absorção é influenciado pelos diferentes grupos funcionais. Aqui vale destacar que tanto a molécula original do triindole, isto é, sem os grupos $\mathrm{CH}_{3}$ ligados aos nitrogênios e sem os grupos funcionais nas extremidades, como também as estruturas funcionalizadas com o $\mathrm{Br}, \mathrm{MeO}$ e Et apresentam força do oscilador irrelevante no primeiro estado excitado. Já no caso do $\mathrm{CHO}$ e $\mathrm{NO}_{2}$, a força do oscilador aumenta em uma e duas ordens de grandeza, respectivamente. Embora ainda seja um valor pequeno, a força do oscilador tem contribuição maior para o espectro de absorção do triindole com esses dois grupos funcionais.

A Figura 4.4 mostra o espectro de absorção da molécula de triindole funcio-

nalizada. Podemos observar que, para cada grupo funcional, ocorre um deslocamento do limiar da banda de absorção quando a estrutura muda da configuração A para as configurações B e C. O mesmo não ocorre quando a estrutura muda da configuração B 

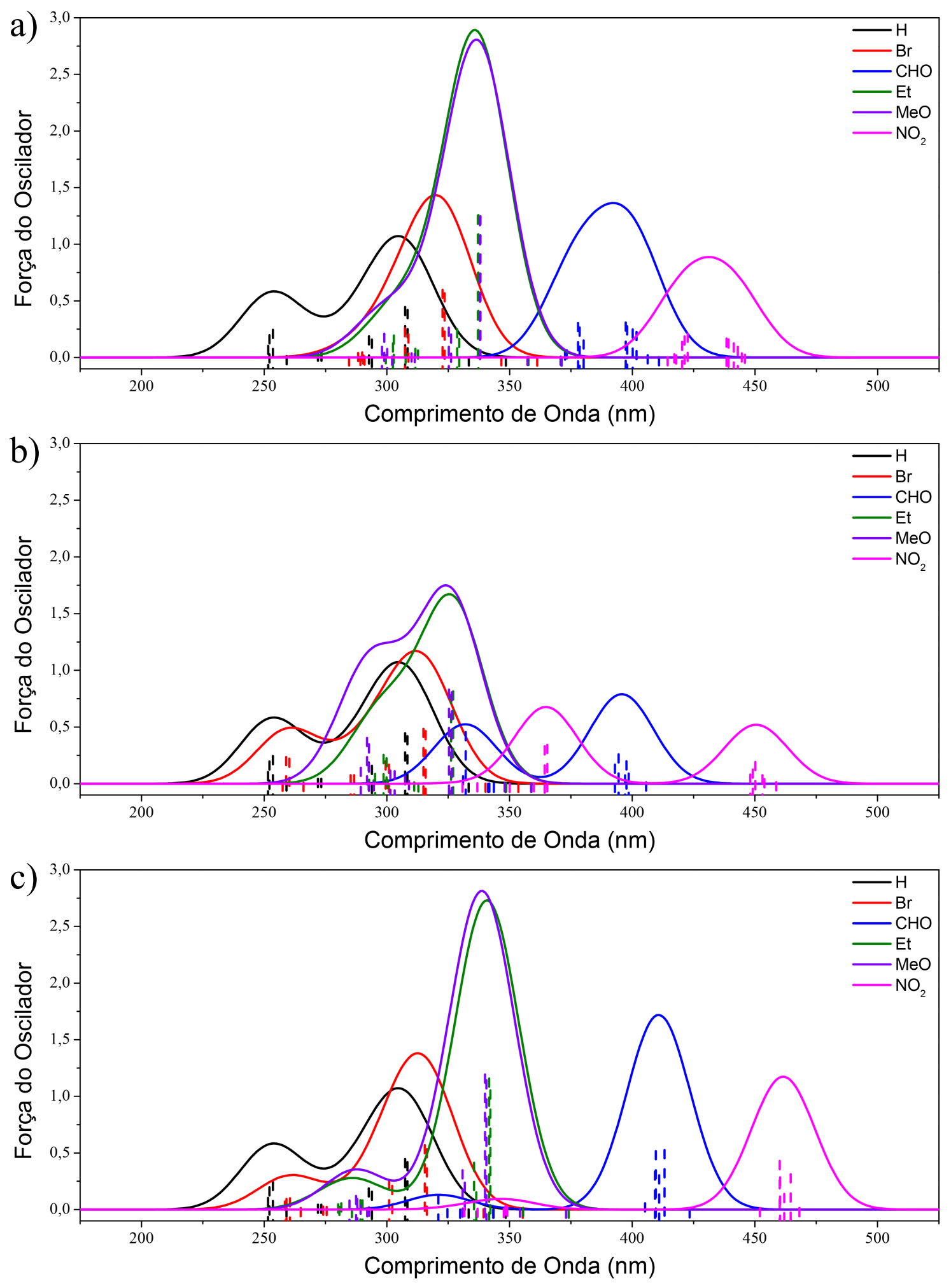

Figura 4.4: Espectro de absorção simulado $(\mathrm{FWHM}=30 \mathrm{~nm})$ para a molécula de triindole funcionalizada determinado com TDDFT a nível de teoria B3LYP/6-31G(d,p) nas configurações (a) A, (b) B e (c) C. 
para C. Também podemos observar, no caso dos grupos funcionais $\mathrm{CHO}$ e $\mathrm{NO}_{2}$ na configuração A, que o espectro de absorção mostra um único pico com uma ampla banda de absorção. Já no caso desses sistemas nas configurações B e C, ocorre o afastamento dos picos de máximo, o que leva o surgimento de duas bandas mais estreitas que no caso desses sistemas na configuração A.

Portanto, a funcionalização das moléculas de triindole levaram tanto a deslocamentos rasoavelmente elevados no limiar da absorção UV-Vis como também a mudanças na amplitude do pico de absorção. Vale lembrar a importância de investigar as propriedades ópticas para aplicação em eletrônica molecular. Por exemplo, temos o caso dos OPVs em que se busca aumentar a largura da banda de absorção, já no caso dos OLEDs procura-se otimizar a posição na qual o sistema molecular apresenta o máximo no pico de absorção, para se chegar a uma determinada cor no espectro RGB.

\subsection{Energia de Reorganização}

Como discutido no capítulo 3, a energia de reorganização é um dos parâmetros que devem ser levados em consideração quando se trata de dispositivos eletrônicos orgânicos com elevada mobilidade de cargas (equação 3.15). Portanto, é de interesse deste trabalho fazer uma análise da energia de reorganização do triindole funcionalizado.

A Tabela 4.2 mostra os valores das energias de relaxação e energia de reorganização do triindole funcionalizado com base no procedimento descrito pela Figura 3.3. Os resultados mostram que a mudança na configuração molecular, como também nos grupos funcionais não provocou alteração significativa nas energias de relaxação $\left(\lambda_{0}\right.$ e $\left.\lambda_{1}\right)$ e nas energia de reorganização intramolecular $\lambda$.

Em geral, as energias de relaxação têm valores aproximadamente iguais $\left(\lambda_{0}=\right.$ $\left.\lambda_{1}\right)$ quando se trata de moléculas planas. Para o caso de moléculas não planas estes valores são diferentes, ou seja, $\lambda_{0} \neq \lambda_{1}$. Entretanto, a Tabela 4.2 mostra valores tipicamente iguais de $\lambda_{0}$ e $\lambda_{1}$ para todas as configurações investigadas. Isto foi verificado através da variação muito pequena nos ângulos de torção dos sistemas no estado fundamental e carregado, da ordem de $3^{\circ}$. Isto indica que pequenas torções na estrutura molecular têm um custo irrelevante na curva de energia potencial da molécula. 


\begin{tabular}{|c|c|c|c|c|}
\hline Configuração & Sistema & $\lambda_{0}(\mathbf{m e V})$ & $\lambda_{1}(\mathbf{m e V})$ & $\lambda(\mathbf{m e V})$ \\
\hline $\mathrm{A}$ & $\mathrm{Br}$ & 104 & 101 & 206 \\
$\mathrm{~A}$ & $\mathrm{CHO}$ & 104 & 100 & 205 \\
$\mathrm{~A}$ & $\mathrm{Et}$ & 95 & 93 & 189 \\
$\mathrm{~A}$ & $\mathrm{MeO}$ & 105 & 102 & 208 \\
$\mathrm{~A}$ & $\mathrm{NO}_{2}$ & 105 & 100 & 205 \\
\hline $\mathrm{B}$ & $\mathrm{Br}$ & 107 & 103 & 211 \\
$\mathrm{~B}$ & $\mathrm{CHO}$ & 104 & 100 & 204 \\
$\mathrm{~B}$ & $\mathrm{Et}$ & 90 & 89 & 180 \\
$\mathrm{~B}$ & $\mathrm{MeO}$ & 96 & 93 & 190 \\
$\mathrm{~B}$ & $\mathrm{NO}$ & 108 & 103 & 211 \\
\hline $\mathrm{C}$ & $\mathrm{Br}$ & 116 & 113 & 230 \\
$\mathrm{C}$ & $\mathrm{CHO}$ & 102 & 100 & 203 \\
$\mathrm{C}$ & $\mathrm{Et}$ & 101 & 100 & 202 \\
$\mathrm{C}$ & $\mathrm{MeO}$ & 113 & 111 & 225 \\
$\mathrm{C}$ & $\mathrm{NO}$ & 102 & 100 & 202 \\
\hline
\end{tabular}

Tabela 4.2: Energias de relaxação (meV) e energia de reorganização intramolecular (meV) para o triindole ligado a diferentes grupos funcionais.

Além disso, vale destacar que os valores de $\lambda$ para os triindoles funcionalizados são consideravelmente altas comparadas à energia de reorganização observada em outros sistemas de interesse para processos de transferência de carga [43]. E, de acordo com a equação 3.15 a taxa de transferência de carga é reduzida com o aumento da energia de reorganização. Portanto, é necessário maximizar o acoplamento eletrônico para se obter elevadas taxas de transferência de carga.

\subsection{Acoplamento Eletrônico}

Nesta seção, apresentamos os resultados para o cálculo do acoplamento eletrônico do dímero de triindole em que grupos $\mathrm{CH}_{3}$ foram substituídos lateralmente na molécula. A inclusão de grupos laterais deve ser considerada por ter um efeito signi- 
ficativo para se alcançar grandes mobilidades de carga [14]. Aqui é feita uma descrição do procedimento computacional adotado para otimizar as moléculas de triindole. Em seguida serão discutidos os resultados do cálculo do acoplamento eletrônico em que foi utilizado o modelo de estados não carregados baseado no teorema de Koopmans [41].

\subsubsection{Procedimentos Computacionais}

O programa Gaussian 09 [42] foi adotado para descrever a estrutura eletrônica dos triindoles. A geometria mais estável da molécula foi obtida em nível Hartree-Fock Restrito (RHF) [44] e também utilizando o método da Teoria do Funcional Densidade (DFT), mantendo o anel benzeno central no plano $x y$. Para os cálculos realizados através do método DFT, foram adotados três tipos de funcionais densidade: o primeiro foi o B3LYP [30,31] que é um dos funcionais híbridos mais utilizados em cálculos DFT por apresentar bons resultados em cálculos ab initio. Entretanto, os métodos DFT falham ao descrever interações fracas, como as forças de dispersão encontradas em empilhamento- $\pi$ aromático.

Para contornar essa dificuldade, nós também realizamos cálculos DFT utilizando os funcionais M05 [32] e M06 [33], que foram parametrizados para descrever adequadamente as interações não covalentes. Estes funcionais, como os outros com este propósito (DFT-D), contêm parâmetros que podem funcionar bem para uma determinada classe de molécula, mas não para outra. Portanto, para a classe de moléculas estudadas neste capítulo (derivados de triindoles), uma validação da utilização destes novos funcionais é necessária.

Em todos os cálculos, foi utilizado o conjunto de base 6-31G estendido por duas funções de polarização adicionais, isto é, 6-31G(d,p). A inclusão da função de polarização é importante para melhorar a descrição dos orbitais virtuais, que podem desempenhar um papel relevante na transferência de elétrons entre moléculas [45]. Este tratamento foi adotado com a finalidade de obtermos uma descrição precisa da molécula com relação à inclusão de efeitos de correlação eletrônica e dispersão sobre a otimização da geometria do estado fundamental.

De posse da geometria otimizada, cálculos de energia foram efetuados variando o ângulo de rotação da molécula no intervalo de $0^{\circ}$ a $120^{\circ}$. Para rotacionar a molécula 
a)

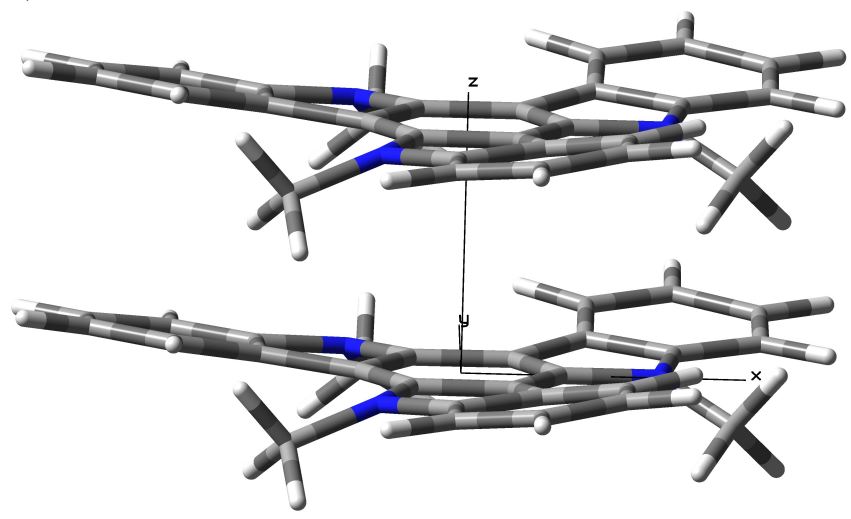

b)

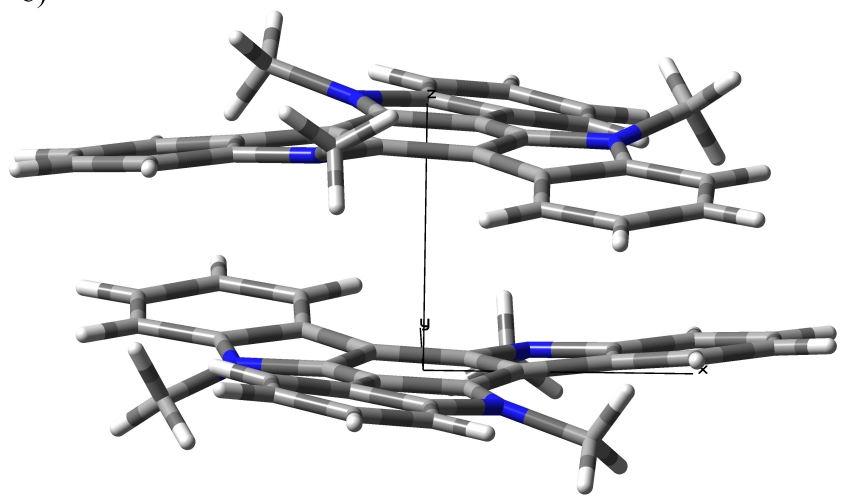

Figura 4.5: (a) Dímero usado para calcular as integrais de transferência associadas às rotações da geometria da molécula de triindole orimizada. (b) Geometria do dímero obtido da estrutura cristalina.

foi escrito um programa em Fortran em que as coordenadas $x$ e $y$ da molécula foram rotacionadas em torno do eixo-z onde definimos o anel benzeno compartilhado pelos três grupos carbazol, com sendo o centro da molécula. Em seguida a molécula foi transladada a uma distância de $3,54 \AA$ (distância entre as moléculas no cristal) ao longo do eixo-z. Essas estruturas (rotacionadas e transladadas) formam a molécula de cima do dímero, enquanto que, a molécula de baixo é mantida no plano-xy e sem sofrer qualquer rotação. Na Figura 4.5 são apresentadas as geometrias da molécula otimizada e da estrutura cristalina do dímero de triindole. A molécula otimizada apresentou diferença significativa na sua estrutura com relação a estrutura do cristal. Isso teve impacto nos valores das integrais de transferência que apresentaremos a seguir. 


\subsubsection{Acoplamento Eletrônico via Teorema de Koopmans}

A Figura 4.6(a) e 4.6(b) representam, respectivamente, as integrais de transferência de buracos e elétrons obtidas para o dímero composto pelas estruturas otimizadas. Como pode ser observado, há um comportamento suave das curvas do acoplamento eletrônico com relação ao ângulo de rotação $\theta$ com uma redução do acoplamento eletrônico a medida que aumentamos a variação de $\theta$. Vale destacar o fato de que os triindoles se empacotam com um ângulo de aproximadamente $60^{\circ}$ [6]. Para esse valor, a integral de transferência de buraco tem valor razoável, enquanto que, a integral de transferência de elétrons é praticamente nula. Isto significa que o acoplamento eletrônico favorece o transporte de buracos, que também é favorecido pelo potencial de ionização e afinidade eletrônica desta molécula.

Para o ângulo $\theta$ na Figura 4.6(a), variando no intervalo $\left(0^{\circ}<\theta<45^{\circ}\right)$, as integrais de transferência de buraco tiveram comportamento semelhante, com exceção para o método Hartree-Fock em que a amplitude da integral de transferência foi maior que as obtidas pelo cálculo DFT. O intervalo $\left(45^{\circ}<\theta<62^{\circ}\right)$ foi o que apresentou maior diferença nos resultados. Aqui podemos observar que há um crescimento na amplitude da integral de transferência de buraco para os casos HF, B3LYP e M05, entretanto, o cálculo com o funcional M06 apresenta um comportamento quase que constante. É importante destacar que o valor das integrais de transferência depende do método usado, mas o fato de ser muito complicado extrair tal valor do experimento, torna isto um ponto não muito relevante aqui. Portanto, o que estamos interessados aqui são as tendências das curvas das integrais de transferência.

Na Figura 4.6(b) as integrais de transferência de elétrons também apresentam comportamento semelhantes para todos os casos, com a amplitude da integral de transferência sendo maior para o caso HF. Aqui o intervalo para o qual a amplitude da curva volta a ter um crescimento é $\left(35^{\circ}<\theta<50^{\circ}\right)$ e, nesse intervalo todas as curvas apresentaram um aumento na amplitude da integral de transferência. Aqui já podemos observar que o acoplamento eletrônico muda conforme o tipo de cálculo empregado na descrição das propriedades eletrônicas da molécula.

Nos dois casos (ver Figura 4.6(a) e (b)) o acoplamento eletrônico máximo ocorre exatamente na configuração cofacial, isto é, em $\theta=0^{\circ}$. Segundo a teoria de 

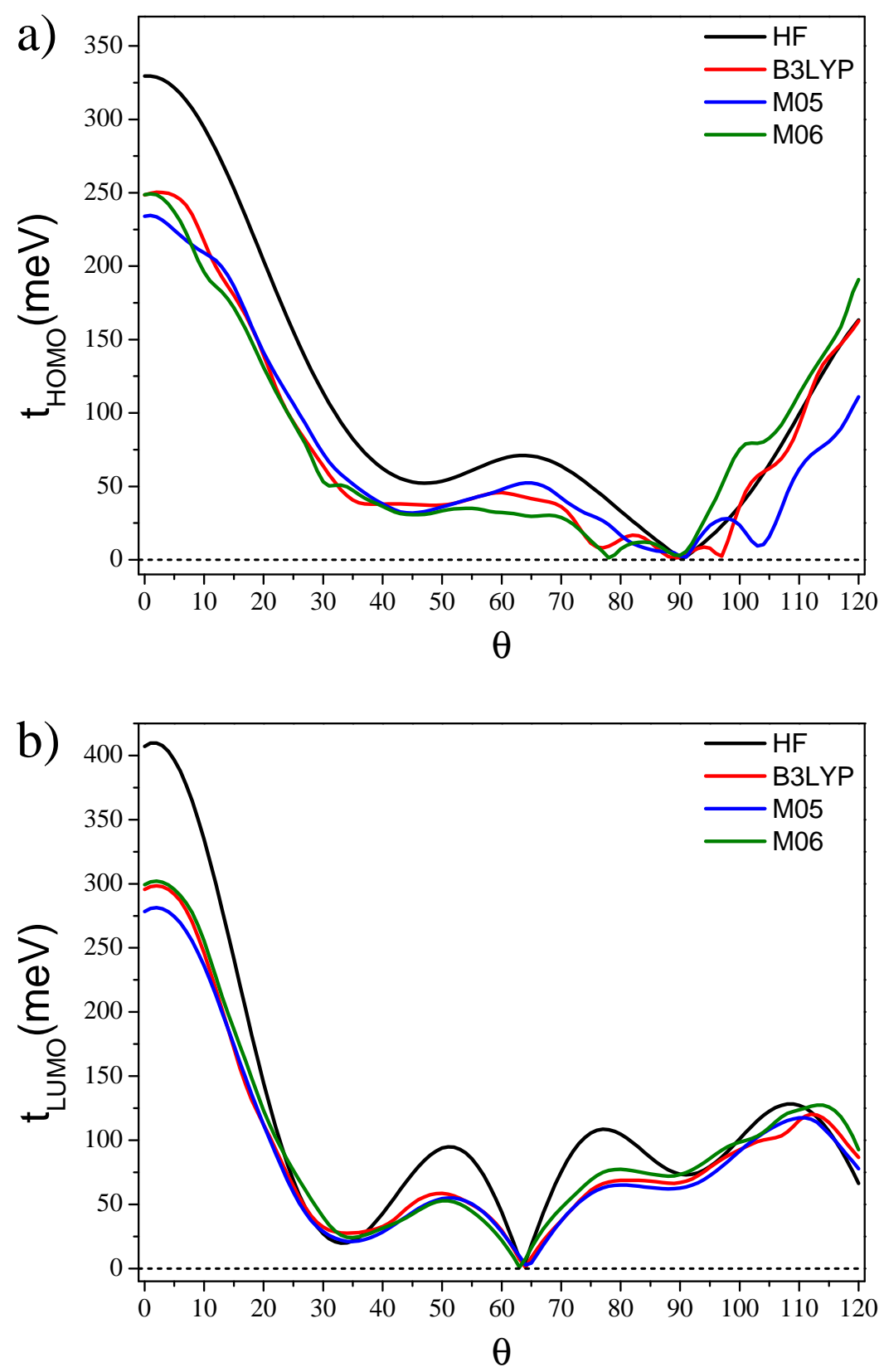

Figura 4.6: Integral de transferência na geometria otimizada como função do ângulo de rotação. a) Integral de transferência de buracos. b) Integral de transferência de elétrons.

Marcus, quanto maior o acoplamento eletrônico maior é a mobilidade dos portadores de carga. Sendo assim, através da engenharia de materiais, pode se fabricar estruturas com esta configuração (dímero cofacial) e, consequentemente, com elevada mobilidade de carga. Não sendo possível obter uma estrutura cofacial estável, deve-se tentar outra configuração que apresente um ponto de máximo no acoplamento eletrônico. Esta situação pode ser observada em $\theta \approx 50^{\circ}$ como é mostrado na Figura 4.6(b). 
Para o caso $\theta \approx 30^{\circ}$ é observado um ponto de mínimo não nulo no valor do acoplamento eletrônico. Este efeito está associado à manifestação da fase da função de onda e é chamado efeito de interferência quântica [46].

$\operatorname{Em} \theta=60^{\circ}$ a integral de transferência de elétrons é nula. Isto significa que os orbitais moleculares LUMO e LUMO+1, neste caso, são degenerados e a mobilidade de elétrons deve tender a zero. Como esse sitema tem periodicidade em $\theta=120^{\circ}$, a tendência da curva seria um comportamento simétrico para valores de $\theta$ maiores que $120^{\circ}$, mas devido à inclusão dos grupos metil ao triindole e à "quebra" da planaridade da estrutura molecular, esse comportamento não pôde ser observado.

\subsubsection{Acoplamento Direto}

O cálculo do acoplamento eletrônico é, frequentemente, baseado no modelo de dois estados, constituído do estado inicial e final do doador e aceitador, respectivamente, separados por um gap de energia dos estados eletrônicos ocupados (HOMO) e desocupados (LUMO). Estes estados estão associados a representações de um elétron efetivo que apresenta localização nas regiões doadora e aceitadora. O método do acoplamento direto trata os estados como cargas localizadas e calcula diretamente os elementos de matriz $H_{12}$ e $S_{12}$ da equação 3.21 .

O pacote computacional Q-Chem v.4.1 recentemente implementou em seu conjunto de software, uma ferramenta para o cálculo do acoplamento eletrônico de uma molécula carregada para outra que se encontra neutra [47], avaliando, de fato, o sistema como sendo carregado e sistema neutro, localizando a carga numa região do espaço, ou seja, na molécula sem a aproximação do Teorema de Koopmans.

O valor do acoplamento é dado em função dos estados de carga carregada,

$$
H_{i j}=t_{i j}=\left\langle\Psi^{+}|H| \Psi^{0}\right\rangle .
$$

O pacote computacional do Q-chem, disponibiliza a aproximação " $1+1$ ” que combina as funções de onda, individualmente, da molécula do doador e aceitador para formar as funções de onda de carga localizada. Com a vantagem do baixo custo computa- 
cional permite um maior número de cálculos em simulações para a transferência de carga com bons resultados.

Como uma ilustração do método do acoplamento direto, nós realizamos o cálculo da integral de transferência de elétrons para a molécula de triindole não funcionalizada mostrada na Figura 4.7. Neste caso, a molécula não funcionalizada não possui os grupos metil que provocam torções na geometria molecular. Dessa forma, a estrutura otimizada do triindole não funcionalizado é plana e apresenta simetria $C_{3}$.

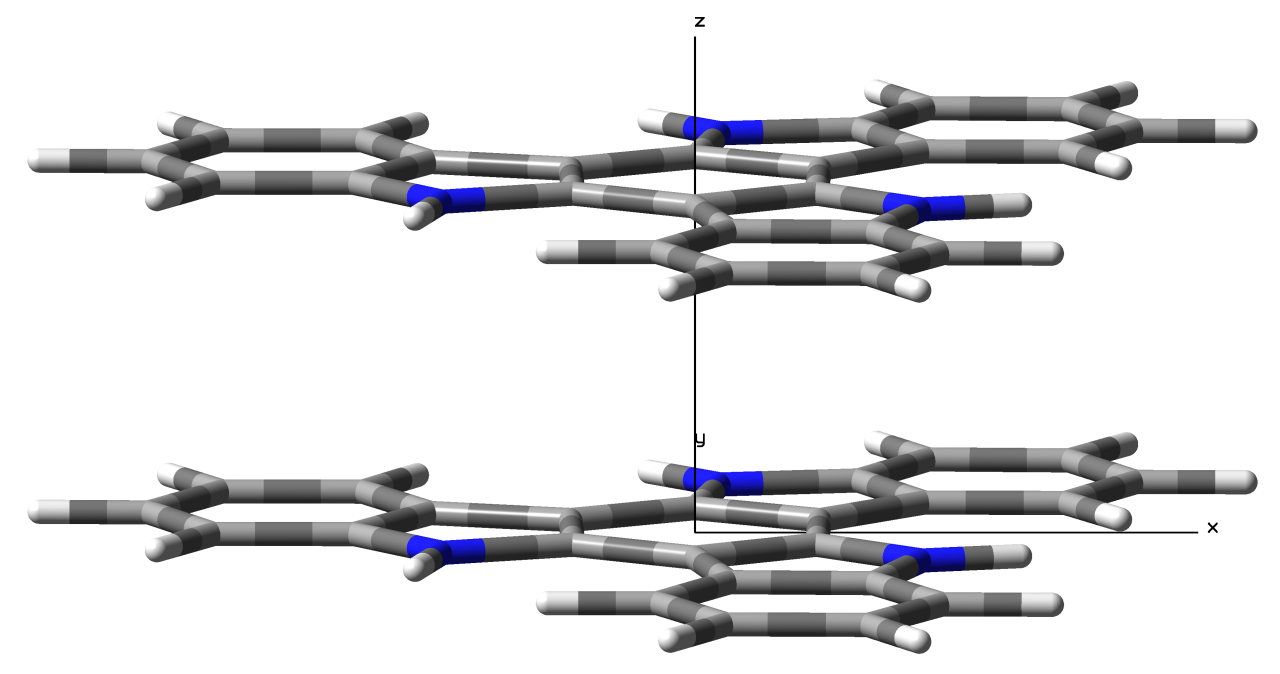

Figura 4.7: Dímero da molécula de triindole não funcionalizada.

A Figura 4.8 mostra o cálculo da integral de transferência eletrônica utilizando o funcional B3LYP e o M06. Podemos observar que o valor máximo é obtido quando o dímero está na configuração cofacial, $\theta=0^{\circ}$. Como dito anteriormente, o sistema apresenta periodicidade em $\theta=120^{\circ}$, o que indica que o máximo valor do acoplamento deve ser alcançado novamente em $\theta=120^{\circ}$, como mostra a Figura 4.8. Além disso, o comportamento da curva deve ser simétrico para valores maiores que $120^{\circ}$. Podemos verificar que o acoplamento eletrônico do dímero de triindole não funcionalizado tem um comportamento diferente do apresentado pelo dímero funcionalizado. A presença dos grupos metil provou uma perda de planaridade (simetria) que também impactou no comportamento simétrico da acoplamento eletrônico.

Portanto, neste capítulo verificamos como as propriedades eletrônicas e ópticas são influenciadas por diferentes grupos funcionais ligados de maneiras diferentes ao núcleo 


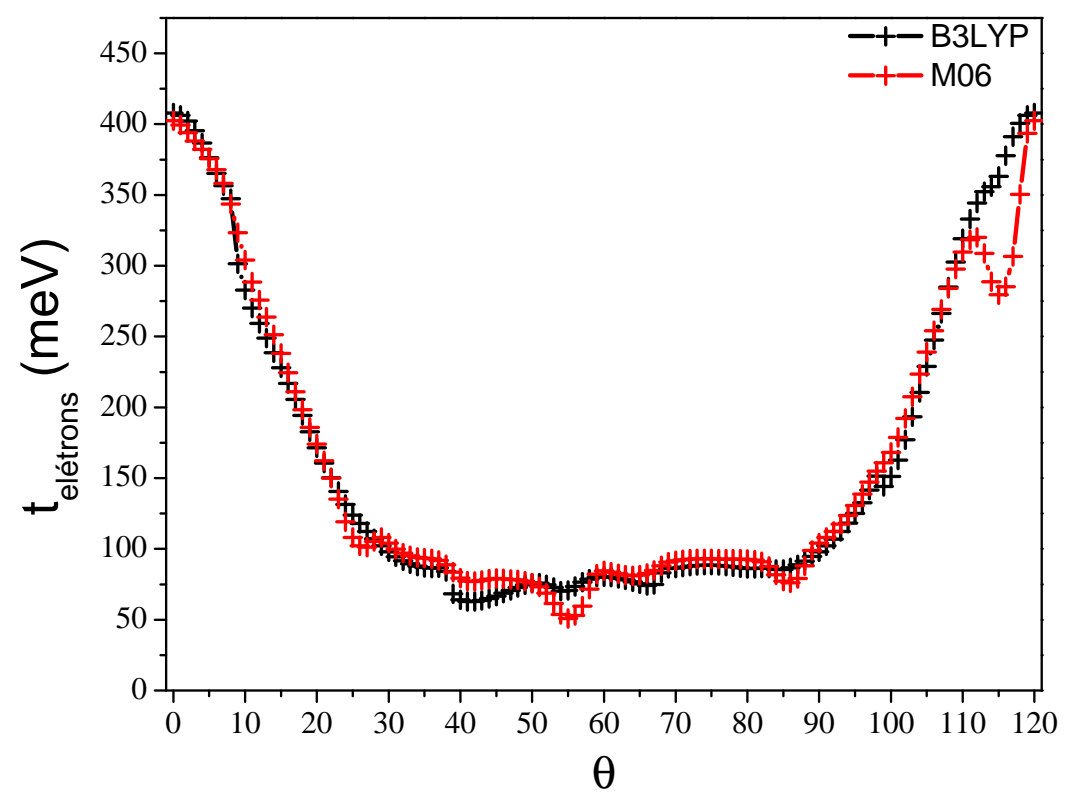

Figura 4.8: Integral de transferência de elétrons da molécula de triindole não funcionalizada como função do ângulo de rotação.

do triindole. Também investigamos dois parâmetros importantes envolvidos nos processos de transporte de carga em semicondutores orgânicos, energia de reorganização e acoplamento eletrônico. No caso da energia de reoganização, vimos que os diferentes grupos funcionais pouco influenciaram no valor de $\lambda$.

Além disso, vimos duas formas de efetuar o cálculo do acoplamento eletrônico, via teorema de Koopmans e via Acoplamento Direto. O cálculo via teorema de Koopmans tem a vantagem de ser mais fácil estimar o acoplamento eletrônico. Entretanto, esta aproximação falha se a diferença de energia de sítio for grande. Por outro lado, o Acoplamento direto tem a vantagem de ser o método mais realístico, mas tem a desvantagem de que a carga pode estar totalmente localizada sobre um único sítio.

Como o valor do acoplamento eletrônico depende no nível de cálculo realizado, nosso interesse aqui foi observar as tendências nas curvas das integrais de transferência. Nos casos investigados, verificamos que as integrais de transferência, ambas de elétrons e buracos, apresentam valor máximo nas situações em que as moléculas do dímero estão na configuração cofacial. Entretanto, sabe-se que na estrutura cristalina, os triindoles se empacotam com ângulo de $\left(\sim 60^{\circ}\right)$. Para este valor, observamos que a integral de transferência de buracos apresenta valor razoável, enquanto que, a integral de transferência 
de elétrons é praticamente nula. Este comportamento é esperado, pois sabe-se que os triindoles favorecem o transporte de buracos.

Também realizamos um cálculo exploratório utlizando o método do Acoplamento Direto para a integral de transferência de elétrons. Neste caso, consideramos o dímero da molécula de triindole não funcionalizado. Aqui verificamos que o triindole não funcionalizado apresenta estrutura plana e simétrica, o que levou a um comportamento também simétrico da curva da integral de transferência de elétrons. 


\section{Caminho de Conjugação Linear vs Ortogonal nos Polímeros Doador-Aceitador}

Polímeros e moléculas $\pi$-conjugadas compostas por unidades doadoras (D) e aceitadoras (A) vem atraindo atenção para aplicação como dispositivos eletrônicos, tais como transistores de efeito de campo (OFETs) e células fotovoltaicas (OPVs) [48-60]. Nos sistemas DA, também chamados sistemas push-pull, grupos doadores (que são ricos em elétrons) e grupos aceitadores (que têm uma baixa densidade eletrônica) são acoplados de forma a manter o caminho de conjugação- $\pi$ ao longo da cadeia conjugada, favorecendo assim o processo de transferência de elétrons intramolecular como também a presença de bandas de absorção que podem ser ajustadas para comprimentos de onda adequados para certos fins tecnológicos [61-64]. Nas situações em que há diferença entre as energias dos orbitais moleculares dos grupos doador e aceitador independentes, em geral, o HOMO tende a encontrar-se localizado no grupo doador enquanto que o LUMO se localiza no grupo aceitador [58]. Esta característica permite que se tenha um bom controle da energia do HOMO (ou seja, do potencial de ionização - IP) e da energia do LUMO (afinidade eletrônica - EA) e portanto, da tensão de circuito aberto $V_{O C}$ nas células solares em heterojunção (bulk heterojunction-BHJ) [65].

a)

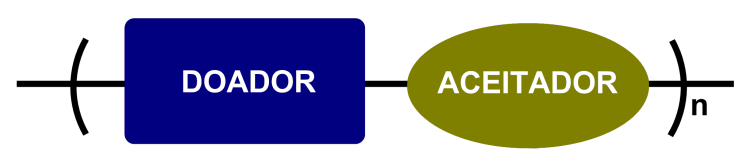

b)

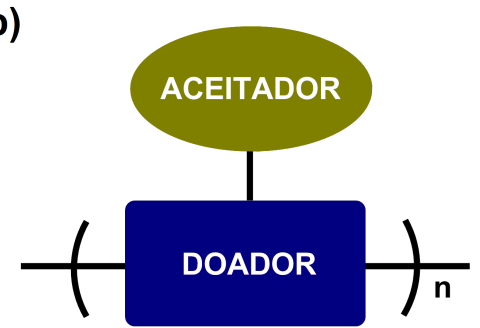

Figura 5.1: Caminho de conjugação (a) linear e (b) ortogonal.

A maioria das moléculas e polímeros dessa classe de sistemas apresentam estruturas em que as unidades doadoras e aceitadoras são ligadas em uma forma linear, 
por exemplo $-D-A-D-A-D-A-$, ou alguma forma derivada dessa (ver Figura 5.1). Recentemente, estruturas conjugadas ortogonalmente - nas quais a unidade D ou A é conjugada lateralmente à cadeia conjugada principal - foram introduzidas como uma estatégia alternativa [66-69]. Grimm e colaboradores, utilizando oligômeros e copolímeros de compostos ciclopentaditiofeno (CPDT) com um grupo imina anexado ortogonalmente ao esqueleto conjugado [70], mostraram como este padrão de conjugação pode levar a transições eletrônicas com baixa energia, embora a força do oscilador (momentos de dipolo de transição) para estas transições sejam pequenos. Li e colaboradores mostraram que, manipulando a força dos grupos aceitadores ligados lateralmente à cadeia conjugada principal do copolímero constituído de unidades carbazol $(\mathrm{Cz})$ e tiofeno (Th), os níveis de energia, as propriedades fotofísicas e o espectro de absorção podem ser efetivamente modificados [68].

Para que tais caminhos conjugados alternativos sejam utilizados para aplicação em dispositivos eletrônicos, é importante estabelecer como as propriedades eletrônicas e ópticas são manifestadas como função desta variação estrutural, a exemplo de transições excitadas de baixa energia com baixa força do oscilador que são características destes sistemas.

\subsection{Metodologia}

Nesta etapa de trabalho cálculos de Teoria do Funcional Densidade (DFT) foram empregados para examinar de forma sistemática as estruturas DA conjugadas linear e ortogonalmente (ver Figura 5.2). Fazendo isso, é possível obter uma melhor compreensão das propriedades geométricas, eletrônicas e ópticas destes sistemas. Aqui as unidades carbazol $(\mathrm{Cz})$ e tiofeno (Th) foram usadas como grupos doadores de elétrons, enquanto que três diferentes unidades aceitadoras foram inseridas no esqueleto conjugado, tanto de forma linear [benzotiadiazol (BT) e tienopirazina (TP)], como também anexados ortogonalmente ao esqueleto conjugado [tienileno-vinileno di-ciano (TVDCN)] para uma avaliação direta dos sistemas reportados por Li e colaboradores [68].

As geometrias das moléculas no estado fundamental $(n=1-4)$ foram otimizadas em nível DFT utilizando o funcional híbrido B3LYP [71-73] com o conjunto de base 6- 

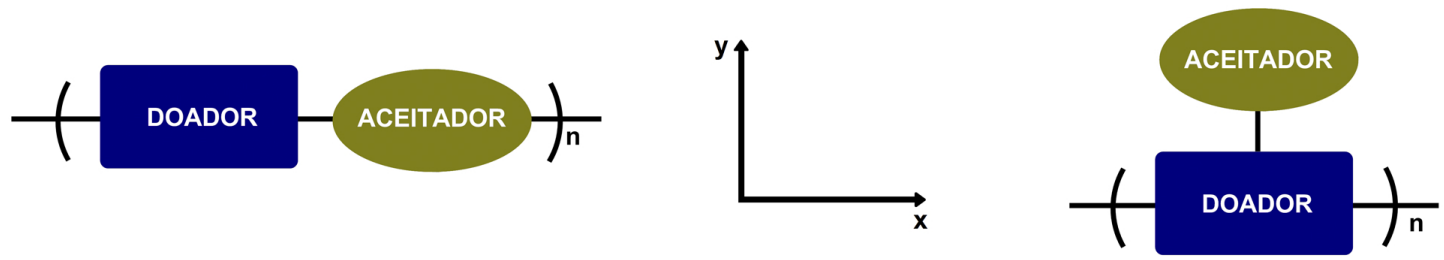

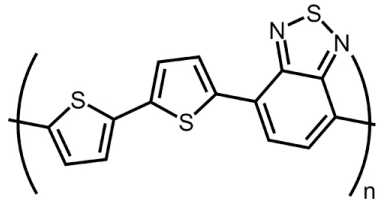

PbTBT

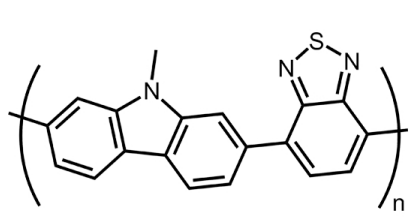

PCzBT

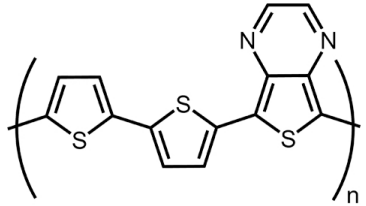

$\mathrm{PbTTP}$

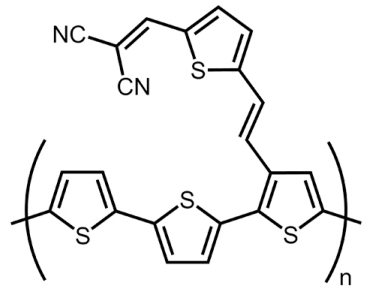

PTTh-TVDCN

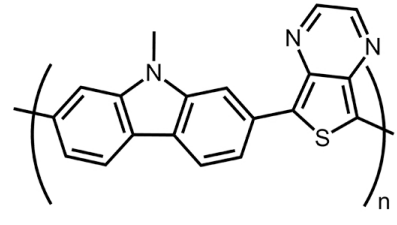

PCzTP

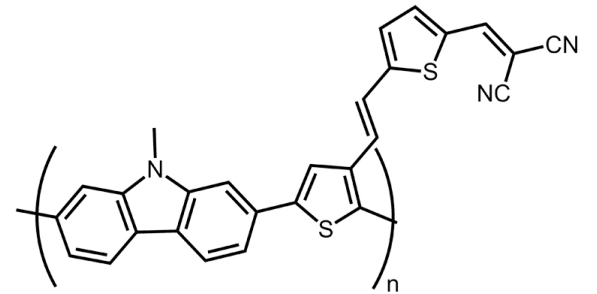

PCzTh-TVDCN

Figura 5.2: Estruturas químicas das unidades monoméricas de: PbTBT $\equiv$ poly $[4-$ methyl-7- (5'-methyl- [2,2'-bithiophen]-5-yl) benzo[c][1,2,5]thiadiazole]; PbTTP $\equiv$ poly [5-methyl-7- (5'-methyl- [2,2'-bithiophen] -5-yl) thieno [3,4-b] pyrazine]; PCzBT $\equiv$ poly [4- (7,9-dimethyl-9H-carbazol-2-yl)-7-methylbenzo[c][1,2,5] thiadiazole]; PCzTP $\equiv$ poly [5- (7,9-dimethyl-9H-carbazol-2-yl)-7-methylthieno[3,4-b] pyrazine]; PCzTh-TVDCN $\equiv$ poly $[(\mathrm{E})-2-((5-(2-(5-(7,9-$ dimethyl-9H-carbazol-2-yl)-2-methylthiophen-3-yl) vinyl) thiophen-2-yl) methylene) malononitrile]; PTTh-TVDCN $\equiv$ poly [(E)-2-((5-(2- $(5,5 "-$ dimethyl- [2,2':5',2"'-terthiophen]-3-yl) vinyl) thiophen-2-yl) methylene) malononitrile].

31G(d,p) [74,75]. É importante observar que os maiores oligômeros, ou seja, oligômeros de tamanho $n=4$, apresentam um caminho de conjugação linear formado por 24 ligações duplas ao longo do esqueleto conjugado, os quais têm demostrado boas tendências em termos de reprodução das propriedades eletrônicas e ópticas dos copolímeros DA [23, 58, 70,76]. É bem conhecido da literatura que os funcionais híbridos convencionais têm limitações associadas a erros de auto-interação, o que pode levar esses funcionais a terem dificuldades na descrição de processos de excitação e transferência de carga [77,78]. Para superar estas limitações, novos funcionais de longo-alcance vêm sendo empregados de modo que 
o parâmetro de separação de curto e longo-alcance é otimizado através do procedimento gap-fitting descrito por Baer e Kronik [25-27]. Este procedimento pode ser descrito pelas seguintes equações:

$$
\begin{gathered}
J_{I P}(\omega)=\left|\epsilon_{H}^{\omega}(N)+E_{g s}^{\omega}(N-1)-E_{g s}^{\omega}(N)\right|, \\
J_{E A}(\omega)=\left|\epsilon_{H}^{\omega}(N+1)+E_{g s}^{\omega}(N)-E_{g s}^{\omega}(N+1)\right|
\end{gathered}
$$

e

$$
J_{\text {gap }}(\omega)=\sqrt{\left(J_{I P}(\omega)\right)^{2}+\left(J_{E A}(\omega)\right)^{2}} .
$$

Aqui, $\epsilon_{H}^{\omega}(N)$ representa a energia do HOMO para um sistema com N elétrons e $E_{g s}^{\omega}(N)$ sua correspondente energia SCF. Analogamente, $\epsilon_{H}^{\omega}(N+1)$ é a energia do HOMO para um sistema de $N+1$ elétrons e $E_{g s}^{\omega}(N+1)$ e $E_{g s}^{\omega}(N-1)$ são as energias SCF do sistema nos estados ânion e cátion, respectivamente. Ou seja, com esta abordagem tenta-se modificar o funcional de modo que o teorema de Koopmans seja exato e o análogo de Koopmans para a afinidade eletrônica também. A partir da estrutura otimizada em nível B3LYP/6-31G(d,p), o parâmetro de separação de curto e longo-alcance $(\omega)$ como também as geometrias moleculares foram iterativamente otimizadas com o objetivo de garantir que o gap HOMO-LUMO obtido em nível LC-BLYP/6-31G(d,p) com o parâmetro $\omega$ otimizado, seja diretamente comparável ao valor experimental.

Os estados excitados singleto foram obtidos nas geometrias otimizadas usando Teoria do Funcional Densidade Dependente do Tempo (TDDFT) com nível de teoria LCBLYP/6-31G(d,p) com o parâmetro $\omega$ otimizado. Os perfis de absorção óptica foram simulados através da convolução das energias de transição vertical $S_{0} \rightarrow S_{1}$ com funções gaussianas caracterizadas pela largura a meia altura $(\mathrm{FWHM}=0,3 \mathrm{eV})$. Todos os cálculos foram realizados usando o programa Gaussian 09 (Revisão A.02 e B.01) [42].

\subsection{Propriedades Geométricas e Eletrônicas}

A análise pode ser iniciada pela discussão das propriedades geométricas das moléculas no estado fundamental como uma função da natureza das unidades repetidas. 
Observa-se que as geometrias das moléculas são muito influenciadas pela escolha dos fragmentos doador e aceitador apresentando diferentes graus de linearidade e/ou planaridade ao longo do esqueleto molecular.

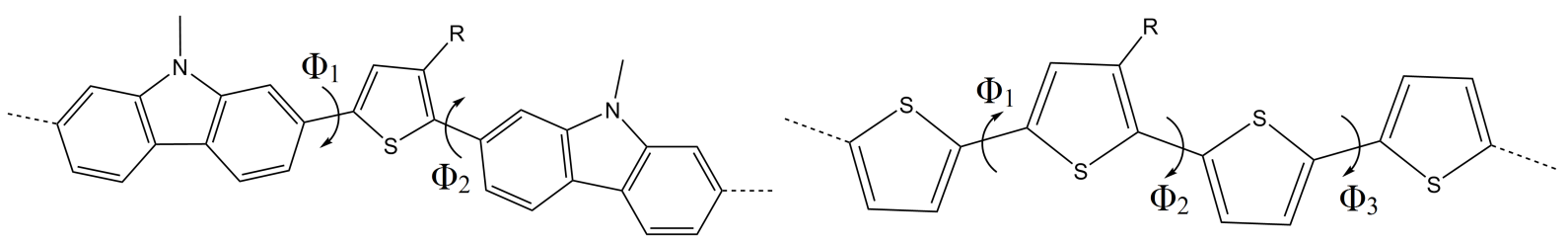

Figura 5.3: Ângulos de torção ao longo do esqueleto conjugado dos oligômeros DA.

\begin{tabular}{|c|c|c|c|c|c|}
\hline & Tetrâmero & $\Phi_{1}$ & $\Phi_{2}$ & $\Phi_{3}$ & anéis \\
\hline \multirow[t]{4}{*}{ Linear } & PbTBT & $0^{o}-1^{o}$ & $0^{\circ}$ & $0^{o}-1^{o}\left(11^{o}\right)$ & $5-6$ \\
\hline & PbTTP & $0^{\circ}$ & $0^{\circ}$ & $0^{\circ}\left(8^{\circ}\right)$ & $5-5$ \\
\hline & $\mathrm{PCzBT}$ & $29^{\circ}-30^{\circ}$ & $29^{\circ}$ & - & $6-6$ \\
\hline & PCzTP & $0^{o}-4^{o}$ & $1^{o}-5^{o}$ & - & $6-5$ \\
\hline \multirow[t]{2}{*}{ Ortogonal } & PCzTh-TVDCN & $26^{\circ}-35^{\circ}$ & $39^{\circ}-41^{\circ}$ & - & $6-5$ \\
\hline & PTTh-TVDCN & $12^{o}-15^{o}$ & $27^{\circ}-29^{\circ}$ & $22^{\circ}-24^{\circ}$ & $5-5$ \\
\hline
\end{tabular}

Tabela 5.1: Ângulos de torção (graus) ao longo do esqueleto conjugado dos tetrâmeros.

A Figura 5.3 mostra as definições e a Tabela 5.1 os valores dos ângulos de torção para os tetrâmeros de cada sistema conjugado. Como é esperado, os sistemas com unidades carbazol apresentam maior desvio da estrutura planar quando comparado aos oligômeros baseados no tiofeno como grupo doador. Isto se deve às interações entre os fenilenos com os grupos aceitadores ligados lateralmente [58]. No caso do PCzBT, por exemplo, os efeitos estéricos ocorrem entre os átomos de hidrogênio dos fenilenos do carbazol e os átomos vizinhos mais próximos do benzotiadiazol, nesse caso a interação entre os anéis dos grupos DA é do tipo 6-6. Já no caso do PCzTP a interação ocorre entre os átomos de hidrogênio do carbazol e os vizinhos mais próximos do tienopirazina e interação é do tipo 6-5. Dessa forma é esperado que o PCzBT tenha um desvio da planaridade maior do que o PCzTP. Portanto, os efeitos estéricos são maiores quando a forma heterocíclica dos anéis dos grupos DA é aumentada.

Embora as estruturas conjugadas ortogonalmente tenham o mesmo padrão de 
substituição ao longo do esqueleto conjugado, os grupos TVDCN anexados lateralmente levam a um grau de torção ainda maior. Além disso, a separação entre os átomos de hidrogênio dos grupos di-ciano e os átomos de hidrogênio mais próximo do esqueleto con-

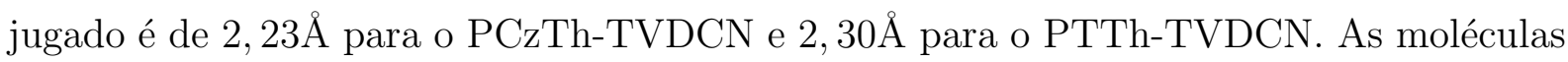
de PbTBT e PbTTP apresentam uma razoável planaridade nas geometrias, com ângulo de torção de $11^{\circ}$ e $8^{\circ}$, respectivamente, no grupo tiofeno localizado na extremidade do esqueleto conjugado. Estes diferentes graus de planaridade devem refletir, de certa forma, no grau de delocalização da função de onda nesses sistemas.

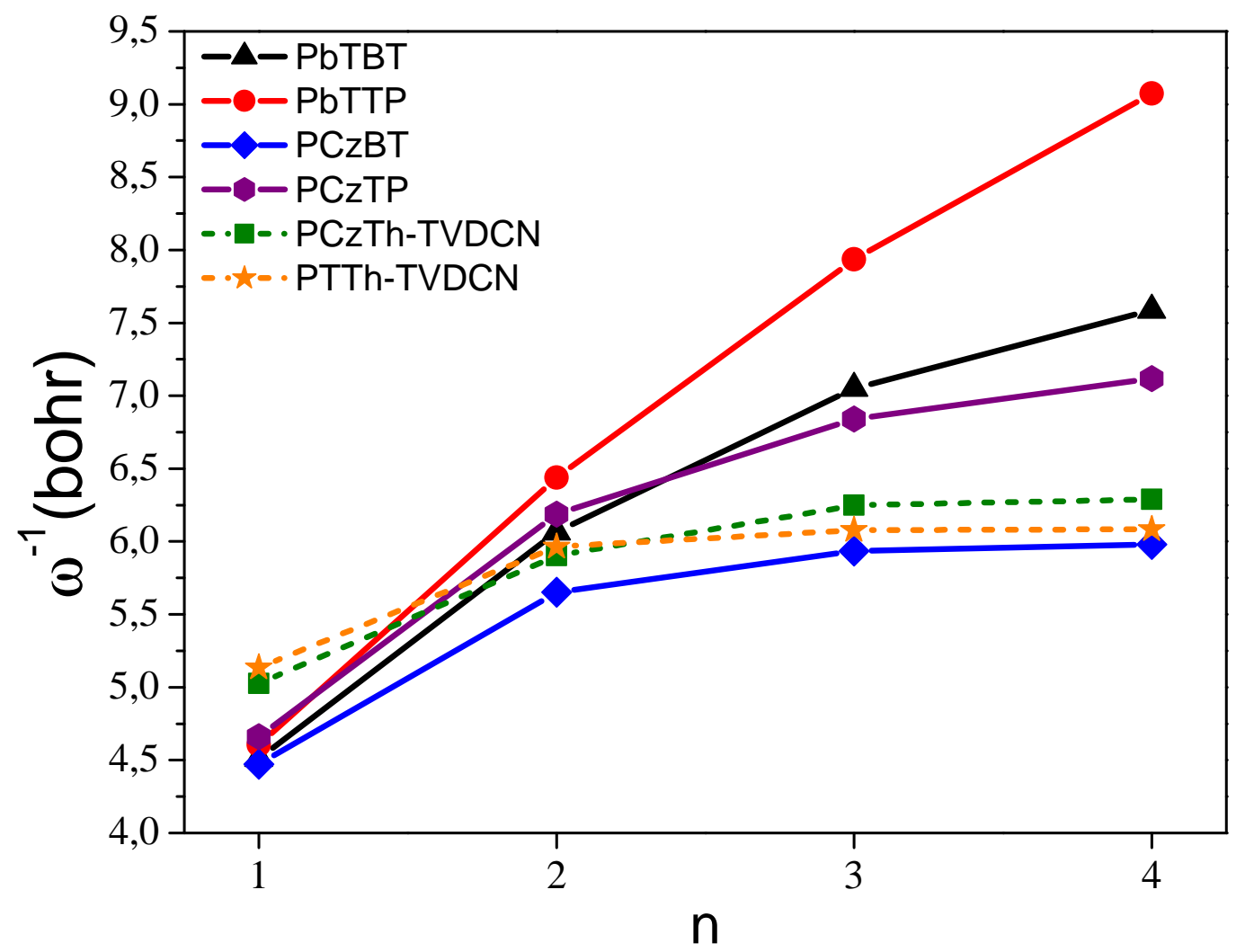

Figura 5.4: Comprimento característico $(1 / \omega)$ como função do tamanho do oligômero obtido usando a nível LC-BLYP/6-31G(d,p). A escala do comprimento característico sobre o qual o tratamento do operador de Coulomb muda de curto-alcance (SR) para longo-alcance (LR) com a diminuição do valor de $\omega$.

Os desvios da planaridade induzem a mudanças na estrutura eletrônica dos oligômeros através da redução da delocalização da função de onda, como pode ser visto através dos valores obtidos para o parâmetro $\omega$ (ver Figura 5.4). Como discutido por Körzdörfer [24], o comprimento característico da correção de longo-alcance $(1 / \omega)$ fornece 
uma forma alternativa para examinar a conjugação- $\pi$. A Figura 5.4 mostra a evolução de $1 / \omega$ como uma função do número de unidades repetidas. Os valores do comprimento característico aumentam com o crescimento do comprimento da cadeia conjugada e tendem a saturar depois de quatro unidades repetidas. Este resultado está de acordo com o comportamento descrito por Pandey e colaboradores [23]. As exceções são as moléculas PbTBT e PbTTP, nas quais o comprimento característico não satura depois de quatro unidades repetidas. Este efeito pode ser atribuído ao fato de que o parâmetro de longoalcance torna-se muito pequeno para estes sistemas altamente conjugados e, portanto, a contribuição Hartree-Fock no funcional é pequena. Além disso, os dados confirmam a dependência do comprimento característico com a natureza e tamanho do sistema [23,24,79]. Para efeito de comparação, os valores de 1/ $\omega$ para os sistemas altamente conjugados, isto é, PbTBT, PbTTP e PCzTP saturam em 7,58, 9,07 e 7,11 Bohr, respectivamente, enquanto que para o sistema linear torcido PCzBT, 1/ $\omega$ satura em 5,98 Bohr. Já para os sistemas ortogonalmente conjugados PCzTh-TVDCN e PTTh-TVDCN, 1/ $\omega$ satura em 6,28 e 6,08 Bohr, respectivamente, em concordância com o desvio da arquitetura coplanar.

A Figura 5.5 apresenta a evolução da energia dos orbitais HOMO e LUMO como uma função do comprimento do oligômero. Nos valores de comprimento analizados, existe uma clara relação linear entre as energias do HOMO (LUMO) e o inverso do número de unidades repetidas. O grupo doador carbazol apresenta os HOMOs mais energeticamente estabilizados na série. Os HOMOs desestabilizados energeticamente são associados às configurações mais planares ao longo do esqueleto conjugado, o que permite uma maior delocalização do HOMO. Portanto, as energias do HOMO para os tetrâmeros sugerem que os potenciais de ionização para os copolímeros DA cescem na seguinte ordem: PbTTP $<$ PCzTP $<$ PbTBT $<$ PTTh-TVDCN $<$ PCzTh-TVDCN $<$ PCzBT (ver Tabela A.2). Da mesma forma, a afinidade eletrônica segue a tendência: PCzTh-TVDCN $>$ PbTTP $>$ PTTh-TVDCN $>$ PbTBT $>$ PCzTP $>$ PCzBT. Além disso, os tetrâmeros com o grupo carbazol no equeleto conjugado apresentam valores de gap HOMO-LUMO mais elevados do que para os sistemas com grupo tiofeno. Os valores de gap HOMOLUMO para cada sistema seguem a seguinte ordem: PCzBT $(5,13 \mathrm{eV})>\operatorname{PCzTP}(4,11$ eV) $>$ PTTh-TVDCN $(4,01 \mathrm{eV})>\operatorname{PCzTh-TVDCN}(3,91 \mathrm{eV})>\operatorname{PbTBT}(3,79 \mathrm{eV})>$ $\operatorname{PbTTP}(3,00 \mathrm{eV})$.

A Figura 5.6 mostra as distribuições das funções de onda HOMO e LUMO para 

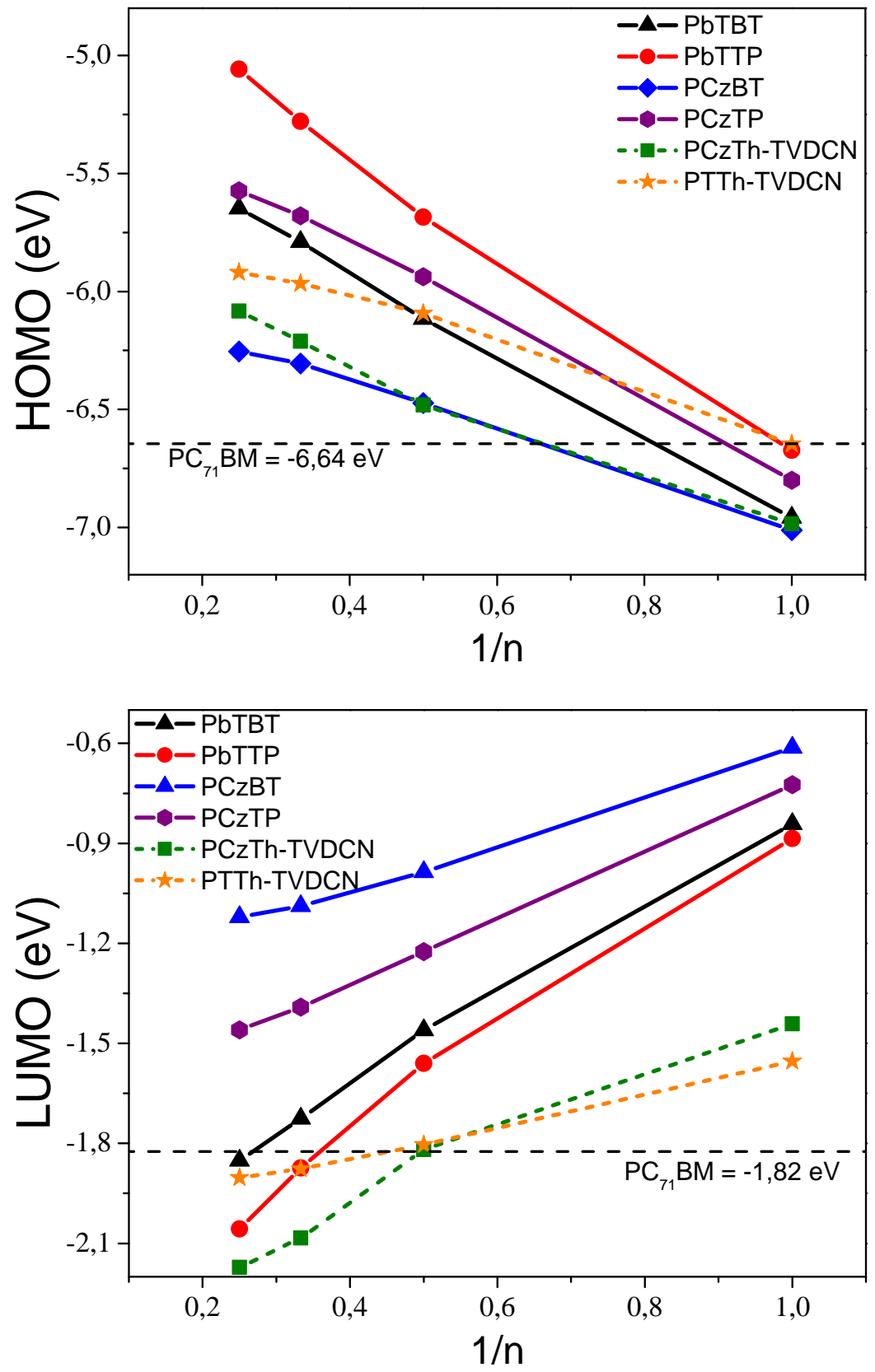

Figura 5.5: Energias do HOMO (topo) e LUMO (abaixo) com relação ao número de unidades repetidas (n) no oligômero. Para referência, a linha tracejada em cada gráfico representa a energia do HOMO (topo) e LUMO (abaixo) para o fulereno $\mathrm{PC}_{71} \mathrm{BM}$. Valores determinados a nível LC-BLYP/6-31G(d,p) com o parâmetro $\omega$ otimizado.

os tetrâmetros da série. Para os sistemas com caminho de conjugação linear os HOMOs são muito delocalizados ao longo do esqueleto conjugado. Por outro lado, os LUMOs apresentam graus de (de)localização da função de onda a depender dos componentes e arquitetura dos oligômeros. Para o PbTBT, PbTTP e PCzTP, a estrutura planar favorece 
a delocalização da função de onda do LUMO ao longo do esqueleto onjugado. Já para o

HOMO

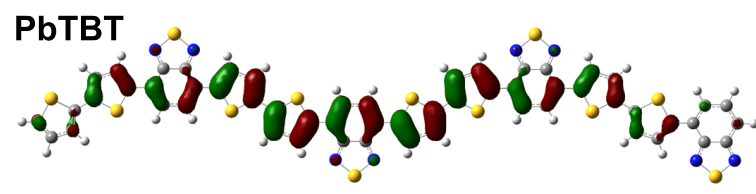

PbTTP

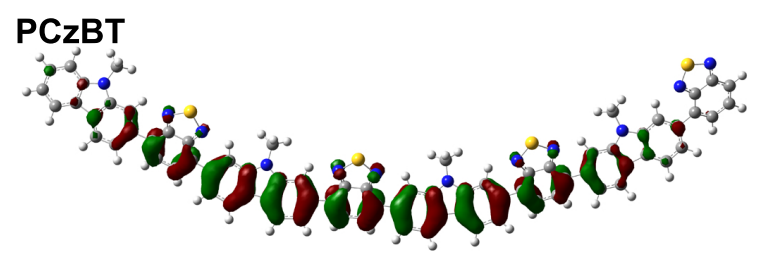

PCzTP
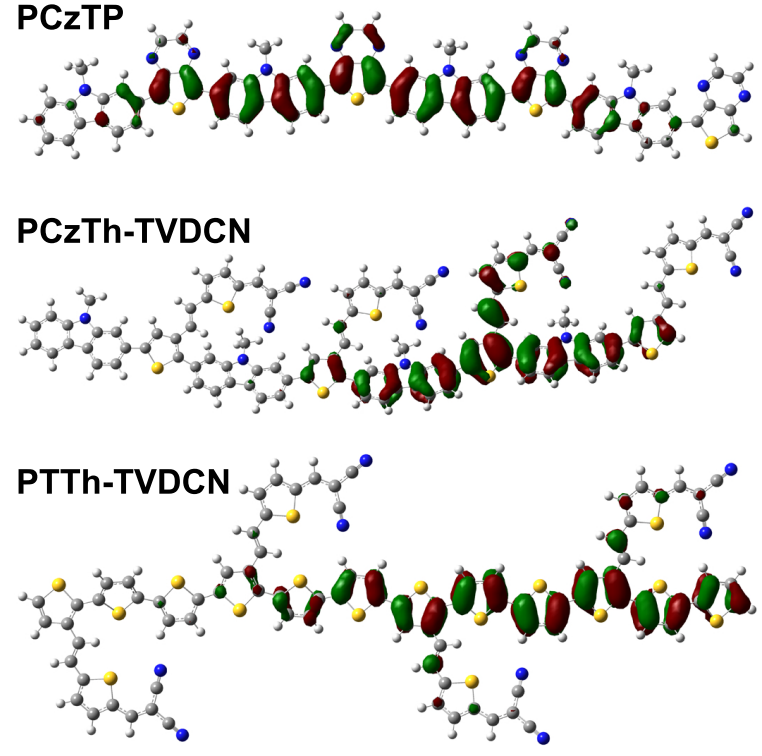

LUMO
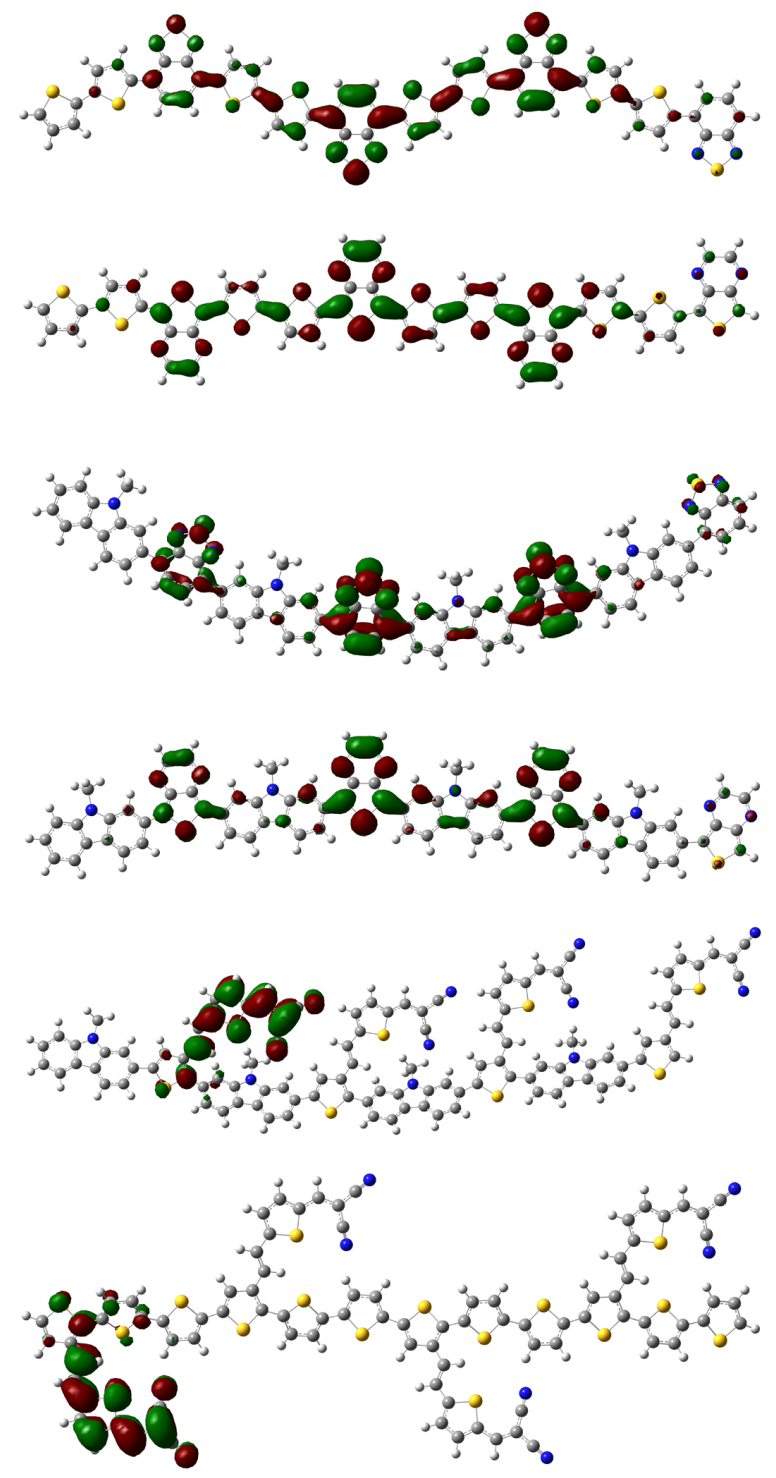

Figura 5.6: Ilustração dos orbitais moleculares de fronteira HOMO e LUMO para os tetrâmeros calculados a nível LC-BLYP/6-31G(d,p) com o parâmetro $\omega$ otimizado.

PCzBT, o LUMO é predominantemente localizado no grupo aceitador benzodiatiazol. Isto é resultado do desvio da coplanaridade no PCzBT que dificulta a delocalização do LUMO ao longo da molécula. Para os sistemas contendo grupos aceitadores ortogonalmente conjugados, a função de onda do HOMO também é delocalizada no esqueleto conjugado, embora menos delocalizado se comparado aos sistemas lineares. O LUMO, no entanto, é principalmente localizado nas unidades aceitadoras. Aqui é importante lembrar que essas 
diferenças no grau de delocalização dos orbitais moleculares de fronteira têm impacto significativo na força das oscilações ópticas.

\subsection{Transições do Estado Excitado Singleto}

A descrição dos processos de excitação no oligômeros permite examinar como as diferenças no caminho de conjugação influenciam nas propriedades do estado excitado. Um ponto importante a ser levado em consideração no contexto de polímeros com baixo gap óptico, é a correnpondência entre as energias de transição calculadas para os oligômeros vs. as energias de excitação óptica medida nos polímeros [80]. Uma variedade de procedimentos de extrapolação derivados empiricamente [81,82] e teoricamente [80] têm sido aplicados para extrair a energia de transição vertical no limite polimérico [83-85]. Esses procedimentos de extrapolação devem ser usados com cuidado, pois os erros associados à hipótese empregada na metodologia computacional empregada podem impactar consideravelmente o melhoramento do valor previsto da energia de transição vertical no limite polimérico [80]. A escolha adequada do procedimento de extrapolação também pode variar, dependendo das características particulares do polímero a ser analizado [83].

Em adição às energias de excitação, outras informações relevantes à natureza do estado excitado, como o momento de dipolo de transição e as configurações eletrônicas por exemplo, podem fornecer uma melhor compreensão de como as unidades doadora e aceitadora interagem no estado excitado. Para uma excitação eletrônica, a probabilidade de ocorrer uma transição entre dois estados é dada pelo momento de dipolo de transição eletrônica dado pela equação 5.4:

$$
\mu=\int \psi_{e}^{*}(\vec{r}) \hat{\mu} \psi_{g}(\vec{r}) d \vec{r}
$$

na qual $\psi_{e}^{*}(\vec{r})$ e $\psi_{g}(\vec{r})$ são as funções de onda do estado fundamental e excitado, respectivamente. $\hat{\mu}$ é o operador momento de dipolo de transição: $e \vec{r}$, em que e é a carga elementar. A equação 5.4 é a base das regras de seleção para as transições eletrônicas. O momento de dipolo de transição eletrônica fornece o coeficiente de excitação molar (no caso do sistema em solução) ou coeficiente de absorção (no caso do filme fino), e portanto fornece uma informação direta sobre a força da absorção.

A Figura 5.7 mostra a evolução das energias verticais $S_{0} \rightarrow S_{1}$ e momentos de 

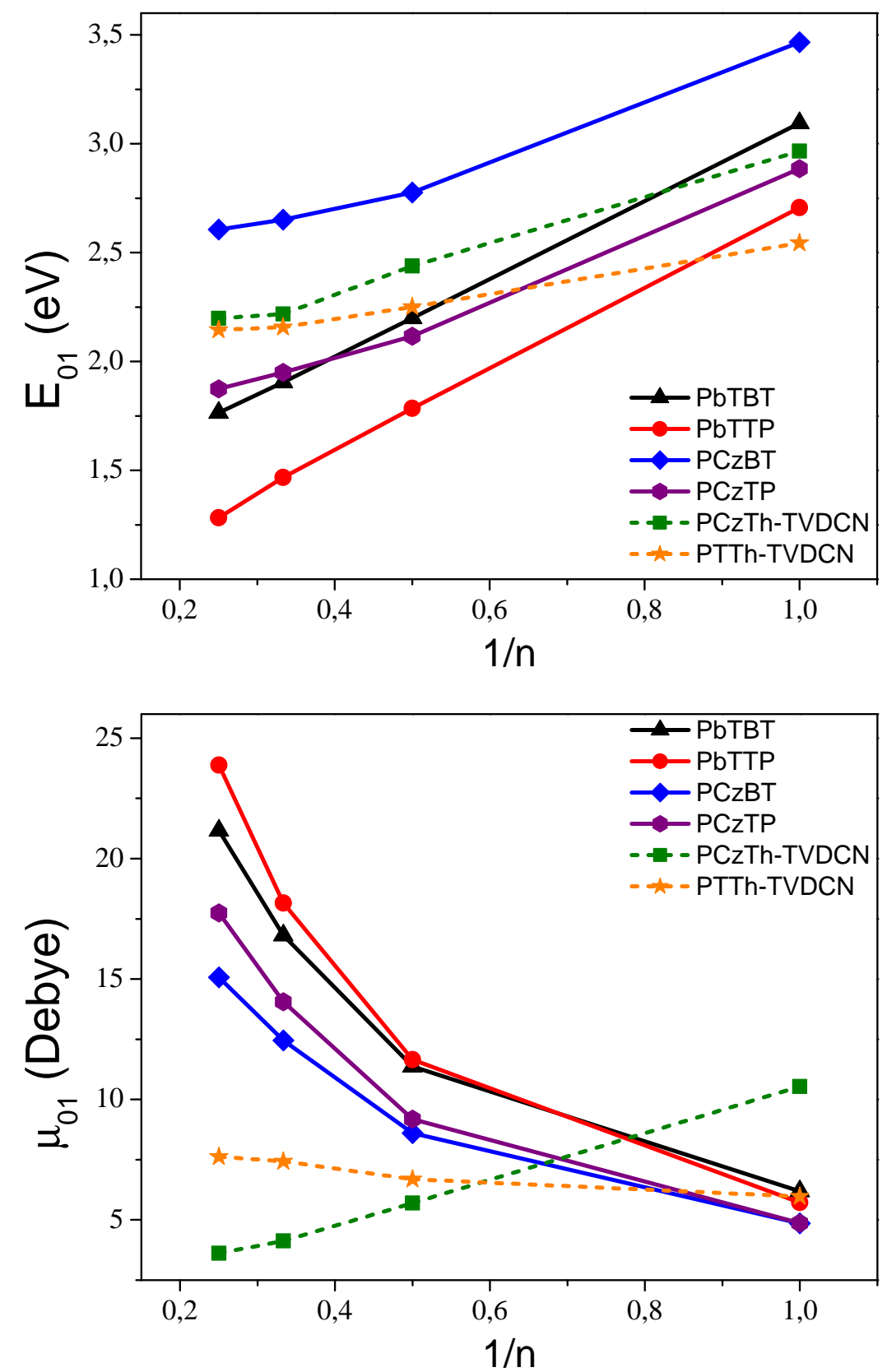

Figura 5.7: Evolução da energia de transição vertical $S_{0} \rightarrow S_{1}$ (topo) e valor absoluto do momento de dipolo de transição (abaixo) com relação ao inverso do número de unidades repetidas $(1 / \mathrm{n})$. Valores determinados em nível LC-BLYP/6-31G(d,p) com o parâmetro $\omega$ otimizado.

dipolo de transição total como uma função do inverso do número de unidades repetidas $(1 / n)$ determinados em nível TD-LC-BLYP/6-31G(d,p). Esta transição é principalmente do orbital HOMO para o LUMO (HOMO $\rightarrow$ LUMO) em todos os casos lineares investigados aqui. No caso dos sistemas ortogonais, no entanto, pode-se observar um conjunto 
de contribuições significativas de diferentes orbitais moleculares. Para estes casos uma análise dos orbitais naturais de transição (NTOs) será apresentada adiante. Para os valores de comprimento analizados, é observada uma relação linear entre o inverso do número de unidades repetidas e a energia de transição vertical para o PbTBT, PbTTP e PCzTP. Também pode ser observado que para os sistemas que apresentam maiores graus de torção no esqueleto conjugado, isto é, PCzBT, PCzTh-TVDCN e PTTh-TVDCN, a energia de transição vertical $S_{0} \rightarrow S_{1}$ tende a saturar para os maiores oligômeros.

\begin{tabular}{|c|c|c|c|c|c|c|c|}
\hline Tetrâmeros & \multirow{2}{*}{$E_{01}(\mathbf{e V})$} & \multirow{2}{*}{$\lambda_{01}(\mathbf{n m})$} & $f$ & \multicolumn{4}{|c|}{$\mu_{01}$ (Debye) } \\
\cline { 5 - 8 } & & & & $x$ & $y$ & $z$ & total \\
\hline PbTBT & 1,76 & 702 & 3,00 & $-21,15$ & 0,42 & $-0,13$ & 21,16 \\
\hline PbTTP & 1,28 & 966 & 2,77 & $-23,88$ & $-0,15$ & $-0,01$ & 23,88 \\
\hline PCzBT & 2,61 & 475 & 2,24 & $-15,05$ & 0,60 & $-0,11$ & 15,06 \\
\hline PCzTP & 1,87 & 661 & 2,23 & $-17,73$ & 0,18 & $-0,03$ & 17,74 \\
\hline PCzTh-TVDCN & 2,19 & 563 & 0,10 & 2,61 & 2,43 & 0,54 & 3,61 \\
\hline PTTh-TVDCN & 2,14 & 577 & 0,47 & $-7,38$ & $-1,79$ & 0,67 & 7,62 \\
\hline
\end{tabular}

Tabela 5.2: Energia de transição vertical $\left(E_{01}\right)$ e comprimento de onda $\left(\lambda_{01}\right)$, força do oscilador $(f)$, momento de dipolo de transição total $\left(\mu_{01}\right)$ e suas componentes $x, y, z$ determinadas para os maiores oligômeros da série. Todos os cálculos foram realizados a nível TD-LC-BLYP/6-31G(d,p) com o parâmetro $\omega$ otimizado.

Como esperado, o momento de dipolo de transição é predominantemente alinhado ao longo do esqueleto conjugado e aumenta com o crescimento do comprimento do oligômero. Os dados revelam que o momento de dipolo de transição cresce com o aumento da planaridade do sistema, o que é esperado pois os orbitais moleculares são mais delocalizados no esqueleto conjugado dos sistemas planares. Para o PTTh-TVDCN, em adição à componente ao longo do esqueleto conjugado (eixo-x), existe também uma significativa contribuição da componente ortogonal, ou seja ao longo do eixo-y devido à delocalização da densidade de transição no grupo aceitador ortogonalmente conjugado (ver Figura 5.8 e Tabela 5.2). Portanto, o momento de dipolo de transição total nesse sistema é fracamente aumentado com o crescimento do comprimento da cadeia conjugada. Este resultado é consistente com o comportamento dos copolímeros DA apresentados por Grimm e colaboradores [70]. Isto sugere que, enquanto a conjugação ortogonal pode levar 

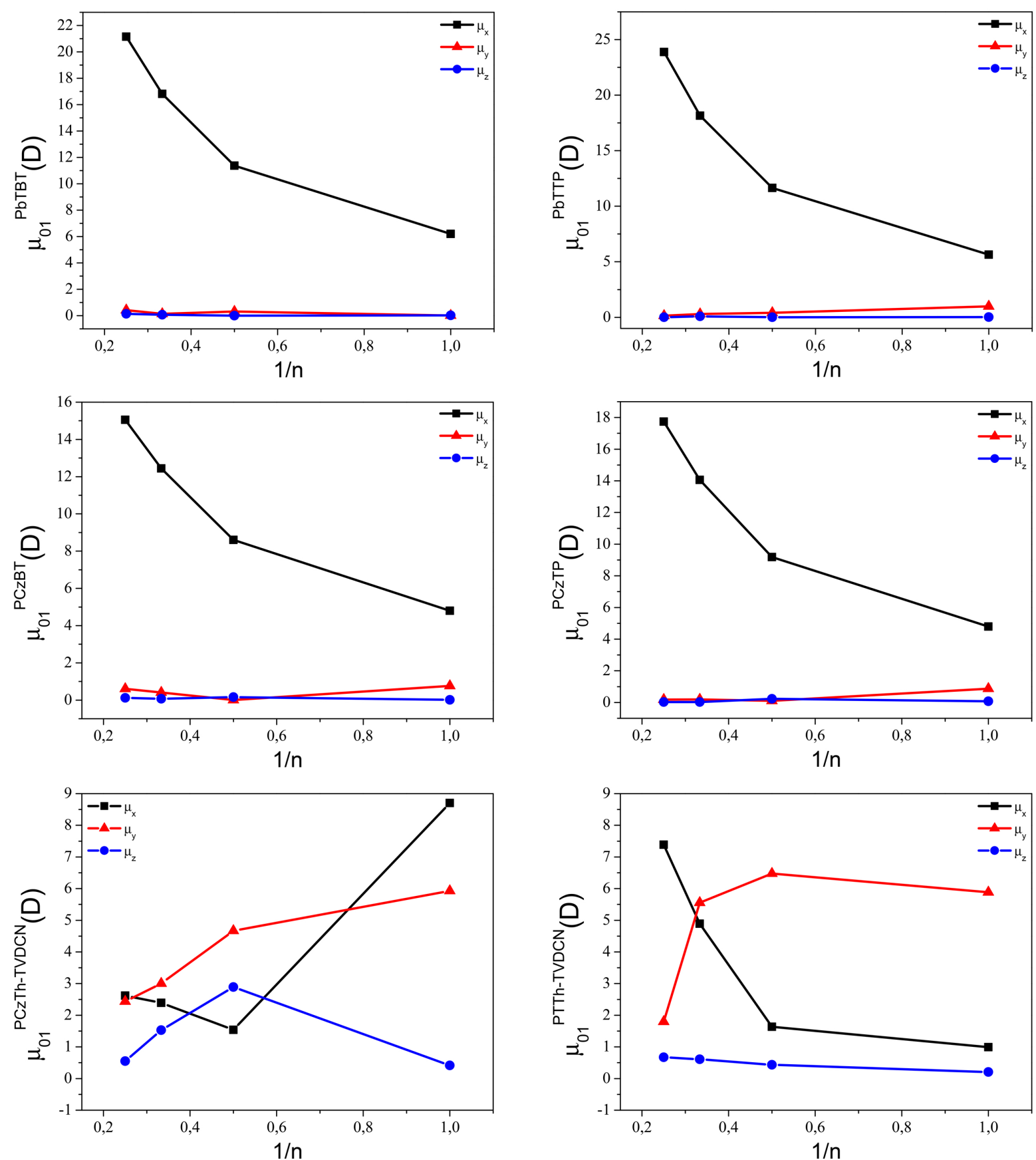

Figura 5.8: Valores absolutos das componentes do momento de dipolo de transição $S_{0} \rightarrow$ $S_{1}$ calculador a nível TD-LC-BYLP/6-31G(d,p) com o parâmetro $\omega$ otimizado.

a materiais com absorções relativamente baixas, os momentos de dipolo de transição limitados, devido ao overlap reduzido entre o estado fundamental e o estado excitado, afetarão a eficiência da absorção do fóton.

A notável exceção na série é o momento de dipolo de transição do PCzThTVDCN. Como ocorre no PTTh-TVDCN, existe uma significante delocalização da den- 
sidade de transição fora do cadeia principal. A natureza altamente torcida da estrutura molecular, entretanto, resulta no momento de dipolo de transição tendo contribuições não desprezíveis nas três componentes $(x, y$ e $z)$, como mostra a Figura 5.8 e a Tabela 5.2. Estas componentes mostram diferentes evoluções com o crescimento do comprimento de conjugação, o que resulta em uma diminuição no momento de dipolo de transição com o crescimento da molécula para o PCzTh-TVDCN.

A Figura 5.9 mostra o espectro de absorção simulado dos tetrâmeros onde as transições verticais foram convoluídas em funções gaussianas com largura a meia-altura $(\mathrm{FWHM}=0,3 \mathrm{eV})$. As posições dos picos das transições verticais também foram incluídas de modo a esclarecer a posição dos estados excitados. O espectro de absorção para os sistemas lineares pode ser caracterizado por uma transição dominante de baixa energia com elevada força do oscilador, seguido por uma segunda transição de energia elevada com força do oscilador mais baixa. Para os sistemas com grupo o aceitador conjugado ortogonalmente, por outro lado, o espectro de absoção apresenta uma transição de baixa energia (ou uma série de transições) com baixa força do oscilador, seguido por um transição de energia maior com elevada força do oscilador.

Como esperado das tendências observadas para as energia do orbitais moleculares, em ambos os casos (com aceitadores carbazol e tiofenos no esqueleto conjugado), ocorre um deslocamento batocrômico significativo quando os grupos aceitadores no esqueleto conjugado são variados do TVDCN ao TP, isto é, das estruturas torcidas para as planares. Portanto, uma clara relação entre o comprimento característico $(1 / \omega)$ e a energia de transição vertical observada $S_{0} \rightarrow S_{1}$. É importante mencionar também que a absorção máxima no PCzTh-TVDCN se encontra a 2,78 eV, e a banda de absorção secundária em 2,29 eV. Estes valores estão em bom acordo com os resultados experimentais reportados por Li e colaboradores [68], portanto, fornecendo confiança a escolha da metodologia DFT para detalhar as propriedades físicas destes sistemas. A presença dos aceitadores conjugados ortogonalmente provoca o surgimento de novas bandas de absorção que são associadas a transições com densidade delocalizadas sobre estes grupos. As bandas de absorção resultante estão localizadas em menores energias e, assim, o efeito global da conjugação ortogonal é reduzir o limiar da banda de absorção.

Os orbitais moleculares são muitas vezes utilizados para descrever as transições 

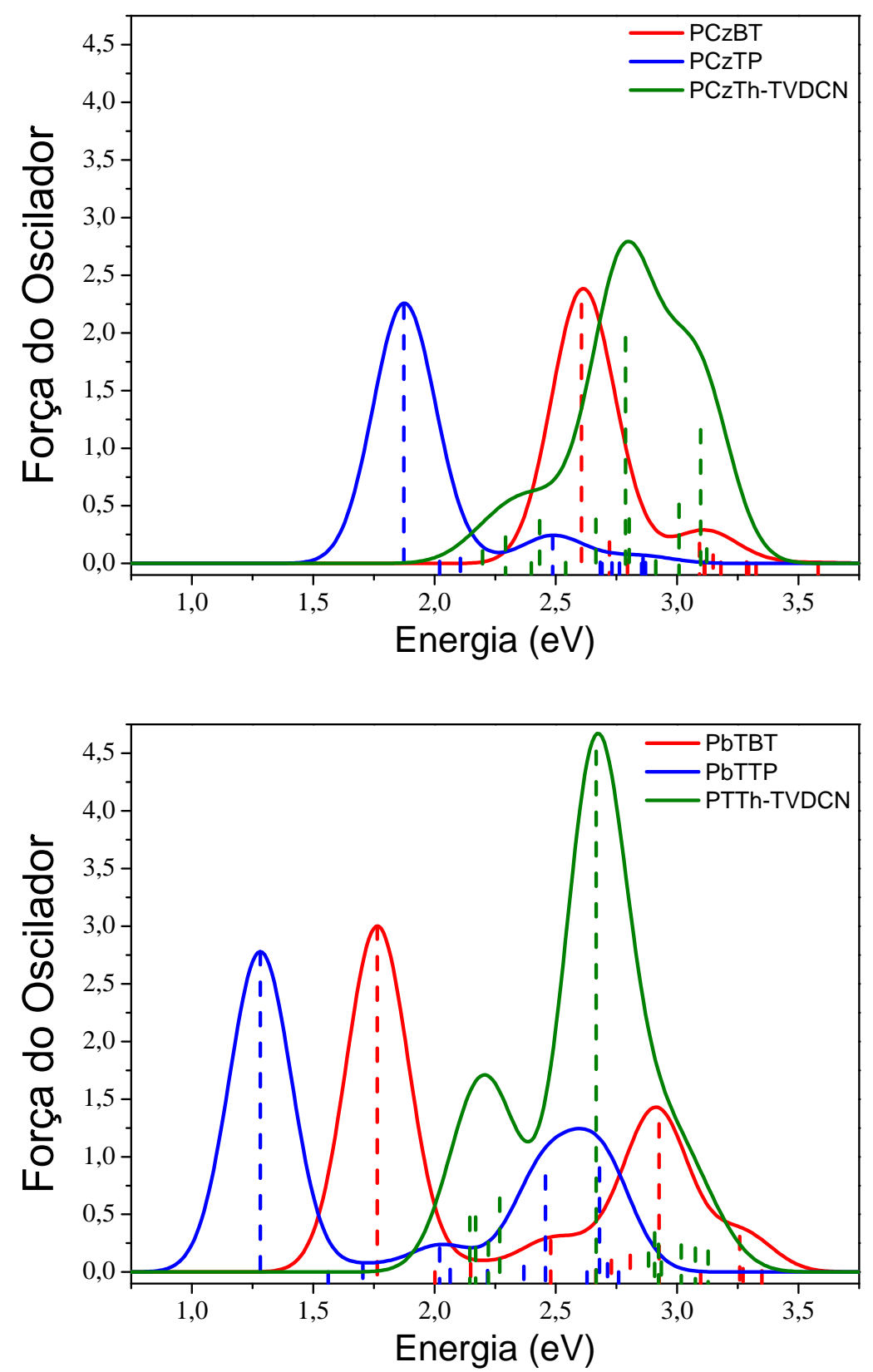

Figura 5.9: Espectro de absorção simulado $(\mathrm{FWHM}=0,3 \mathrm{eV})$ para os tetrâmeros determinados com TDDFT a nível de teoria LC-BLYP/6-31G(d,p) com parâmetro $\omega$ otimizado: (topo) sistemas com carbazol e (abaixo) com tiofeno no esqueleto conjugado.

eletrônicas de baixa energia nos sistemas conjugados. No entanto, às vezes não existe uma configuração dominante, o que torna complicado a interpretação do estado excitado. Uma forma alternativa de examinar a natureza das transições eletrônicas é através das análise dos orbitais naturais de transição (NTOs) [51,86]. A abordagem dos NTOs se baseia em encontrar uma representação orbital compacta para a matriz densidade de transição 
eletrônica. Isto é feito aplicando transformações unitárias separadamente aos orbitais ocupados e virtuais. Dessa forma, pode-se obter uma correspondência entre o excitado

\begin{tabular}{|c|c|}
\hline PbTBT & PbTTP \\
\hline $\mathrm{HOMO}-2 \rightarrow \mathrm{LUMO}+2(6 \%)$ & $\mathrm{HOMO}-2 \rightarrow \mathrm{LUMO}+2(4 \%)$ \\
\hline $\mathrm{HOMO}-1 \rightarrow \mathrm{LUMO}+1(17 \%)$ & $\mathrm{HOMO}-1 \rightarrow \mathrm{LUMO}+1(15 \%)$ \\
\hline $\mathrm{HOMO} \rightarrow$ LUMO $(66 \%)$ & $\mathrm{HOMO} \rightarrow \operatorname{LUMO}(74 \%)$ \\
\hline PCzBT & PCzTP \\
\hline $\mathrm{HOMO}-8 \rightarrow \mathrm{LUMO}+3(2 \%)$ & $\mathrm{HOMO}-2 \rightarrow \mathrm{LUMO}+2(10 \%)$ \\
\hline $\mathrm{HOMO}-6 \rightarrow \mathrm{LUMO}+2(8 \%)$ & $\mathrm{HOMO}-1 \rightarrow \mathrm{LUMO}+1(19 \%)$ \\
\hline $\mathrm{HOMO}-1 \rightarrow \mathrm{LUMO}+1(18 \%)$ & HOMO $\rightarrow$ LUMO (58\%) \\
\hline $\mathrm{HOMO} \rightarrow$ LUMO $(51 \%)$ & \\
\hline $\mathrm{HOMO} \rightarrow \mathrm{LUMO}+1(2 \%)$ & \\
\hline PCzTh-TVDCN & PTTh-TVDCN \\
\hline HOMO-11 $\rightarrow$ LUMO $(6 \%)$ & $\mathrm{HOMO}-3 \rightarrow \mathrm{LUMO}+1(4 \%)$ \\
\hline HOMO-5 $\rightarrow$ LUMO (30\%) & $\mathrm{HOMO}-2 \rightarrow \mathrm{LUMO}+2(10 \%)$ \\
\hline HOMO-3 $\rightarrow$ LUMO (3\%) & $\mathrm{HOMO}-1 \rightarrow \mathrm{LUMO}+1(18 \%)$ \\
\hline HOMO-2 $\rightarrow$ LUMO (4\%) & $\mathrm{HOMO} \rightarrow \mathrm{LUMO}+1(8 \%)$ \\
\hline HOMO-1 $\rightarrow$ LUMO $(38 \%)$ & $\mathrm{HOMO} \rightarrow \mathrm{LUMO}+2(35 \%)$ \\
\hline $\mathrm{HOMO}-1 \rightarrow \mathrm{LUMO}+1(2 \%)$ & $\mathrm{HOMO} \rightarrow \mathrm{LUMO}+4(4 \%)$ \\
\hline $\mathrm{HOMO} \rightarrow$ LUMO $(6 \%)$ & $\mathrm{HOMO} \rightarrow \mathrm{LUMO}+5(3 \%)$ \\
\hline
\end{tabular}

Tabela 5.3: Configurações eletrônicas determinadas para os maiores oligômeros da série determinados a nível TD-LC-BLYP/6-31G(d,p) com o parâmetro $\omega$ otimizado.

"elétron" e o vazio "buraco", sem que a matriz densidade de transição sofra alterações relevantes. Em outras palavras, os NTOs são uma forma conveniente de examinar a natureza da absorção $S_{0} \rightarrow S_{1}$ quando existe uma mistura de outras transições eletrônicas além de $\mathrm{HOMO} \rightarrow$ LUMO para descrever esta excitação. A contribuição do par elétronburaco para uma dada transição eletrônica descrita pelos NTOs pelo autovalor $\lambda$.

A Tabela 5.3 mostra as configurações eletrônicas e as Figuras 5.10 e 5.11 as representações pictóricas dos NTOs e seus correspondentes valores de $\lambda$ para transição dominante $S_{0} \rightarrow S_{1}$ nos tetrâmeros da série. Para os sistemas lineares, as transições 
buraco

elétron

Рвтвт : $0_{0}^{0}$

РвтTP

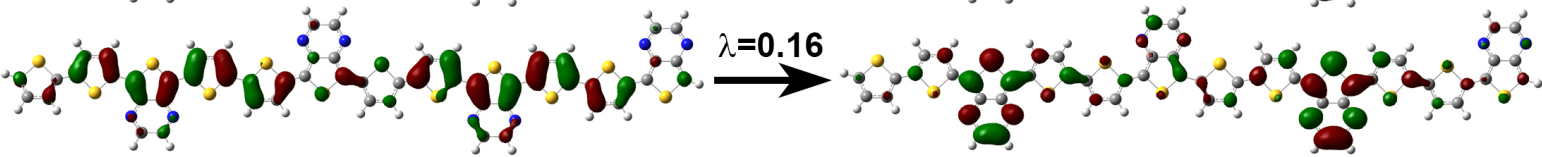

PCzBT

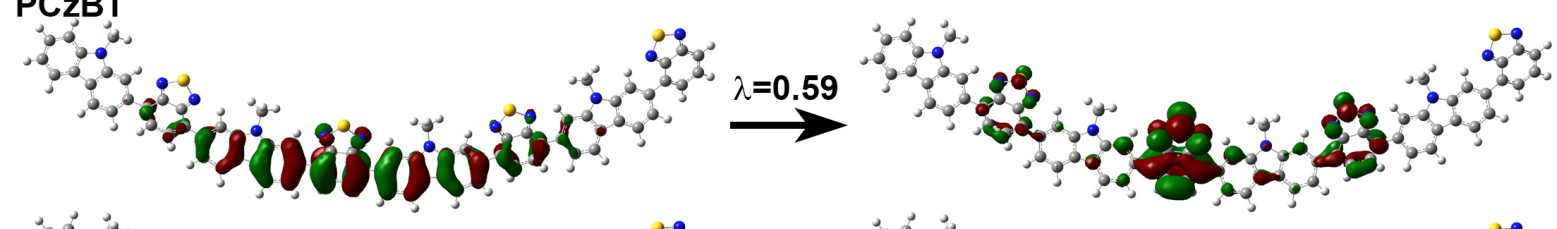

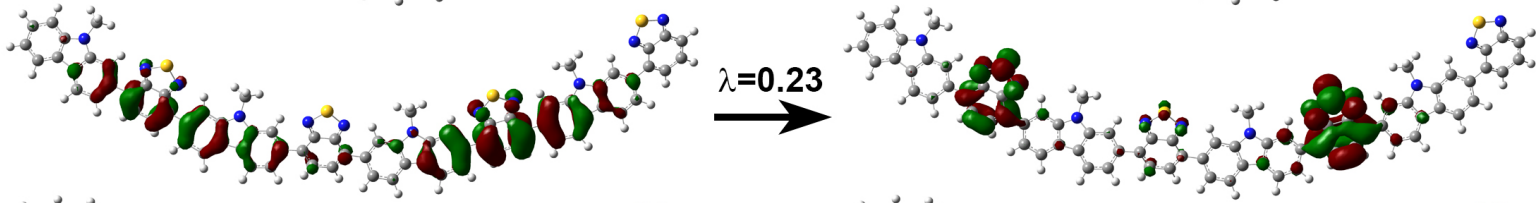

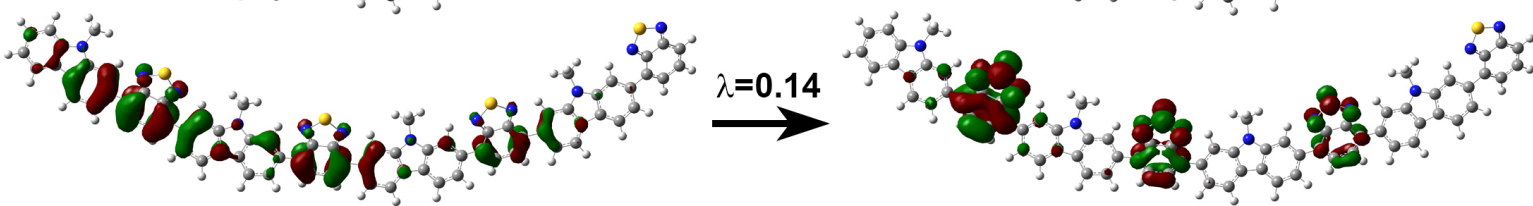

PCzTP

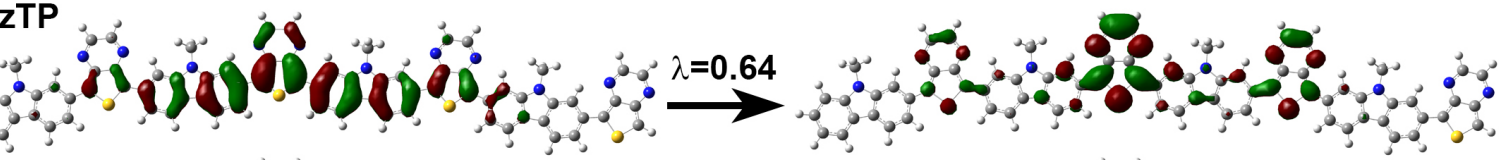
$0^{0}$ $\log ^{0}$

Figura 5.10: Ilustração dos orbitais naturais de transição (NTO) descrevendo a transição $S_{0} \rightarrow S_{1}$ para os sistemas lineares determinados a nível TDDFT LC-BLYP/6-31G(d,p) com o parâmetro $\omega$ otimizado. $\lambda$ representa o peso associado à contribuição partículalacuna para uma dada transição eletrônica descrita pelos NTOs. 
$S_{0} \rightarrow S_{1}$ são predominantemente $\mathrm{HOMO} \rightarrow \mathrm{LUMO}$, de forma que espera-se que os correspondentes NTOs tenham caráter similar à distribuição da função de onda do orbital molecular apresentada na Figura 5.6. Para o PbTBT, PbTTP e PCzTP, ambos elétron e buraco são predominantemente delocalizados sobre o esqueleto conjugado. Entretanto, o elétron é principalmente localizado nos fragmentos aceitadores para o PCzTP, o qual determina o caráter parcial de transferência de carga da excitação. Para o PCzBT, por outro lado, enquanto o buraco está significativamente delocalizado sobre o esqueleto conjugado, o elétron encontra-se localizado sobre os fagmentos benzodiatiazol. A análise

\section{buraco}

elétron
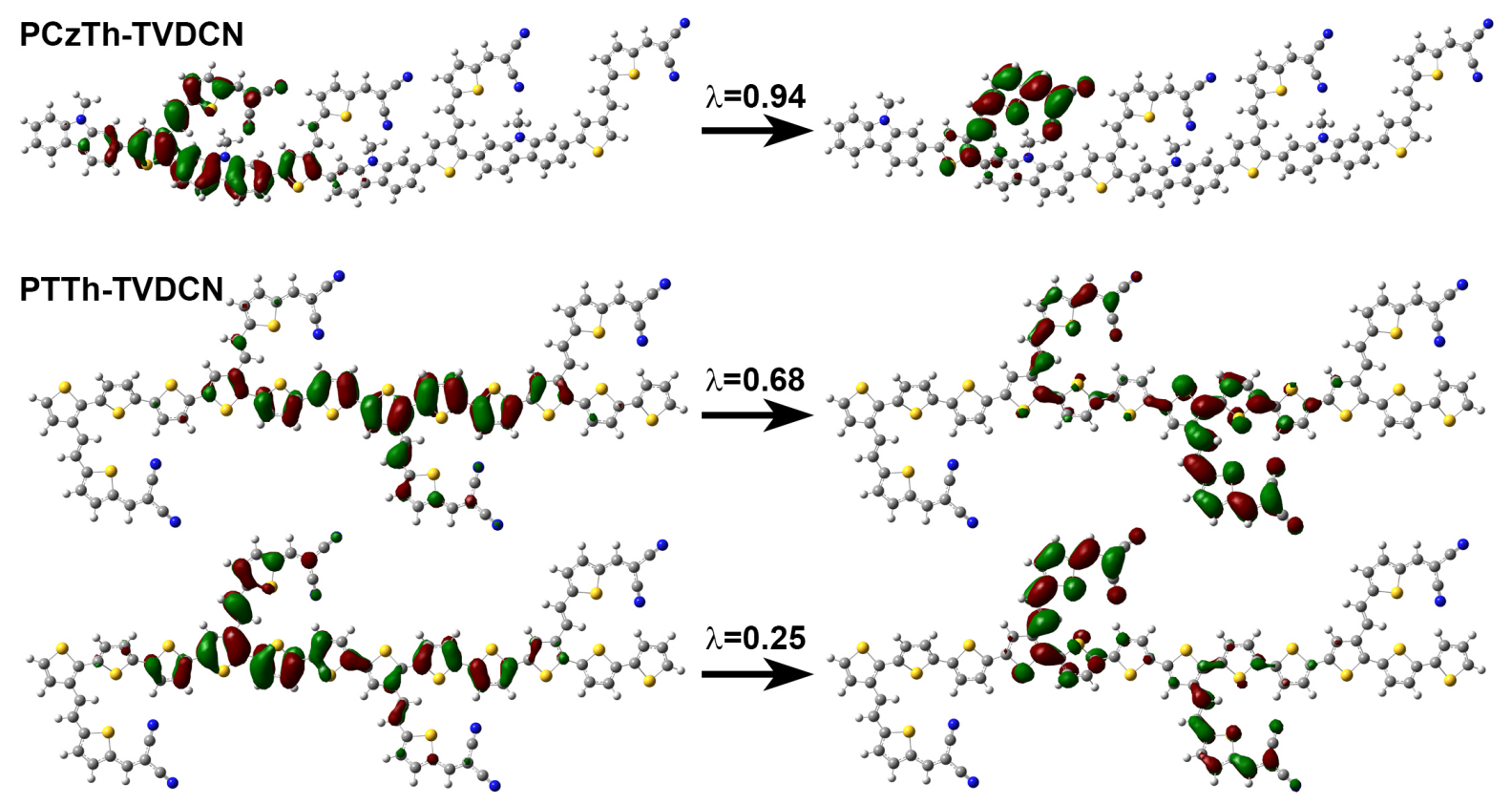

Figura 5.11: Ilustração dos orbitais naturais de transição (NTO) descrevendo a transição $S_{0} \rightarrow S_{1}$ para os sistemas ortogonalmente conjugados determinados a nível TDDFT LCBLYP/6-31G(d,p) com o parâmetro $\omega$ otimizado.

NTO para as transições $S_{0} \rightarrow S_{1}$ nos sistemas ortogonais mostrou que o buraco é significativamente delocalizado sobre o esqueleto conjugado e o elétron é muito localizado sobre os grupos aceitadores ortogonalmente conjugados; isso indica que o esqueleto do polímero é conjugado com o aceitador ortogonalmente, o que está em acordo com os resultados experimentais apresentados por Li e colaboradores [68]. É importante observar que o elevado overlap espacial entre os NTOs do elétron e buraco induz a valores relevantes para o momento de dipolo de transição $S_{0} \rightarrow S_{1}$ e, o baixo valor do momento de 
dipolo de transição para os sistemas ortogonais - PTTh-TVDCN e PCzTh-TVDCN - é devido ao elevado grau de localização dos NTOs no aceitador ortogonalmente conjugado.

Concluímos este capítulo com um resumo geral do que foi estudado aqui. Nós utilizamos os funcionais híbridos de longo alcance (LRC) para investigar um conjunto de oligômeros conjugados de baixo gap-óptico contendo benzotiadiazol e pirazina como grupos aceitadores anexados linearmente em série com unidades doadoras, e unidades aceitadoras de tienileno-vinileno di-ciano ligados de forma ortogonal ao esqueleto conjugado formado somente por unidades doadoras. Vimos que a planaridade é bastante influenciada por efeitos estéricos entre os grupos doador e aceitador, mesmo no caso ortogonal. A análise através do parâmetro $\omega$ confirma-se como uma medida efetiva da extensão da conjugação. O grau da conjugação, por sua vez, tem efeitos significativos nas propriedades eletrônicas e ópticas dos sistemas investigados. Resultados adicionais para estes sistemas DA obtidos via método B3LYP/6-31G(d,p) são fornecidos no Apêndice A desta tese.

De maneira geral, os resultados confirmam que os copolímeros DA ortogonalmente conjugados podem levar a absorção na região vermelha do espectro visível, embora os momentos de dipolo de transição para estas transições sejam limitados. O uso de polímeros ortogonalmente conjugados é também uma alternativa na busca de melhorar as propriedades eletrônicas e ópticas dos polímeros orgânicos para produzir materiais de alta performance, bem como melhorar as metodologias utilizadas na descrição dessas propriedades. 


\section{Propriedades Eletrônicas e Ópticas dos Carotenóides}

Dentre todos os pigmentos naturais, os carotenóides são, provavelmente, os de maior destaque. Esta classe de moléculas é formada por um grupo de compostos dos quais mais de 700 tipos já foram identificados e cerca de 500 desses têm sua estrutura eletrônica estabelecida [87]. Estes compostos moleculares são encontrados em abundância em plantas, animais e microorganismos. A grande variedade permite que os carotenóides sejam divididos em dois grupos: os carotenos e as xantofilas. Os carotenos são pigmentos alaranjados e puramente compostos de carbono e hidrogênio. Já as xantofilas podem apresentar coloração que varia do amarelo ao marrom-avermelhado e sua estrutura molecular é composta de carbono, hidrogênio e oxigênio.

Formados por 40 átomos de carbono, a característica que mais se destaca nos carotenóides é uma extensa cadeia conjugada, responsável por várias de suas propriedades e funções biológicas. Em decorrência da alta quantidade de ligações duplas conjugadas presentes nos carotenóides, estes podem ocorrer nas configurações cis ou trans, muito embora, na natureza, observa-se uma maior ocorrência de carotenóides com ligações duplas na configuração totalmente trans (all-trans), que é termodinâmicamente mais estável e menos solúvel. A sua estrutura conjugada é o mecanismo responsável pelo espectro de absorção dessas moléculas, característica essa que faz com que os carotenóides possuam um grande potencial de aplicação em dispositivos fotovoltaicos orgânicos. Esta classe de moléculas apresenta uma forte absorção óptica na região visível entre 400nm e 500nm para os isômeros trans, enquanto que os isômeros cis e cis/trans exibem absorção próxima ao ultraviolêta, em torno de 320nm [88]. Portanto, os carotenóides apresentam propriedades ópticas interessantes, o que sugere uma investigação mais completa sobre seu potencial no uso para aplicações em dispositivos de eletrônica molecular.

Dentro dessa perspectiva, um conjunto dos cinco principais carotenóides presentes no óleo de Buriti (Mauritia flexuosa L.) foi escolhido para uma investigação de 
suas propriedades eletrônicas e ópticas (ver Figura 6.1). O buriti é uma palmeira típica da flora brasileira e com ampla distribuição em todo o território nacional, sendo mais recorrente na região amazônica. Do fruto do buriti é extraído o seu óleo, que possui composição química e propriedades ópticas extremamente interessantes. A extração da polpa do fruto de buriti feita com $\mathrm{CO}_{2}$ supercrítico mostra que o óleo é basicamente composto por ácidos graxos, tocoferóis e carotenóides, especialmente o $\beta$-caroteno [89,90].

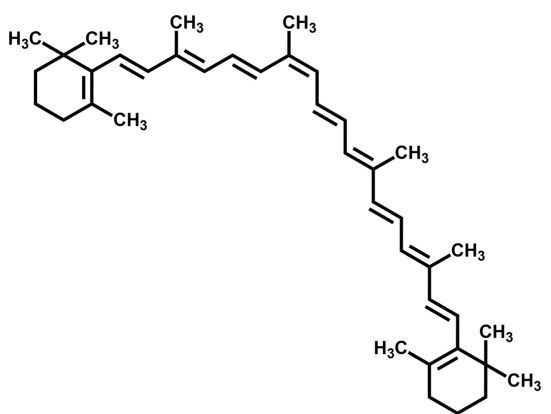

13-cis- $\beta$-caroteno

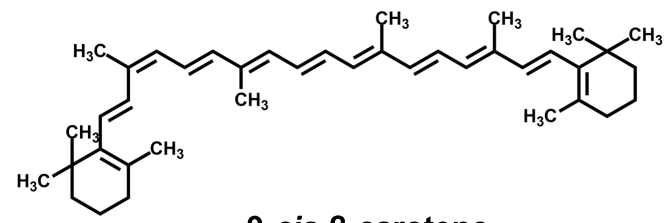

9-cis- $\beta$-caroteno

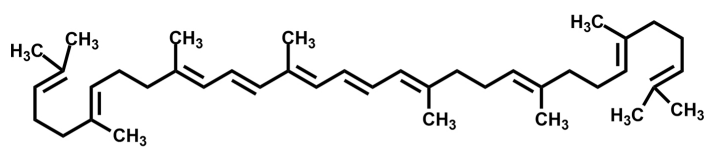

fitoflueno

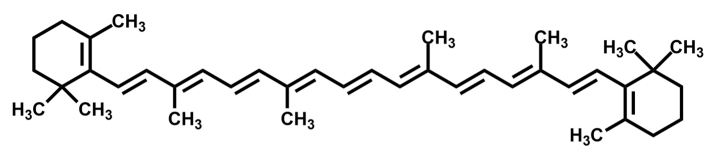

trans- $\beta$-caroteno

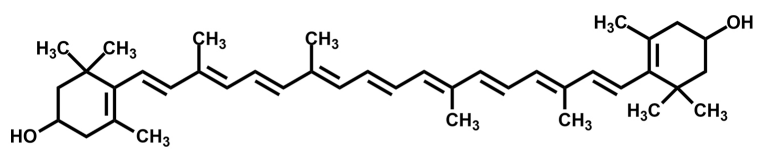

zeaxantina

Figura 6.1: Estruturas químicas dos carotenóides.

Recentemente, Martins e colaboradores [91] conduziram um estudo sobre o espectro de absorção dessas cinco moléculas de carotenóides por diferentes abordagens, dentre as quais o método DFT via cálculo B3LYP/6-31G(d,p) forneceu os melhores resultados. Aqui, para a investigação das propriedades eletrônicas e ópticas dos carotenóides foram utilizadas abordagens DFT e TDDFT, considerando os funcionais B3LYP, LCBLYP e $\omega$ B97. Como mencionado no capítulo 4, o B3LYP é um funcional tradicionalmente usado dentro das metodologias aqui abordadas e, como a maioria dos funcionais híbridos conhecidos, apresenta limitações associadas a erros de auto-interação. Para uma abordagem mais precisa, utilizamos os funcionais LC-BLYP e $\omega$ B97 que incluem um parâmetro de correção de longo alcance $(\omega)$. O parâmetro $\omega$ foi otimizado segundo o procedimento gap-fitting que foi descrito no Capítulo 5. É importante observar que os carotenóides estudados aqui podem ser classificados no grupo de moléculas do tipo doador-aceitador 
(DA), em que a cadeia principal tem o papel doador de elétrons, enquanto que, nas extremidades da molécula são anexados grupos aceitadores de elétrons. Essa característica permite que o processo de gap-fitting seja aplicável a esses sistemas. Os funcionais de longo alcance com os valores do parâmetro $\omega$ otimizados foram avaliados com o objetivo de fornecer melhores resultados para propriedades de estado excitado quando comparados aos da abordagem usual. Todos os cálculos foram realizados através do programa Gaussian 09 (Rev.D.01) [42].

\subsection{Propriedades Estruturais e Eletrônicas}

O processo de otimização de geometria no estado fundamental das cinco estruturas foi realizado inicialmente em nível DFT utilizando o funcional híbrido B3LYP com o conjunto de base 6-31G(d,p). Pode ser observado que, com exceção do fitoflueno, todas as estruturas moleculares apresentam 9 ligações duplas no esqueleto conjugado. $\mathrm{O}$ menor grau de conjugação do fitoflueno, isto é, 5 ligações duplas na cadeia principal, quando comparado as outras estruturas deve indicar diferenças significativas no comprimento característico $(1 / \omega)$, como também nas suas propriedades eletrônicas e ópticas.

Podemos iniciar a discussão dos resultados pela análise das geometrias moleculares otimizadas no estado fundamental. A Figura 6.2 apresenta as definições e a Tabela 6.1 os valores dos ângulos diedrais para as cinco moléculas carotenóides. Observa-se que as moléculas que possuem a cadeia principal totalmente conjugada apresentam um certo grau de planaridade na estrutura molecular, com ângulos de torção nas extremidades devido a presença dos grupos funcionais. Em geral, para o mesmo funcional, os valores de ângulo encontrados são muito semelhantes. A exceção é o fitoflueno que apresenta diferenças consideráveis nos ângulos de torção na sua cadeia principal devido a presença de ligações $\sigma$ em sua cadeia principal. A diferença estrutural apresentada pelo fitoflueno deve ser manifestada na menor delocalização da função de onda nessa molécula em comparação às outras.

Conforme afirmamos no capítulo 5 , o comprimento característico $(1 / \omega)$ fornece uma forma alternativa de investigar a extensão do comprimento de conjugação- $\pi$ de um sistema molecular. Dessa forma, as estruturas no estado fundamental e o parâmetro 

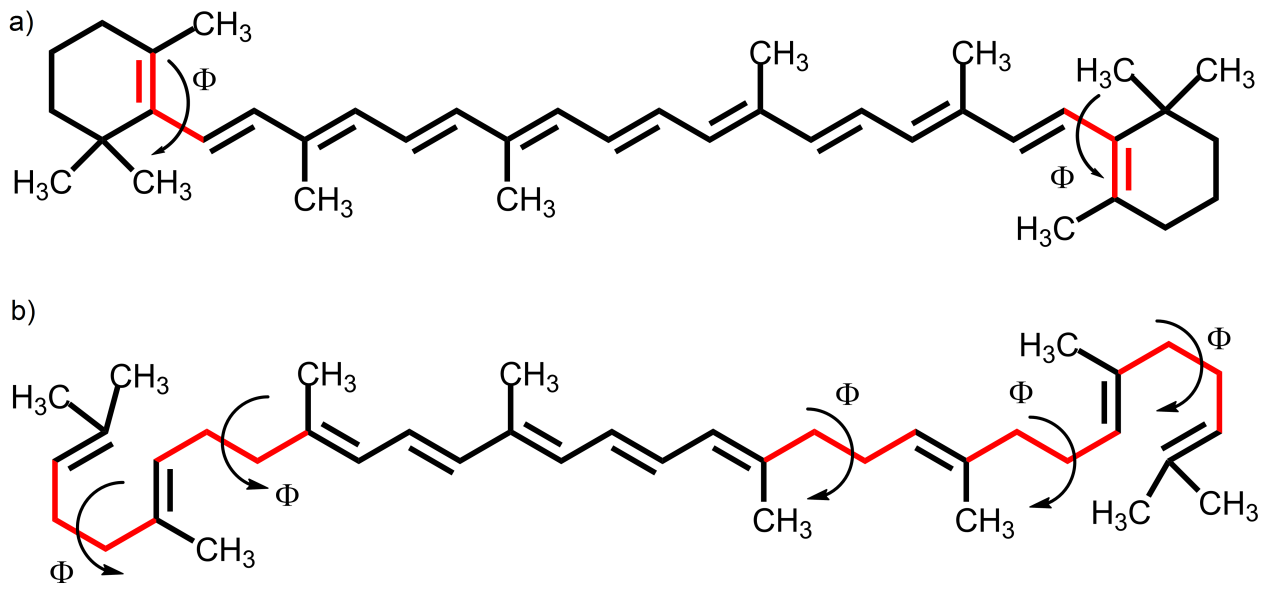

Figura 6.2: Ângulos de torção ao longo do esqueleto conjugado dos carotenóides.

\begin{tabular}{|c|c|c|c|}
\hline Molécula & B3LYP & LC-BLYP-opt. & $\omega$ B97-opt. \\
\hline 13-cis- $\beta$-caroteno & $48^{\circ}$ & $42^{\circ}$ & $51^{\circ}$ \\
\hline 9-cis- $\beta$-caroteno & $48^{\circ}$ & $41^{\circ}$ & $51^{\circ}$ \\
\hline fitoflueno & $178^{\circ}$ & $178^{\circ}, 179^{\circ}$ & $178^{\circ}, 179^{\circ}$ \\
\hline trans- $\beta$-caroteno & $48^{\circ}$ & $42^{\circ}$ & $51^{\circ}$ \\
\hline zeaxantina & $47^{\circ}$ & $41^{\circ}$ & $51^{\circ}$ \\
\hline
\end{tabular}

Tabela 6.1: Ângulos de torção $(\Phi)$ ao longo do esqueleto conjugado dos carotenóides.

de longo alcance $\omega$ foram iterativamente otimizados segundo o procedimento gap-fitting descrido pelas equações 5.1,5.2 e 5.3, de modo a garantir que o gap HOMO-LUMO seja diretamente comparável ao valor experimental.

A Tabela 6.2 mostra os valores otimizados do parâmetro de longo alcance $\omega$ e os valores correspondentes de comprimento característico $1 / \omega$ para os carotenóides, obtidos através dos funcionais LC-BLYP e $\omega$ B97 com uso do conjunto de base 6-31G(d,p). Podemos observar que, com exceção do fitoflueno, todos os casos apresentam valores otimizados de $\omega$ e $1 / \omega$ muito semelhantes, independentemente do funcional utilizado. Essa é uma consequência direta da diferença estrutural na cadeia principal do fitoflueno com relação às demais moléculas, que apresentam cadeia principal totalmente conjugada e plana. Como veremos adiante, as diferenças estruturais e nos valores otimizado do parâmetro $\omega$ são refletidas nas propriedades eletrônicas e ópticas dessas moléculas. 


\begin{tabular}{|c|c|c|c|c|}
\hline \multirow{2}{*}{ Molécula } & \multicolumn{2}{|c|}{ LC-BLYP-opt. } & \multicolumn{2}{c|}{$\omega$ B97-opt. } \\
\cline { 2 - 5 } & $\omega$ & $1 / \omega$ & $\omega$ & $1 / \omega$ \\
\hline 13-cis- $\beta$-caroteno & 0,152 & 6,579 & 0,150 & 6,667 \\
\hline 9-cis- $\beta$-caroteno & 0,152 & 6,579 & 0,150 & 6,667 \\
\hline fitoflueno & 0,193 & 5,181 & 0,187 & 5,347 \\
\hline trans- $\beta$-caroteno & 0,151 & 6,622 & 0,149 & 6,711 \\
\hline zeaxantina & 0,149 & 6,711 & 0,147 & 6,803 \\
\hline
\end{tabular}

Tabela 6.2: Valores otimizados do parâmetro $\omega\left(\mathrm{Bohr}^{-1}\right)$ e comprimento característico $1 / \omega$ (Bohr) para os cinco carotenóides determinados pelos funcionais LC-BLYP e $\omega$ B97 usando o mesmo conjunto de base $6-31 G(d, p)$. Os valores de referência para o $(\omega)$ são: $\omega_{(L C B L Y P)}=0,47$ e $\omega_{(\omega B 97)}=0,4 \mathrm{Bohr}^{-1}$.

É importante notar o caráter poliênico dos carotenóides e a dificuldade do método para descrever estes sistemas [92]. Isso pode ser melhor compreendido analisando o comportamento da BLA (bond-length alternation) nesses sistemas. A BLA em cadeias conjugadas longas tem sido um tema bastante discutido pela comunidade científica há várias décadas e desempenha papel importante nas propriedades eletrônicas das cadeias moleculares conjugadas [93]. Entretanto, obter valores confiáveis da BLA através dos métodos de estrutura eletrônica está longe de ser uma tarefa simples. Em geral, a teoria Hartree-Fock superestima significativamente a BLA, enquanto que os métodos MP2 e o DFT com as aproximações comumente usadas para o funcional de troca-correlação tendem a subestimar o valor da BLA. Aqui estamos interessados em observar como o valor da BLA varia dependendo do funcional aplicado no cálculo DFT. A Figura 6.3 apresenta as ligações químicas consideradas no cálculo da BLA e a Tabela 6.3 os valores obtidos através de diferentes funcionais.

Observa-se que para as cinco moléculas investigadas o funcional B3LYP apresentou os menores valores para a BLA. Já os funcionais LRC com os valores padrão para o $\omega$ apresentaram os valores mais elevados. Isto está associado a contribuição Hartree-Fock no termo de troca-correlação que implica numa delocalização, no caso do B3LYP e, numa maior localização da função de onda no caso dos funcionais LRC.

O procedimento de otimização do parâmetro $\omega$ nos funcionais LRC implica no 

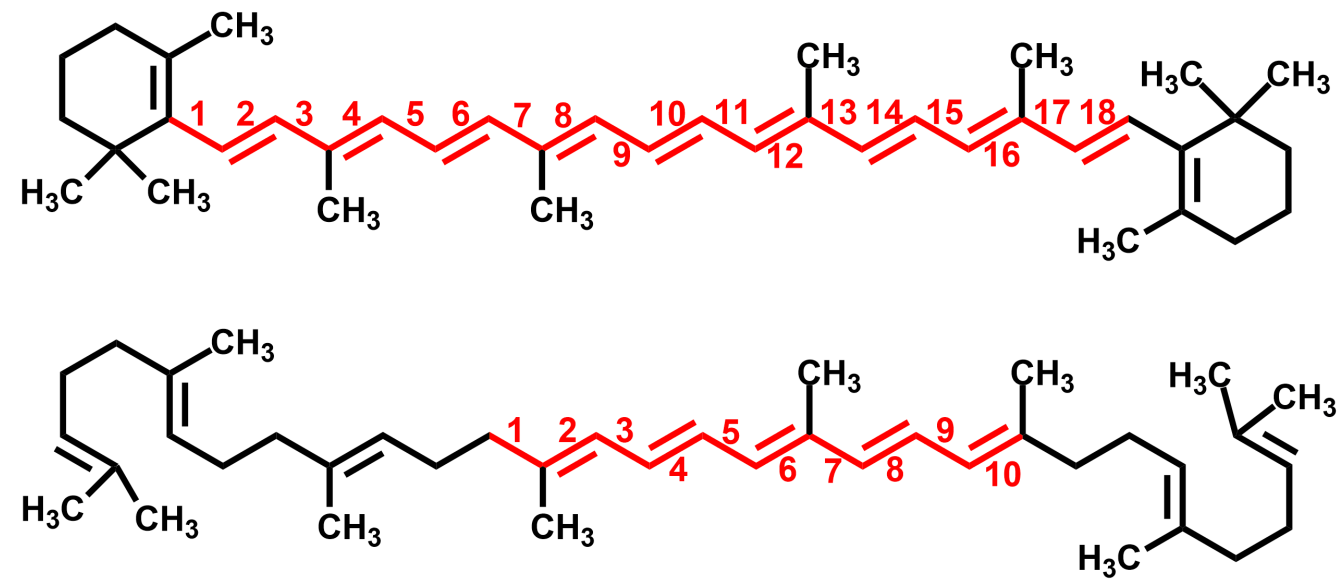

Figura 6.3: Ligações químicas consideradas para o cálculo da BLA ao longo da cadeia dos carotenóides.

\begin{tabular}{|c|c|c|c|c|c|}
\hline Molécula & B3LYP & LC-BLYP & $\omega$ B97 & LC-BLYP-opt. & $\omega$ B97-opt. \\
\hline 13-cis- $\beta$-caroteno & 0,079 & 0,120 & 0,118 & 0,083 & 0,089 \\
\hline 9-cis- $\beta$-caroteno & 0,079 & 0,120 & 0,118 & 0,083 & 0,089 \\
\hline fitoflueno & 0,098 & 0,127 & 0,126 & 0,104 & 0,108 \\
\hline trans- $\beta$-caroteno & 0,078 & 0,120 & 0,118 & 0,083 & 0,089 \\
\hline zeaxantina & 0,076 & 0,119 & 0,117 & 0,081 & 0,087 \\
\hline
\end{tabular}

Tabela 6.3: Valores da BLA obtidas via funcional B3LYP e pelos funcionais LRC, LCBLYP e $\omega$ B97, ambos utilizando os valores padrão e otimizado para o parâmetro ômega.

ajuste desse parâmetro e, consequentemente em uma redução da (de)localização eletrônica. Assim, o cálculo da BLA utilizando os funcionais LRC com o $\omega$ otimizado motra valores intermediários, ou seja, menores que os LRC-padrão e maiores que o B3LYP. No entanto, é importante lembrar que o procedimento de otimização do $\omega$ não significa que obteremos valores precisos da BLA. Körzdörfer e colaboradores [92] mostraram comportamento semelhante para o poliacetileno e, embora a otimização do parâmetro $\omega$ nos funcionais LRC reduza os erros de auto-interação, eles fornecem uma descrição imprópria para a BLA. Portanto, espera-se que nos carotenóides altamente conjugados (13-cis- $\beta$ carotene, 9-cis- $\beta$-carotene, trans- $\beta$-carotene e zeaxantina) tenhamos valores que não se aproximam do comportamento experimental. Esta deficiência dos métodos teóricos de estrutura eletrônica tem impacto direto na descrição precisa de uma série de propriedades 
eletrônicas. Como exemplo disso, mostraremos adiante que a descrição incorreta da BLA provoca alterações na posição do máximo de absorção.

Agora chamamos atenção para as propriedades eletrônicas dos carotenóides. Podemos observar que a diferença estrutural do fitoflueno, como também as similaridades estruturais entre as outras moléculas são manifestadas nas energias dos orbitais moleculares. A Figura 6.4 apresenta as energias dos orbitais moleculares de fronteira HOMO e

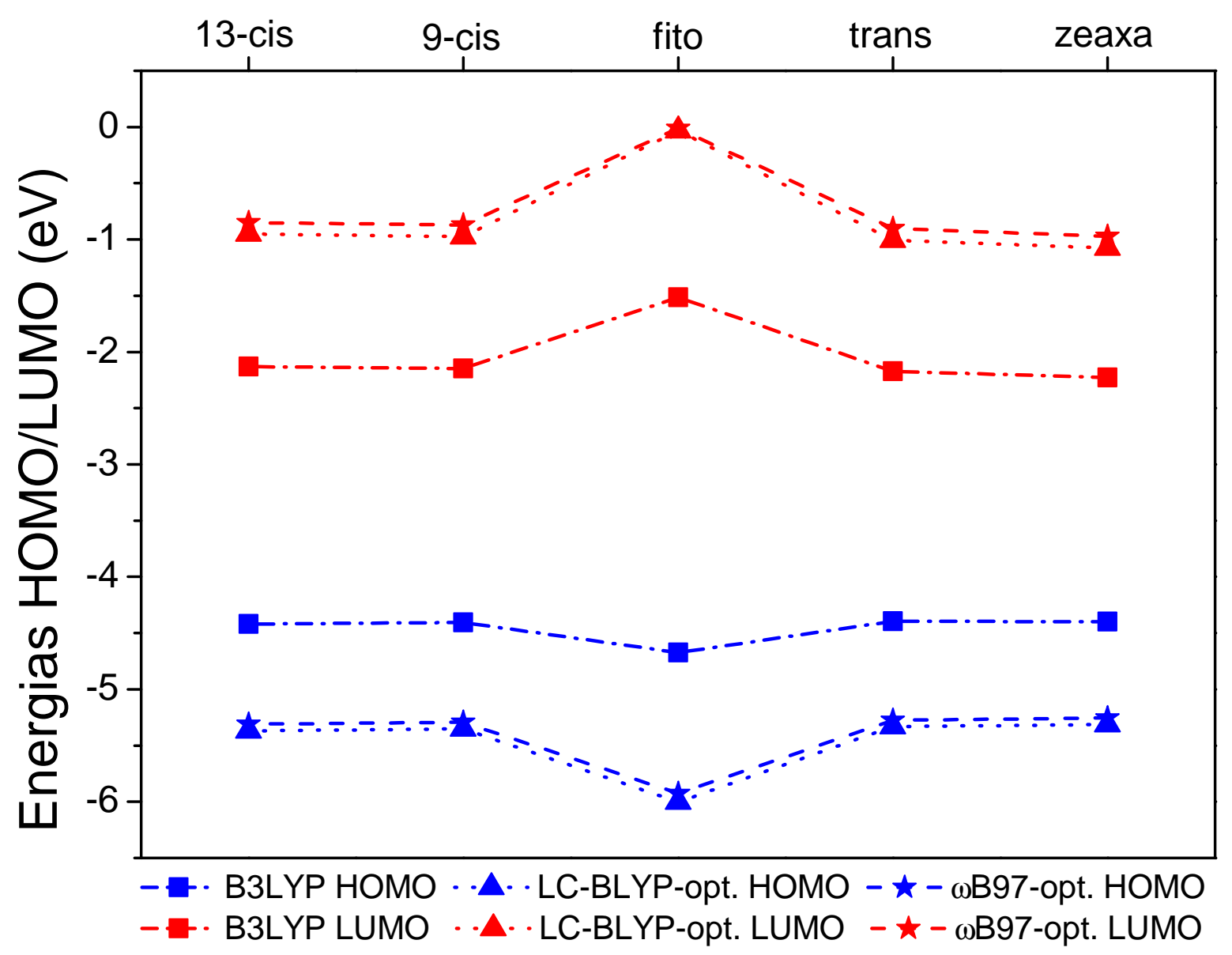

Figura 6.4: Energia dos orbitais moleculares de fronteira, HOMO e LUMO, determinados através do funcional B3LYP, como também através dos funcionais LC-BLYP e $\omega$ B97 com o parâmetro $\omega$ otimizado. Todos os cálculos foram realizados usando o conjunto de base $6-31 G(d, p)$.

LUMO para todos os carotenóides da série, calculados através do funcional híbrido global B3LYP e também com os funcionais de longo alcance LC-BLYP e $\omega$ B97 usando os valores de $\omega$ otimizados. Podemos facilmente observar, nos três métodos utilizados, que as energias do HOMO e do LUMO para o fitoflueno têm um comportamente diferente 
das outras moléculas de carotenóides, apresentando valor de gap HOMO-LUMO maior que as demais moléculas. Este comportamento está diretamente associado ao padrão de conjugação menor do fitoflueno. Como foi observado anteriormente para o parâmetro $\omega$, as demais estruturas apresentam valores de gap similares e menores que o fitoflueno. Portanto, os resultados indicam que o fitoflueno apresenta características de isolante se comparado aos outros carotenóides investigados neste trabalho. Vale destacar que os valores de gap de energia obtidos pelos funcionais híbridos de longo alcance (LC-BLYP e $\omega$ B97) são maiores que os calculados via B3LYP. Este fato é consequência do procedimento de otimização do $\omega$ para os funcionais LRC. Como foi dito anteriormente, a idéia do procedimento gap-fitting é obter funções de onda localizadas mais realistas, que são importantes no tratamento de transferência de carga, por exemplo. Portanto, é esperado que o procedimento gap-fitting nos funcionais LRC forneça valores de gap HOMO-LUMO maiores que os funcionais híbridos padrão, como é o caso do B3LYP, que tem apresentam funções de onda delocalizadas na descrição dos sistemas moleculares.

É importante saber que os funcionais LRC com o parâmetro de longo alcance otimizado fornecem uma descrição mais localizada das funções de onda dos copolímeros DA. Dessa forma, esta metodologia apresenta uma melhor descrição das propriedades eletrônicas e ópticas desses sistemas. A notável diferença nos valores de gap de energia calculados via B3LYP e utilizando o gap-fitting indicam que este tratamento não é só esperado, como também é mais adequado para tratar processos que envolvem transferência de carga.

A Figura 6.5 mostra as distribuições das funções de onda HOMO e LUMO para os carotenóides calculados em nível LC-BLYP/6-31G(d,p). Aqui, podemos observar que para as moléculas de 13-cis- $\beta$-caroteno, 9-cis- $\beta$-caroteno, trans- $\beta$-caroteno e zeaxantina, as funções de onda do HOMO e do LUMO são amplamente delocalizadas ao longo do esqueleto conjugado. Isto se deve ao fato dessas moléculas apresentarem estrutura molecular plana e cadeia principal totalmente conjugada. Já para o fitoflueno, o menor grau de conjugação e a estrutura molecular torcida (não-plana) induz um certo grau de localização das funções de onda HOMO e LUMO sobre o caminho de conjugação formado apenas por 5 ligações duplas na cadeia principal. No Apêndice B apresentamos resultados adicionais para as distribuições das funções de onda HOMO e LUMO carotenóides calculados em nível $\omega$ B97/6-31G(d,p), que mostram comportamente semelhante ao descrito 
HOMO

\section{3-cis- $\beta$-caroteno}

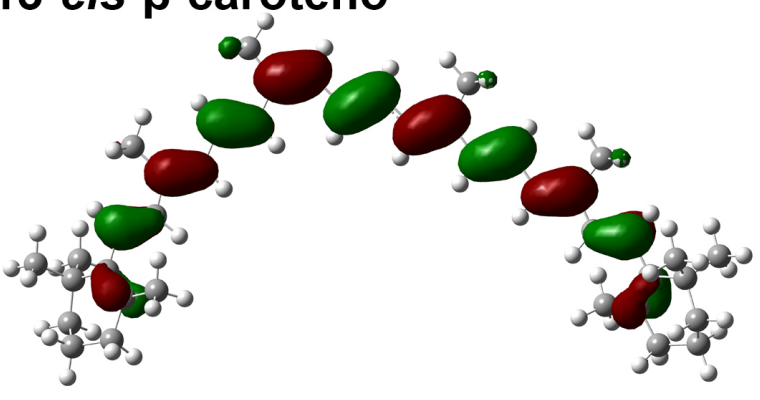

LUMO

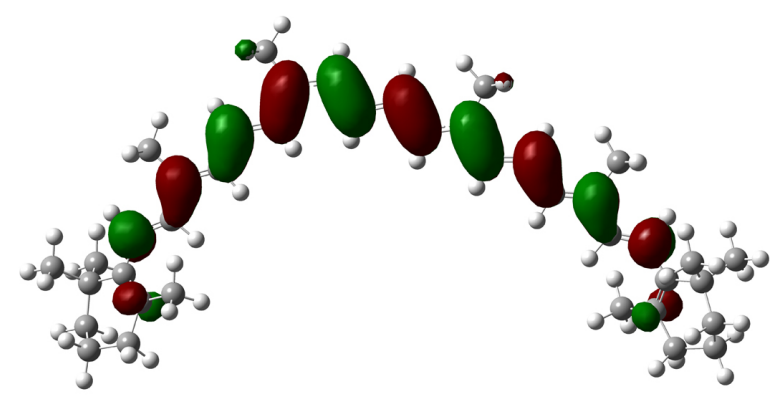

9-cis- $\beta$-caroteno
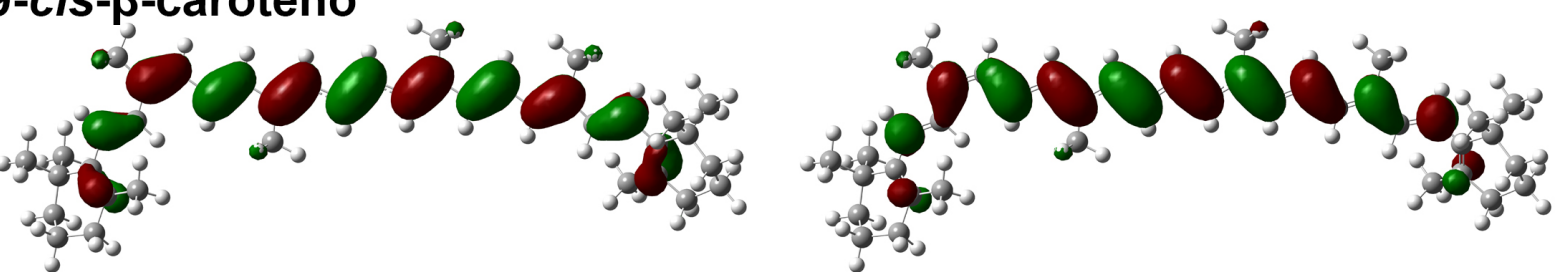

\section{fitoflueno}

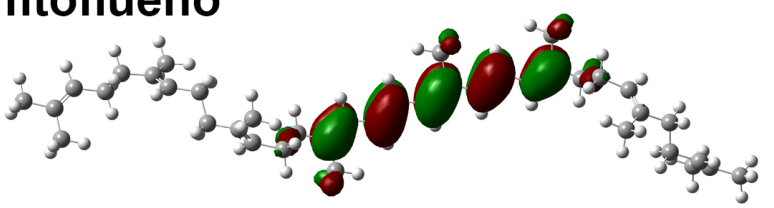

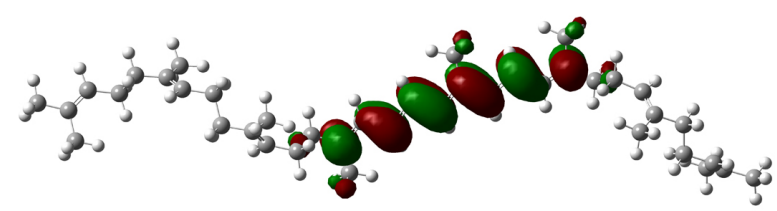

\section{trans- $\beta$-caroteno}
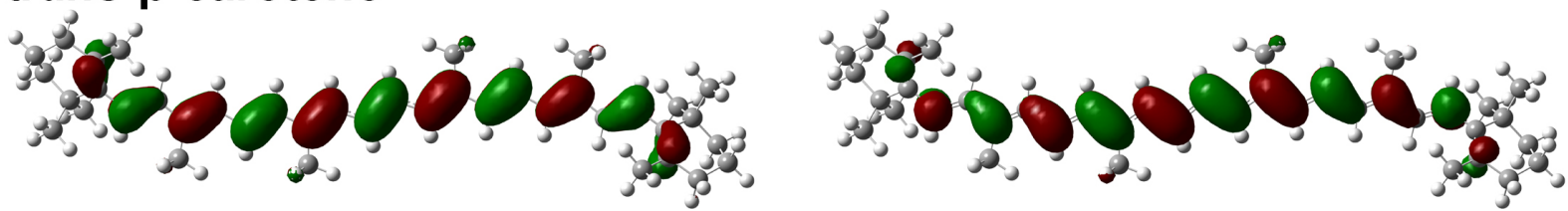

\section{zeaxantina}
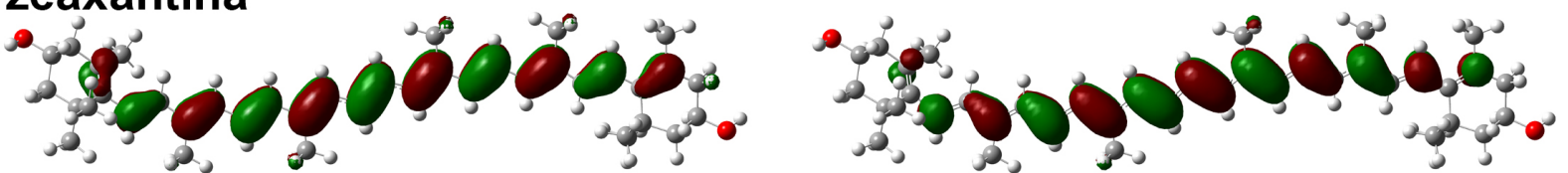

Figura 6.5: Ilustração dos orbitais moleculares de fronteira HOMO e LUMO para os carotenóides calculados a nível LC-BLYP/6-31G(d,p) com o parâmetro $\omega$ otimizado.

pelo LC-BLYP. 


\subsection{Propriedades Ópticas}

Até aqui, detalhamos como o menor grau de conjugação na estrutura do fitoflueno leva esse sistema a ter propriedades eletrônicas diferente das apresentadas pelos carotenóides totalmente conjugados, 13-cis- $\beta$-caroteno, 9-cis- $\beta$-caroteno, trans- $\beta$ caroteno e zeaxantina. Esse comportamento também devem ser refletido no espectro de absorção dos carotenóides, que é o foco principal desta Seção. Para investigar a propriedades ópticas desses sistemas, cálculos TDDFT foram realizados com largura a meia altura igual a $0,3 \mathrm{eV}$, nos quais foram empregados o funcional híbrido B3LYP, e os funcionais LRC (LC-BLYP e $\omega$ B97) com os valores do parâmetro separação $\omega$ otimizados e padrão. Para fins de comparação, a Figura 6.6 apresenta o espectro de absorção para os cinco carotenóides da série calculados via TD-B3LYP/6-31G(d,p) e TD-LC-BLYP/6$31 \mathrm{G}(\mathrm{d}, \mathrm{p})$. Por questão de concisão, os resultados obtidos via TD- $\omega$ B97/6-31G(d,p) são apresentados no Apêndice B, uma vez que são muito semelhantes aos da Figura 6.6 para o LC-BLYP. A característica mais importante observada aqui é o deslocamente dos espectros de absorção para o LC-BLYP otimizado quando comparado ao tradicional B3LYP. Isto significa que os valores obtidos via LC-BLYP otimizado apresentam uma tendência geral do pico de absorção máxima ser mais próximo dos valores experimentais quando comparado ao B3LYP, isto é, $\lambda_{\max }$ é deslocado para regiões de energia mais elevada. É importamte observar também que o sistema que possui o menor grau de conjugação, isto é, o fitoflueno, apresenta $\lambda_{\max }$ deslocado para região de energia mais elevada quando comparado aos valores do $\lambda_{\max }$ para os carotenóides totalmente conjugados.

Além disso, também realizamos cálculos TD-LC-BLYP/6-31G(d,p) e TD- $\omega$ B97 /6-31G(d,p) com os valores de $\omega$ padrão para uma comparação com o método de gapfitting. A Tabela 6.4 mostra que, para o caso do fitoflueno, os resultados obtidos com os funcionais LRC otimizados (LC-BLYP-opt. e $\omega$ B97-opt) estão de bom acordo com os valores experimentais, superando a performance do B3LYP e do LC-BLYP e $\omega$ B97 com os valores de $\omega$ padrão. Nesse caso, o procedimento de otimizar o parâmetro de longo alcance $(\omega)$ para cada molécula permite que os funcionais LRC apresentem resultados mais precisos que os obtidos sem o procedimento de otimização do $\omega$ e pelo B3LYP. Já para os sistemas totalmente conjugados isto não pode ser verificado. Nesses casos, o procedimento gap-fitting não forneceu valores do $\lambda_{\max }$ tão precisos quanto para o caso do 

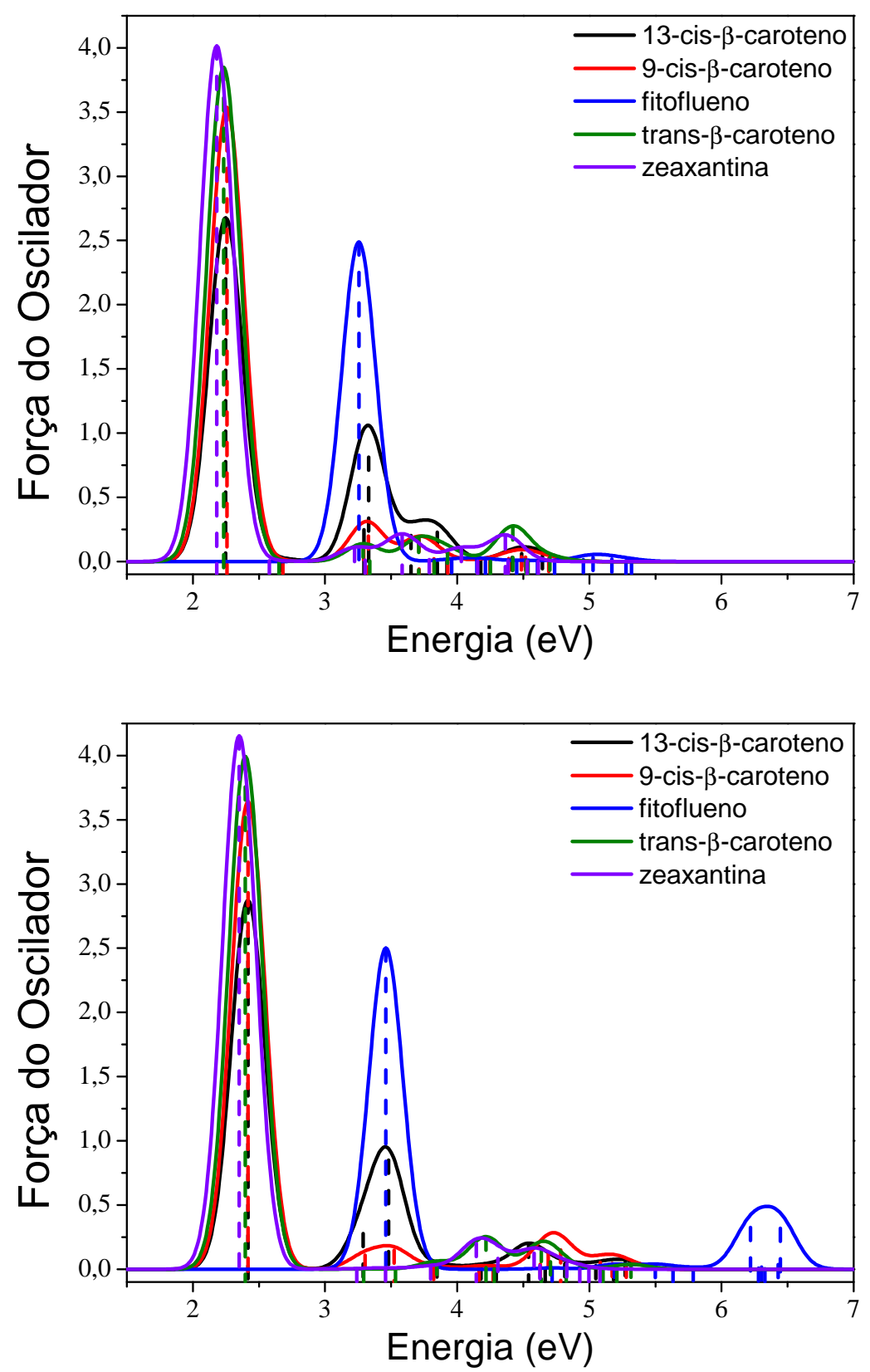

Figura 6.6: Espectro de absorção para as cinco moléculas calculadas a nível B3LYP/6$31 \mathrm{G}(\mathrm{d}, \mathrm{p})$ (topo) e LC-BLYP/6-31G(d,p) (abaixo).

fitoflueno. Isto pode ser atribuído a uma pobre descrição da BLA que tem impacto direto na posição do $\lambda_{\max }$. Embora os resultados apresentados tenham uma precisão menor, ainda assim, podemos observar que os valores de $\lambda_{\max }$ obtidos através dos funcionais LRC (LC-BLYP e $\omega$ B97) com o parâmetro $\omega$ otimizado estão em melhor acordo com os valores experimentais se comparados ao B3LYP e aos funcionais LRC com o $\omega$ padrão.

Como foi dito anteriormente, os métodos teóricos de estrutura eletrônica fa- 


\begin{tabular}{|c|c|c|c|c|c|}
\hline Molécula & 13-cis- $\beta$. & 9-cis- $\beta$. & fitoflueno & trans- $\beta$. & zeaxantina \\
\hline experimental & $443[94]$ & $445[94]$ & $350[98]$ & $448[95], 450[96]$ & $450[97]$ \\
\hline B3LYP & 551 & 549 & 381 & 555 & 569 \\
\hline LC-BLYP & 348 & 350 & 293 & 352 & 355 \\
\hline LC-BLYP-opt. & 513 & 513 & 358 & 517 & 527 \\
\hline$\omega$ BB97 & 363 & 364 & 303 & 366 & 370 \\
\hline wB97-opt. & 507 & 506 & 362 & 511 & 522 \\
\hline
\end{tabular}

Tabela 6.4: Comprimentos de onda de absorção máxima $\lambda_{\max }$. Valores experimentais, B3LYP, LC-BLYP e $\omega$ B97 com os valores de $\omega$ otimizado e padrão.

lham na descrição da BLA de sistemas moleculares com cadeias conjugadas longas e, consequentemente, nas propriedades eletrônicas e ópticas dessas moléculas [92]. Aqui observamos que os métodos DFT tem uma descrição consideravelmente melhor para o fitoflueno, que tem um caminho de conjugação menor (5 ligações duplas) do que para descrever os demais sistemas que têm a cadeia principal altamente conjugada (9 ligações duplas). Também vale ressaltar as diferenças na descrição do $\lambda_{\max }$ com os funcionais LRC padrão e otimizados, enquanto os LRC-padrão apresentam $\lambda_{\max }$ deslocados para comprimentos de onda menores, os LRC-otimizados fornecem $\lambda_{\max }$ deslocados para comprimentos de onda maiores que os valores experimentais. Isso se deve ao fato de que estes funcionais com o valor do $\omega$ padrão apresentam uma contribuição Hartree-Fock maior do que quando o parâmetro $\omega$ é otimizado. E, consequentemente, os funcionais LRC padrão fornecem uma maior localização da função de onda se comparado ao mesmo com o $\omega$ otimizado.

Finalizamos a discussão dos resultados investigando as transições descritas acima. A Tabela 6.5 apresenta os valores para as energias de transição vertical $S_{0} \rightarrow S_{1}$, força do oscilador, momentos de dipolo de transição e as configurações eletrônicas para analisar a natureza da absorção $S_{0} \rightarrow S_{1}$. Aqui podemos destacar que o momento de dipolo de transição dos carotenóides é predominantemente alinhado ao eixo molecular. Além disso, em todos os casos a transição vertical do estado fundamental para o primeiro estado excitado $\left(S_{0} \rightarrow S_{1}\right)$ é principalmente do orbital HOMO para o LUMO $(\mathrm{HOMO} \rightarrow \mathrm{LUMO})$. Dessa forma, espera-se que uma análise dos NTOs tenha um caráter 


\begin{tabular}{|c|c|c|c|c|c|c|c|}
\hline \multirow[t]{2}{*}{ Molécula } & \multirow[t]{2}{*}{$E_{01}(\mathrm{eV})$} & \multirow[t]{2}{*}{$f$} & \multicolumn{4}{|c|}{$\mu_{01}$ (Debye) } & \multirow{2}{*}{$\begin{array}{l}\text { Configuração } \\
\text { Eletrônica(\%) }\end{array}$} \\
\hline & & & $\mathrm{x}$ & $\mathrm{y}$ & z & total & \\
\hline $\begin{array}{l}13 \text {-cis- } \beta \text { - } \\
\text { caroteno }\end{array}$ & 2,41 & 2,87 & 17,69 & $-0,41$ & 0,02 & 17,70 & $\begin{array}{c}\mathrm{HOMO}-1 \rightarrow \mathrm{LUMO}+1(5) \\
\mathrm{HOMO} \rightarrow \mathrm{LUMO}(94)\end{array}$ \\
\hline $\begin{array}{l}9 \text {-cis- } \beta \text { - } \\
\text { caroteno }\end{array}$ & 2,42 & 3,64 & 19,88 & 1,25 & $-0,01$ & 19,92 & $\begin{array}{c}\mathrm{HOMO}-1 \rightarrow \mathrm{LUMO}+1(6) \\
\mathrm{HOMO} \rightarrow \mathrm{LUMO}(94)\end{array}$ \\
\hline fitoflueno & 3,46 & 2,50 & 13,17 & 4,09 & 0,07 & 13,79 & $\mathrm{HOMO} \rightarrow \mathrm{LUMO}(98)$ \\
\hline $\begin{array}{l}\text { trans- } \beta- \\
\text { caroteno }\end{array}$ & 2,39 & 3,99 & $-20,94$ & $-0,35$ & 0,10 & 20,95 & $\begin{array}{c}\mathrm{HOMO}-1 \rightarrow \mathrm{LUMO}+1(6) \\
\mathrm{HOMO} \rightarrow \mathrm{LUMO}(94)\end{array}$ \\
\hline zeaxantina & 2,35 & 4,15 & 21,43 & 2,40 & $-0,08$ & 21,57 & $\begin{array}{c}\mathrm{HOMO}-1 \rightarrow \mathrm{LUMO}+1(6) \\
\mathrm{HOMO} \rightarrow \mathrm{LUMO}(94)\end{array}$ \\
\hline
\end{tabular}

Tabela 6.5: Energias de transição vertical $S_{0} \rightarrow S_{1}\left(E_{01}\right)$, força do oscilador $(f)$, momentos de dipolo de transição $\left(\mu_{01}\right)$, e configurações eletrônicas dos carotenóides determinados a nível de teoria LC-BLYP/6-31G(d,p) com o parâmetro $\omega$ otimizado.

similar à distribuição da função de onda destes orbitais moleculares, portanto, não se faz necessária sua apresentação neste momento. Vale destacar também que a zeaxantina e o trans- $\beta$-caroteno apresentam maiores valores de força do oscilador, o que deve ser levado em consideração quando trata-se da probabilidade de transição óptica. Os resultados mostram que os sistemas carotenóides apresentam espectro de absorção óptico na região do visível e, dessa forma, se apresentam como possíveis candidatos para aplicação em dispositivos de optoeletrônica.

Portanto, neste capítulo mostramos que para sistemas com caminhos de conjugação curtos, o procedimento de otimização dos funcionais LRC via gap-fitting realmente fornece uma descrição mais precisa dos estados excitados nos polímeros de baixo gap-óptico em comparação ao funcional B3LYP. Isto não pode ser afirmado quando tratamos com sistemas altamente conjugados, pois é conhecido que os métodos DFT falham na descrição da BLA dos sistemas com cadeias poliênicas longas. Körzdörfer e colaboradores [92] mostraram que, embora o procedimento gap-fitting nos funcionais LRC reduza o erro de auto-interação, isto não garante uma descrição precisa da BLA. É importante também mencionar que este não é o procedimento único para ajuste dos funcionais LRC. 
Outras propriedades, como por exemplo, a mínima polarizabilidade ou máxima dureza podem ser o parâmetro escolhido para ajustar o funcional. Isto vai depender das propriedades de interesse a serem investigadas. 


\section{Considerações Finais}

Nesta tese, apresentamos um estudo teórico a nível $a b$ initio da estrutura eletrônica de três diferentes tipos de moléculas conjugadas. Inicialmente investigamos as propriedades eletrônicas e ópticas da molécula de triindole, que é um sistema que apresenta simetria $C_{3}$ e sobre o qual já existe uma série de estudos experimentais que indicam mobilidades relativamente alta para os semicondutores orgânicos. A análise das propriedades eletrônicas e ópticas do triindole incluiu uma investigação de como diferentes grupos funcionais ligados de maneira diferente ao núcleo do triindole influenciaram nas energias dos orbitais moleculares e no espectro de absorção UV-Vis. Vimos que os grupos funcionais, como também a maneira na qual estão ligados à molécula influenciam no limiar do espectro de absorção e no valor do gap de energia $\mathrm{HOMO} \rightarrow \mathrm{LUMO}$, sendo que os grupos $\mathrm{NO}_{2}$ e $\mathrm{CHO}$ apresentaram os menores valores do gap de energia. Ainda considerando a molécula de triindole funcionalizada, examinamos como a energia de reorganização intramolecular varia com a mudança dos grupos funcionais e a posição na qual são ligados ao triindole. Esta análise mostrou que a variação é muito pequena das energias de relaxação e energia de reorganização, com variação máxima de 13 meV para $\lambda_{0}$ e $\lambda_{1}$ e $50 \mathrm{meV}$ para $\lambda$.

Além disso, analisamos os valores das integrais de transferência de elétrons e buracos usando a aproximação do teorema de Koopmans. Dentro dessa abordagem avaliamos a dependência dos valores das integrais de transferência com relação ao funcional utilizado no cálculo de química quântica. Também realizamos o cálculo do acoplamento eletrônico através do método direto, que utiliza a idéia da função de onda de cargalocalizada. Este método tem a vantagem de ser mais realístico do que a aproximação via teorema de Koopmans. Nos dois casos verificamos que o valor do acoplamento eletrônico depende do ângulo de rotação entre as moléculas que compõem o dímero e a maior amplitude das integrais de transferência foi observada na situação em que as moléculas estão cofaciais, isto é, $\theta=0^{\circ}$. O triindole é molécula de simetria $C_{3}$ e tem periodicidade em $\theta=120^{\circ}$, portanto, devemos esperar um comportamento simétrico para o acoplamento 
eletrônico a cada $120^{\circ}$. No entanto, quando anexamos grupos metil ao triindole, a molécula perde sua planaridade e consequentemente, o acoplamento eletrônico não apresenta comportamento simétrico. É importante destacar que na sua estrutura cristalina, o ângulo entre os dímeros do triindole é de $60^{\circ}$. Nesse caso, o cálculo do acoplamento eletrônico via Koopmas mostrou que a integral de transferência de buracos apresenta valor razoável, o que deve ser esperado pelo fato de o triindole ser um transportador de buracos [6].

Neste trabalho também utilizamos os novos funcionais híbridos de longo alcance para investigar as propriedades eletrônicas e ópticas de um conjunto de moléculas conjugadas do tipo doador-aceitador. Estes sistemas têm como característica os diferentes caminhos de conjugação. Isto é, um grupo de moléculas que possui grupos doadores e aceitadores alternados e linearmente ligados ao longo da cadeia conjugada e, outro grupo em que a cadeia conjugada possui apenas grupos doadores e os aceitadores são ligados ortogonalmente à cadeia conjugada. Vimos que a planaridade é bastante influencida por efeitos estéricos das unidades doadoras e aceitadoras. A análise do parâmetro $\omega$ e o comprimento característico se confirma como uma forma alternativa de medirmos a extensão do grau de conjugação. Este, por sua vez, tem efeitos significativos nas propriedades eletrônicas e ópticas dos sistemas investigados. Além disso, dentro das limitações do método, o procedimento de otimização do parâmetro $\omega$ (método gap-fitting) permite a obtenção de um funcional exato para cada molécula.

Também usando o procedimento de gap-fitting investigamos as propriedades eletrônicas e ópticas dos princiais carotenóides presentes no óleo de buriti. Estes carotenóides tem como característica serem formados por 40 átomos de carbono e a presença de ligações conjugadas em sua estrutura molecular. Dentro do grupo de moléculas investigadas, quatro delas possuem uma longa cadeia conjugada ao longo de toda a molécula e, uma única molécula (fitoflueno) possui um caminho de conjugação menor seguido por ligações $\sigma$. Este fato é determinante para que o fitoflueno apresente comportamento diferente, tanto das propriedades geométricas, como também nas propriedades eletrônicas e ópticas. Também é importante destacar que os métodos teóricos de estrutura eletrônica têm dificuldades de tratar sistemas que apresentam longas cadeias conjugadas, como é o caso dos carotenóides. Isto foi verificado comparando os valores do $\lambda_{\max }$ com os dados experimentais. Embora o gap-fitting tenha apresentado melhor performance comparado ao B3LYP, os valores obtidos ainda assim estão distantes dos valores experimentais. 


\section{A Propriedades Eletrônicas e Ópticas dos} Sistemas DA via B3LYP/6-31G(d,p)
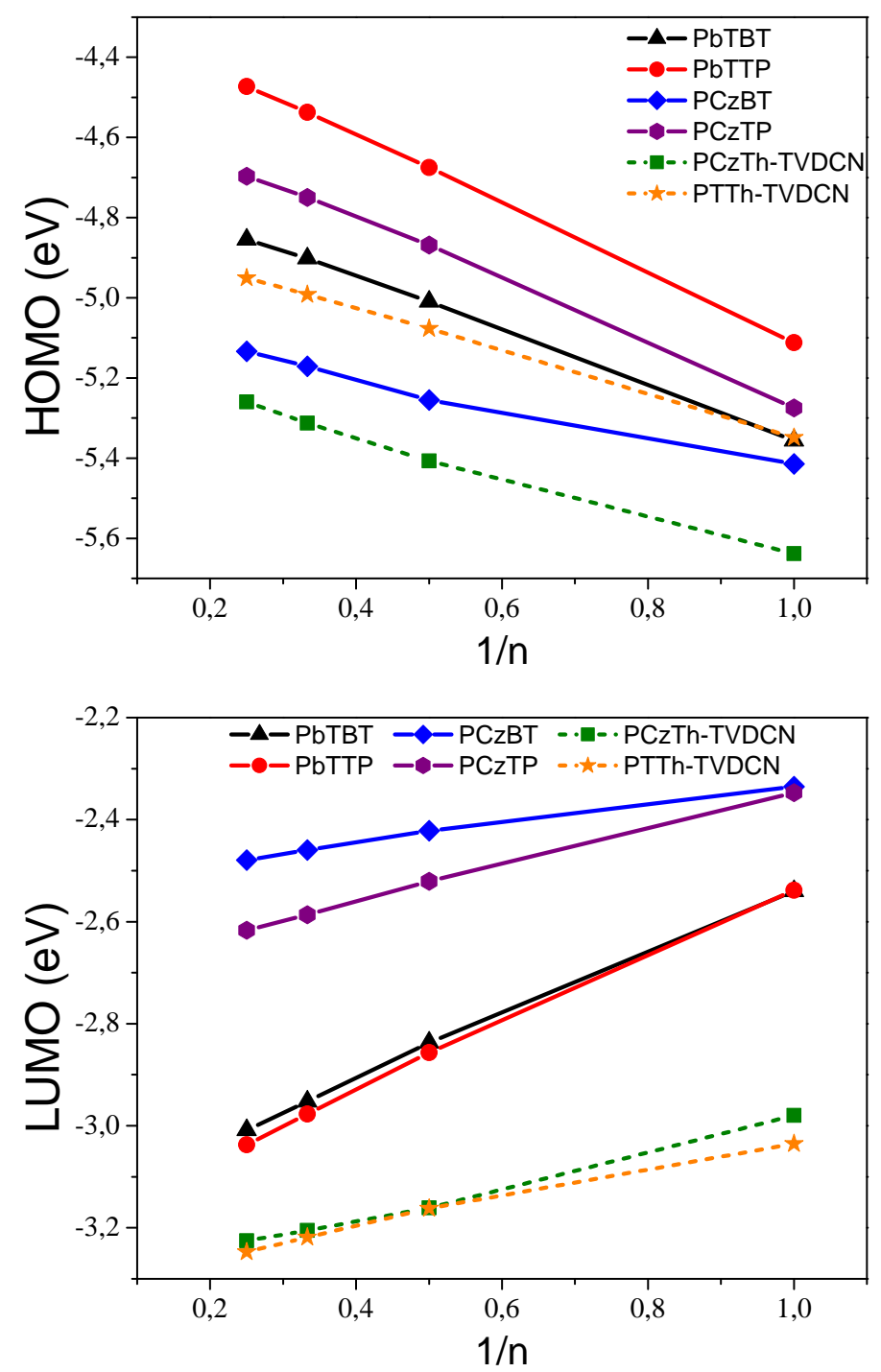

Figura A.1: Evolução das energias dos orbitais HOMO (topo) e LUMO (abaixo) como função do inverso do número de unidades repetidas $(1 / n)$ nos oligômeros calculados a nível B3LYP/6-31G(d,p). 

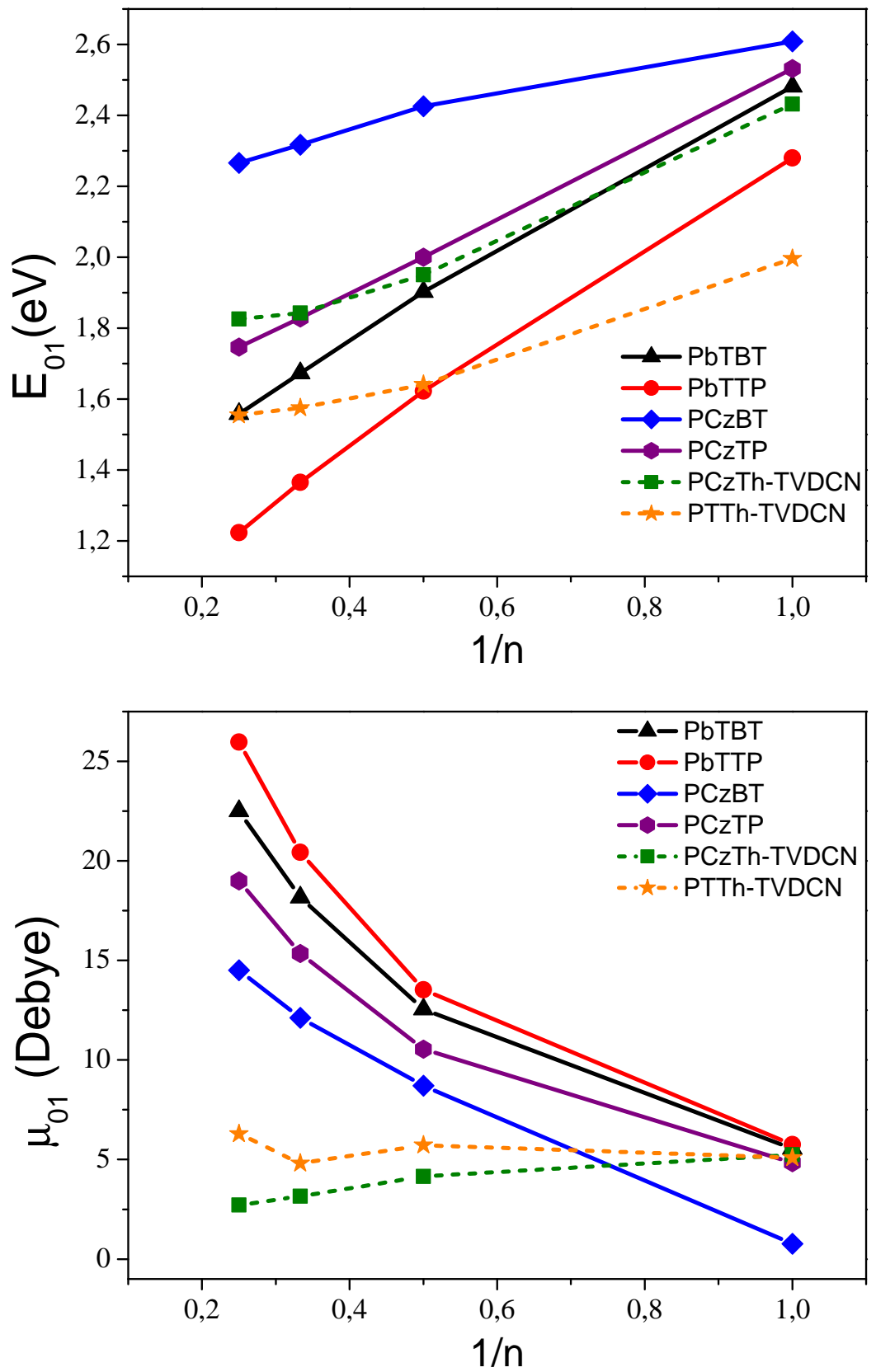

Figura A.2: Evolução da energia de transição vertical $S_{0} \rightarrow S_{1}$ (topo) e valor absoluto do momento de dipolo de transição (abaixo) como função do inverso do número de unidades repetidas $(1 / \mathrm{n})$, calculados a nível B3LYP/6-31G(d,p). 


\begin{tabular}{|c|c|c|c|}
\hline Conjugação & Molécula & $\mathbf{n}$ & $\omega\left(\right.$ bohr $\left.^{-1}\right)$ \\
\hline \multirow[t]{16}{*}{ Linear } & \multirow[t]{4}{*}{ PbTBT } & 1 & 0,222 \\
\hline & & 2 & 0,165 \\
\hline & & 3 & 0,142 \\
\hline & & 4 & 0,132 \\
\hline & \multirow[t]{4}{*}{ PbTTP } & 1 & 0,217 \\
\hline & & 2 & 0,155 \\
\hline & & 3 & 0,126 \\
\hline & & 4 & 0,110 \\
\hline & \multirow[t]{4}{*}{ PCzBT } & 1 & 0,223 \\
\hline & & 2 & 0,177 \\
\hline & & 3 & 0,168 \\
\hline & & 4 & 0,167 \\
\hline & \multirow[t]{4}{*}{ PCzTP } & 1 & 0,215 \\
\hline & & 2 & 0,161 \\
\hline & & 3 & 0,146 \\
\hline & & 4 & 0,140 \\
\hline \multirow[t]{8}{*}{ Ortogonal } & \multirow[t]{4}{*}{ PCzTh-TVDCN } & 1 & 0,199 \\
\hline & & 2 & 0,169 \\
\hline & & 3 & 0,160 \\
\hline & & 4 & 0,159 \\
\hline & \multirow[t]{4}{*}{ PTTh-TVDCN } & 1 & 0,195 \\
\hline & & 2 & 0,168 \\
\hline & & 3 & 0,164 \\
\hline & & 4 & 0,164 \\
\hline
\end{tabular}

Tabela A.1: Valores de $\omega\left(\right.$ bohr $\left.^{-1}\right)$ otimizados determinados via gap-fitting a nível de cálculo LC-BLYP/6-31G(d,p). 


\begin{tabular}{|c|c|c|c|c|}
\hline Funcional & Tetrâmero & HOMO & LUMO & $\mathbf{E}_{\text {gap }}$ \\
\hline LC-BLYP-opt. & PbTLYP) & $-5,64$ & $-1,85$ & 3,79 \\
& & $(-4,85)$ & $(-3,00)$ & $(1,84)$ \\
\cline { 2 - 5 } & PbTTP & $-5,05$ & $-2,05$ & 3,00 \\
& & $(-4,47)$ & $(-3,03)$ & $(1,43)$ \\
\cline { 2 - 5 } & PCzBT & $-6,25$ & $-1,12$ & 5,13 \\
& & $(-5,13)$ & $(-2,47)$ & $(2,65)$ \\
\cline { 2 - 5 } & & $-5,57$ & $-1,45$ & 4,11 \\
& PCzTP & $(-4,69)$ & $(-2,61)$ & $(2,07)$ \\
\cline { 2 - 5 } & & $-6,08$ & $-2,17$ & 3,91 \\
& & $(-5,25)$ & $(-3,22)$ & $(2,03)$ \\
\cline { 2 - 5 } & PTTh-TVDCN & $-5,91$ & $-1,90$ & 4,01 \\
& & $(-4,95)$ & $(-3,24)$ & $(1,70)$ \\
\hline
\end{tabular}

Tabela A.2: Energias dos orbitais moleculares HOMO e LUMO e gap HOMO-LUMO $\left(\mathrm{E}_{\text {gap }}\right)$ determinados via funcional LC-BLYP e B3LYP com o conjunto de base 6-31G(d,p). 


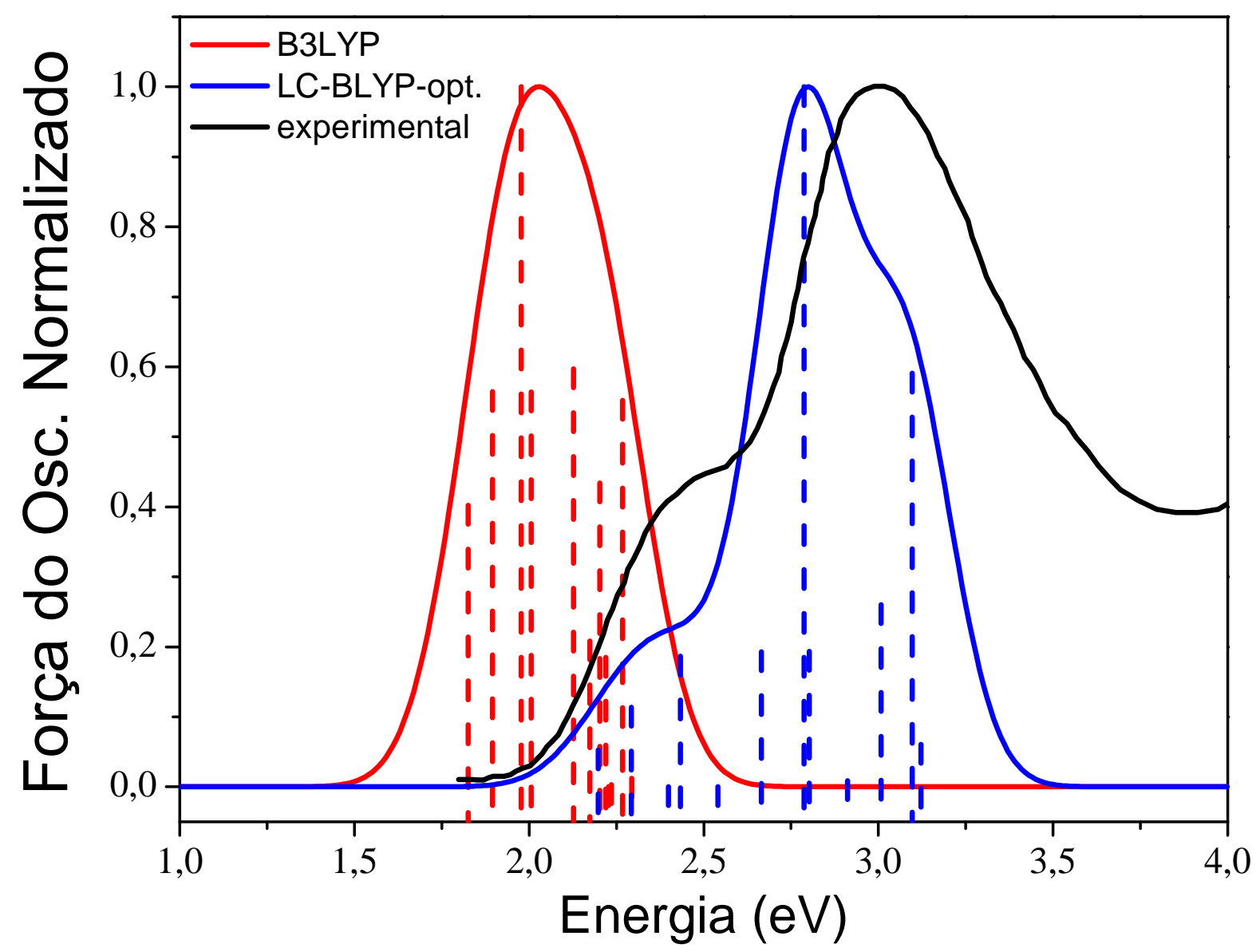

Figura A.3: Espectro de absorção UV-Vis do PCzTh-TVDCN calculados a nível B3LYP/6-31G(d,p) e LC-BLYP/6-31G(d,p) com o parâmetro $\omega$ otimizado. A curva experimental foi extraída da referência [68] para uma comparação com os resultados teóricos. 


\section{B Propriedades Eletrônicas e Ópticas dos Carotenóides via $\omega \mathrm{B} 97 / 6-31 \mathrm{G}(\mathrm{d}, \mathrm{p})$ com o Parâmetro $\omega$ Otimizado}

\begin{tabular}{|c|c|c|c|c|c|c|c|}
\hline \multirow[t]{2}{*}{ Molécula } & \multirow[t]{2}{*}{$E_{01}(\mathrm{eV})$} & \multirow[t]{2}{*}{$f$} & \multicolumn{4}{|c|}{$\mu_{01}($ Debye $)$} & \multirow{2}{*}{$\begin{array}{l}\text { Configuração } \\
\text { Eletrônica(\%) }\end{array}$} \\
\hline & & & $\mathrm{x}$ & $\mathrm{y}$ & $\mathrm{z}$ & total & \\
\hline $\begin{array}{l}13 \text {-cis- } \beta \text { - } \\
\text { caroteno }\end{array}$ & 2,44 & 2,83 & 17,47 & $-0,36$ & $-0,14$ & 17,48 & $\begin{aligned} \mathrm{HOMO}-1 & \rightarrow \mathrm{LUMO}+1(5) \\
\mathrm{HOMO} & \rightarrow \mathrm{LUMO}(94)\end{aligned}$ \\
\hline $\begin{array}{l}9 \text {-cis- } \beta \text { - } \\
\text { caroteno }\end{array}$ & 2,45 & 3,65 & 19,76 & 1,37 & $-0,17$ & 19,81 & $\begin{array}{c}\mathrm{HOMO}-1 \rightarrow \mathrm{LUMO}+1(6) \\
\mathrm{HOMO} \rightarrow \operatorname{LUMO}(94)\end{array}$ \\
\hline fitoflueno & 3,42 & 2,50 & 13,27 & 3,96 & 0,45 & 13,86 & $\mathrm{HOMO} \rightarrow \operatorname{LUMO}(98)$ \\
\hline $\begin{array}{l}\text { trans- } \beta \text { - } \\
\text { caroteno }\end{array}$ & 2,43 & 3,92 & 20,62 & 0,87 & $-0,09$ & 20,63 & $\begin{aligned} \mathrm{HOMO}-1 & \rightarrow \mathrm{LUMO}+1(5) \\
\mathrm{HOMO} & \rightarrow \mathrm{LUMO}(94)\end{aligned}$ \\
\hline zeaxantina & 2,37 & 4,10 & 21,15 & 2,69 & 0,13 & 21,33 & $\begin{array}{c}\mathrm{HOMO}-1 \rightarrow \mathrm{LUMO}+1(6) \\
\mathrm{HOMO} \rightarrow \mathrm{LUMO}(94)\end{array}$ \\
\hline
\end{tabular}

Tabela B.1: Energias de transição vertical $S_{0} \rightarrow S_{1}\left(E_{01}\right)$, força do oscilador $(f)$, momentos de dipolo de transição $\left(\mu_{01}\right)$, e configurações eletrônicas dos carotenóides determinados a nível de teoria $\omega \mathrm{B} 97 / 6-31 \mathrm{G}(\mathrm{d}, \mathrm{p})$ com o parâmetro $\omega$ otimizado. 
HOMO

\section{3-cis- $\beta$-caroteno}

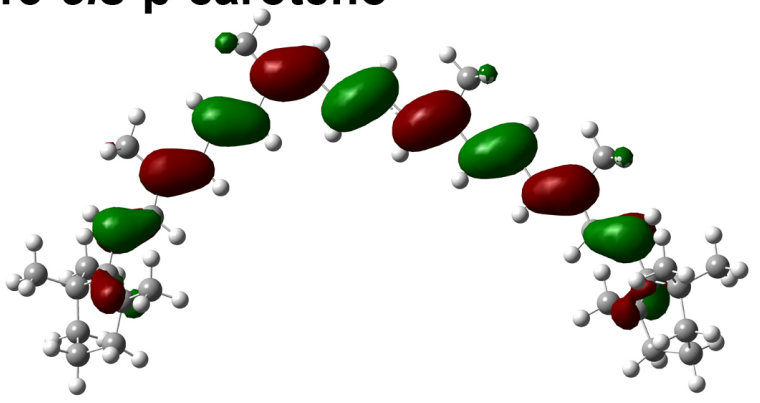

LUMO

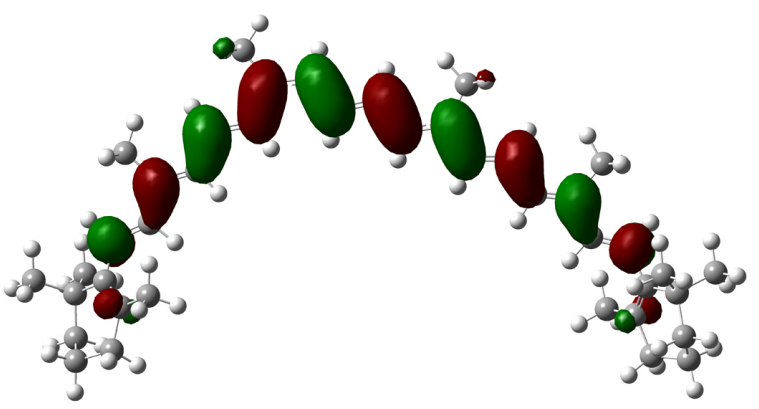

\section{9-cis- $\beta$-caroteno}
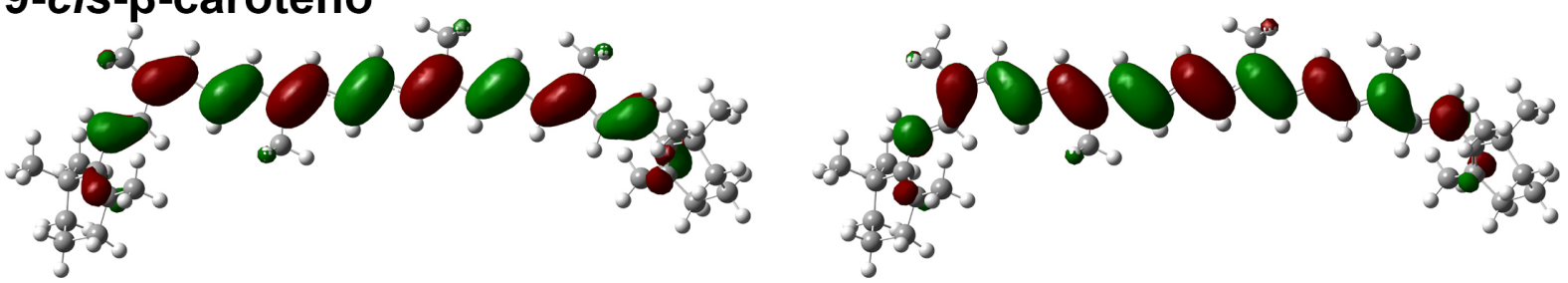

\section{fitoflueno}

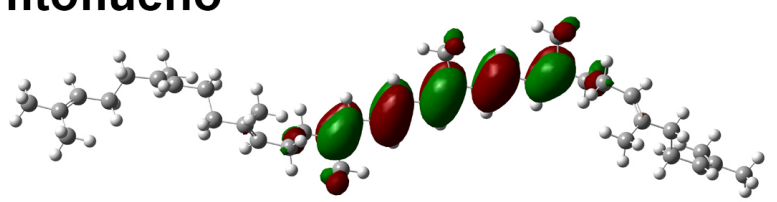

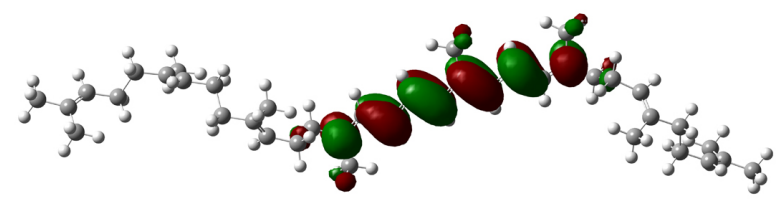

\section{trans- $\beta$-caroteno}
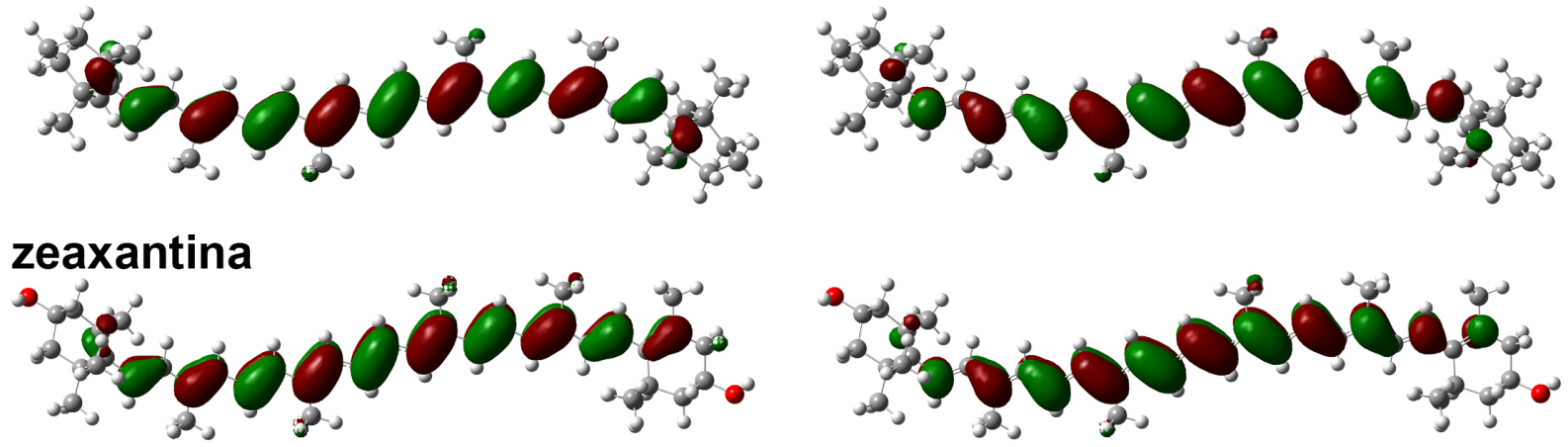

Figura B.1: Ilustração dos orbitais moleculares de fronteira HOMO e LUMO para os carotenóides calculados a nível $\omega \mathrm{B} 97 / 6-31 \mathrm{G}(\mathrm{d}, \mathrm{p})$ com o parâmetro $\omega$ otimizado. 


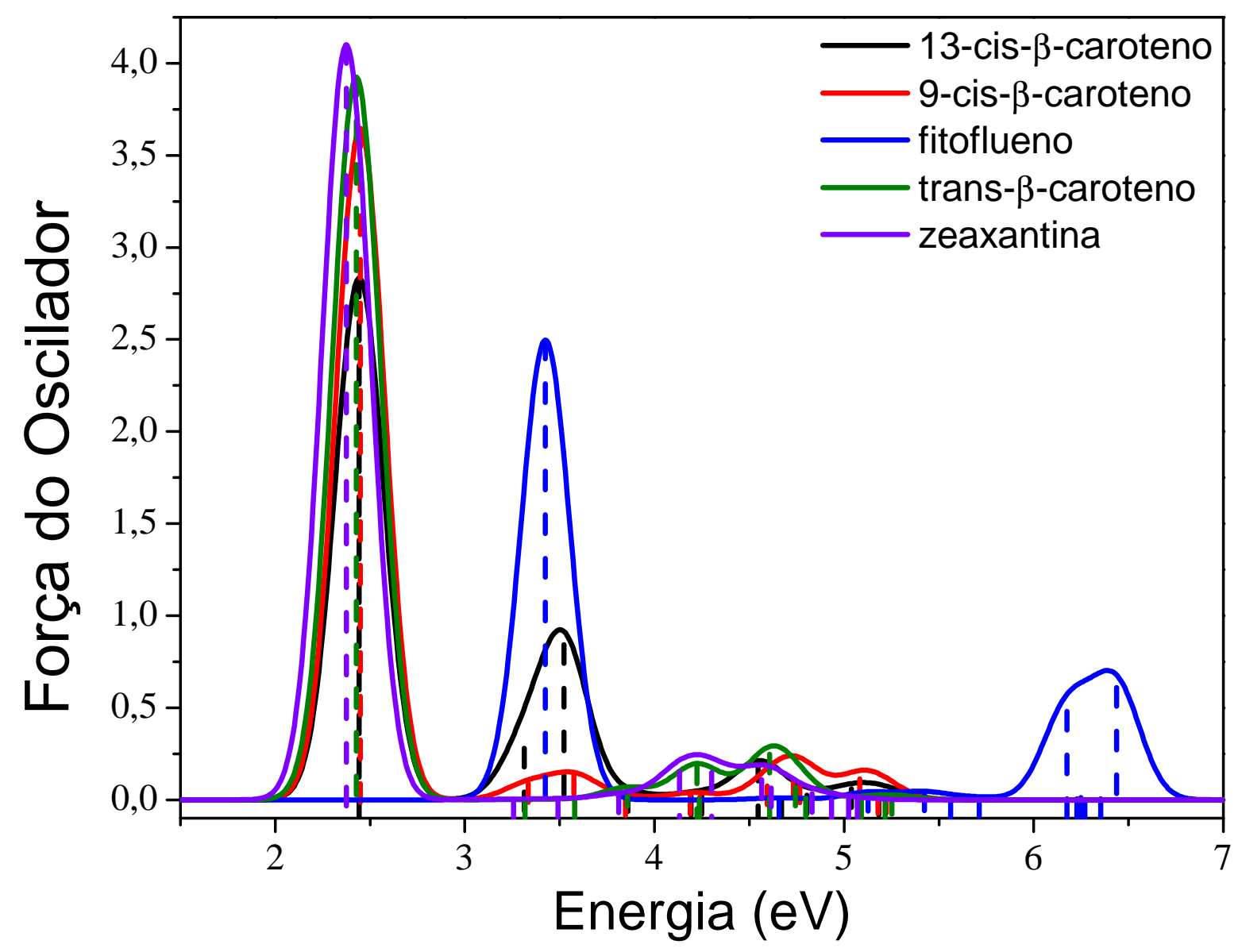

Figura B.2: Espectro de absorção para as cinco moléculas calculadas a nível $\omega$ B97/6$31 \mathrm{G}(\mathrm{d}, \mathrm{p})$. 


\section{Artigo 1}

Interplay of alternative conjugated pathways and steric interactions on the electronic and optical properties of donor-acceptor
conjugated polymers

Igo T. Lima Chad Risko Saadullah G. Aziz Demétrio A. da Silva Filho Jean-Luc Brédas 
Journal of Materials Chemistry C

\section{PAPER}

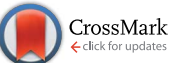

Cite this: J. Mater. Chem. C, 2014, 2 8873

\section{Interplay of alternative conjugated pathways and steric interactions on the electronic and optical properties of donor-acceptor conjugated polymers $\dagger$}

Igo T. Lima, ${ }^{\mathrm{ab}}$ Chad Risko, ( $^{\star a}$ Saadullah G. Aziz, ${ }^{\mathrm{c}}$ Demétrio A. da Silva Filho*b and Jean-Luc Brédas $\S^{\star a c}$

Donor-acceptor $\pi$-conjugated copolymers are of interest for a wide range of electronic applications, including field-effect transistors and solar cells. Here, we present a density functional theory (DFT) study of the impact of varying the conjugation pathway on the geometric, electronic, and optical properties of donor-acceptor systems. We consider both linear ("in series"), traditional conjugation among the donoracceptor moieties versus structures where the acceptor units are appended orthogonally to the linear, donor-only conjugated backbone. Long-range-corrected hybrid functionals are used in the investigation with the values of the tuned long-range separation parameters providing an estimate of the extent of conjugation as a function of the oligomer architecture. Considerable differences in the electronic and optical properties are determined as a function of the nature of the conjugation pathway, features that should be taken into account in the design of donor-acceptor copolymers.
Accepted 22nd August 2014

DOI: $10.1039 / \mathrm{c} 4 \mathrm{tc0} 01264 \mathrm{j}$

www.rsc.org/MaterialsC molecule/polymer-based materials. ${ }^{14-18}$ Most systems in this materials class employ a structural motif where the donor and acceptor units are linked in a linear fashion, i.e., $-\mathrm{D}-\mathrm{A}-\mathrm{D}-\mathrm{A}-\mathrm{D}-$ A-, or some variant thereof (Fig. 1). Recently, orthogonally conjugated structures - where the acceptor (or donor) is appended to the side of the main, conjugated backbone - have been introduced as an alternative strategy. ${ }^{19-22}$ For instance, Zhang and co-workers showed that manipulating the electronwithdrawing strength of the acceptor groups attached to a backbone consisting of carbazole (Cz) and thiophene (Th) units, allowed the redox and optical properties to be effectively tuned. ${ }^{21}$ In addition, Grimm and co-workers, using oligomers and copolymers comprised of cyclopentadithiophene (CPDT) with an imine functionality appended to the CPDT bridgehead position, ${ }^{23}$ demonstrated how orthogonal conjugation can lead to systems with low-energy (long wavelength) optical transitions, though the oscillator strengths (transition dipole moments) for these transitions tend to be small.

If such alternative conjugated pathways are to find broad use in materials applications, it is important to establish how the electronic and optical properties manifest as a function of such structural variations of the conjugation. In this work, we employ density functional theory (DFT) to investigate a systematic series of linear and orthogonally conjugated DA structures (see Fig. 1) to establish a broad comparison of the geometric, electronic, and optical properties., ${ }^{9,11,21}$ Here, carbazole $(\mathrm{Cz})$ and bisthiophene (Th) moieties are used as the donor groups, while three acceptor units were used to study the effects of the linear

\section{Lexington, Kentucky, 40506, USA.}

New Permanent Address: Department of Chemistry, University of Kentucky,

§ New Permanent Address: Physical Sciences and Engineering Division, King Abdullah University of Science and Technology (KAUST), Thuwal 23955-6900, Kingdom of Saudi Arabia. 'Departme

$\dagger$ Electronic supplementary information (ESI) available: Additional details †
\end{abstract}



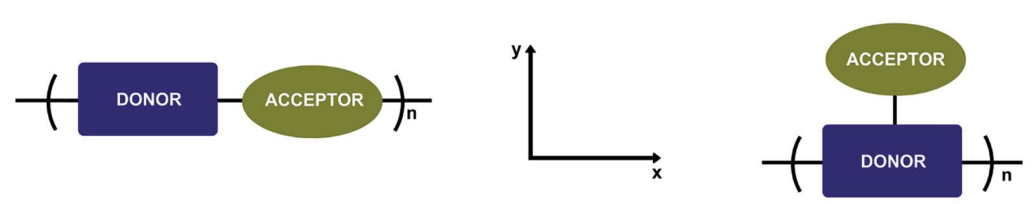

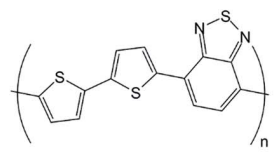

PbTBT

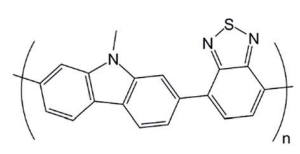

PCzBT

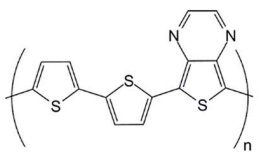

PbTTP

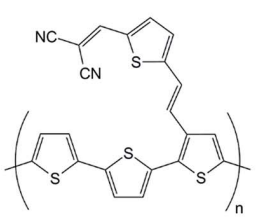

PTTh-TVDCN

Fig. 1 Chemical structures of the repeat units for: PbTBT $\equiv$ poly[4-methyl-7-(5'-methyl-[2,2'-bithiophen]-5-yl)benzo[c] [1,2,5]thiadiazole]: $\mathrm{PbTTP} \equiv$ poly[5-methyl-7-(5'-methyl-[2,2'-bithiophen]-5-yl)thieno[3,4-b]pyrazinel; PCzBT $\equiv$ poly[4-(7,9-dimethyl-9H-carbazol-2-yl)-7methylbenzo[c][1,2,5]thiadiazole]: PCzTP $\equiv$ poly[5-(7,9-dimethyl-9H-carbazol-2-yl)-7-methylthieno[3,4-b]pyrazine]: PCzTh-TVDCN $\equiv$ poly $[(E)-2-((5-(2-(5-(7,9-$ dimethyl- $9 \mathrm{H}$-carbazol-2-yl)-2-methylthiophen-3-yl)vinyl)thiophen-2-yl)methylene)malononitrile]; and PTTh-TVDCN $\equiv$

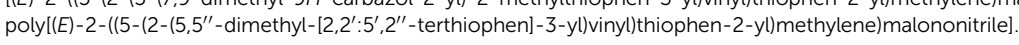

[benzothiadiazole (BT) and thienopyrazine (TP)] and orthogonal [thienylene-vinylene di-cyano (TVDCN)] conjugation pathways. ${ }^{21}$ These acceptor units were specifically chosen to be consistent with linear and orthogonal donor-acceptor copolymers reported in the literature.

\section{Computational methodology}

To model the DA copolymers, we considered oligomers with length $n=1-4$, i.e., from monomer to tetramer. The groundstate oligomer geometries were initially optimized via density functional theory (DFT) with the global hybrid B3LYP functional $^{24-26}$ and a $6-31 \mathrm{G}(\mathrm{d}, \mathrm{p})$ basis set. ${ }^{27,28}$ We note that the longest oligomers $(n=4)$ present a linear conjugation pathway along the backbone of 24 double bonds, a conjugation length that has been shown to be long enough to produce accurate trends concerning the electronic and optical properties of DA copolymers. ${ }^{11,23,29,30}$

Conventional semi-local and standard hybrid DFT functionals, due to the limitations associated with multi-electron self-interaction errors, can lead to poor descriptions of the charge-transfer-like excitations expected in DA systems. ${ }^{31,32}$ To overcome these limitations, we employ long-range-corrected hybrid functionals where the long-range separation parameter $\omega$ is tuned through the gap-fitting procedure proposed by Baer and Kronik: ${ }^{33-33}$

$$
\begin{gathered}
J_{\mathrm{IP}}(\omega)=\left|\varepsilon_{\mathrm{H}}{ }^{\omega}(N)+E_{\mathrm{gs}}{ }^{\omega}(N-1)-E_{\mathrm{gs}}{ }^{\omega}(N)\right| \\
J_{\mathrm{EA}}(\omega)=\left|\varepsilon_{\mathrm{H}}{ }^{\omega}(N+1)+E_{\mathrm{gs}}{ }^{\omega}(N)-E_{\mathrm{gs}}{ }^{\omega}(N+1)\right| \\
J_{\mathrm{gap}}(\omega)=\sqrt{\left(J_{\mathrm{IP}}(\omega)\right)^{2}+\left(J_{\mathrm{EA}}(\omega)\right)^{2}}
\end{gathered}
$$

Here, $\varepsilon_{\mathrm{H}}{ }^{\omega}(N)$ is the HOMO energy for an $N$-electron system and $E_{\mathrm{gs}}{ }^{\omega}(N)$ the corresponding SCF energy. Analogously, $\varepsilon_{\mathrm{H}}{ }^{\omega}(N+1)$ is the SOMO (singly occupied molecular orbital) energy for an $N+$ 1-electron system and $E_{\mathrm{gs}}{ }^{\omega}(N+1)$ and $E_{\mathrm{gs}}{ }^{\omega}(N-1)$ are the corresponding SCF energies of the anion and cation states, respectively. Starting from the optimized B3LYP/6-31G(d,p) structure, both the long-range separation parameter $\omega$ of the LC-BLYP functional and the geometry were iteratively optimized to guarantee that the HOMO-LUMO gap obtained from the optimized functional is directly comparable to the fundamental gap; notably, the tuned LC-BLYP functional has been shown to produce results that correlate well with the properties of both linearly and orthogonally conjugated polymers. ${ }^{23}$

The central idea surrounding the use of range-separated functionals for molecules is to partition the Coulomb operator into a short-range (SR) component, where a semilocal exchange-correlation functional is often used, and a long-range (LR) component, where the exchange part is treated at the exact nonlocal Hartree-Fock level. This approach allows one both to take advantage of the strengths of the semilocal approximations to the exchange-correlation functional and to minimize their 
shortcomings. ${ }^{36}$ The range separation is usually introduced through use of the error function (erf):

$$
\frac{1}{r}=\frac{\operatorname{erf}(\omega r)}{r}+\frac{\operatorname{erfc}(\omega r)}{r}
$$

with the value of $\omega$ determining the distance where the description switches from SR to LR. Importantly, the optimal value of the range-separation parameter has been shown to be sensitive to the system under consideration, ${ }^{30,37}$ with the $\omega$ tuning procedure introduced by Baer and Kronik (and used here) showing improvements in the description of the electronic and optical properties of atomic and molecular systems (e.g., the fundamental gap) and in particular charge-transfer excitations. $^{33-35}$

Low-lying singlet excited states were evaluated with the iteratively tuned LC-BLYP/6-31G(d,p) optimized geometries using time-dependent density functional theory (TDDFT). Optical absorption profiles were simulated through convolution of the vertical transition energies with Gaussian functions with a full width at half-maximum (FWHM) equal to $0.3 \mathrm{eV}$. All calculations were performed with the Gaussian 09 (Rev.A.02 and B.01) code. ${ }^{38}$

\section{Results and discussion}

(a) Geometric structure and degree of conjugation

We begin our analysis by discussing the ground-state geometric properties as a function of the nature of the donor and acceptor units. As might be expected, the relative degree of planarity along the main conjugated backbone is determined by the architecture of the donor and acceptor units. Fig. 2 and Table 1 provide definitions and collect representative torsion angles (for tetramers) along the main conjugated backbone. For the linear DA oligomers, the steric interactions induced by the phenylene protons ortho to the carbazole-acceptor linkage lead to larger torsions along the backbone as compared to the very planar thiophene-thiophene-linked systems. Importantly, the pendant TVDCN groups in the orthogonally DA conjugated structures, even though they are appended to the side of the main conjugated backbone, lead to an even larger degree of backbone twisting: the hydrogen atoms on the di-cyano group and the nearest-neighbor hydrogen atoms on the backbone are separated by $2.23 \AA$ in PCzTh-TVDCN and $2.30 \AA$ in PTTh-TVDCN, and steric relief arises through twisting the backbone.

It is expected that these deviations in torsion angle, though it is generally considered that some effective degree of conjugation is maintained up to torsion angles of about $40^{\circ},{ }^{39}$ will induce changes in the oligomer electronic structures through
Table 1 Torsion angles $\left(^{\circ}\right)$ along the conjugated backbone of the tetramers

\begin{tabular}{llll}
\hline Tetramers & $\Phi_{1}$ & $\Phi_{2}$ & $\Phi_{3}$ \\
\hline PbTBT & $0-1$ & 0 & $0-1(11)$ \\
PbTTP & 0 & 0 & $0(8)$ \\
PCzBT & $29-30$ & 29 & - \\
PCzTP & $0-4$ & $1-5$ & - \\
PCzTh-TVDCN & $26-35$ & $39-41$ & - \\
PTTh-TVDCN & $12-15$ & $27-29$ & $22-24$
\end{tabular}

reduction of the wave-function delocalization. To a first approximation, this can be estimated from the values of the optimized range-separation parameters. As discussed by Körzdörfer and co-workers, ${ }^{37}$ the optimized characteristic length, $1 / \omega$, of the long-range corrected density functional provides a means to examine the extent of $\pi$-conjugation. Fig. 3 shows the evolution of the characteristic length $1 / \omega$ as a function of the number of repeat units. The characteristic length indeed increases with increasing chain length and then saturates at lengths of 3 to 4 repeat units, results in accordance with the behavior described by Pandey and co-workers. ${ }^{30}$ However, PbTTP, and to some extent PbTBT, is an exception, as the characteristic length has not saturated after 4 repeat units. This effect can be attributed to the range-separation parameter becoming too small (i.e., the functional having too little non-

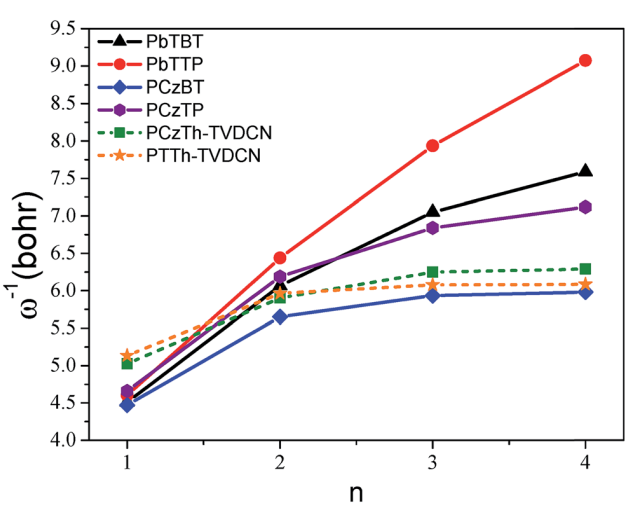

Fig. 3 Characteristic length $1 / \omega$ (i.e., the length over which the treatment of the Coulomb operator switches from short-range to long-range) as a function of oligomer size as determined at the tuned LC-BLYP/6-31G(d,p) level of theory.

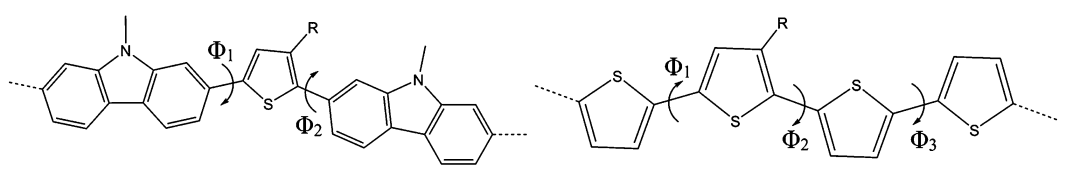

Fig. 2 Definition of the torsion angles along the conjugated backbone of the DA oligomers. 
local Hartree-Fock exchange) for this highly conjugated, planar system. ${ }^{30,37,40}$ For the tetramers, $1 / \omega$ is found to be longer in the case of the more planar systems, e.g., $3.84 \AA$ in PCzTP, $4.10 \AA ̊$ in PbTBT, and $4.90 \AA$ in PbTTP. The more twisted PCzBT structure has a $1 / \omega$ value of $3.23 \AA$ while the $1 / \omega$ values for the orthogonally conjugated systems PCzTh-TVDCN and PTTh-TVDCN are $3.39 \AA$ and $3.28 \AA$, respectively. These results are consistent with the more twisted structures having lower degrees of conjugation, which will manifest in the electronic and optical characteristics.

\section{(b) HOMO and LUMO charateristics}

Fig. 4 shows the evolution as a function of oligomer length of the LC-BLYP/6-31G(d,p) HOMO and LUMO energies, which correspond in the present context to the vertical ionization potential and electron affinity values. Within the range of oligomer lengths analyzed, there is a clear linear relationship
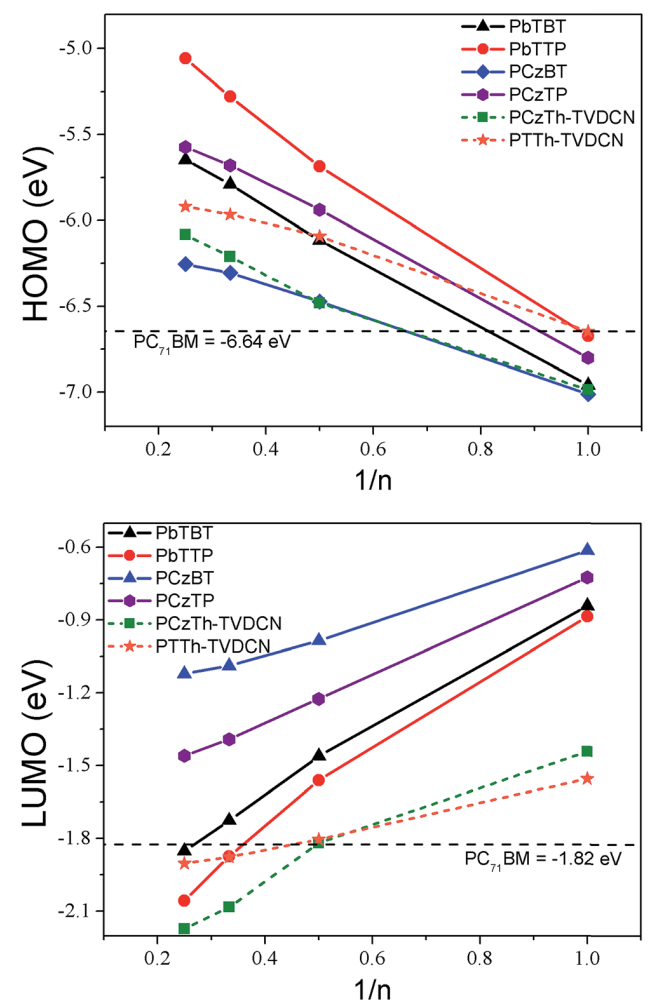

Fig. 4 Evolution of the HOMO (top) and LUMO (bottom) energies (eV) with respect to the inverse number of repeat units $(n)$ in the oligomer as determined at the tuned-LC-BLYP/6-31G(d,p) level of theory. For reference, the dashed line in each plot represents the $\mathrm{HOMO}$ (top) and $\mathrm{LUMO}$ (bottom) energy of $\mathrm{PC}_{71} \mathrm{BM}$ as determined at the same level of theory. between these energies and the inverse number of repeat units. Thus, the ionization potentials for the DA copolymers are found to increase on going from PbTTP $<$ PCzTP $<$ PbTBT $<$ PTThTVDCN $<$ PCzTh-TVDCN $<$ PCzBT. The smaller IPs are associated with a more coplanar configuration across the backbone, which allows for a more delocalized HOMO (see below). The electron affinities follow the trend PCzTh-TVDCN $>$ PbTTP $>$ PTTh-TVDCN $>$ PbTBT $>$ PCzTP $>$ PCzBT. The DA tetramers with carbazole in the backbone present larger HOMO-LUMO gaps compared to the thiophene-based systems in the following order: PCzBT $(5.13 \mathrm{eV})>$ PCzTP $(4.11 \mathrm{eV})>$ PTTh-TVDCN $(4.01 \mathrm{eV})>$ PCzTh-TVDCN $(3.91 \mathrm{eV})>\operatorname{PbTBT}(3.79 \mathrm{eV})>\operatorname{PbTTP}(3.00 \mathrm{eV})$.

Fig. 5 illustrates the tuned LC-BLYP HOMOs and LUMOs of PbTTP and PTTh-TVDCN, taken as representatives for the tetramer series. For the linear systems, the HOMOs are delocalized along the conjugated backbone; the LUMOs, on the other hand, show varying degrees of (de)localization based on the components and oligomer architecture, e.g., the more coplanar backbones of PbTBT, PbTTP and PCzTP lead as expected to greater delocalization of the LUMO along the backbone as compared to the more localized LUMO on the benzothiadiazole acceptor of PCzBT. For the orthogonally conjugated systems, the HOMO is also largely delocalized along the main backbone, although to a somewhat lesser extent when compared to the linear systems; the LUMO, on the other hand, is mainly localized on the acceptor units as a result of the departure from planarity.

\section{(c) Excited-state properties and optical absorption}

We now turn our attention to the description of the excited-state properties of these oligomers to examine how the different conjugation pathways influence optical absorption. Fig. 6 shows the evolution of the $S_{0} \rightarrow S_{1}$ vertical energies and transition dipole moments as a function of the number of repeat units as determined with TDDFT at the tuned-LC-BLYP/6-31G(d,p) level of theory. For the four linearly conjugated systems, these transitions primarily involve a HOMO $\rightarrow$ LUMO excitation (87 to 91\%); PCzBT, however, does present a more mixed transition character, as a consequence of its twisted nature. The orthogonal systems by and large show significant contributions from electronic transitions among additional frontier orbitals (see the ESI $\dagger$ for further details).

The $S_{0} \rightarrow S_{1}$ transition dipole moments are predominantly aligned along the main conjugated backbone $(x$-axis, as defined

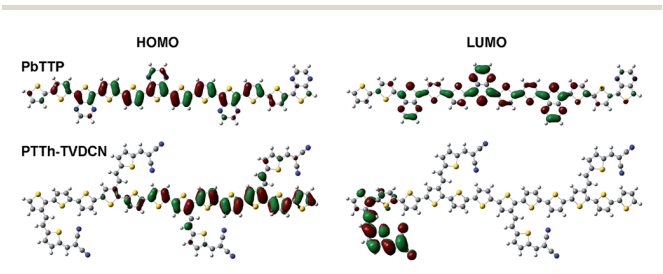

Fig. 5 Illustration of the tetramer frontier molecular orbitals determined at the tuned-LC-BLYP/6-31G(d,p) level of theory. 

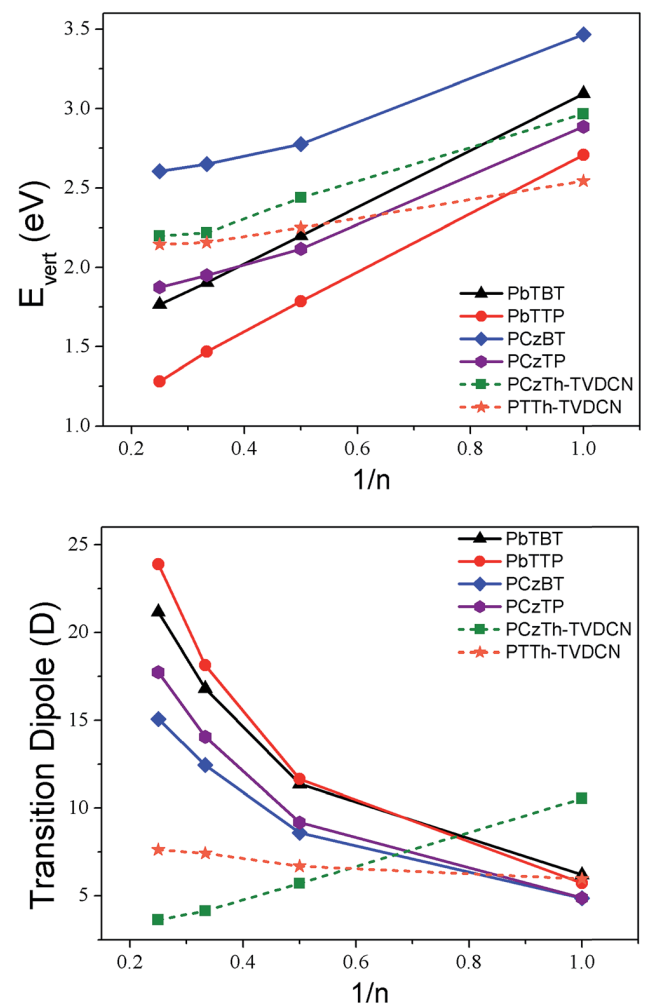

Fig. 6 Evolution of the $S_{0} \rightarrow S_{1}$ vertical transition energy (top) and absolute value of the transition dipole moment (bottom) with respect to the inverse number of repeat units $(1 / n)$, as calculated with TDDFT at the tuned-LC-BLYP/6-31G(d,p) level of theory.

in Fig. 1) and increase in magnitude with increasing oligomer length. For PTTh-TVDCN, in addition to that along the $x$-axis, there is significant contribution from the $y$-axis component arising from the delocalization of the transition density on the orthogonally conjugated acceptor; hence, the overall transition dipole moment only weakly increases with increasing conjugation length (see ESI $\dagger$ ), a result consistent with the findings of Grimm and co-workers. ${ }^{23}$ This result suggests that while orthogonal conjugation can lead to materials with relatively low-energy absorptions, the limited transition dipole moments - due to reduced overlap between the ground state and first excited state (see below) - will affect the efficiency of photon absorption.

The notable exception to the series is the $S_{0} \rightarrow S_{1}$ transition dipole moment for PCzTh-TVDCN. As with PTTh-TVDCN, there is a significant delocalization of the transition density outside the main backbone. The highly twisted nature of the structure, however, results in the transition dipole moment having nonnegligible contributions coming from all three $(x, y$, and $z$ ) components. These transition dipole moment components, interestingly, show a differing evolution with increasing conjugation length, which results in a net decrease in transition dipole moment with increasing size for PCzTh-TVDCN.

Fig. 7 collects the simulated absorption spectra where the vertical transitions are convoluted with Gaussian functions $(\mathrm{FWHM}=0.3 \mathrm{eV})$. The positions of the vertical transitions are included to highlight the energies of the electronic states. As expected from the trends observed for the molecular orbital energies, there is a substantial bathochromic shift in the $\mathrm{S}_{0} \rightarrow$ $S_{1}$ vertical transitions when going from twisted to more planar structures. Hence, a clear relationship between the characteristic length $(1 / \omega)$ and the $S_{0} \rightarrow S_{1}$ energy is observed. The spectra of the linear systems can be characterized as having one dominant low-energy transition with a large oscillator strength followed by a higher-energy transition with smaller oscillator strength. For the systems with orthogonally conjugated acceptors, on the other hand, the spectra present one low-energy transition (or series of transitions) with small oscillator strength
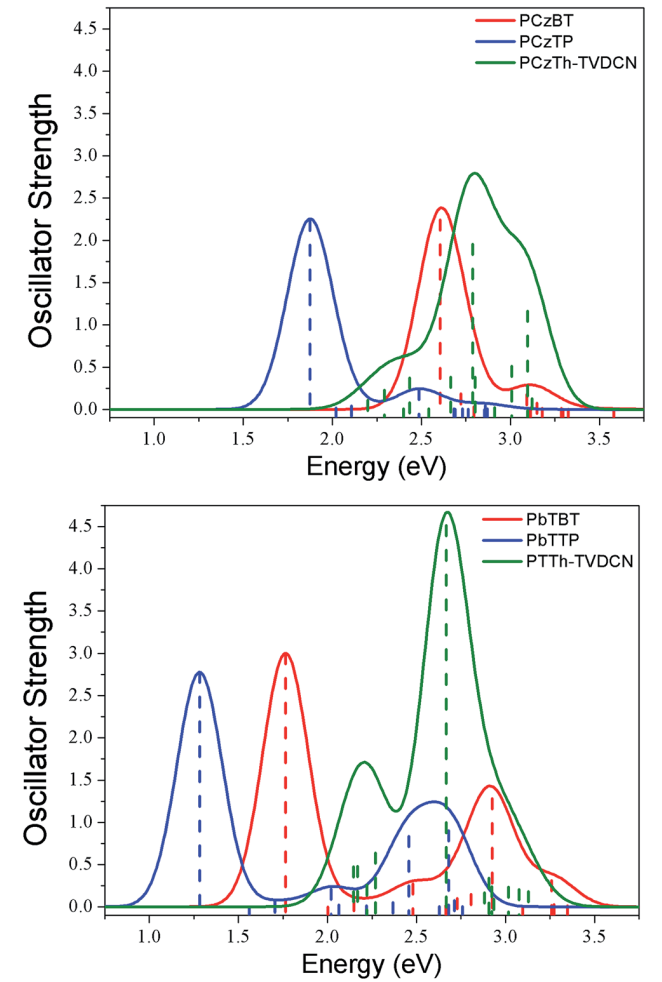

Fig. 7 Simulated absorption spectra (FWHM $=0.3 \mathrm{eV}$ ) for the tetramers as determined with TDDFT at the tuned-LC-BLYP/6-31G(d,p) level of theory: (top) systems with carbazole units and (bottom) systems with thiophene units along the backbone. 
(see above) followed by a higher-energy transition with large oscillator strength. We note that the simulated spectrum for PCzTh-TVDCN is in good agreement with the experimental spectrum reported by $\mathrm{Li}$ and co-workers, ${ }^{21}$ hence providing confidence in the chosen DFT methodology to detail the intrinsic physical properties of these polymers.

Natural transition orbitals (NTOs) ${ }^{4,41}$ have been used to further examine the nature of $\mathrm{S}_{0} \rightarrow \mathrm{S}_{1}$ absorption as there is mixing of other electronic transitions beyond HOMO $\rightarrow$ LUMO to describe this excitation. Fig. 8 provides representations of the NTOs and corresponding $\lambda$ values (hole-particle contribution for a given electronic transition) for the $S_{0} \rightarrow S_{1}$ transitions of representative tetramers. For the linear systems, i.e., PbTBT, PbTTP, PCzBT, and PCzTP, the $\mathrm{S}_{0} \rightarrow \mathrm{S}_{1}$ transitions are predominantly HOMO $\rightarrow$ LUMO and hence the NTOs strongly resemble these molecular orbitals (Fig. 5). For PbTBT and PbTTP, the excitation is mainly a contribution of two particlehole pairs where both the hole and electron are largely delocalized across the conjugated backbone; in PCzTP and PCzBT, the excitation is a contribution of three particle-hole pairs where the electron tends to localize more strongly on the acceptor unit (see ESI $\dagger$ for further details). The large spatial overlap among the hole and electron NTOs is consistent with the significant $S_{0} \rightarrow S_{1}$ transition dipole moment in these systems.

For the orthogonally conjugated systems, the NTO for PCzTh-TVDCN is a single dominant particle-hole pair, while in PTTh-TVDCN, the excitation is a contribution of two particle-hole pairs. In both cases, the hole is delocalized over the conjugated backbone and the orthogonally conjugated acceptor, while the electron is largely localized on the acceptor. Here, the limited overlap of the hole and electron NTOs reveals the reasons behind the small transition dipole moments in the lowest optical transitions of PTTh-TVDCN and PCzTh-TVDCN, while pointing to the nature of the sizable transition dipole moment components orthogonal to the backbone.

\section{Conclusion}

In summary, we have used long-range-corrected density functionals to investigate a series of low optical-gap conjugated oligomers that contain benzothiadiazole and pyrazine acceptors appended in serial fashion with the donor moieties and thienylene vinylene di-cyano acceptors appended in an orthogonal manner. The system planarity, as expected, is very much influenced by the steric effects between donor and acceptor groups, even in the orthogonally conjugated case.

The value of the tuned range-separation parameter $\omega$ is confirmed to provide an effective measure of the extent of conjugation. The degree of conjugation, in turn, has significant effects on the electronic and optical properties of the systems under study. Interestingly, one of the orthogonally conjugated systems has a transition dipole moment that decreases with increasing conjugation length, a result not $a$ priori expected. Our results confirm that orthogonally conjugated DA copolymers can lead to absorption into the red portion of the visible spectrum, though the transition dipole moments for these transitions should be expected to be rather limited.

\section{Acknowledgements}

ITL and DASF gratefully acknowledge the financial support from the Brazilian research agencies CAPES, CNPq and FAP-DF. The work at Georgia Tech was supported by the Deanship of Scientific Research (DSR), King Abdulaziz University, Jeddah, Saudi Arabia, under International Collaboration Grant no. D001-433 and by the Office of Naval Research under Grant no. N00014-14-1-0171.

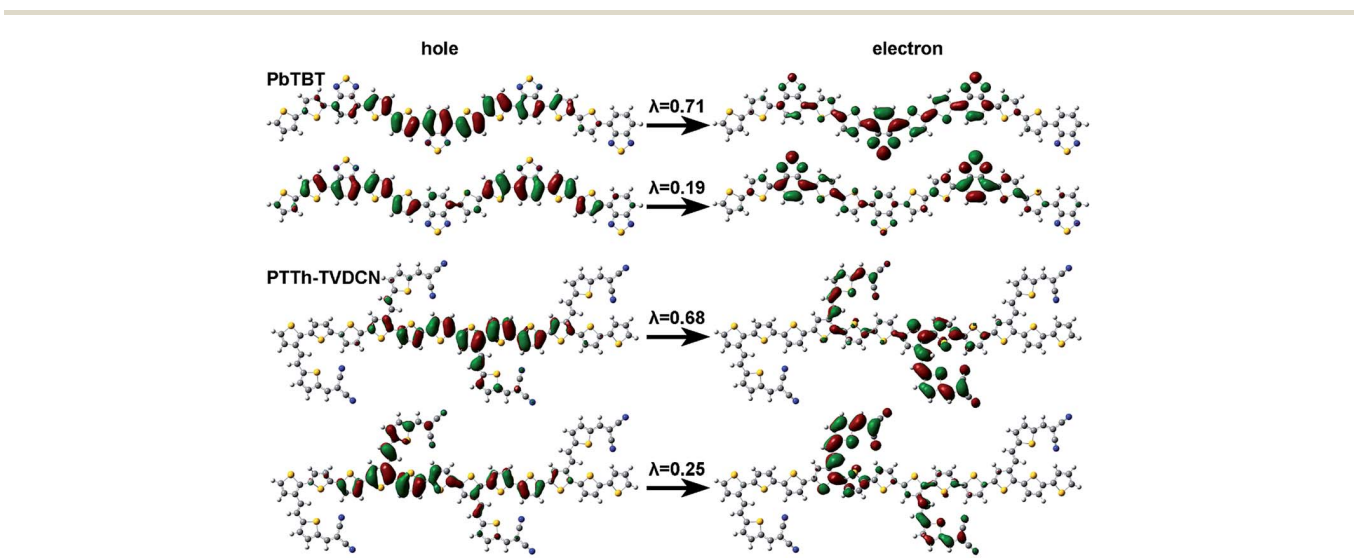

Fig. 8 Illustration of the natural transition orbitals (NTO) describing the $\mathrm{S}_{0} \rightarrow \mathrm{S}_{1}$ transition for the PbTBT and PTTh-TVDCN tetramers as determined with TDDFT at the tuned-LC-BLYP/6-31G(d,p) level of theory; $\lambda$ denotes the associated weight to the hole-particle contribution for the given electronic transition described by the NTOs. 


\section{References}

1 Y. F. Li and Y. P. Zou, Adv. Mater., 2008, 20, 2952-2958. 2 N. Blouin, A. Michaud and M. Leclerc, Adv. Mater., 2007, 19, 2295-2300.

3 E. Bundgaard and F. C. Krebs, Sol. Energy Mater. Sol. Cells, 2007, 91, 954-985.

4 A. Facchetti, Chem. Mater., 2011, 23, 733-758.

5 G. Lu, H. Usta, C. Risko, L. Wang, A. Facchetti, M. A. Ratner and T. J. Marks, J. Am. Chem. Soc., 2008, 130, 7670-7685.

6 H. N. Yi, S. Al-Faifi, A. Iraqi, D. C. Watters, J. Kingsley and D. G. Lidzey, J. Mater. Chem., 2011, 21, 13649-13656.

7 J. M. Szarko, J. C. Guo, Y. Y. Liang, B. Lee, B. S. Rolczynski, J. Strzalka, T. Xu, S. Loser, T. J. Marks, L. P. Yu and L. X. Chen, Adv. Mater., 2010, 22, 5468-5472.

8 J. H. Hou, M. H. Park, S. Q. Zhang, Y. Yao, L. M. Chen, J. H. Li and Y. Yang, Macromolecules, 2008, 41, 6012-6018.

9 B. Y. Fu, J. Baltazar, Z. K. Hu, A. T. Chien, S. Kumar, C. L. Henderson, D. M. Collard and E. Reichmanis, Chem. Mater., 2012, 24, 4123-4133.

10 L. E. Polander, L. Pandey, S. Barlow, P. Tiwari, C. Risko, B. Kippelen, J. L. Bredas and S. R. Marder, J. Phys. Chem. C, 2011, 115, 23149-23163.

11 L. Pandey, C. Risko, J. E. Norton and J. L. Bredas, Macromolecules, 2012, 45, 6405-6414.

12 T. Yasuda, Y. Sakai, S. Aramaki and T. Yamamoto, Chem. Mater., 2005, 17, 6060-6068.

13 Z. G. Zhang, K. L. Zhang, G. Liu, C. X. Zhu, K. G. Neoh and E. T. Kang, Macromolecules, 2009, 42, 3104-3111.

14 E. E. Havinga, W. Tenhoeve and H. Wynberg, Polym. Bull., 1992, 29, 119-126.

15 E. E. Havinga, W. Tenhoeve and H. Wynberg, Synth. Met., 1993, 55, 299-306.

16 C. Piliego, T. W. Holcombe, J. D. Douglas, C. H. Woo, P. M. Beaujuge and J. M. J. Frechet, J. Am. Chem. Soc., 2010, 132, 7595-7597.

17 Y. P. Zou, A. Najari, P. Berrouard, S. Beaupre, B. R. Aich, Y. Tao and M. Leclerc, J. Am. Chem. Soc., 2010, 132, 53305331.

18 Y. Y. Liang and L. P. Yu, Acc. Chem. Res., 2010, 43, 1227-1236. 19 Y. F. Li, Acc. Chem. Res., 2012, 45, 723-733.

20 Y. P. Zou, W. P. Wu, G. Y. Sang, Y. Yang, Y. Q. Liu and Y. F. Li, Macromolecules, 2007, 40, 7231-7237.

21 Z. G. Zhang, H. J. Fan, J. Min, S. Y. Zhang, J. Zhang, M. J. Zhang, X. Guo, X. W. Zhan and Y. F. Li, Polym. Chem., 2011, 2, 1678-1687.

22 P. Shen, H. J. Bin, X. W. Chen and Y. F. Li, Org. Electron., 2013, 14, 3152-3162.

23 B. Grimm, C. Risko, J. D. Azoulay, J. L. Bredas and G. C. Bazan, Chem. Sci., 2013, 4, 1807-1819.
24 C. T. Lee, W. T. Yang and R. G. Parr, Phys. Rev. B: Condens. Matter Mater. Phys., 1988, 37, 785-789.

25 A. D. Becke, Phys. Rev. A: At., Mol., Opt. Phys., 1988, 38, 30983100

26 A. D. Becke, J. Chem. Phys., 1993, 98, 5648-5652.

27 M. M. Francl, W. J. Pietro, W. J. Hehre, J. S. Binkley, M. S. Gordon, D. J. Defrees and J. A. Pople, J. Chem. Phys., 1982, 77, 3654-3665.

28 P. c. Harihara and J. A. Pople, Theor. Chim. Acta, 1973, 28, 213-222.

29 C. Risko, M. D. McGehee and J. L. Bredas, Chem. Sci., 2011, 2, 1200-1218.

30 L. Pandey, C. Doiron, J. S. Sears and J. L. Bredas, Phys. Chem. Chem. Phys., 2012, 14, 14243-14248.

31 J. D. Chai and M. Head-Gordon, J. Chem. Phys., 2008, 128

32 A. L. Sobolewski and W. Domcke, Chem. Phys., 2003, 294, 7383.

33 L. Kronik, T. Stein, S. Refaely-Abramson and R. Baer, $J$ Chem. Theory Comput., 2012, 8, 1515-1531.

34 N. Kuritz, T. Stein, R. Baer and L. Kronik, J. Chem. Theory Comput., 2011, 7, 2408-2415.

35 R. Baer, E. Livshits and U. Salzner, Annu. Rev. Phys. Chem., 2010, 61, 85-109.

36 R. Baer and D. Neuhauser, Phys. Rev. Lett., 2005, 94, 043002.

37 T. Korzdorfer, J. S. Sears, C. Sutton and J. L. Bredas, J. Chem. Phys., 2011, 135, 204107.

38 M. J. Frisch, G. W. Trucks, H. B. Schlegel, G. E. Scuseria, M. A. Robb, J. R. Cheeseman, G. Scalmani, V. Barone, B. Mennucci, G. A. Petersson, H. Nakatsuji, M. Caricato, X. Li, H. P. Hratchian, A. F. Izmaylov, J. Bloino, G. Zheng, J. L. Sonnenberg, M. Hada, M. Ehara, K. Toyota, R. Fukuda, J. Hasegawa, M. Ishida, T. Nakajima, Y. Honda, O. Kitao, H. Nakai, T. Vreven, J. A. Montgomery, Jr, J. E. Peralta, F. Ogliaro, M. Bearpark, J. J. Heyd, E. Brothers, K. N. Kudin, V. N. Staroverov, R. Kobayashi, J. Normand, K. Raghavachari, A. Rendell, J. C. Burant, S. S. Iyengar, J. Tomasi, M. Cossi, N. Rega, J. M. Millam, M. Klene, J. E. Knox, J. B. Cross, V. Bakken, C. Adamo, J. Jaramillo, R. Gomperts, R. E. Stratmann, O. Yazyev, A. J. Austin, R. Cammi, C. Pomelli, J. W. Ochterski, R. L. Martin, K. Morokuma, V. G. Zakrzewski, G. A. Voth, P. Salvador, J. J. Dannenberg, S. Dapprich, A. D. Daniels, Ö. Farkas, J. B. Foresman, J. V. Ortiz, J. Cioslowski and D. J. Fox, Gaussian 09, Revisions A.02 \& B.01, Gaussian Inc., Wallingford C. T., 2009.

39 J. L. Bredas, G. B. Street, B. Themans and J. M. Andre, J Chem. Phys., 1985, 83, 1323-1329.

40 S. Refaely-Abramson, R. Baer and L. Kronik, Phys. Rev. B: Condens. Matter Mater. Phys., 2011, 84, 075144.

41 R. L. Martin, J. Chem. Phys., 2003, 118, 4775-4777. 


\section{Referências Bibliográficas}

[1] Ling, Q. D.; Liaw, D. J.; Zhu, C. X.; Chan, D. S. H.; Kang, E. T.; Neoh, K. G., Prog. Polym. Sci., 33, 917-978 (2008).

[2] Raymo, F. M., Adv. Mater., 14, 401-414 (2002).

[3] Yang, Y.; Ouyang, J.; Ma, LP.; Tseng, R. J. H.; Chu, C. W., Adv. Funct. Mater., 16, 1001-1014 (2006).

[4] Aviram, A.; Ratner, M. A., Chem. Phys. Lett., 29, 277-283 (1974).

[5] Coropceanu, V.; Cornil, J.; da Silva Filho, D. A.; Olivier, Y.; Silbey, R.; Brédas, J.L., Chem. Rev., 107, 926-952 (2007).

[6] García-Frutos, E. M.; Gutierrez-Puebla, E.; Monge, M. A.; Ramírez, R.; de Andrés, P.; Ramírez, R.; Gómez-Lor, B., Org. Electron., 10, 643-652 (2009).

[7] García-Frutos, E. M.; Omenat, A.; Barberá, J.; Serrano, J. L.; Gómez-Lor, B., J. Mater. Chem., 21, 6831-6836 (2011).

[8] García-Frutos, E. M.; Pandey, U. K.; Termine, R.; Omenat, A.; Barberá, J.; Serrano, J. L.; Golemme, A.; Gómez-Lor, B., Angew. Chem. Int. Ed., 50, 7399-7402 (2011).

[9] Gallego-Gómez, F.; García-Frutos, E. M.; Villalvilla, J. M.; Quintana, J. A.; Gutierrez-Puebla, E.; Monge, A.; Díaz-García, M. A.; Gómez-Lor, B., Adv. Func. Mater., 21, 738-745 (2011).

[10] Gómez-Lor, B.; Hennrich, G.; Alonso, B; Monge, A.; Gutierrez-Puebla, E.; Echavarren, A. M., Angew. Chem. Int. Ed., 45, 4491-4494 (2006).

[11] Gómez-Lor, B.; Alonso, B; Omenat, A.; Serrano, J. L., Chem. Commun., 45, 5012$5014(2006)$.

[12] García-Frutos, E. M.; Gómez-Lor, B.; Monge, A.; Gutierrez-Puebla, E.; Alkorta, I.; Elguero, J., Chem. Eur. J., 14, 8555-8561 (2008). 
[13] García-Frutos, E. M.; Hennrich, G.; Gutierrez, E.; Monge, A.; Gómez-Lor, B., J. Org. Chem., 75, 1070-1076 (2010).

[14] García-Frutos, E. M.; Gómez-Lor, B., J. Am. Chem. Soc., 130, 9173-9177 (2008).

[15] Talarico, M.; Termine, R.; García-Frutos, E. M.; Omenat, A.; Serrano, J. L.; GómezLor, B.; Golemme, A., Chem. Mater., 20, 6589-6591 (2008).

[16] Szabo, A.; and Ostlund, N. S., Modern Quantum Chemistry: Introduction to Advanced Eletronic Structure Theory, Dover Publications, (1989).

[17] Cramer, C. J., Essentials of Computational Chemistry: Theories and Models, 2nd ed., John Wiley and Sons, Ltd.: Chichester, UK, (2004).

[18] da Silva Filho, D. A., Estudo Teórico da Fluorescência Dupla em 9-Antril Oligotiofenos e da Adsorção de Moléculas Orgânicas em uma Superfície de Grafite, Tese de Doutorado - Universidade Estadual de Campinas, Campinas, SP, (2003).

[19] Vianna, J. D. M.; Fazzio, A.; Canuto, S., Teoria Quântica de Moléculas e Sólidos: Simulação Computacional, Editora Livraria da Física, São Paulo, (2004).

[20] Hohenberg, P.; Kohn, W., Physical Review B, 136, 864-871 (1964).

[21] Kohn, W.; Sham, L. J., Physical Review, 140, 1133-1138 (1965).

[22] Baer, R.; Neuhauser, D., Phys. Rev. Lett., 94, 043002 (2005).

[23] Pandey, L.; Doiron, C.; Sears, J. S.; Brédas, J. L., Phys. Chem. Chem. Phys., 14, 14243-14248 (2012).

[24] Körzdörfer, T.; Sears, J. S.; Sutton, C.; Brédas, J. L., J. Chem. Phys., 135, 204107, (2011).

[25] Kronik, L.; Stein, T.; Refaely-Abramson, S.; Baer, R., J. Chem. Theory. Comput., 8, 1515-1531 (2012).

[26] Kuritz, N.; Stein, T.; Baer, R.; Kronik, L., J. Chem. Theory Comput., 7, 2408-2415 (2011).

[27] Baer, R.; Livshits, E.; Salzner, U., Annu. Rev. Phys. Chem., 61, 85-109 (2010). 
[28] Runge, E.; Gross, E. K. U., Phys. Rev. Lett., 52, 997-1000 (1984).

[29] Vieira, D., Correções de Auto-Interação na Teoria do Funcional da Densidade: Investigação em Modelos de Sistemas de Muitos Corpos, Tese de Doutorado - Universidade de São Paulo, São Carlos, SP, (2010).

[30] Becke, A. D., J. Chem. Phys., 98, 1372-1377 (1993).

[31] Lee, C.; Yang, W.; Parr R. G., Phys. Rev. B, 37, 785-789 (1988).

[32] Zhao, Y.; Schultz, N. E.; Truhlar, D. G., J. Chem. Phys., 123, 161103 (2005).

[33] Zhao, Y.; Truhlar, D. G., Theor. Chem. Acc., 120, 215-241 (2008).

[34] Marcus, R. A., J. Chem. Phys., 24, 966-978 (1956).

[35] Marcus, R. A., J. Chem. Phys., 24, 979-989 (1956).

[36] Marcus, R. A.; Sutin, N., Biochim. Biophys. Acta., 811, 265-322 (1985).

[37] Cohen-Tannoudji, C.; Diu, B.; Laloe, F., Quantum Mechanics: Volume Two, Willey, (1977).

[38] Marcus, R. A., Rev. Mod. Phys., 65, 599-610 (1993).

[39] Balzani, V., Electron Transfer in Chemistry, Weinheim, New York: Wiley-VCH, (2001).

[40] da Silva Filho, D. A.; Kim, E. G.; Brédas, J. L., Adv. Mat., 17, 1072-1076 (2005).

[41] Valeev, E. F.; Coropceanu, V.; da Silva Filho, D. A.; Salman, S.; Brédas, J.L., J. Am. Chem. Soc., 128, 9882-9886 (2006).

[42] Frisch, M. J.; Trucks, G. W.; Schlegel, H. B.; Scuseria, G. E.; Robb, M. A.; Cheeseman, J. R.; Scalmani, G.; Barone, V.; Mennucci, B.; Petersson, G. A.; Nakatsuji, H.; Caricato, M.; Li, X.; Hratchian, H. P.; Izmaylov, A. F.; Bloino, J.; Zheng, G.; Sonnenberg, J. L.; Hada, M.; Ehara, M.; Toyota, K.; Fukuda, R.; Hasegawa, J.; Ishida, M.; Nakajima, T.; Honda, Y.; Kitao, O.; Nakai, H.; Vreven, T.; Montgomery Jr, J. A.; Peralta, J. E.; Ogliaro, F.; Bearpark, M.; Heyd, J. J.; Brothers, E.; Kudin, K. N.; Staroverov, V. N.; Kobayashi, R.; Normand, J.; Raghavachari, K.; Rendell, A.; 
Burant, J. C.; Iyengar, S. S.; Tomasi, J.; Cossi, M.; Rega, N.; Millam, J. M.; Klene, M.; Knox, J. E.; Cross, J. B.; Bakken, V.; Adamo, C.; Jaramillo, J.; Gomperts, R.; Stratmann, R. E.; Yazyev, O.; Austin, A. J.; Cammi, R.; Pomelli, C.; Ochterski, J. W.; Martin, R. L.; Morokuma, K.; Zakrzewski, V. G.; Voth, G. A.; Salvador, P.; Dannenberg, J. J.; Dapprich, S.; Daniels, A. D.; Farkas, O.; Foresman, J. B.; Ortiz, J. V.; Cioslowski, J.; Fox, D. J., Gaussian Inc., Wallingford C. T., (2009).

[43] Brédas, J. L.; Beljonne, D; Coropceanu, V.; Cornil, J., Chem. Rev., 104, 4971-5003 (2004).

[44] Roothaan, C. C. J., Rev. Mod. Phys., 23, 69-89 (1951).

[45] Sitha, S.; Bhanuprakash, Choudary, B. M., Synthetic Metals, 148, 227-235 (2005).

[46] Kazmaier, P. M.; Hoffmann, R., J. Am. Chem. Soc., 116, 9684-9691 (1994).

[47] Adams, T. R.; Adamson, R. D.; Guzik, A. A.; Austin, B.; Baer, R.; Baker, J.; Bell, A. T.; Beran, G. J. O.; Bernard, Y.; Besley, N. A.; Bravaya, K.; Brooks, B.; Brown, S. T.; Byrd, E. C.; Casanova, D.; Challacombe, M.; Chai, J. D.; Chakraborty, A. K.; Chang, C. M.; Cheng, C. L.; Chien, S. H.; Chipman, D. M.; Cramer, C.; Crittenden, D.; Dachsel, H.; Deng, J.; DiStasio Jr, R. A.; Doerksen, R. J.; Dombroski, J. P.; Dreuw, A.; Dunietz, B. D.; Dutoi, A. D.; Edgar, R.; Feng, X.; Florian, J.; Furlani, T. R.; Epifanovsky, E.; Gan, Z.; Ghosh, D.; Ghysels, A.; Gilbert, A. T. B.; Gill, P. M. W.; Goddard III, W.; Goldey, M.; Gordon, M.; Gordon, M. H.; Gwaltney, S. R.; Hawkins, G.; Hehre, W. J.; Herbert, J. M.; Heyden, A.; Hohenstein, E. G.; Hirata, S.; Hsu, C. P. C.; Ishikawa, N.; Jacobson, L. D.; Johnson, B. G.; Jung, Y.; Kaduk, B.; Kaliman, I.; Kedziora, G.; Keil, F. J.; Kelly, C.; Khaliullin, R. Z.; Khistyaev, K.; Klunzinger, P.; Kong, J.; Korambath, P. P.; Kosenkov, D.; Krylov, A. I.; Kurlancheek, W.; Kus, T.; Kussmann, J.; Lambrecht, D.; Landau, A.; Lange, A.; Laurent, A.; Lawler, K.; Lee, A. M.; Lee, M.; Levchenko, S. V.; Liang, W.; Lin, C. Y. L.; Liotard, D.; Liu, F.; Liu, J.; Livshits, E.; Lochan, R. C.; Lotan, I.; Manohar, P.; Marenich, A.; Mao, S. P.; Maslen, P. E.; Maurice, D. R.; Molnar, L. F.; Nair, N.; Oana, M.; O’Neill, D. P.; Neuhauser, D.; Ochsenfeld, C.; Olson, R.; Oumi, M.; Parkhill, J.; Peters, B.; Pieniazek, P. A.; Pople, J. A.; Proynov, E. I.; Rassolov, V. A.; Rhee, Y.; Ritchie, J. P.; Rohrdanz, M. A.; Rosta, E.; Russ, N.; Schaefer III, H. 
F.; Shao, Y.; Sherrill, C. D.; Schmidt, M.; Schultz, N. E.; Sharada, S.; Shenvi, N.; Simmonett, A. C.; Slipchenko, L. V.; Sodt, A.; Steele, R. P.; Su, Y. C.; Subotnik, J. E.; Sundstrom, E.; Thanthiriwatte, K.; Thom, A. J. W.; Truhlar, D. G.; Vanovschi, V.; Voorhis, T. V.; Vydrov, O.; Wang, T.; Warshel, A.; Watson, M.; White, C.; Williams, C. F.; Woodcock III, H. L.; Wormit, M.; Wu, Q.; Xu, X.; Yeganeh, S.; You, Z. Q.; Zhang, W.; Zhao, Y.; Zimmerman, P.; Zuev, D., Q-Chem Inc., 5001 Baum Bldv, 4.1, (2013).

[48] Li, Y. F.; Zou, Y. P., Adv. Mater., 20, 2952-2958 (2008).

[49] Blouin, N.; Michaud, A.; Leclerc, M., Adv. Mater., 19, 2295-2300 (2007).

[50] Bundgaard, E.; Krebs, F. C., Sol. Energy Mater. Sol. Cells, 91, 954-985 (2007).

[51] Facchetti, A., Chem. Mater., 23, 733-758 (2011).

[52] Lu, G.; Usta, H.; Risko, C.; Wang, L.; Facchetti, A.; Ratner, M. A.; Marks, T. J., J. Am. Chem. Soc., 130, 7670-7685 (2008).

[53] Yi, H. N.; Al-Faifi, S.; Iraqi, A.; Watters, D. C.; Kingsley, J.; Lidzey, D. G., J. Mater. Chem., 21, 13649-13656 (2011).

[54] Szarko, J. M.; Guo, J. C.; Liang, Y. Y.; Lee, B.; Rolczynski, B. S.; Strzalka, J.; Xu, T.; Loser, S.; Marks, T. J.; Yu, L. P.; Chen, L. X., Adv. Mater., 22, 5468-5472 (2010).

[55] Hou, J. H.; Park, M. H.; Zhang, S. Q.; Yao, Y.; Chen, L. M.; Li, J. H.; Yang, Y., Macromolecules, 41, 6012-6018 (2008).

[56] Fu, B. Y.; Baltazar, J.; Hu, Z. K.; Chien, A. T.; Kumar, S.; Henderson, C. L.; Collard, D. M.; Reichmanis, E., Chem. Mater., 24, 4123-4133 (2012).

[57] Polander, L. E.; Pandey, L.; Barlow, S.; Tiwari, P.; Risko, C.; Kippelen, B.; Brédas, J. L.; Marder, S. R., J. Phys. Chem. C, 115, 23149-23163 (2011).

[58] Pandey, L.; Risko, C.; Norton, J. E.; Brédas, J. L., Macromolecules, 45, 6405-6414 (2012). 
[59] Yasuda, T.; Sakai, Y.; Aramaki, S.; Yamamoto, T., Chem. Mater., 17, 6060-6068 (2005).

[60] Zhang, Z. G.; Zhang, K. L.; Liu, G.; Zhu, C. X.; Neoh, K. G.; Kang, E. T., Macromolecules, 42, 3104-3111 (2009).

[61] Havinga, E. E.; Tenhoeve, W.; Wynberg, H., Polym. Bull., 29, 119-126 (1992).

[62] Havinga, E. E.; Tenhoeve, W.; Wynberg, H., Synth. Met., 55, 299-306 (1993).

[63] Jenekhe, S. A.; Lu, L.; Alam, M. M., Macromolecules, 34, 7315-7324 (2001).

[64] Zhu, Y.; Champion, R. D.; Jenekhe, S. A., Macromolecules, 39, 8712-8719 (2006).

[65] Xiao, S.; Stuart, A. C.; Liu, S.; You, W., ACS Appl. Mater. Interfaces, 1, 1613-1621 (2009).

[66] Li, Y. F., Acc. Chem. Res., 45, 723-733 (2012).

[67] Zou, Y. P.; Wu, W. P.; Sang, G. Y.; Yang, Y.; Liu, Y. Q.; Li, Y. F., Macromolecules, 40, 7231-7237 (2007).

[68] Zhang, Z. G.; Fan, H. J.; Min, J.; Zhang, S. Y.; Zhang, J.; Zhang, M. J.; Guo, X.; Zhan, X. W.; Li, Y. F., Polym. Chem., 2, 1678-1687 (2011).

[69] Shen, P.; Bin, H. J.; Chen, X. W.; Li, Y. F., Org. Electron., 14, 3152-3162 (2013).

[70] Grimm, B.; Risko, C.; Azoulay, J. D.; Brédas, J. L.; Bazan, G. C., Chem. Sci., 4, 1807-1819 (2013).

[71] Lee, C. T.; Yang, W. T.; Parr, R. G., Phys. Rev. B, 37, 785-789 (1988).

[72] Becke, A. D., Phys. Rev. A, 38, 3098-3100 (1988).

[73] Becke, A. D., J. Chem. Phys., 98, 5648-5652 (1993).

[74] Francl, M. M.; Pietro, W. J.; Hehre, W. J.; Binkley, J. S.; Gordon, M. S.; Defrees, D. J.; Pople, J. A., J. Chem. Phys., 77, 3654-3665 (1982).

[75] Harihara. P. c.; Pople, J. A., Theor. Chim. Acta, 28, 213-222 (1973).

[76] Risko, C.; McGehee, M. D.; Brédas, J. L., Chem. Sci., 2, 1200-1218 (2011). 
[77] Chai, J. D.; Head-Gordon, M., J. Chem. Phys., 128, 084106 (2008).

[78] Sobolewski, A. L.; Domcke, W., Chem. Phys., 294, 73-83 (2003).

[79] Refaely-Abramson, S.; Baer, R.; Kronik, L., Phys. Rev. B, 84, 075144 (2011).

[80] Gierschner, J.; Cornil, J.; Egelhaaf, H. J., Adv. Mater., 19, 173-191 (2007).

[81] Wudl, F.; Kobayashi, M.; Heeger, A. J., Journal of Organic Chemistry, 49, 3382-3384 (1984).

[82] Meier, H.; Stalmach, U.; Kolshorn, H., Acta Polym., 48, 379-384 (1997).

[83] Zade, S. S.; Zamoshchik, N.; Bendikov, M., Acc. Chem. Res., 44, 14-24 (2011).

[84] Mondal, R.; Ko, S.; Norton, J. E.; Miyaki, N.; Becerril, H. A.; Verploegen, E.; Toney, M. F.; Brédas, J. L.; McGehee, M. D.; Bao, Z. N., J. Mater. Chem., 19, 7195-7197 (2009).

[85] Mondal, R.; Miyaki, N.; Becerril, H. A.; Norton, J. E.; Parmer, J.; Mayer, A. C.; Tang, M. L.; Brédas, J. L.; McGehee, M. D.; Bao, Z. A., Chem. Mater., 21, 3618-3628 (2009).

[86] Martin, R. L., J. Chem. Phys., 118, 4775-4777 (2003).

[87] Britton, G.; Liaaen-Jensen, S.; Pfander, H., Carotenoids: Handbook, (2004).

[88] Frank, H. A.; Josue, J. S.; Bautista, J. A.; van der Hoef, I.; Jansen, F. J.; Lugtenburg, J.; Wiederrecht, G.; Christensen, R. L., J. Phys. Chem. B, 106, 2083-2092 (2002).

[89] França, L. F.; Reber, G.; Meireles, M. A. A.; Machado, N. T.; Brunner, G., Journal of Supercritical Fluids, 14, 247-256 (1999).

[90] Albuquerque, M. L. S.; Guedes, I.; Alcantara Jr., P.; Moreira, S. G. C.; Barbosa Neto, N. M.; Correa, D. S.; Zilio, S. C., J. Braz. Chem. Soc., 16, 1113-1117 (2005).

[91] Martins, J. B. L.; Durães, J. A.; Sales, M. J. A.; Vilela, A. F. A.; Silva, G. M.; Gargano, R., Int. J. Quantum Chem., 109, 739-745 (2009).

[92] Körzdörfer, T.; Parrish, R. M.; Sears, J. S.; Sherrill, C. D.; Brédas, J.L., J. Chem. Phys, 137, 124305 (2012). 
[93] Brédas, J.L.; Adant, C.; Tackx, P.; Persoons, A.; Pierce, B. M., Chem. Rev., 94, 243-278 (1994).

[94] Rodríguez, A. M.; Sastre, S.; Ribot, J.; Palou, A., Biochim. Biophys. Acta, 1740, $132-138$ (2005).

[95] Craft, N. E.; Soares, J. H., J. Agric. Food Chem., 40, 431-434 (1992).

[96] Macpherson, A. N.; Gillbro, T., J. Phys. Chem. A, 102, 5049-5058 (1998).

[97] Billsten, H. H.; Zigmantas, D.; Sundström, V.; Polivka, T., Chem. Phys. Lett., 355, 465-470 (2002).

[98] Takaichi, S., Photosynth. Res., 65, 93-99 (2000). 